\title{
IMISCOE
}

RESEARCH

\section{International Migration}

\section{in Europe}

New Trends and New Methods of Analysis

CORRADO BONIFAZI, MAREK OKÓLSKI, JEANNETTE SCHOORL \& PATRICK SIMON (EDS.)

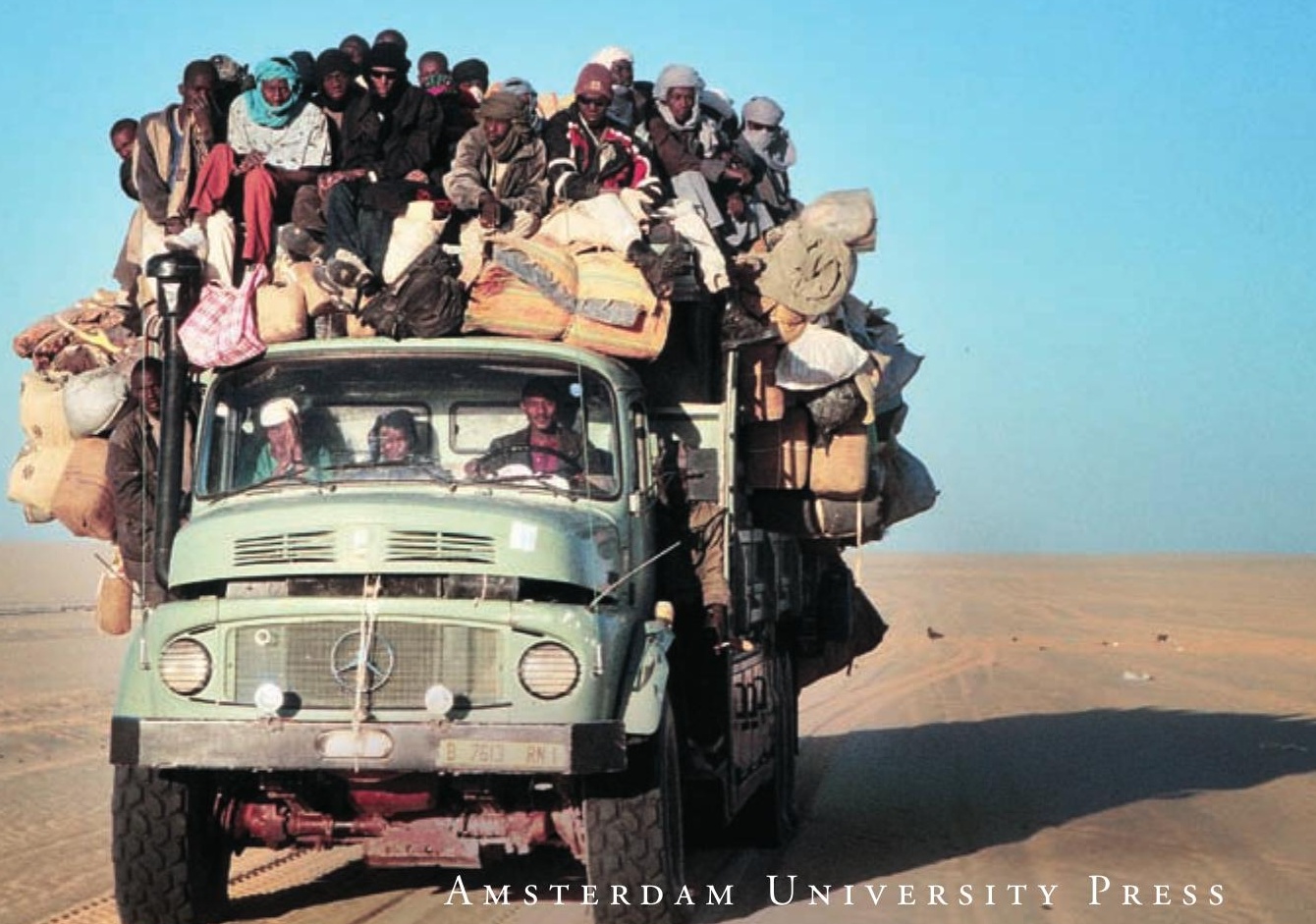


International Migration in Europe 


\section{IMISCOE (International Migration, Integration and Social Cohesion)}

IMISCOE is a Network of Excellence uniting over 500 researchers from various institutes that specialise in migration studies across Europe. Networks of Excellence are cooperative research ventures that were created by the European Commission to help overcome the fragmentation of international studies. They amass a crucial source of knowledge and expertise to help inform European leadership today.

Since its foundation in 2004, IMISCOE has advanced an integrated, multidisciplinary and globally comparative research programme to address the themes specified in its name, short for: International Migration, Integration and Social Cohesion in Europe. IMISCOE members come from all branches of the economic and social sciences, the humanities and law. The Network draws from existing studies and advances innovative lines of inquiry key to European policymaking and governance. Priority is placed on developing a theoretical design to promote new research and offer practical alternatives for sound policy.

The IMISCOE-Amsterdam University Press Series was created to make the Network's findings and results available to researchers, policymakers, the media and the public at large. High-quality manuscripts authored by IMISCOE members and cooperating partners are published in one of four distinct series.

Research

Reports

Dissertations

Textbooks

The RESEARCH series presents empirical and theoretical scholarship addressing issues of international migration, integration and social cohesion in Europe. Authored by experts in the field, the works provide a rich reference source for researchers and other concerned parties.

The REPORTS series responds to needs for knowledge within IMISCOE's mandated fields of migration research. Compiled by leading specialists, the works disseminate succinct and timely information for European policymakers, practitioners and other stakeholders.

The DISSERTATIONS series showcases select PhD monographs written by IMISCOE doctoral candidates. The works span an array of fields within studies of international migration, integration and social cohesion in Europe.

The TEXTBOOKS series produces manuals, handbooks and other didactic tools developed by specialists in migration studies. The works are used within the IMISCOE training programme and for educational purposes by academic institutes worldwide.

IMISCOE Policy Briefs and more information on the Network can be found at www.imiscoe.org. 


\title{
International Migration in Europe
}

New Trends and New Methods of Analysis

\author{
edited by \\ Corrado Bonifazi \\ Marek Okólski \\ Jeannette Schoorl \\ Patrick Simon
}

IMISCOE Research 
Cover illustration: @ Piet den Blanken / Hollandse Hoogte

Cover design: Studio Jan de Boer BNO, Amsterdam

Layout: The DocWorkers, Almere

$\begin{array}{ll}\text { ISBN } & 978905356894 \mathrm{I} \\ \text { e-ISBN } & 978904850 \text { I54 O } \\ \text { NUR } & 74 \mathrm{I} / 763\end{array}$

(C) Corrado Bonifazi, Marek Okólski, Jeannette Schoorl, Patrick Simon / Amsterdam University Press 2008

All rights reserved. Without limiting the rights under copyright reserved above, no part of this book may be reproduced, stored in or introduced into a retrieval system, or transmitted, in any form or by any means (electronic, mechanical, photocopying, recording or otherwise) without the written permission of both the copyright owner and the authors of the book. 


\section{Contents}

$\begin{array}{ll}\text { Preface } & 7\end{array}$

I Introduction 9

Corrado Bonifazi, Marek Okólski, Jeannette Schoorl

and Patrick Simon

\section{PART I NEW Forms of Migration in Europe}

$2 \quad$ Managing new migrations in Europe: Concept and reality in the ICT sector John Salt

3 On the demand side of international labour mobility: The structure of the German labour market as a causal factor of seasonal Polish migration

Barbara Dietz and Pawel Kaczmarczyk

4 Migrant smuggling and trafficking in Portugal: Immigrants, networks, policies and labour markets since the I990s João Peixoto

5 Romanian migration movements: Networks as informal transnational organisations Swanie Potot

PART II EVOlution OF REgIONAL PATTERNS OF INTERNATIONAL MIGRATION IN EURope

6 Evolution of regional patterns of international migration in Europe Corrado Bonifazi

7 Long-term international migration scenarios for Europe, 2002-2052

Jakub Bijak, Anna Kicinger, Dorota Kupiszewska and Marek Kupiszewski 
8 Foreign immigration in Southern European receiving countries: New evidence from national data sources Alessio Cangiano and Salvatore Strozza

9 The post-enlargement migration space Paolo Ruspini

Part III Measuring integration: Immigrants AND the SECOND GENERATion

Io The integration of migrants in the Netherlands monitored over time: Trend and cohort analyses I99 Rob V. Bijl, Aslan Zorlu, Roel P.W. Jennissen and Martine Blom

II What integrates the second generation? Factors affecting family transitions to adulthood in Sweden Calvin Goldscheider, Eva Bernhardt and Frances Goldscheider

I2 Discrimination despite integration: Immigrants and the second generation in education and the labour market in France

Dominique Meurs, Ariane Pailhé and Patrick Simon

Part IV SpeCial SURVEYS IN INTERNATIONAL MigRATION STUdiES

I3 One-way or both-ways migration surveys Jean Louis Rallu

I4 Design of samples for international migration surveys: Methodological considerations and lessons learned from a multi-country study in Africa and Europe George Groenewold and Richard Bilsborrow

I5 Quality of asylum decisions: Uses and limitations of surveys of asylum case files Işık Kulu-Glasgow 


\section{Preface}

The working group on international migration in Europe of the European Association for Population Studies aims to promote discussion on migration issues. This book contains selected papers presented at the working group's second conference, which was held in Rome in November 2004. Some 130 researchers from 23 countries attended the conference for three days of stimulating debate. The conference was organised by the working group chair, Corrado Bonifazi from the Institute of Research on Population and Social Policies (IRPPS), part of Italy's National Research Council (CNR) in Rome, Marek Okólski from the Centre of Migration Research at the University of Warsaw, Jeannette Schoorl from the Netherlands Interdisciplinary Demographic Institute (NIDI) in The Hague and Patrick Simon from the National Demographic Institute (INED) in Paris. The IRPPS acted as organising body for the meeting. The conference was generously supported by a grant from the Population, Migration and Environment Foundation.

The Editors 



\section{Introduction}

\section{Corrado Bonifazi, Marek Okólski, Jeannette Schoorl and Patrick Simon}

Some of the most rapid and radical changes in the history of European international migration have taken place over the last fifteen to twenty years. After 45 years of real socialism, the fall of the Berlin Wall has brought Central and Eastern Europe (CEE), previously isolated by the Iron Curtain, back into the continental migration system. All this has occurred in a context that, since the end of the I980s, was already witnessing important new developments. The Southern European countries have emerged as centres of attraction and have become the new promised land for migrants coming from both old and new sending countries. In turn, the Western European countries have been looking for a new type of immigrant - better educated and possessing skills that can be adapted to modern and fast-developing technologies. At the same time, these countries have suddenly been confronted with integrating the children of immigrants recruited for employment in the first 25 years after the end of World War II. The result has been a radical transformation of all the aspects related directly and indirectly to migration dynamics, including the direction and size of migration flows, migration policies, the role of various countries in the continental migration panorama, and the rising concerns for integration processes both at the policy and scientific levels.

New destinations, new regions of origin and new flows have thus emerged. Economic transition, political changes and ethnic conflicts in CEE have affected the size and direction of European migration flows, while flows from non-European countries have continued to account for a sizeable part of migration in Europe. At the same time, increasingly restrictive immigration policies have produced a shift from the traditional migrant workers and their families to large flows of asylum seekers and undocumented migrants. The extraordinary increase of the immigrant populations in Southern European receiving countries after the regularisations of recent years reflects the current magnitude of unofficial channels of recruitment. Although most of the traditional national migration models have proved to be inadequate, there have been major changes in migration policies, and new regulatory regimes have been implemented in most of the European countries. Moreover, the European Union is becoming more closely involved in migration is- 
sues, and the EU enlargement process is reinforcing its role in making and implementing migration policies. New regulations in this field have illustrated the move towards a harmonization of migration and integration policies in Europe. Two EU Council Directives enacted in 2003 have clearly set a framework which determines the status of migrants in EU countries: Directive 2003/109/EC concerning the status of third-country nationals who are long-term residents, and Directive $2003 / 86 /$ EC on the right to family reunification.

The recent regulation on Community statistics on migration and international protection (asylum) is a step further in the standardisation of policies by setting common grids for national statistics offices to produce statistics on migration. As regards integration issues, the Europeanisation of policies is still at a very soft level. The 'Common Basic Principles on Integration' were agreed by the Council of the European Union (I9 November 2004) and the common agenda for integration now offers a benchmark for stakeholders and policymakers. The assumption that migration and integration should be strongly linked at the policy level is shared at the EU level and aims to influence member states. As a result, more and more national laws on migration and the legal status of third-country nationals relate the right to residency to some kind of integration proof. Integration is thus not only a sociological concept, it is more than ever a normative expectation of the majority population in multicultural societies towards the minorities.

As for migration, the measurement of migrant integration creates conceptual pitfalls and methodological difficulties. The rise of secondgeneration issues in old immigration countries has generated a new field of research. The riots in the French banlieues, the participation of first- and second-generation immigrants in the Madrid and London terrorist attacks, the problems in the Netherlands after the murder of film director Theo van Gogh, as well as the persistence of ethnic discrimination and inequality in European countries have, more than ever before, dramatically brought to the forefront a perception of how immigration and integration processes are linked to the demand for security in host societies. The difficulties now being encountered by the multicultural model aimed at integrating immigrants, especially in the United Kingdom and the Netherlands, have already been experienced by the countries that favoured the assimilationist and guest-worker models. In the policy agendas of many European countries and various international organisations, the search for an approach providing a satisfactory response to the needs and concerns of the societies of immigration is now of prime importance.

One of the main consequences of these changes is the growing importance of migration issues in academic and political debate. Some of these emerging issues are examined in this book, in an attempt to deal 
with the new aspects of European international migration from various points of view, to gain a wider panorama.

There were two main points of reference for the research: to underline the new trends in migration and to evaluate new methods of analysis. The aim was to outline, and then examine, the new aspects of migration dynamics and the links between migration trends and the search for more adequate methods of analysis. This approach has been followed in the choice of the research themes considered and of the subsequent contributions that appear in the book. In particular, four research themes have been considered: new forms of migration in Europe, the evolution of regional patterns of European international migration, the issue of the intergenerational process of migrant integration, and the uses and limitations of special surveys in international migration studies.

The first and second research themes directly regard migration trends and consider new forms and the evolution of regional patterns. These are two key issues since, besides revealing present characteristics, they also provide the basis for a slightly better forecast of possible future scenarios. The third research theme, rather than the migration process itself, involves the integration of immigrants and their descendants (i.e. the second generation). Strictly speaking, this topic is not entirely a migration issue, since the members of the second generations are born in the receiving country where their parents live, and are not therefore migrants. Undoubtedly, however, the processes of migration and integration are closely related, and integration, with all its specific implications, cannot be sufficiently analysed without taking into account migration dynamics and their effects on the receiving societies. The last research theme specifically regards methodology and considers those special surveys that are now an indispensable additional tool for research on international migration, since traditional statistical methods are no longer sufficient to measure all the different aspects.

New population movements in Europe that emerged or took on a mass scale after the late I980s constitute the first research theme of this volume. At about the same time, a wide complex of largely mutually independent factors came to affect European and many non-European societies, including the life strategies of their members. Those strategies involved a variety of population movements that differed distinctly from conventional settlement migration or fixed-term labour migration.

The successive restructuring of Western economies that began in I973 or shortly thereafter, which ran parallel with the end of migrant worker recruitment and, a little later, the termination of any meaningful immigration related to family reunion, paved the way to mobilising alternative sources of foreign labour. The following inflow of migrants 
took on different forms of which the most prominent were: inflows of low-skilled seasonal workers, inflows of workers with special and rare skills, inflows of foreign students, and inflows of people seeking protection on humanitarian grounds or pretending to be in such a situation. Some of those flows that responded to various demand-based signals from labour markets were reinforced by what is called 'the business of migration' - when the state and other economic actors are seeking direct or indirect benefits from bringing into the country human capital that is costly to produce ('the brain drain') or offering educational services to various categories of foreign students. Increasingly, another factor contributing to the diversity of migration flows in Western countries was their own demographic situations, especially the ageing of their populations.

In quite another part of the continent a societal transition, a departure from totalitarian rule and central economic planning towards democratic rule and the free market economy, released a huge migration potential. Geographic directions and forms of the ensuing mobility were determined by three basic facts: the economic backwardness of the East compared with the West; the political decomposition of the Eastern bloc and some of its states in particular; and imbalances in the labour markets of the EU, especially the increase in the demand for low-paid workers who would accept unstable or irregular employment, and precarious jobs at that. A combination of these and other factors gave rise to the unprecedented, economically motivated circular mobility of Eastern Europeans ('false tourists') to Western countries. In addition, several other East-to-West flows of people were also observed, such as: outflows of refugees from civil war areas, outflows of certain ethnic minorities (German, Jewish), movements of seasonal workers, or cross-border commuting of workers. A great part of that mobility was channelled by means of bilateral agreements concluded between some Eastern and some Western states.

Simultaneously, the former communist countries of CEE underwent rapid economic and political polarisation. Besides the fact that nearly all these countries became hosts to migrant workers and asylum seekers from third countries, and transit areas for various irregular migrants heading for the West, some CEE countries started to attract migrant workers and people seeking protection on humanitarian grounds from other countries of the region.

Finally, growing migration pressures in developing countries combined with the immigration policies of 'fortress Europe' followed by Western countries led to massive flows of illegal migrants from many post-communist or non-European areas. Some of these flows took on the form of movements of mala fide refugees, while some others took on the much more perverse form of human smuggling and trafficking. 
All these forms contributed to a mosaic of population movements of a complexity previously unknown. This present volume addresses many of the new forms, root causes, metamorphoses and consequences of these movements. Salt highlights the role of employers in shaping the international mobility of highly skilled labour in information and communication technologies. Dietz and Kaczmarczyk focus their attention on the flows between Poland and Germany, considering the pull forces of labour mobility. They consider the situation from both sides of the border, referring to the results of a quantitative survey conducted on Polish seasonal workers and of qualitative interviews conducted on German employers of this type of worker. Next, Peixoto considers the issue of migrant smuggling and trafficking in Portugal. He analyses the situation since the late I990s and considers the links between these forms of migration and regular flows. Finally, Potot concentrates her attention on Romanian migration and the informal transnational organizations that seem to drive the movements between Romania and several countries of the EU.

The recent evolution of European international migration has been characterised by a general trend towards the enlargement of the migration system centred on EU countries. In fact, former emigration countries of Southern Europe have increasingly been affected by immigration flows, radically changing their position in migration dynamics. In the future, new EU members will probably experience a very fast process of integration, also in the migration field. This integration has already started in migration policy issues. Notwithstanding these processes, differences persist and contribute to strongly differentiate trends, patterns, issues, and possible evolution at the European regional level. In this context, Bonifazi describes the overall evolution of European regional patterns from the end of World War II to the present, highlighting the importance of the political factor in migration dynamics as well as some possible lines of development. Starting from the regional approach, Bijak, Kicinger, Kupiszewska and Kupiszewski seek to determine the European migration scenarios in the first half of the present century, showing the usefulness of this approach in identifying future migration trends. Cagiano and Strozza analyse one of the most extraordinary cases of migration increase: the countries of Southern Europe in recent years have been the most important destinations of the continent. Ruspini concludes this section of the book by examining the link between the enlargement of EU migration space and the ongoing formulation of a common EU immigration policy.

Fifty years after the beginning of mass migration in most of the European countries, the process of integration has reached a new phase. Since the end of the I970s for Northern Europe, and the end of the I980s for the South, it is obvious that all major European countries 
have become migration receiving countries and have to construct policies to promote the integration of immigrants. A decade of debate and studies later, we know a bit more about the slow journey towards the social integration of different immigrant groups. But while we were compiling analyses of the changes that occurred in socio-demography and the economic positions of the immigrants, a new issue was emerging on social and political agendas: 'diversity management'. The rise of a 'second generation', made up of the offspring of immigrants in the former countries of immigration, has produced a new context that needs to be analysed. European societies must address the crucial issues of the way in which former and current 'migration societies' are significantly shaped by the effects of migration in the long run and of how they learn to be 'multicultural' in the sense that the diversity of their population in ethno-cultural terms challenges the dynamic towards the unity of nation-states. To improve our understanding of integration in the long run, social sciences, and especially demography, should stimulate observations and analyses of the second generation's socioeconomic positions and trajectories. The fact is that integration has mainly been studied by sociologists and political scientists in a qualitative way, drafting monographs of interethnic relations in immigrant neighbourhoods or thorough analysis of political models of incorporation. Quantitative approaches of the integration process have remained scarce in Europe, in contrast with the US and Canadian scientific literature, for various reasons. The first has to do with the difficulties involved in translating theoretical inputs and conceptual frameworks in measurements and indicators of integration. The second reason is the lack of a dataset designed for these kinds of analysis. Even if immigrants and second generations are now forming significant proportions of the European population, they remain demographic minorities when broken down by origin, not to mention political minorities. Therefore, they are invisible in most official statistics, and very rarely observed through demographic or economic surveys. This situation is now changing rapidly and some countries are producing new data on immigrants and second generations that can be used to describe and analyse the process of integration.

One of the most sophisticated statistical resources can be found in the Netherlands, explains Rob Bijl in his chapter on the integration monitor. By bridging different sources from administrative records and registers, Statistics Netherlands has produced the Social Statistics Database (SSB), which is then used to monitor integration through a number of indicators linked to an analytical grid. Rob Bijl presents the background of the integration monitor and gives a selection of findings describing the situation of allochtones and, in particular, first- and second-generation Turks and Moroccans in the Netherlands. Goldscheider, 
Bernhardt and Goldscheider look into the very heart of integration by focusing on the family formation nexus. Using Swedish data collected in a special survey conducted in I999, the authors build indicators of gender and ethnic differences in family life among the adult children of immigrants, and discuss the different routes to assimilation by focusing on de-cohabitation from the parental home, intermarriage and finding a partner, and the adjustment of second generation couples to Swedish family standards of gender equality. Meurs, Pailhé and Simon deal with the economic dimension of integration and stress the specific position in education and the labour market of the French second generation. Using a dataset recently collected in France, their findings provide new insights on the extent of discrimination in the labour market against certain groups despite their relative improvement in terms of school credentials.

If the analysis of the future of the second generation requires new data and somehow new theories and concepts to describe their position in their societies, the description of the new trends of migration is even more methodologically challenging. While general migration statistics provide data on the size of migration flows and the stock of migrant populations, statistics often lack details on the characteristics of migrants and on the determinants, mechanisms and consequences of migration processes. Special surveys may fill this gap to some extent but they are expensive, often providing one-off measurements only, thus suffering from problems of generalisation. Nevertheless, in recent years, surveys have increasingly been used to study various aspects of the migration process. In his contribution, Rallu discusses the potential of complex 'both-ways' migration surveys, where data are collected at both the sending and the receiving ends of the migration process, to collect unbiased data on various types of migrants. The paper by Groenewold and Bilsborrow focuses on sample design for international migration surveys. They discuss, among other things, how to overcome problems related to the absence of suitable sample frames and, as a consequence, the difficulties associated with finding rare migrants in large populations, using the example of a multi-country survey carried out in several countries in Africa and Europe. Finally in this section of the book, Kulu-Glasgow discusses the strengths and weaknesses of surveying individual asylum dossiers for analysing various aspects of the process of formal decision procedures. Here, the advantage of having longitudinal data, and therefore the opportunity to study procedures and events over time, is counterbalanced by issues around qualitative research in general, such as inter-researcher reliability, privacy protection and labour- and time-intensity.

Obviously, research and policymaking share a common concern: without data, there is no knowledge-based decision or analysis. When 
it comes to migration and integration, we all know that stereotypes, prejudices and fears are framing the way public opinion and policymakers consider the issues. In this context, we hope that this book will meet its goal of providing new insights and new tools for a better understanding of one of the most crucial questions in our democratic societies. 


\section{PART I}

New forms of migration in Europe 



\title{
2 Managing new migrations in Europe: Concept and reality in the ICT sector
}

\author{
John Salt
}

The aim of this chapter is twofold. First, it proposes a theoretical framework for explaining migration that takes into account the complexities of the subject and the need to focus on routes of entry. Second, it highlights the role of employers in orchestrating the international mobility of highly skilled labour through the lens of the Information, Communications and Technology (ICT) sector. The ICT sector is new and has developed rapidly over the last fifteen years or so, as has the mobility of staff associated with it. The chapter presents the main findings of an international research project.

\subsection{Migration, mobility and routes of entry}

Any explanation of migration patterns and trends must first get to grips with the complexities of the phenomenon. The last decade or so has seen an explosion of academic, policy and media interest in international migration. Unfortunately, much of that interest has been characterised by a reductionism that has led to oversimplification and misunderstanding, prompting the question: what do we mean by migration?

The answer to this question is by no means straightforward. As indicated above, there is an increasing diversity of flows that challenges traditional notions of 'migration'. Indeed, it is tempting to suggest that there is no such person as 'a migrant', but rather a wide range of people exhibiting different forms of mobility that constitute different types of migration streams. Migration is thus a subcategory of a wider concept of 'movement', embracing various types and forms of human mobility from commuting to permanent emigration. What we define as migration is an arbitrary choice about where we draw the line and that may be time-specific. Migration streams are dynamic, involve different types of people and motivations, have different roles and different implications for host and sending societies, and are influenced and managed by different agencies and institutions.

Each of these migration streams has a corresponding 'route of entry' into a country, based on the government policies and rules which are 
designed to regulate entry, allowing governments to fine-tune overall migration flows. In dealing with different scales and types of movement, governments are presented with a range of management challenges. For example, asylum seekers come to Europe for a variety of reasons; they originate in a wide range of countries; they have diverse educational backgrounds and skills; some come alone and others with family members, and there are increasing numbers of unaccompanied minors claiming asylum. There are similar diversities affecting other migration streams. Family reunion and formation, for instance, is generally accepted as a fundamental human right and is the rationale behind both immigration and emigration of close family members. Government actions here are circumscribed by international human rights legislation, agreements and norms. Other types of movement have quite different roots and proceed in different ways. Retirement migration usually occurs on the basis of personal decisions, tempered by social security and pension arrangements. Educational institutions, rather than governments, play a leading role in the promotion and selection of foreign students and usually there are no numerical limits imposed. In contrast, some countries have established quotas for entries of (often seasonal) low-skilled workers in the agriculture, hospitality and food-processing industries, with intermediary institutions such as gangmasters playing a pivotal role. Employers are usually the driving force behind the migration of the highly skilled, many of whom are intra-company transferees within large transnational corporations and for whom governments frequently make special entry arrangements.

In the remainder of this paper the focus will be on the management of labour migration. Particular attention will be paid to the mobility of staff in the ICT sector where types of mobility and practice are relatively new.

\subsection{Migration as a business}

\subsubsection{The emergence of a global migration market}

The last two decades have seen the emergence of a global migration market. It affects all levels of skill, but the real competition is for those with high levels of human expertise and there is now a complex pattern of movement by professional, managerial and technical staff (OECD 2002). Since these movements are multi-directional, involving most states to a greater or lesser degree, we may call them 'international brain circulation'. Some countries are now more active than others in seeking to make net gains from this movement.

The main stimulus for competition in the global migration market has come from governments. Competition was led in the I980s by 
Australia and Canada, followed in the I990s by the United States. Europe held itself largely aloof until very recently, with little action and almost no debate about competition in the migration skills market. Employers worldwide are now facing the problem of integrating new processes and technologies which require specific skills but are finding they must compete internationally, where the main competitors are the US, Australia and Canada and a growing number of European states (McLaughlan \& Salt 2002).

The migration market for expertise has two main drivers. The first is the attempt to increase the national bank of expertise through the acquisition of high-level human resources; the other is the development of policies to counter specific skill shortages.

Underlying the first of these is evidence that highly skilled migrants bring economic benefits to the host economy. Although some of the results are ambiguous or contradictory, studies from as far afield as the United Kingdom, Denmark, Germany, Australia, Singapore and the US have shown that the higher the skill level of immigrants, the greater the likelihood of net fiscal gains to the economy (Gott \& Johnston 2002; DIMIA 2004). Put bluntly, the more skilled a country's immigrants, the greater the economic benefit.

A relative newcomer in the debate about labour immigration policy is the perceived shortage of specific skills and the need for new schemes to deal with it. Work permit systems have long existed to bring in skills from abroad that are in short supply. Mostly they have been seen as short-term measures to deal with temporary shortages, or to bring in specialists and corporate assignees. Nowadays, many developed countries have shortage lists for specific skills and have adopted new government schemes or programmes to deal with them. Skill shortages can occur because of the inefficiencies of the international labour market and because of mismatches caused by growth in demand outstripping local training capability or by an inadequacy of supply at the prevailing wage rate. In many countries in recent years, substantial skill shortages have occurred among two groups in particular: the ICT sector (including those working as practitioners and as users); and the more skilled end of public services, especially health (particularly nurses) and education. Developing strategies and procedures to recruit specific skills in shortage occupations has been predominantly employer-led, with governments acting as facilitators.

\subsubsection{Managing the migration market}

Over the last quarter century or so, the theoretical basis for explaining international labour mobility has developed substantially (Massey et al. I998). Although there are exceptions, notably in the financial sector 
(Beaverstock \& Boardwell 2000; Beaverstock 2002), the role of individual agency has tended to be disregarded (Baganha \& Entzinger 2004). A particular weakness is the lack of attention to the role of employers, whose decision-making with respect to labour recruitment and deployment can be fundamental in the orchestration of movement, and to other institutions which are involved in setting the context in which movement occurs.

In order to understand how migration is managed, an explanatory framework is needed that allows consideration of all the relevant actors. Here it is postulated that international labour migration may be conceptualised as a business; it is populated by a range of institutions, each of which has some influence on the processes, patterns and outcomes of movement. These institutions include employers and trade unions, government, regulatory bodies, migrant organisations and facilitators such as lawyers. They each have their own operational strategies, and to achieve their objectives they negotiate with each other in order to reach compromise accommodations that produce migration outcomes. They also constitute networks of interrelationships, some of which are more important than others.

It is only comparatively recently that the role of institutions in orchestrating migration has come under serious investigation, and most migration theories continue to emphasise migrants and their actions as key to understanding processes of movement (Koser \& Salt 1997). Among the institutions influencing migration patterns, employing organisations play a key role through their acquisition and deployment of human skills. Their actions in this regard are determined by their business models, as well as by a suite of constraints and opportunities which impinge upon them, including such matters as welfare-state arrangements, regulatory frameworks and the policies and actions of other institutional actors.

For most commercial employers, recruitment and mobility decisions and processes are determined by the need to maximise profitability. Transnational corporations seek to make best use of their internal expertise and add to it through recruitment in the external labour market. However, it is clear that circumstances vary between sectors and by type of employer because of the nature of each organisation's predominant activities. Every employment sector has its own distinguishing characteristics in size, skill mix and training requirements, geographical spread of operations, ownership, nature of service or product and trends in product/service demand, all of which are relevant to international recruitment.

For example, recruitment of labour among construction employers is, above all, project-based and makes substantial use of labour subcontracting: it can involve movement of skills and expertise both nationally 
and internationally depending on project location (Balch et al. 2004). In the health sector, most employers operate only in one country so there is no possibility of transferring staff internationally. Funding comes mainly from government and for the most part employers do not compete for business in a global market (Den Adel et al. 2004). In the ICT sector, in contrast, firms operate in a highly globalised environment where mobility in recent years has been concentrated in corporate internal labour markets (OECD 2002; Kolb et al. 2004). They routinely acquire, develop and disseminate various sorts of knowledge through mobility within the firm and in often intensive interaction with clients and competitors. ${ }^{1}$

The significance of corporate internal labour markets in the international mobility of highly skilled workers varies. Table 2.I shows recent data from the UK for selected sectors of the economy. It records the number and proportion of work permits for non-European Economic Area (EEA) citizens given to intra-company transferees and to those recruited through the external labour market. This form of mobility is particularly important in the computer services sector where large numbers of staff are sent, often for relatively short periods, to work

Table 2.1 Intra-company transfer (ICT) work permits (WP) approved by branch, UK 2006

\begin{tabular}{lrrr}
\hline Branch & Total ICTs & Total WPs & $\begin{array}{c}\text { ICTs as } \\
\text { \% of WPs }\end{array}$ \\
& & & \\
& & & 81.3 \\
Computer services & 22,695 & 27,914 & 67.1 \\
Telecommunications & 1,769 & 2,637 & 57.1 \\
Extractive industries & 1,078 & 1,888 & 50.7 \\
Manufacturing & 2,053 & 4,052 & 44.2 \\
Financial services & 4,999 & 11,305 & 40.1 \\
Utilities: gas, electricity, water & 501 & 1,248 & \\
Administration, business and & & & 38.7 \\
management services & 6,387 & 16,512 & 33.3 \\
Transport & 476 & 1,429 & 23.9 \\
Construction and land services & 1,073 & 4,498 & 22.8 \\
Retail and related services & 507 & 2,226 & 22.8 \\
Security and protective services & 43 & 189 & 21.6 \\
Law related services & 330 & 1,527 & 15.3 \\
Real estate and property services & 60 & 393 & 4.3 \\
Agriculture activities & 24 & 552 & 4.1 \\
Entertainment and leisure services & 216 & 5,296 & 1.9 \\
Education and cultural activities & 212 & 11,188 & 1.8 \\
Government & 18 & 991 & 1.3 \\
Health and medical services & 417 & 32,208 & 1.3 \\
Hospitality and catering & 154 & 11,911 & 0.2 \\
Sporting activities & 4 & 2,223 & 30.7 \\
Total & 43,016 & 140,187 & \\
\hline Source: Border and Immigration Asen & & \\
\hline
\end{tabular}

Source: Border and Immigration Agency 
with clients. The dominance of large and mature energy and mining companies accounts for the high proportion in extraction industries. Similar reasons explain their prevalence in manufacturing. In these and the other sectors that use intra-company transfers heavily, mobility is the result of a suite of reasons that include career development, project management and client relations. Furthermore, transnational companies (TNCs) have a range of different types of mobility within their internal labour markets at their disposal, including long-term, short-term and commuting assignments, business travel and virtual mobility, not all of which require a work permit.

\subsection{Mobility in the ICT sector}

The analysis of mobility in the ICT sector presented here is based on original research carried out as part of the Political Economy of Migration in an Integrating Europe (PEMINT) project, funded under the European Commission's Fifth Framework programme. It involved six research teams in Germany, Italy, the Netherlands, Portugal, Switzerland and the UK who carried out interview surveys during 2003 and 2004 with twelve to fifteen employers in each of three sectors - construction, health and ICT - in each country. The survey was designed to elicit information on how companies recruited and moved labour internationally, in both the external and internal labour markets. The dominating feature of the ICT sector is the importance of the internal labour market.

The ICT sector is a relatively new one in which companies have grown rapidly, new forms of mobility have been developed and flow management has to some extent been ceded by governments to large employers. The results of the project presented here demonstrate how international business competition and corporate development create a sectoral mobility syndrome involving the international acquisition and deployment of human resources. ${ }^{2}$

\subsubsection{Trends in the sector}

The ICT sector is by no means a conventional sector. ICT occupations, i.e. jobs that intensively use modern technologies of information and communication, cross-cut all economic sectors. The sector is young and dynamic and characterised by short-term economic constraints. From around the mid-I99os a rapid expansion of the sector occurred. This was driven by several factors, including the widespread adoption of email, the development of the web and lower computing costs that brought technological developments into the realm of the individual, 
both at work and at home. New markets were created worldwide. These developments were supplemented by a series of events that increased the demand for ICT support and development staff, notably including the publicity about the potential 'millennium bug' and the adoption of the euro.

Meanwhile, in the telecommunications sector parallel developments were occurring, linked in many ways to the mainstream IT developments mentioned above. The new generation of mobile phones coming onstream in the early i99os brought telecoms into the hands of individuals, attracted by low prices and convenience. More recently, the socalled third-generation implements have extended the market for purposes of both business and pleasure (and perhaps even fashion).

These technological developments in the sector were accompanied by a pronounced demographic slant in the market. A new, young generation was trained at school in computer use, devoting academic and leisure time to the internet and game consoles. At the same time, this generation was embracing mobile phone technology at an astonishingly rapid rate. There was thus an enormous surge in demand for ICT products and services in precisely the group that would normally be expected to enter the market for them at later ages.

The early consequence of these developments was to highlight the dissonance between education and training on the one hand and the explosive growth in demand for new skills on the other. Put simply, the need by all types of organisations for ICT-literate staff exceeded the ability of the educational system in most European countries to provide the supply required.

Shortages of ICT skills became manifest in many countries during the late I99os. International recruitment was an inevitable response and a number of governments introduced special schemes or treatment to expedite the immigration of appropriate skills. By the turn of the century ICT skill shortages were common and wages were being pressed upwards. The combination of waves of technical developments (for example, three generations of mobile phones), swift penetration of both business and private markets, specific events such as the millennium $\left(\mathrm{Y}_{2} \mathrm{~K}\right)$, the explosion of silicon chip power in a multitude of products and the rapid and widespread growth of education and training provision in Europe and beyond (notably India) served to create an almost unique environment in which international recruitment took place.

Looking back, it is striking how rapid but short-lived this boom phase of the ICT sector was. Economic and labour market conditions changed and, by 2002 and 2003 , new international recruitment was at a low ebb. In an effort to reduce costs outsourcing was becoming more common, at first of more routine operations, by both ICT product com- 
panies and ICT user companies, then of managerial and supervisory occupations. ICT employers adapted their recruitment practices to changing technological and market conditions. Since then, in some countries at any rate, international ICT recruitment has bounced back. For the UK there was a 39 per cent increase in work permits given to information and communications technology professionals between 2005 and 2006.

\subsubsection{Characteristics of the ICT sector affecting international recruitment}

The PEMINT survey showed that the sector is characterised by several features that individually and collectively affect international recruitment.

\section{Low degree of institutionalisation of professions and occupations}

The rapid growth of the sector and the organic nature of occupational evolution has seen companies in both the dedicated ICT and user sectors building their own structures of positions, careers and salaries related to their functional needs, one consequence of which has been only a slow growth of professional institutionalisation. Nevertheless, there are some commonalities with respect to the structure of occupations. First, many jobs require high qualifications (though not always formally acquired ones). These are the ones where international mobility is most likely. However, the sector also comprises a substantial tranche of lower-level operatives, like data inputters, many of whom have seen their jobs outsourced. Second, many jobs and functions are internally defined, emerging from the business specifics of the organisation, such as the development of new hardware or software. This means that the coupling between the formal education and training systems that produce the skills and employers may be more or (frequently) less strong. Where the latter is the case, intra-organisational mobility is more likely than external recruitment.

\section{Cycles and the need for flexible responses}

The sectoral characteristics discussed above, particularly the speed of boom and bust and the instability created, emphasise the need for flexible responses by employers. Unintended accelerators, such as the euro and $\mathrm{Y}_{2} \mathrm{~K}$, have been major forces for change which have challenged human resource departments to provide instant but short-term solutions to labour shortages. Recruitment in these circumstances has had to react quickly, while at the same time allowing longer term strategies to be nurtured and developed. In response to these challenges, international mobility in various forms grew rapidly in the late I990s and 
around the turn of the millennium, but then almost halted as market conditions changed.

\section{Institutions in the fledgling stages}

The new ICT sector, to some extent along with its older parent in electronic engineering, has developed rapidly as technology has dictated. Sectoral institutions such as employers' organisations and trade unions are only partly developed and have not easily adapted to the rapid organic growth. Collective bargaining is not well developed and company agreements on wages and working conditions are common. The low level of institutionalisation also means that the constraining influence of actors external to the organisation is lower than in some other sectors. The consequence for international recruitment is that employers have greater freedom of action to develop their own policies and practices, actions that reinforce their tendency to move staff within their corporate internal labour markets.

\section{Oligopolistic tendencies}

Despite the youth of the sector, several companies have become dominant in their own countries, examples including Philips (the Netherlands), Siemens (Germany) and Vodafone (the UK). On a global scale, IBM, Intel and Microsoft have also achieved large shares of the market. Thus, a few companies generate a high proportion of the total market volume. Oligopolistic tendencies are aggravated by mergers and acquisitions, though this is more characteristics of ICT-dedicated rather than ICT-user employers. The implication of this situation for international migration is that recruitment in the sector as a whole is strongly affected by the human resources policies of the major players.

\section{Skill composition of the workforce}

The ICT sector is very labour intensive and has a wide skills profile. At one end are highly skilled workers, such as systems and software engineers and those engaged in research and development (R\&D). In the middle is a substantial group in analysis and application. Often these two groups work together to bring about a rapid and unproblematic rollout from development laboratories to production and service provision. At the lower end is a large but diminishing group of routine occupations, such as those in data inputting and call centres, many of which are being outsourced to cheaper locations. Most international recruitment is among the highly skilled, although not necessarily those at the technological frontier. In both ICT-dedicated and ICT-user companies, other functions, such as product management, are routinely traded internationally, usually within internal labour markets (ILMs). The extent of international mobility among these various occupations 
varies from employer to employer, depending on the stage of product, process, technological and marketing development reached.

\subsubsection{General findings for the ICT sector}

In all six countries, ICT has become a global sector where companies freely move capital, resources and labour. All the major companies are now setting up new branches abroad - especially in India - to bring the cheaper but high-level expertise there into an extended ILM.

The corporate ILM is central to mobility in the sector

One of the main findings of the survey was the high volume and proportion of ILM flows amongst all international ICT flows, both during and after the boom. By ILM flows are meant movements of personnel in the framework of organisations, in this case multinational companies. These companies have created international internal channels for moving their human resources, constituting the bulk of international ICT movements in current times. Most of this mobility has been shortterm and project-related (Millar \& Salt 2006).

The main rationale for ILM movements within multinational companies is the flexible use of existing staff, allocated according to functional and technical needs. Reasons for mobility are: knowledge of the firm, products and jobs by the assignees; the filling of local functional and technical temporary labour needs; and the aim of obtaining and giving training in the firm's products. The underlying basis for flows is the advantage of scale on the part of large firms. One implication of these causes is that labour costs are not a main reason for migration. Instead, the main reason to move personnel is to create optimal allocation of factors, even when costs involved are high.

Much of the movement that goes on in ILMs is in the form of temporary assignments or secondments, which may last from some weeks to two to three years. As a result, employees remain contractually linked to the sending firm. Few permanent (long-term) movements were detected, although localisations (changes of contractual link) are increasing, in order to reduce costs. The situation is evolving, with more localisation of personnel (changes of contractual links, even when temporary), extended business trips (international commuting) and virtual assignments (virtual mobility). Some organisations were reducing their ILM flows by substituting them for partnerships through the use of contractors and subcontractors.

The central importance of the ILM for ICT companies is confirmed by the strategies of reinforcement of firms through mergers, acquisitions and the opening up of new branches, including cases of relocation of functions. Mergers and acquisitions reinforce the overall inter- 
nal competencies of the firm, reuniting in a common hierarchy a wide array of skills. This strategy is accompanied in some cases by the relocation of functions to foreign countries, either manufacturing facilities or software development centres, for example to India. The rationale is mainly the lower labour costs and perceived local surpluses of those countries but increasingly this advantage is supplemented by growing recognition of high-level project management skills in these locations as well.

\section{Firms in all countries have a common recruitment process}

The process is characterised by the use of the most economic option, except for a small number of high-level appointments where headhunters are used. In essence, the recruitment process starts locally then expands outwards. This means that the ILM is tapped first; it also means that national external labour markets are probed before the job search goes international. High costs deter international recruitment.

Once a vacancy has been agreed it is advertised on the firm's intranet worldwide, usually for two weeks. If this is not successful, the job advertisement is placed on the internet. All applications are expected to be made online. Large ICT companies build up databases of applicants, which may be used for future vacancies. Several informal methods of attracting applicants are used, including 'find a friend'. Qualifications for high-level technical specialists are often checked through the informal networks of people already working for the organisation.

International recruitment is linked with corporate culture and corporate careers Earlier research on international mobility within TNCs has shown its importance as both a vehicle for promoting corporate culture through the creation of a feeling of 'belonging' and also a response to the development of the concept of corporate career. One of our findings was that in the young, dynamic companies that populate the ICT sector, corporate cultures and careers are less well developed, with consequences for mobility. There is evidence that career development in the organisation is no longer so tied to corporate culture: for example, 'own your own employability' implies a less paternalistic approach by the company. The larger TNCs have shifted the emphasis for initiating an international relocation away from the company and on to the individual. In these new circumstances, international mobility within ILMs follows from employees responding to advertisements on the firm's intranet rather than being asked to take temporary assignments.

Furthermore, corporate culture is now more related to the technological product than to the company itself. For example, people see themselves as specialists in Windows, Oracle, etc. This means that there are different functional careers within companies, with a broad distinction 
between product (often technologically based) and marketing, sales and so on. These careers may be linked to the different natures of national businesses within the overall TNC. Thus, someone in a country where the company has a predominantly sales function will have a different career trajectory from someone in the same company in a different country where there is a strong element of R\&D.

\section{Education, training and employers are loosely coupled}

The sector is linked with national educational systems, which do not always provide the right quantity, quality and skills balance required. When the upsurge of demand for skilled personnel in the mid-I99os occurred, formal education and training systems could not meet it, resulting in shortages. Subsequent educational expansion, combined with the decline in demand, led in several countries to an oversupply of young people with technical skills. The link between formal education in ICT skills and employer requirements is currently being tested by the increasing preference in some companies in some countries for experience and expertise rather than for new graduates and in the growing importance of generic over commodity skills. Overall, there seems to have been a move towards quality rather than quantity in those recruited. Thus, whereas a few years ago there was a shortage of technical skills, these are now available and it is generic skills that are needed - including applications, management, using technical skills and products. Companies are looking to recruit in places where these skills are available.

There are two main reasons why the ICT sector is only loosely coupled to the educational system. First, the continuing development of new technology means that formal courses have difficulty keeping up. Second, the lack of formal legislation governing qualifications in the sector means that there is no formal accreditation that is internationally accepted. Thus, the development of ICT expertise is done inside the firms in a relatively autonomous manner and outside formal educational and professional institutions. This is reflected in the huge importance of training in many of these companies. As a result, individuals develop their skills largely inside the firm, going beyond the knowledge they have gained from formal education. In the face of this effervescent internal knowledge production, firms prefer to rely, as much as they can, on the mobility of internal human resources, instead of turning to external workers and competencies. National policy regulations have become relatively less important in light of these powerful global firm mechanisms. 


\section{Size of firm is a critical variable}

The survey revealed major differences in recruitment practices between employers in different countries, depending on the size, ownership and function of the national company. In the case of TNCs, the national companies of foreign-owned firms tend to be engaged in sales and marketing and/or producing craft or niche products for local application. Large-scale R\&D and application tends to be done in a few locations only, usually in the headquarters country and region, where recruitment of high-level specialists is focused. One consequence of this is the creation of geographical channels of mobility between headquarter locations and national locations elsewhere, with much less mobility between non-headquarter parts of the corporate network. In the case of small- and medium-sized enterprises (SMEs), production and application is usually done locally so that national recruitment is the norm.

Large TNCs and small SMEs have different rationales governing their processes of recruitment. For SMEs particularly, recruitment is mainly in the national external labour market, for several reasons: practical difficulties of recruitment abroad (for example, costs of interviewing); better 'observability' of qualifications, leading to preference for recruitment through national networks; importance of generic and social skills, including languages; constraints imposed by the regulatory framework regarding foreigners (mainly non-EU); and the limited importance of labour costs as a rationale for flows.

National cultural and linguistic issues are superimposed on the sector. The lingua franca in the sector is English and more often than not large companies are American-owned. Among small- and mediumsized companies, national cultural attributes are much more in evidence. This limits their international recruitment.

\section{Technology is exploited}

Technology is heavily exploited in the recruitment process. It allows the maximum advertisement for the minimum cost and, through online application and processing, it is also used in the selection process. It also allows firms to build up databases of potential recruits worldwide to be exploited as and when necessary.

The universality of technology in the sector also encourages subcontracting and outsourcing, mostly of the routine activities carried out by less skilled staff. In general, and particularly among the larger firms, core activities are not outsourced because the aim is to preserve the firm's knowledge and competencies. Smaller national firms subcontract more often, sometimes for core activities, but only occasionally with international partners. When subcontracting occurs with firms in other countries, it is usually for less-skilled jobs. 


\section{Constraints on mobility are not a major issue}

ICT firms were not greatly concerned about the bureaucratic constraints (such as taxation and welfare systems, labour market regulations) on mobility. The basic message was that if the best person for the job had been identified, whatever was necessary to expedite the move was done. Where there were hindrances to mobility it was usually over matters of detail rather than fundamental principles. As one company put it in relation to assignments, constraints are irritants not major hurdles.

Work permit systems vary strongly between countries but for the most part did not prevent firms recruiting the skills they needed, especially through the ILM. Professional qualifications are rarely an issue, companies being more interested in practical experience with specific packages or skills. However, different qualification titles can be confusing in different countries and some concern was expressed about the difficulty of evaluating the quality of university degrees from different foreign institutions. In such circumstances it is not surprising that companies prefer to recruit from what they know - those they already employ - or from sources with which they have some familiarity.

Frequently, the major obstacles to international mobility in the ICT sector are of a social and cultural nature. Factors such as language and social networks of support were cited as the main barriers to inflows and outflows of foreign and indigenous professionals. A consequence of this is the tendency to recruit from countries where there is a common language. Knowledge of the local language was often considered as an advantage even in large multinational software firms and even though the firm's products are available in English, the common language in software. On a larger scale, it explains the generalised preference for national employees in ICT firms and the recourse to foreign staff mainly for temporary project development. The advantage of scale in large multinational corporations is evident in this field, since they are able to combine the particularity of national markets and branches with a potentially very mobile international workforce.

In the overall context of enlargement, an important finding from the survey was the low importance attached to the EU provision for free movement of labour in influencing ICT international labour mobility. True, the bureaucracy of work permits and other administrative issues relating to non-EEA citizens was to some extent an obstacle: for example, there was some feeling that work permits, stay permits and residence authorisations are cumbersome and demotivating. However, these problems seemed to constitute only minor frictions to labour mobility in the sector and EU belonging was never considered to be a major asset. Recognition of qualifications, increasingly dealt with within an EU framework, is not considered relevant for ICT firms, where ex- 
pertise is largely built inside the firm and is practical rather than based on formal qualifications.

\section{Mobility policy in the sector encourages movement}

The need for migration or mobility was for most ICT actors self-evident. The sector is not highly institutionalised. Government policy formulation frequently transcends ministerial boundaries, employers' organisations are not well developed and tend to be supportive of movement, while trade unions are less well developed than in more traditional sectors and in many cases are more concerned with organising foreign workers than preventing their inflow. Due to this fragmentation, institutional arrangements are less important than in other sectors for the definition of migration policy and, if they exist, they have a more positive impact for SMEs.

Special entry schemes, or modifications to existing ones, for highly skilled ICT workers have been common. They usually result from situations in which employers are strong, the work permit regime is formalised and no strong trade union opposition exists. In light of skill shortages, and with the connivance of the social partners, some firms are able to use foreign labour in informal ways.

Their global reach, together with government desire for foreign investment, means that large TNCs often act on their own and achieve preferential access to decision-makers. Overall, in the absence of strong trade unions in the sector, the presence of TNCs, and the international character of the sector, national labour conditions have not been a major concern to the extent that they hinder migration. With rising unemployment this might change. Education seems to be more of a complement than a substitute for migration.

\subsection{Conclusions}

Migration is an uneasy concept. Lacking homogeneity, it displays enormous complexity. Different mobility streams, summed up in terms of routes of entry, have different rationales, characteristics and implications for host and sending societies as well as for the migrants themselves. It is helpful to set explanatory frameworks in the context of the wide range of institutions and actors whose decisions bear upon the individual's propensity to move. One such framework perceives migration in business terms. This approach is particularly (but not only) apt in the explanation of labour migration, especially among the highly skilled. Among those moving within corporate internal labour markets it is particularly apposite. 
While it is possible to identify some of the actors in the migration business and their role in managing flows, current knowledge of their precise role, and of how much they gain economically from migration, is still limited. This is especially the case for new migrations. There is much research to be done on the characteristics and motivations of the institutions involved. We need to know their aims and objectives, and how they function; who owns them, their size and scales of operation. It means going beyond a simple 'institutions' approach to one that emphasises business objectives. The business concept necessitates a review of the management process. In effect we can view the institutions that drive migration as having their own management processes and criteria. To some extent these negotiations already take place where the social partners get together to determine quotas or changes to existing practice. Migration is thus the result of a set of negotiations between these institutions, leading to accommodation and compromise with respect to business objectives.

The ICT example demonstrates that in order to understand the changing pattern and flow of international migrants, it is necessary to focus on specific sectoral characteristics and to look beyond the atomised decisions of individual migrants to the many institutions and agencies, contextual factors and constraints, which help to shape international migration. The role of employers is fundamental. How they perceive their international business and turn that perception into human resource recruitment and deployment determines the scale of staff mobility, what sort of people move, where and when.

\section{Notes}

I For a recent review of types of knowledge and their relationship to migration, see Williams (2007).

2 For further details, see Sabino et al. (2004) and Kolb et al. (2004).

\section{References}

Baganha, M. \& H. Entzinger (2004), 'The political economy of migration in an integrating Europe: An introduction', IMIS-Beitrage 25: 7-22.

Balch, A., I. Fellini, A. Ferro, G. Fullin. \& U. Hunger (2004), 'The political economy of labour migration in the European construction sector', IMIS-Beitrage 25: I79-I99.

Beaverstock J. V. (2002), 'Transnational elites in global cities: British expatriates in Singapore's financial district', Geoforum 33: 525-538.

Beaverstock J. V. \& Boardwell, J. T. (2000), 'Negotiating globalisation, transnational corporations and global city financial centres in transient migration studies', Applied Geography 20: 277-304. 
Den Adel, M., W. Blauw, J. Dobson, K. Hoesch \& J. Salt (2004), 'Recruitment and the migration of foreign workers in health and social care', IMIS-Beitrage 25: 20I-230.

DIMIA (Department of Immigration and Multicultural and Indigenous Affairs) (2004), The Changing Labour Force Experience of New Migrants, DIMIA, Australia.

Gott, C. \& K. Johnston (2002), The migrant population in the UK: Fiscal effects, RDS Occasional Paper No. 77. London: Home Office.

Kolb, H., S. Murteira, J. Peixoto \& C. Sabino (2004), 'Recruitment and migration in the ICT sector', IMIS-Beitrage 25: I47-I77.

Koser, K. \& J. Salt (1997), 'The geography of highly skilled international migration', International Journal of Population Geography 3: 285-303.

Massey, D. S., J. Arango, G. Hugo, A. Kouaouci, A. Pellegrino \& J. E. Taylor (I998), Worlds in Motion. Oxford: Clarendon Press.

McLaughlan, G. \& J. Salt (2002), 'Global competition for skills: An evaluation of policies', in Migration: Benefiting Australia. Conference Proceedings, Sydney 7-8 May 2002, 20I243. Sydney: DIMIA (Department of Immigration and Multicultural and Indigenous Affairs).

Millar, J. \& J. Salt (2007), 'In whose interests? IT migration in an interconnected world economy', Population, Space and Place I3: 4I-58.

OECD (2002), International Mobility of the Highly Skilled. Paris: OECD.

Sabino, C., S. Murteira, J. Peixoto \& H. Kolb (2004) Employer recruitment and migrations in the ICT sector. PEMINT working paper, January.

Williams, A. (2007), 'Listen to me, learn with me: International migration and knowledge transfer', British Journal of Industrial Relations 45 (2): 36I-382. 



\title{
3 On the demand side of international labour mobility: The structure of the German labour market as a causal factor of seasonal Polish migration
}

\author{
Barbara Dietz and Pawel Kaczmarczyk
}

\subsection{Introduction}

Since the adoption of a bilateral agreement signed by the Polish and German governments in 1990, Polish workers have been allowed to take up seasonal employment (short-term and legal) in specific sectors of the German economy. According to the agreement's provisions, the seasonal workers ${ }^{1}$ from Poland can undertake working activities in Germany for a period of three months. This relatively new form of migration has constituted a large part of Polish migration in the last couple of years: since the year 2000, over 250,000 workers have taken seasonal employment in Germany annually.

The agreement was generated by mutual will to minimise the negative effects of the economic and political transition in Poland in the I990s, and to control and restrict East-West labour movements to Germany which were expected to increase rapidly because of the opening up of Eastern Europe and the high differences in income and living standards between East and West. These arguments were presented on both sides, but it is clear that the need for low-skilled labour in several sectors of the German economy was the main force driving Germany to open selective paths to its labour market to Polish workers, but also, in limited numbers, to skilled workers or trainees, especially in the construction sector. In addition, the agreement with the Polish government provided for the legalisation of illegal employment, so prevalent in the previous decade.

It is the aim of this chapter to analyse the demand-side causes of (seasonal) labour migration in the context of the German labour market - the most important receiving labour market for Polish migrants since the I990s (at least prior to the EU enlargement in 2004). The study is based on two unique empirical data sets: on a quantitative survey with Polish seasonal workers and on a qualitative interview study with German employers of Polish seasonal migrants. The authors ar- 
gue that the recruitment process initiated in the early I950s influenced the structure of the German labour market in a very substantial way, leading to labour market segmentation in certain sectors. The hypothesis of labour market homogeneity/heterogeneity will be examined with reference to the dual labour market theory. The participation, position and mobility of foreign labour in the German economy will be emphasised. Against this background, seasonal migration from Poland to Germany as a demand-based movement in the perspective of existing labour market policies in Germany will be analysed. Using quantitative data from a nationally representative survey of Polish seasonal workers, the authors attempt to interpret the scale and patterns of this kind of mobility within the segmentation framework. Looking at the process from the demand side and based on a qualitative interview study with employers of Polish seasonal workers in Germany, the recruitment practices of enterprises and the evaluation of workers' performance are explored to confirm the hypothesis of a demand-driven labour migration on the enterprise level. The concluding part of the chapter shows the significance of seasonal employment for the German economy and gives an outlook for the future of seasonal EastWest migration in an expanding Europe.

\subsection{Recruitment of foreign labour and its consequences for the German labour market}

According to official data, in 2004 there were 7.28 million foreigners in Germany; they constituted 8.8 per cent of the whole population. This stock is the result of the inflow that has taken place over the last 40 years, mainly as a consequence of so-called recruitment programmes, predominantly between I955 and I973. It seems that the recruitment process is of key importance for understanding the contemporary situation in certain segments of the German labour market.

\subsubsection{German recruitment policies}

At the beginning of the I950s, European countries entered a new phase of economic prosperity. Between I953 and I958 industrial production in Europe increased by 30 per cent, and in some countries (France, Germany), even by 50 per cent (Harris I995). Because the demand for labour was large, and the supply could not satisfy it, ${ }^{2}$ employers were prompted to compete for workers, usually by paying higher wages and offering better working conditions. The factors supporting the development were undoubtedly an increase in female labour force 
participation and the globalisation of production. However, regardless of this, many countries started to seek sources of labour abroad.

This process had its greatest consequences in Germany. The first serious employment deficit was revealed in the mid-I950s. Disequilibrium on the labour market was not only the result of ever-growing economies, but also of the nature of supply. Among other things, the fertility rate plummeted, and the rate of labour force participation of native workers decreased as well. In the meantime, full employment was reached, and together with prosperity the expectations and aspirations of the native working force grew. The pool of jobs perceived as unattractive for their working conditions, low wages, or inadequate social status widened. Parents were helping their children to get a better education, which later on would strengthen their position in the labour market. Because of that social process the number of economically active people further decreased (Frey \& Mammey I996; Rhoades I978).

The inflow of workers from East to West Germany had the most significant impact until the Berlin Wall was built (approximately I.8 million refugees), but after I96r that flow was almost totally cut off. In fact, recruitment action had started even before then. It was conducted mainly in the Mediterranean countries, and bilateral agreements were signed with Italy (I955), Greece and Spain (I960), Turkey (I96I), Morocco (I963), Portugal (I964), Tunisia (I965), Yugoslavia (I968) and even Korea (I973). All agreements not only provided for the desired inflow of labour, but also established German recruitment institutions in the sending countries. It was clear right from the start that the recruitment programme was not only about the inflow of labour, but also about its rigorous control and adjustment to the needs of the German economy.

At the beginning, the immigrants followed those lines, and the 'rotation rule' worked almost flawlessly. The first significant change occurred between I960 and 1966, when the number of foreign workers grew from 279,390 to I,314,03I, and the quota of foreigners in employment increased from I.3 per cent to 6.3 per cent. The system was tested during the recession of I966-1967, when the German institutions managed to reduce the number of foreign workers by about 500,000 (46 per cent). However, in the period of fast economic growth in the years I968-1973 their number grew again from about I.6 million to 2.6 million foreign workers (Angenendt I992; Frey \& Mammey I996). By allowing such an increase, German recruiters confirmed that guest workers can constitute a manpower reservoir. Moreover, one could see the signs indicating that a foreign workforce does not lose its attractiveness even in the times of recession. Foreigners concentrated in narrow branches and niche professions, usually avoided by the native labour 
force, and gradually became indispensable even during periods of the worst economic climates (Rhoades I978).

In 1973 there were perhaps seven million foreign workers in Western European countries, amounting to 9 per cent of the labour force. In Germany, the number was 2.6 million, approximately I2 per cent of all employed people (Collinson 1994; Bender \& Seifert 1997; Frey \& Mammey I996). However, the recession caused by the oil crisis brought the 'full employment' era to an end, and economic prosperity came to an abrupt end in most Western European countries. From then on new jobs were created mainly in the service sector and not in industry, as in previous decades. Demographic pressure from the native population was growing, competition on the job market was fierce, especially in the most attractive branches, and the level of unskilled workers' wages, and thus standards of living, was decreasing. For the first time in the post-war period, unemployment reached relatively high levels (in the case of Germany, the unemployment rate in the mid-I970s was close to 5 per cent as compared to less than I per cent in the I96os). The need to stop immigration became ever more present in public debates. As a consequence, in 1973 the end of the recruitment programme was announced in Germany (Anwerbestopp) ${ }^{3}$

Officially, since the mid-I97os, Germany has not conducted any recruitment programmes, and the aim of its immigration policy was to limit the inflow of foreign workers who were not citizens of member states of the European Community (later on, the EU). Moreover, the policy was to support the integration of foreigners staying legally on German territory. Regardless of the new restrictions and general discouragement, the number of immigrants, some nationalities in particular, was still growing (see figure 3.I).

The migratory regulations became even more restrictive at the beginning of the I980s. In 1982, the German government announced that the Federal Republic of Germany was not a country of immigration and that the inflow of immigrants should be limited by all possible legal means. However, some extraordinary options for immigrants were introduced later on. One of them was the possibility of employment for seasonal workers from the Central and Eastern European (CEE) countries, regulated by bilateral agreements since I990 (see part 2).

The recruitment of foreign labour had far-reaching consequences for the German economy. First, it was a driving force behind the export boom and the dynamic development of the economy. Second, thanks to the inflow of foreign immigrants to the industrial sector, the service sector could develop without negative effects on employment in the traditional branches. Last but not least, important social changes took place. Guest workers made it possible for native workers to climb up the social and the professional ladders. It is estimated that between 


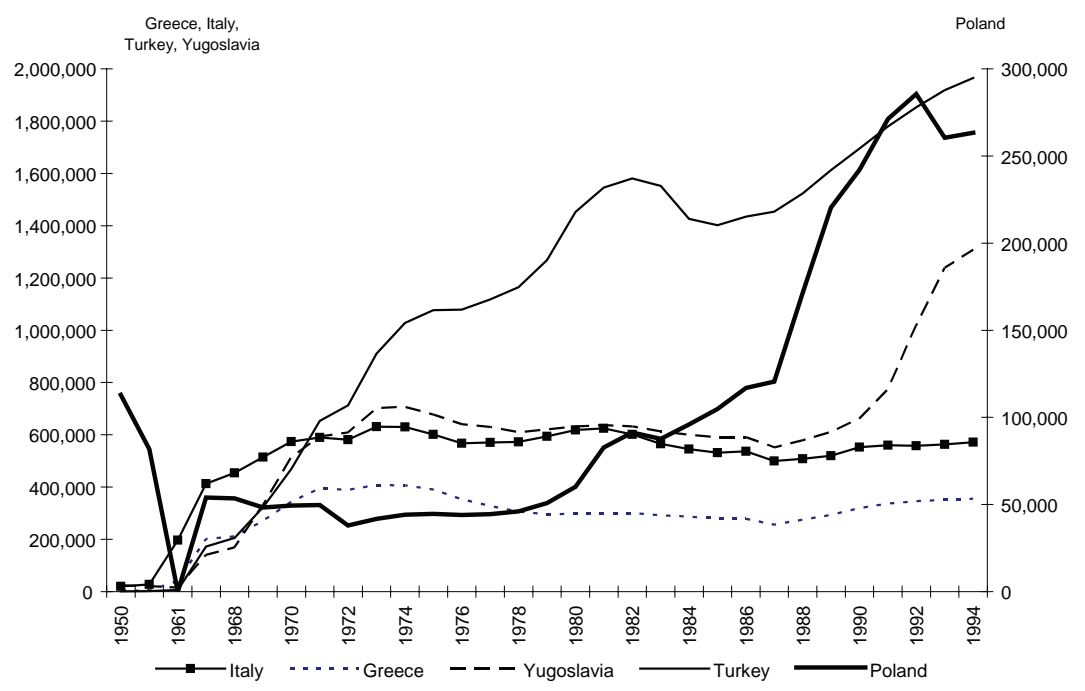

Figure 3.1 Stock of immigrants in Germany by selected countries of origin, 1950, 1955, 1961, $1967-1994$

Source: own calculations based on Frey and Mammey 1996: 140

I96I and I968 about I.I million Germans moved from blue-collar to white-collar positions. This was only possible because they were replaced by 500,000 foreigners (Harris I995).

Moreover, we argue that the recruitment programmes have influenced not only past migration, but also the present inflows to the country. Due to historical processes, the German labour market is to a large extent heterogeneous. Recruitment was meant to fill the gaps in the labour market, but it was not foreseen by German authorities that the German economy would gradually adjust to the presence of the foreign workforce (as explained in the upcoming section on the relationship between institutional changes within the economy and the labour market's structure). The German example shows that migrant workers are not only an additional element, a substitute for the native workforce, but an important growth factor, which remains significant even in times of globalisation and technological revolution. ${ }^{4}$

\subsubsection{Recruitment of foreign labour and the dual labour market theory}

According to the human capital theory, the position of an individual in the labour market is determined by her/his qualifications and skill level, the labour market is homogenous and the entry to specific parts/ sectors of the labour market is not blocked. In this context, people are 
moving in order to find the highest return from a given level of human capital. These assumptions have been challenged by Piore and others in the so-called dual labour market theory (Doeringer \& Piore I97I; Piore 1979). The theory states that highly developed economies may witness the process of creation and preservation of the dual structure of the labour market. This describes a labour market structure, where two sectors coexist: a primary labour market with secure employment conditions, comparatively high wages and social security standards; and a secondary labour market with low wages, little security and difficult working conditions. The boundaries between the markets/segments are to a large extent non-permeable for employees, which heavily influences their occupational mobility and professional career. ${ }^{5}$

Obviously, people in the labour force would prefer to take up employment in the primary sector but the chances of entering this sector are seriously limited (e.g. due to the relatively rigid structure of the economy). On the other hand, employment in the secondary sector is only attractive for a few groups: women (who combine professional activity with work at home), young people (students or graduates entering the labour market), individuals working on a temporary or seasonal basis, and foreigners. In the case of an excess demand in the secondary labour market segment, this will most likely not lead to an increase in sectoral wages (as is foreseen in the compensating wage theory, e.g. Ehrenberg \& Smith 2000; Borjas 2005), but in the hiring of immigrants. If legal immigration is restricted, undocumented migration often occurs.

A number of studies were published which attempted to test the dual labour market hypothesis with respect to Germany. Blossfeld and Meyer (I988) clearly confirmed the heterogeneity of the German labour market. Their analysis proves that the decisive role in the process of segmentation was played by extra-educational factors and that access to the market was seriously limited. The analysis of labour market structures through job characteristics also confirmed the hypothesis of the dual labour market. It indicated that the jobs offered in the secondary market provided worse working conditions, lower wages and larger fluctuations of employment (Szydlik I99I). Using classical demarcating criteria (number of employees in a company and required skills of workers), Szydlik (I99I) estimated that the secondary segment could amount to 2I.5 per cent of total labour force (1989). ${ }^{6}$

In the period of immigrant recruitment (I955-I973), foreigners were recruited mainly for employment in the industrial sector and partly in the secondary segment. In order to examine whether that process changed the structure of the German labour market in a lasting way and in consequence caused its relatively high heterogeneity, the position of immigrants in the contemporary labour market must be analysed. In 
I989, despite the fact that the peak period of the recruitment programme had occurred almost two decades previously, foreigners were still concentrated in industry ( 64 per cent of the employed) and in construction (I3 per cent). The position of the native workers was quite different: the share of the natives employed in industry and construction amounted to 35 per cent and 6 per cent, respectively (Seifert I995; Frey \& Mammey 1996). In 2004 the share of foreign workers employed in industry was still about eight percentage points higher than in the case of natives (33 per cent versus 25 per cent). The lower share of foreigners employed in industry is not necessarily to be attributed to occupational upward mobility but rather to a significant change in the German economy, namely the shift from growth driven by traditional, i.e. industrial branches to a development based on the so-called third sector.

The heterogeneity of the German labour market is also reflected in the segmentary structure of employment of natives and foreign labour. According to German estimates, in the I980s, foreigners employed legally in Germany were concentrated in the secondary segment, although in a span of five years the share of foreign workers decreased from 6I per cent (I984) to 49 per cent (I989). By the end of the I980s, only I6 per cent of Germans were employed in the secondary segment, mainly young people (I7 per cent), women (24 per cent) and individuals with a very low level of education. The immigrant population is not homogenous and the second generation of immigrants, in particular, seems to be doing better. However, some of the groups, especially foreign women and Turks, had been effectively 'excluded' from the primary segment ( 72 per cent and 53 per cent of the employed in the secondary segment in 1989 , respectively) (Seifert 1995). ${ }^{7}$

The main controversy with respect to the participation of foreigners in the labour market and to the segmentation hypothesis concerns the comparability of the qualification levels (human capital) of natives and migrants. Therefore, it is hard to define what factors can be responsible for participation in a given sector, wages, labour mobility, etc. Below, selected results of more advanced analyses dealing with the question of discrimination in, and the segmentation of, the German labour market are presented.

Szydlik (I99I) examined the significance of such factors as age, sex, length of employment and nationality for participation in a given segment of the labour market (controlling for level of qualifications). It turned out that the most important factor influencing employment in the secondary segment was nationality (the fact of being a foreigner). According to the author, the over-representation of foreigners in the lower segments of labour market is not the result of a qualification gap, but of systematic discrimination in the access to more qualified jobs. 
Seifert (I996a, I996b) analysed the position of the so-called 'new immigrant groups' in the German labour market. The focus was on individuals who came to Germany in the second half of the I980s and in the I990s. 8 The researched groups differed by 'cultural conformity' (migrants from East Germany), by the scale of the state support (ethnic Germans) and a significantly higher level of completed education, in comparison to the migrants from the 1960s and 1970s. ${ }^{9}$ Econometric analysis showed that in the cases of the new immigrant groups, their levels of education and qualifications had almost no influence on employment opportunities, and thus on their presence in the labour market.

Velling (I997) showed that wage discrimination for foreigners is confirmed when using an econometric model. This effect was clearly visible in the case of the CEE immigrants: with respect to this particular group the income gap equalled 20.8 per cent, 13.5 per cent of which should be attributed to discriminatory practices.

Constant and Massey (2003) proposed an analysis of potential discrimination against foreigners, with respect first to the allocation of people to occupations, and second to the attainment of earnings by given groups. Using data from the German Socioeconomic Panel they found that in the case of the initial occupation, the return on human capital was much lower for foreigners than for Germans. Moreover, the status gap between Germans and immigrants widened with time spent in the labour market. This shows that foreigners are less able than natives to translate their human capital into occupational status. Constant and Massey concluded that there is a significant degree of ethnic discrimination in the allocation of people to sectors and jobs but there is no evidence of earnings discrimination.

Radu (2003) analysed the labour market performance of migrants from Eastern Europe in Germany. In order to assess the wage differentials between Germans and immigrants he used individual data from the Federal Labour Office and applied the so-called Oaxaca Blinder decomposition with 'assimilation' and 'cohort' effects. He concluded that Eastern Europeans have a very restricted access to jobs in the primary sector and that their labour market mobility is seriously limited. As a consequence, there are no assimilation effects, either in terms of earnings or in terms of human capital characteristics.

The studies quoted above confirm that foreigners are indeed concentrated in the secondary segment of the German labour market, and that they follow different career/occupational mobility patterns from those of the native population. In addition, these differences primarily result not from the level of human capital, but rather from the fact of being a foreigner. Considering these arguments, we can accept the hypothesis about the segmentation of the German labour market and about ethnicity as a key factor determining participation in a given seg- 
ment. This situation is a direct consequence of the recruitment programme as a result of labour shortages and shows how durable such structures are, especially if they are reinforced by institutional elements (migration policy, legal regulations, labour market institutions and mechanisms freezing certain solutions). Furthermore, this situation explains why when an excess demand for workforce in the secondary sector cannot be satisfied, the demand for migrant workers again increases. If the government is willing to minimise the negative effects associated with an excess demand for labour (including migrant labour), extraordinary immigration regulations come into force. One such extraordinary regulation was the opening of the German labour market to CEE workers, especially seasonal workers; although this opening is regulated in a very restrictive and precisely defined way.

In the case of seasonal labour migration to Germany, CEE workers can only be recruited if no German or foreigner living in Germany is available for the job in question. This being proven, a German employer can hire Eastern European workers for up to three months a year (with the exception of exhibitions - up to nine months a year). Seasonal workers have to be paid the same wage as a comparable German worker and the payment of social security contributions according to German standards is obligatory. ${ }^{10}$ In addition, the employment of seasonal workers from Eastern Europe is basically restricted to the agricultural sector, restaurants and hotels. Theoretically, the recruitment process is strictly controlled. The recruitment is conducted by the German National Labour Office in collaboration with the Voivodeship (Regional Administration) Offices in Poland (Okólski 2004). In practice, employers make use of indirect channels to contact potential employees.

\subsection{Seasonal labour migration from Poland in the light of German immigration and labour market policies}

After the bilateral agreements on labour migration between Germany and Poland came into force, the inflow of seasonal labour migrants from Poland started dynamically. In I99I, approximately 78,600 seasonal Polish workers entered Germany, while in 1992 137,000 Poles arrived. In 2002, the number of Polish seasonal workers increased to over 280,000 and in 2004 to 320,000 people (see figure 3.2 ).

Although seasonal workers from Poland do not have an important weight in the foreign labour force in Germany (approximately 2.5 per cent), their share in the seasonal agricultural labour force is huge (nearly 90 per cent).

For years, a contradictory discussion has been going on in Germany concerning the employment of low-skilled (seasonal) labour migrants 


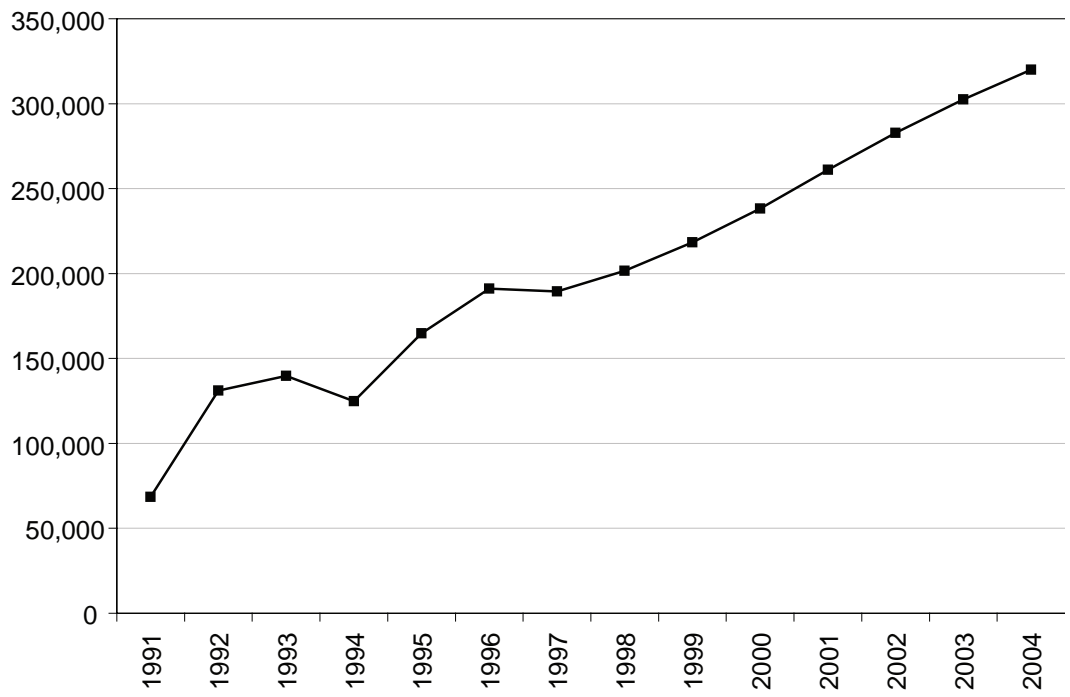

Figure 3.2 Seasonal Polish workers employed in Germany, 1991-2004

Source: own calculations based on the data of the Polish Ministry of Economy and Labour

from Eastern Europe, particularly in agriculture. Despite a persistent and high rate of unemployment, especially with respect to low-skilled labour, German farmers have great difficulties in hiring unskilled seasonal workers. ${ }^{11}$ Thus, German (agricultural) employers strongly approve the bilateral agreements on seasonal labour migration, arguing that seasonal labour migrants have contributed considerably to the recent development of German agriculture. As Germany is the biggest agricultural producer in Europe with 191,400 permanent and 289,200 temporary (mostly seasonal) workers employed (in the year 2003), this is an important argument in favour of seasonal labour migration (DBV 2003: 104). In this context, it is also worth mentioning that every tenth job in Germany is dependent on agricultural production or on agriculture-related industries (BVEL 2003).

Against the background of an excessive demand for seasonal jobs in agriculture, local labour offices in Germany started a number of initiatives to motivate low-qualified unemployed natives to take up seasonal jobs (Spahn I999). In retrospect, it must be admitted that these efforts have more or less failed. According to the labour office and to employers, most of the newly hired natives did not appear at the workplace or they left the job after a short working period. In this context it has to be mentioned though that seasonal jobs in agriculture are low paid yet demand a high level of motivation and a good physical constitution. Furthermore, seasonal jobs in agriculture belong to the so-called $3 \mathrm{D}$ 
jobs (dirty, dangerous and degrading), which most natives are not willing to accept. Thus, seasonal work in agriculture is characterised by features typical for jobs in the secondary segment of the labour market.

Another important reason for the failure to recruit low-qualified seasonal labour in the native German labour market may be found in the comparatively high unemployment and social security benefits (Bonin, Kempe \& Schneider 2003). To increase the readiness of unemployed natives to accept low-paid seasonal work, either wages for seasonal labour would have to be increased considerably or welfare payments would have to be reduced. ${ }^{12}$ A similar effect is expected from the introduction of the so-called 'workfare concept' which connects welfare payments to obligatory work in the social sector. As wages based on welfare payments are low, the workfare concept might motivate the unemployed to accept low-paid jobs. Despite the fact that no alternative to seasonal migrant workers has been presented yet, bilateral agreements on seasonal labour migration have been strongly criticised, especially by trade unions. A basic argument is that permanent jobs in agriculture have been turned into seasonal jobs, leading to increased unemployment among natives (Spahn 1999). Although this has been proven in certain cases in Germany, no empirical evidence exists for significant job destruction in agriculture as a result of seasonal labour migration (Hönekopp 2001). A further argument against the employment of seasonal labour migrants is the problem of wages and social dumping (EIRO 2003). This means that foreigners might depress native wages and put pressure on working and social security standards.

Nevertheless, to evaluate the effects of seasonal labour migration in general, some theoretical considerations have to be introduced. According to economic theory, immigration might influence income distribution, wages and employment in the receiving country (Bauer \& Zimmermann I999; Bauer 2000). In a simple model with homogenous labour and wage flexibility, labour migration causes native wages to decrease, whereas the output and income of capital owners increase. If wages are not flexible - the typical situation for most economic sectors in Germany - labour migration might result in native unemployment.

However, in the case of heterogeneous labour (Bauer \& Zimmermann I999) the impact of labour migration on wages and employment is dependent on whether foreign workers are complements or substitutes to native workers. Economic theory predicts that the immigration of foreign labour that substitutes native workers will tend to reduce the wages of the substituted natives and increase their unemployment risk. In contrast, the immigration of foreigners who are complements to native workers will very likely lead to a wage growth for the complemented natives and a reduction of unemployment. In a model 
with two types of labour, low- and highly qualified, the immigration of low-qualified workers would in all probability cause a decrease in wages for low-qualified natives and/or an increase in their unemployment. Highly qualified natives, on the other hand, would be better off. Accordingly, the immigration of qualified workers would support a wage increase or unemployment decline for unskilled natives, whereas the wages of highly skilled workers would most likely decrease. Put simply, the immigration of foreigners who substitute native workers tends to reduce the wages of the substituted natives and increase their unemployment risk. In contrast, the immigration of foreigners who are complements to native workers will very likely lead to wage growth for the complemented natives and to a reduction of unemployment.

With respect to seasonal agricultural labour migrants in Germany it can be argued that, because of the excessive demand for workers in this labour market segment, migrant workers are most likely to be complements to native labour, especially in relation to more qualified agricultural jobs and to jobs in related downstream and upstream industries.

\subsection{Polish seasonal workers in Germany: analysis based on quantitative data}

\subsubsection{Data}

The empirical basis for the following analyses are data gathered during a survey conducted among Polish seasonal workers in 2002 (April to May). We were able to make use of the complete address list of the individuals who had received seasonal work offers in the years I998200I. Thus for the first time in Poland, we had a unique opportunity of conducting countrywide migration research based on a representative sample. The value of the representative data is of crucial importance in the context of the analyses presented below. For the first time while doing research in this field we could go further than the limited official data provided by the German and Polish institutions.

The data relate to 804 randomly selected individuals, 65 per cent of whom were men and 35 per cent women, aged predominantly between twenty and 39 years. Because we had access to the database on Polish seasonal migrants for the years I998-200I, the survey does not necessarily encompass all people who took up seasonal employment in Germany prior to 1998 . However, it follows from the analysis that over 40 per cent of the interviewed people were employed in Germany in the years 1990 through 1997 (about 20 per cent during the first three years after concluding the bilateral agreement). As a consequence, the 
presented survey data do not only describe the actual situation but also the dynamics of the process since I990.

\subsubsection{Seasonal employment in Germany in the context of the segmentation hypothesis}

According to the dual labour market theory, two characteristics are crucial to identify the primary and secondary sectors. Classical demarcation criteria are based on the size of the company and the human capital (qualification) requirements. ${ }^{13}$ In order to test the segmentation hypothesis with respect to seasonal employment in Germany, it is also necessary to look first at the characteristics of the companies where Polish seasonal workers were employed. As a next step, the analysis will be devoted to the relationship between human capital on the individual level and labour market performance.

\section{Company size and type of work}

Because of legal restrictions the seasonal work sector open to Polish workers is limited to those branches of the economy related to agriculture and food processing. Over 90 per cent of all seasonal workers find employment in agriculture (40 per cent of them in vegetable gardening, approximately 35 per cent in orchards, and over Io per cent in vineyards). The second most popular sector, i.e. catering and hotels is of marginal importance only (around 3 per cent). The presented shares are relatively stable over time, even though agriculture is becoming increasingly predominant. As for the last employment of a given worker, 90 per cent of the surveyed workers found jobs in companies employing fewer than 200 people, and approximately I8 per cent in firms employing fewer than five people. Firms employing Polish workers are usually small and medium in size - the average size was 145 employees. ${ }^{14}$ The type of production (agriculture) indicated that they are active primarily in the regional and local markets.

As for the next criterion used in the estimation of the labour market segmentation, i.e. the level of required qualifications, the data leaves no doubts. Activities performed by Polish seasonal workers were extremely simple and were limited to harvesting vegetables and fruit and gardening (about 80 per cent of cases in total), or to sorting and working in warehouses (a further 9 per cent). Only in the case of very small percentage of workers can we assume that the work they performed required some qualifications. The data referred mainly to the individuals employed as cooks, drivers, fix-all workers, and individuals performing simple supervisory tasks. Thus we can state that the seasonal work market offers mainly simple jobs, and it does not demand any qualifications from the employees. ${ }^{15}$ 
The structure of employment

The owners of the majority of the companies employing Polish seasonal workers were German. However, not all of them employed Germans (except for the supervisory positions). From the information provided by respondents, it is clear that approximately 35 per cent of all firms employing Polish workers did not employ Germans (apart from supervisory positions). In addition, in half of the cases the employed Germans were permanent workers. In other cases they performed temporary or seasonal jobs, or they were members of the owner's family. The share of the permanent German employees is relatively higher in larger companies. However, this suggests that even in large companies, apart from the 'core positions' usually filled by the native employees, there are also structures reminiscent of a secondary labour market, where foreigners predominate.

Because Germans were employed in non-supervisory positions in only 65 per cent of the analysed companies, foreign workers have become the most important source of labour for the companies surveyed. Obviously, there was at least one person from Poland working in each of these companies, ${ }^{16}$ but in 95 per cent of cases there were more than one. Poles are not the only foreigners employed in the seasonal work sector. Information provided by the respondents indicates that about 40 per cent of businesses employed other foreigners too; tables 3.1 and 3.2 indicate the changes in the employment structure in the 1990 s with respect to the nationality of the workers.

Table 3.1 Share of companies where foreigners (excluding Polish workers) were employed (during first seasonal migration of Polish workers) by percentage ${ }^{17}$

\begin{tabular}{|c|c|c|c|c|c|}
\hline \multirow[t]{2}{*}{ Country of origin } & \multicolumn{5}{|l|}{ Period } \\
\hline & $\begin{array}{l}\text { Until } \\
1994\end{array}$ & $\begin{array}{l}1994- \\
1996\end{array}$ & $\begin{array}{l}1997- \\
2000\end{array}$ & $\begin{array}{l}2000 \text { and } \\
\text { later }\end{array}$ & $\begin{array}{l}\text { All } \\
\text { years }\end{array}$ \\
\hline Central and Eastern Europe & 14.4 & 18.0 & 21.5 & 13.9 & 18.1 \\
\hline Asia & 4.3 & 4.4 & 6.7 & 7.4 & 5.9 \\
\hline Africa & 3.6 & 3.1 & 3.7 & 2.5 & 3.3 \\
\hline 'Recruitment countries'* & 41.0 & 30.2 & 21.5 & 17.3 & 26.0 \\
\hline EU countries & 4.7 & 1.8 & 0.4 & 3.7 & 2.1 \\
\hline Other countries & 0.7 & 0.5 & 0.3 & - & 0.4 \\
\hline \multicolumn{6}{|c|}{$\begin{array}{l}\text { Share of companies where other } \\
\text { foreigners (excluding Polish workers) }\end{array}$} \\
\hline were employed & 49.9 & 41.8 & 40.4 & 32.9 & 40.9 \\
\hline Number of respondents & 135 & 192 & 332 & 147 & 804 \\
\hline
\end{tabular}

* Turkey, Yugoslavia, Portugal, Spain, Greece, Morocco, Tunisia and Italy Source: Centre of Migration Research, University of Warsaw 
Table 3.2 Share of companies where foreigners (excluding Polish workers) were employed (during last seasonal migration of Polish workers) by percentage

\begin{tabular}{|c|c|c|c|c|c|c|}
\hline \multirow[t]{2}{*}{ Country of origin } & \multicolumn{6}{|l|}{ Period } \\
\hline & $\begin{array}{l}\text { Until } \\
1999\end{array}$ & 1999 & 2000 & 2001 & 2002 & $\begin{array}{l}\text { All } \\
\text { years }\end{array}$ \\
\hline Central and Eastern Europe & 18.0 & 14.0 & 18.2 & 19.2 & 17.0 & 17.9 \\
\hline Asia & 1.7 & 5.8 & 4.6 & 6.6 & 3.0 & 4.9 \\
\hline Africa & 4.3 & 3.1 & 2.2 & 3.7 & 3.2 & 3.4 \\
\hline 'Recruitment countries'* & 27.2 & 22.6 & 14.6 & 21.8 & 11.2 & 20.7 \\
\hline EU countries & 1.9 & 0.6 & 2.7 & 1.4 & - & 1.5 \\
\hline Other countries & - & 0.8 & - & - & - & 0.1 \\
\hline $\begin{array}{l}\text { Share of companies where } \\
\text { other foreigners (excluding } \\
\text { Polish workers) were em- }\end{array}$ & & & & & & \\
\hline ployed & 41.7 & 34.7 & 32.5 & 37.9 & 27.8 & 36.3 \\
\hline Number of respondents & 149 & 116 & 161 & 324 & 57 & 804 \\
\hline
\end{tabular}

* Turkey, Yugoslavia, Portugal, Spain, Greece, Morocco, Tunisia and Italy

Source: Centre of Migration Research, University of Warsaw

The presented data prove that the seasonal labour market is not equally attractive for all immigrant groups. At the beginning of the last decade, apart from Poles, the immigrants from 'recruitment countries' still played an important role in this sector, especially Turks. Gradually, this group diminished under the pressure of the immigrants from the CEE countries, Asia and Africa. The survey data clearly confirm that Polish workers or foreigners in general predominated in some of the seasonal work sectors in Germany.

The data collected on the employment structure in the analysed companies show that foreigners constituted nearly 80 per cent of the employees. In addition, the recruitment of Polish seasonal workers satisfies approximately 70 per cent of the labour demand in the seasonal

Table 3.3 Share of Polish and foreign workers in company total employment (during last seasonal migration of Polish workers job, averages) by percentage

\begin{tabular}{|c|c|c|c|c|c|c|}
\hline \multirow[b]{2}{*}{ Category } & \multicolumn{6}{|l|}{ Period } \\
\hline & $\begin{array}{l}\text { Until } \\
1999\end{array}$ & 1999 & 2000 & 2001 & 2002 & $\begin{array}{l}\text { All } \\
\text { years }\end{array}$ \\
\hline Polish workers & 65.7 & 71.6 & 69.8 & 68.0 & 59.5 & 68.2 \\
\hline $\begin{array}{l}\text { Foreign workers } \\
\text { (including Polish workers) }\end{array}$ & 75.2 & 80.2 & 77.5 & 75.7 & 64.7 & 76.2 \\
\hline Number of respondents & 146 & 113 & 159 & 320 & 57 & 797 \\
\hline
\end{tabular}

Source: Centre of Migration Research, University of Warsaw 
work sector. Due to the fact that seasonal workers are strongly concentrated in agriculture, the predominance of foreigners (mainly Poles) is obvious in agriculture, slightly less in construction (approximately 6o per cent of all workers) and catering/hotel services (47 per cent) (see also section 3.5.4).

\section{Sector characteristics and the seasonal worker's profile}

Seasonal labour is characterised by the lack of qualification requirements, which may be perceived as a direct consequence of the fact that the performed activities are usually of a simple nature. It is interesting to see if these characteristics tally with the characteristics of the foreign workers actually performing these activities, and in consequence, what is the return rate of human capital in this sector.

Theoretically, the secondary sector, due to the characteristics of the offered jobs, attracts mainly young workers, just before or at the starting point of their career, and older workers for whom the seasonal work is merely an additional occupation. This is also true for seasonal employment in Germany. Seasonal labour migration involves mainly young and middle-aged people (the average age when starting seasonal work is 32 years for men and women). The ratio between people of different sexes is stable. The labour market offers jobs primarily for men, but women also come to Germany in large numbers (their share amounts to 40 per cent). As for age and sex the seasonal job market reveals characteristics typical for labour migration from Poland: migrants are relatively young, and the share of women is unexpectedly high (see Jaźwińska \& Okólski 200I).

Despite the fact that the jobs offered in the seasonal sector are not very attractive and do not require high skills, almost 40 per cent of Polish seasonal workers in Germany had completed at least secondary school and only twelve per cent had only primary education (see table 3.4). In fact, the educational structure of seasonal workers was more or less representative for the total Polish population (with over-representation of people with vocational education).

Table 3.4 Educational level of Polish seasonal workers

\begin{tabular}{lc}
\hline Level of education & Share (\% of total) \\
\hline & \\
Primary & 11.8 \\
Vocational & 47.5 \\
Secondary & 29.9 \\
Post-secondary (tertiary not completed) & 5.5 \\
Tertiary & 5.3 \\
Number of respondents & $\mathbf{8 0 2}$ \\
\hline
\end{tabular}

Source: Centre of Migration Research, University of Warsaw 
Moreover, seasonal workers are relatively highly qualified. More than II per cent were in professions in Poland requiring specialised skills. The most numerous group was constituted by skilled workers (50 per cent in the case of the first job and 37 per cent in the case of the last job performed in Poland). Despite the fact that the jobs in Germany are offered mainly in agriculture and related branches, only a small percentage of people involved in agriculture in Poland were present among the seasonal workers (Io per cent in the case of the last job). The majority of the surveyed individuals had completed a certain stage of their career; only about ro per cent of young people had never had a stable job, and the share of unemployed choosing to leave for seasonal work increased significantly only at the end of the I99os. The quoted data indicate that the seasonal labour market is an example of an unskilled labour market giving employment mostly (even predominantly) to skilled workers. Therefore, the job profile does not usually match the profile of the employee.

By using wage regression, Kaczmarczyk (2005) has shown that factors related to work intensity and not to the level of human capital were crucial for monthly net earnings of seasonal workers. Language skills turned out to be the only 'qualification measure' that influenced the wages of seasonal workers in a significant and positive way. In general, wage regression confirms that the analysed labour market sector does not provide any return on human capital, which is a characteristic of the secondary segment of the labour market.

With regard to the mobility of Polish seasonal workers on the German labour market, survey data have proven that for a large group of people seasonal migration has become a recurrent economic strategy. Nearly 75 per cent of all seasonal workers migrated more than once. At the same time, only a small fraction of migrants is interested in other forms of migration. Over half of the respondents ( 52 per cent) declared an intention to work in Germany as seasonal workers in the following years. Some of them wished to work in Germany on a different basis as well, but the number of such people was significantly lower (22 per cent). Additionally, most of them would like to combine this work with seasonal migration as foreseen by the I990 Bilateral Agreement. Consequently, only 6 per cent of all workers surveyed wished to work in Germany on a different basis. Seasonal migration to Germany can thus be perceived as a specific migration strategy - an option extensively used by people who do not have previous experience with labour migration (80 per cent of surveyed workers) and in general, not interested in taking up illegal employment abroad (including employment in other sectors of the German economy) (Kaczmarczyk 2004, 2005). 


\subsection{Seasonal labour migrants from the point of view of German employers: analysis based on a qualitative survey}

The analysis of the employment characteristics of Polish seasonal workers essentially confirms the segmented structure of the German (agricultural) labour market for seasonal low-skilled jobs. This evaluation is confirmed by the behaviour of German employers in recruiting and managing Polish seasonal labour migrants as a reaction to and thus a reinforcement of the segmented character of the seasonal agricultural job market. To examine these topics in more detail, the selected findings of a qualitative survey study with agricultural enterprises in Germany that employ Polish seasonal workers will be presented.

\subsubsection{Data}

Altogether sixteen agricultural firms and one restaurant participated in the study, which was conducted in Germany between March and June 2003. Additionally, representatives of the trade union and the Bavarian and the German farmers' unions were questioned. All interviews were face to face, carried out on the basis of a structured questionnaire. It was the aim of the study to obtain a comprehensive picture of recruitment practices, the labour situation, remuneration and the impact of Polish seasonal workers on agricultural production and the (seasonal) labour market in Germany.

The structure of the enterprises that participated in the survey can be characterised as follows: regionally they were located in more or less the same parts of Bavaria and North Rhine-Westphalia. With the exception of one restaurant, all the enterprises were engaged in agricultural production and gardening, growing hops, lettuce, vegetables, cucumber, asparagus and strawberries, for example. As is typical for agricultural production, most enterprises (88 per cent) were family owned.

Depending on the type of agricultural production, seasonal workers were employed for fourteen days, as for example in hop production, or up to ten months, as in vegetable production. Because seasonal workers are not allowed to be employed for longer than three months a year in Germany, seasonal labour migrants are replaced if workers are needed for a longer time period.

The number of recruited seasonal workers differed significantly: whereas some enterprises hired only five seasonal workers, others occupied many more, up to 675 people. The ratio between permanent and seasonal workers also varied notably: some enterprises, especially in cucumber, asparagus and strawberry production, employed a maximum number of 300 seasonal workers per year although they had not 
occupied any permanent workers. As has already been pointed out by the quantitative study, a comparatively high percentage of permanent workers were foreigners. In contrast, a number of firms employed seasonal workers in addition to their permanent staff - on average the questioned firms employed seven permanent workers and I2I seasonal workers. Concerning social security expenses (which have to be paid if workers are occupied for longer than two months), more than half (52 per cent) of the interviewed enterprises only employed seasonal labour in the context of social security-free work contracts. Whereas 30 per cent of the questioned employers occupied seasonal workers with and without social security payments, i8 per cent employed all seasonal workers on the basis of contracts, including social security benefits.

Most of the investigated enterprises readily participated in the interview study. In all cases the interviewed farmers emphasised the great importance of Polish seasonal workers for their production and services. It was repeatedly argued that seasonal workers from Poland were essential for agricultural performance.

In the survey, problematic points, for example wage dumping, illegal employment and poor housing conditions, were approached as well. Overall, the interviewed farmers disapproved these practices, arguing that they might lead to distorted competition. It cannot be excluded, however, that the sample of the questioned firms was positively selected.

Table 3.5 Occupation and number of seasonal workers

\begin{tabular}{ll}
\hline Category & Number of companies \\
\hline Occupation & 1 \\
$<1$ month & 4 \\
$2-4$ months & 9 \\
$5-7$ months & 3 \\
$8-10$ months & \\
Number of seasonal workers & 3 \\
$<10$ & 3 \\
$11-20$ & 2 \\
$21-50$ & 5 \\
$51-100$ & 1 \\
$101-200$ & 3 \\
$>200$ & \\
Number of permanent workers & 7 \\
None & 2 \\
Help on an hourly basis & 3 \\
$<5$ & 2 \\
$5-10$ & 3 \\
$11-40$ & \\
\hline
\end{tabular}

Source: Institute for East European Studies, Munich 


\subsubsection{The results of the survey study}

As far as the initial reason for recruiting seasonal migrant workers in agriculture is concerned, the respondents pointed to severe shortages in local labour markets, which had increasingly become a problem since the end of the ig7os. When the employment of seasonal workers from Poland was officially allowed in I990, German agricultural enterprises immediately took up the chance to satisfy their demand for lowskilled seasonal workers by using migrants from Poland. In the opinion of the questioned employers, the labour market for seasonal agricultural jobs reveals the typical characteristics of a secondary labour market segment: the work is heavy, often dirty, no specific qualifications are required, wages are low and seasonal agricultural employment usually does not result in a more secure or long- term position. All interviewed employers argued that the seasonal character of agricultural production and the competition in selling agricultural products would not allow them to increase wages or to offer permanent jobs in order to attract native workers. To try and discuss an alternative, the questioned employers were confronted with the debate on the import of cheap labour into the US, particularly in California. To avoid the immigration of foreign workers which often takes place illegally, American researchers have suggested supporting the introduction of laboursaving new technologies to get rid of a high labour immigration, potentially resulting in distorted competition, wage dumping and socially unacceptable working conditions for (illegal) foreigners (Krikorian 2004; Bowe 2003; Martin 2004). ${ }^{18}$ As Krikorian (2004) has pointed out, in the US:

... the period from I960 to I975 (roughly from the end of the 'Bracero' Program, which imported Mexican farm workers, to the beginning of the mass illegal immigration we are still experiencing today) was a period of considerable agricultural mechanisation. But a continuing increase in the acreage and number of crops harvested mechanically did not materialise as expected, largely because the supply of workers remained artificially large due to the growing illegal immigration we were politically unwilling to stop.

In contrast to these arguments, all interviewed farmers in Germany emphasised that because of the specific conditions in agricultural production, labour-saving technologies would be no alternative to seasonal labour in German agriculture.

In recruiting seasonal migrant workers, the employers referred to personal contacts which had originally been established either by the in- 
itiative of the firm itself, by Polish workers, or by other enterprises already giving jobs to Polish migrants. In general, enterprises requested the same workers every year, except in very rare cases where employers were not satisfied with the labour results. In any event, new workers were recruited with the help of employed Polish personnel. The role of the German labour office in the recruitment process is purely formal. This points to the significance of migrant networks in the recruitment process, which also stresses the strong position of foreign workers in the respective labour market segment.

In general, the firms in the sample did not demand any specific skills or occupations from Polish seasonal workers. It is worth noting that although none of the analysed firms explicitly looked for Polish workers with German language skills, all of them had at least one seasonal worker from Poland with good German language competence on their staff. As none of the employers spoke Polish, German-speaking migrant workers usually acted as interpreters and often had a more privileged position. Although seasonal labour migrants only did lowskilled jobs, the employers noted a comparably good education and qualifications for a considerable number of their seasonal migrant workers. As has already been pointed out, this mismatch is reinforced by the fact that short-term labour migrants act as a buffer for labour market shortages.

According to the interviewed firms, seasonal workers were paid the standard wage for seasonal work in agriculture. ${ }^{19}$ In addition to this form of remuneration, most enterprises had introduced a payment system rewarding more qualified workers or those who had already worked for a long time for the respective firms. These payments were not usually included in the work contract but had the character of bonus payments instead. Because of economic reasons, approximately half of the interviewed firms employed seasonal workers in general for less than 50 days to avoid social insurance payments. Furthermore, it has to be mentioned that some interviewed enterprises pointed critically to the fact that a number of agricultural firms occasionally paid lower than standard wages, thus distorting competition in certain agricultural segments.

All interviewed enterprises explained their motivation in recruiting Polish seasonal workers by their need to find people to perform heavy low-skilled work on a daily seasonal basis, but not being able to hire such people on the German labour market. All employers emphasised the high commitment, capability, flexibility and productivity of Polish seasonal workers, which may be related to the comparatively high qualifications and skills that Polish seasonal labour migrants bring along. Some employers remarked that Polish workers had no family, friends and social responsibilities in Germany, therefore they are willing to 
work extra hours as well as on Saturdays and Sundays, and they pointed out that an alternative, meaning natives with a comparable commitment to work in these jobs, did not exist. A number of interviewed employers explicitly mentioned that they would be unable to keep up their production if they were not allowed to hire seasonal migrant workers any more.

Because of the continuing criticism against seasonal labour migration as potentially leading to natives' unemployment, firms were asked if seasonal labour migrants had been hired to replace a native labour force. Uniformly, employers pointed to the permanent shortages of seasonal low-skilled labour in local markets, thus making them dependent on migrant labour under the existing conditions in agricultural production. It is noteworthy that in cases where firms employed Polish seasonal workers and natives, the study found a complementary relationship between native permanent workers and migrants, thus indicating no specific unemployment threats from seasonal migrants. Because of the seasonal nature of at least parts of their production, the economic survival of agricultural and gardening firms is dependent on the efficient management of a comparatively high seasonal workload. As a result, the questioned firms argue that the employment of permanent workers is often dependent on the recruitment of seasonal labour migrants. Agricultural production - this was the conclusion of most interviewed firms - would not be manageable any more in Germany if seasonal labour migration from Poland or other lower-wage countries were to be abandoned.

If it should happen that wage increases in Poland diminished seasonal labour migration, some of the questioned enterprises had already started to contact other Eastern European countries with labour agreements with Germany, for example Romania. In addition, some firms voted for an extension of bilateral agreements on labour migration to other Eastern European states, for example to Ukraine, Belarus, Moldova or the Baltic states.

\subsection{Conclusion and perspectives}

The presented analysis confirms that the seasonal (agricultural) work sector in Germany meets the most important criteria proposed by labour market segmentation theorists. Polish workers are employed primarily in small- to medium-sized companies and in branches where no qualifications are required, predominantly in agriculture. The work is simple, though performed in difficult conditions, and the wages are distinctly lower than the average wages of German workers, similar to the wages of other foreign workers employed in the secondary labour 
market. The seasonal work sector has a specific place in the German labour market, as is demonstrated by its structure: a relatively low share of permanent German workers and a large share of foreign temporary workers. This observation does not relate to the whole German labour market, only to some branches (e.g. to agriculture) where the described structures predominate.

The data concerning the structure of employment in the secondary sector indicates that there is a large diversification of the foreign population. Some immigrant groups have been able to achieve social and professional advancement, but others still remain in the lowest segment of the German labour market. The diminishing share of nationals from the recruitment countries in the agricultural sector can be explained not only by the fact that the majority of them find better jobs, but also by the 'unmotivating' social security system in Germany (indicated by a growing percentage of people who are not active in the labour market). Other workers need to be found to fill their places and do their jobs, with the exception of heavy industry, for example. The bilateral agreement between the Polish and the German governments created a chance for a new immigrant group to emerge. In a very short time that group became predominant in the seasonal - mainly agricultural - sector. It is likely that Polish workers will be replaced by other immigrant groups as a consequence of Poland's EU membership, especially by immigrants from other CEE countries.

In general, our study confirms that a significant demand for seasonal low-qualified labour exists in Germany, which cannot be satisfied by the native labour market. Nonetheless, the recruitment of seasonal migrant workers in (former) non-EU countries remains a very controversial issue. Whereas employers strongly support bilateral agreements on seasonal labour with (former) non-EU countries, trade unions and some politicians oppose it. So far, the critics of seasonal labour migration have not presented a feasible strategy to overcome seasonal labour market shortages. Therefore the elimination of (former) non-EU seasonal labour migration would lead to an increase in undocumented migration. Nevertheless, it has to be taken into account that seasonal labour migration might lead to wage or social dumping or to market distortions. With respect to these problems it seems crucial to insist on governmental regulations to steer immigration and to guarantee standard wage payments, regular working conditions and decent housing for seasonal labour migrants. In the light of the economically and socially harmful consequences of employing illegal foreign labour, it is in the interests of the public and the government to secure legal standards with respect to (seasonal) labour migration. Otherwise social tensions between native and foreign workers may result or labour conflicts and distorted competition between firms may occur. 
After the successive EU enlargements that began in 2004, East-West migration will gradually become easier and the eastern borders of the expanded EU will unquestionably mark a new migration space. Labour and undocumented migrations from poorer and more insecure countries in the East will confront not only German, but all EU governments, with the problem of an efficient management of potential (seasonal) labour movements. Already today, many EU countries suffer from shortages in seasonal local labour markets, particularly in agriculture, where these jobs are typical for the secondary labour market segment. In a number of cases, this situation has already attracted considerable illegal immigration of people from non-EU countries willing to work in EU countries. Because of an almost certainly persistent demand for low-skilled seasonal labour migrants, it seems reasonable to think about the establishment of an EU-wide system of migration control which facilitates the movement of regular - including seasonal migrants on the one hand and prevents illegal border crossings on the other. In addition, the likely growth of circular, short-term labour migrations challenges Germany and many other European states to work out integration regulations which secure the economic and social rights of native and migrant workers alike.

\section{Notes}

I So-called 'programme employment' not only accounts for seasonal workers, but also contract workers, guest workers, borderland workers, trainees and students.

2 At first, the labour market was shaped by the significant human losses during the war, then by sectoral imbalances caused by rapid economic growth.

3 One may argue that the decision was taken on political and not economic grounds. For example, Collinson (I994), quoting OECD reports, underlines that actions aiming at curbing immigration occurred well before I973, and they originated not from the competition on the labour market but from the growing political and social costs of immigration.

4 Ruhs (2003) analysed temporary foreign workers' programmes in five countries: Germany (Gastarbeiter Programme), the US (Bracero Programme, H-IB Program), Switzerland (Auslaenderausweis B Programme), Kuwait (Kafala-Visa I8 Programme) and Singapore (Employment Pass R Programme). He found that while there are significant differences between the policies of the programmes and instruments applied, the consequences of foreign workers' recruitment are quite similar, including the emergence of immigrant sectors in the host country's labour market (with Kuwait as a perfect example), the tendency to become longer in duration and bigger in size than foreseen (e.g. Germany) and the emergence of illegal foreign workers (e.g. the Bracero Program in the US).

5 That the heterogeneous structure of contemporary labour markets truly exists has been proved through analyses conducted for the US and Canada (e.g. Rivera-Batiz I998; Borjas I994; Richmond I992; Card I990; Grossman I982), as well as for the Western European countries (Fassmann et al. I995; Velling I997; Werner I996; Fassmann, Münz \& Seifert I997; Biffl 2002). 
6 Blossfeld and Mayer (I988) proposed a three-segment approach to the labour market analysis. Apart from the primary and secondary segment they introduced the segment of standard professions (fachspezifischer Arbeitsmarkt). This modification derives from the educational model in Germany, especially from the existence of vocational training controlled by the state and by enterprises. According to Szydlik (I99I), in 1989 about 46 per cent of workers were employed in this segment.

7 The cited results refer only to legal immigrants, in particular those coming from the most important recruitment countries (Turkey, Yugoslavia, Italy, Greece and Spain).

8 The research included three immigrant groups: individuals from East Germany (exceptionally treated as migrants, and not 're-settlers'), ethnic Germans from CEE countries and other migrants from those countries.

9 In the case of ethnic Germans, the percentage of individuals with a level of education higher than elementary school amounted to 30 per cent, in the case of 'new immigrants' from CEE countries it was even higher and amounted to 44 per cent.

IO Because social insurance only has to be deducted if the employment exceeds 50 days, many employers occupy seasonal workers for a shorter time period.

II For an international comparison, see Stalker (2000: I32).

I2 One might argue that the so-called Hartz IV reforms of the German social security system are a step towards forcing the unemployed to take up low-paid jobs.

I3 With the assumption that the secondary sector is related mainly to small to medium enterprises and to low requirements with regard to skills.

I4 Due to the very nature of the database, the information on the employment relates to the phase of seasonal employment i.e. to the phase of highest work intensity. As a consequence, the data encompasses both permanent workers and seasonal workers and it is not possible to separate these two groups.

I5 Because of strict tariff regulation, the wages of Polish seasonal workers are quite similar to German workers holding similar positions (average pay for one hour was 8.50 DM in 1999). Nevertheless, their earnings are much lower than in non-seasonal sectors. Average net earnings for seasonal work in agriculture amounted to I,858 DM for women, and 2,009 DM for men. At the same time (1999), the average gross earnings in the sector of food processing amounted to 4,IO० DM, and in production over 5,200 DM (DSI).

I6 We have to acknowledge methodological problems, as the sample is biased in the sense that it includes information on companies employing at least one foreigner (auto-selection). It is thus possible that there are companies with similar characteristics employing only Germans, and thus having different employment features. However, we argue that to prove the presented hypotheses it would be sufficient to show that there is at least one segment of the labour market where the strong, structural demand for a foreign workforce does exist.

I7 Data in tables 3.I and 3.2 relate to the first and last (most current) seasonal job of a given person in Germany.

I8 In addition, it has been argued that the availability of cheap foreign labour has actually prevented the development of new labour-saving technologies in American agriculture (Sarig et al. 2000).

I9 In the years 2002 and 2003 the remuneration for seasonal agricultural work amounted to $€ 5.10$ per hour in Bavaria and to $€ 5.04$ per hour in North RhineWestphalia; this wage had to be paid independently of nationality and citizenship. In this context trade unions and even some employers argued that the remuneration for seasonal agricultural jobs is very low for German standards (or people living in Germany). 


\section{References}

Angenendt, S. (1992), Ausländerforschung in Frankreich und der Bundesrepublik Deutschland: Gesellschaftliche Rahmenbedingungen und inhaltliche Entwicklung eines aktuelles Forschungsbereiches. Frankfurt, New York: Campus.

Bauer, T. (2000), 'Arbeitsmarkteffekte der Zuwanderung nach Deutschland', Wochenbericht des DIW 2I.

Bauer, T. \& K. F. Zimmermann (I999), 'Assessment of possible migration pressure and its labour market impacts following EU enlargement to Central and Eastern Europe: Studie im Auftrag des britischen Ministeriums für Bildung und Beschäftigung'. Bonn: IZA.

Bender, S. \& W. Seifert (I997), 'Die Auswirkungen der Globalisierung auf die lokalen Arbeitsmärkte für Zuwanderer in Deutschland', Demographie aktuell II.

Biffl, G. (2002), 'Labor market performance of indigenous and foreign workers in Austria: An insider-outsider analysis', unpublished manuscript. Vienna: WIFO.

Blossfeld, H. P. \& K. U. Mayer (I988), 'Labor market segmentation in the Federal Republic of Germany: An empirical study of segmentation theories from a life course perspective', European Sociological Review 4 (2): I23-I40.

Bonin, H., Kempe, W. \& H. Schneider (2003), 'Kombilohn oder Workfare? Zur Wirksamkeit zweier arbeitsmarktpolitischer Strategien', Vierteljahreshefte zur Wirtschaftsforschung 72 (I): $5 \mathrm{I}-67$.

Borjas, G. (I994), 'The economics of migration', Journal of Economic Literature 32.

Borjas, G. (I999), 'Economic research on the determinants of immigration: Lessons for the European Union', World Bank Technical Papers 438.

Borjas, G. (2005), Labor Economics. New York: McGraw-Hill.

Bowe, J. (2003), 'Nobodies. Does slavery exist in America?', The New Yorker 2I \& 28 April, IO6-133.

Bundesministerium für Verbraucherschutz, Ernährung und Landwirtschaft (BVEL) (2003), 'Ernährungs- und agrarpolitischer Bericht der Bundesregierung', Bonn: BVEL.

Bundesministerium für Verbraucherschutz, Ernährung und Landwirtschaft (BVEL) (2002), 'Situation der ausländischen Arbeitnehmer und ihrer Familienangehörigen in der Bundesrepublik Deutschland: Repräsentativuntersuchung 200I. Teil B: Polnische Werkvertragsarbeitnehmer, Gastarbeitnehmer und Saisonarbeiter in der gesamten Bundesrepublik'. Offenbach \& München: Bundesminsterium für Arbeit und Sozialordnung.

Card, D. (I990), 'The impact of the Mariel boatlift on the Miami labor market', Industrial and Labor Relations Review 43 (2): 245-257.

Collinson, S. (1994), Europe and International Migration. London, New York: Pinter Publishers.

Constant, A. \& D. S. Massey (2003), 'Labor Market Segmentation and the Earnings of German Guestworkers', IZA Discussion Paper 774.

DBV (Deutscher Bauernverband) (2002), 'Situationsbericht 2003: Trends und Fakten zur Landwirtschaft'. Bonn: Deutscher Bauernverband.

Deutscher Bundestag (2000), 'Neunter Bericht der Bundesregierung über Erfahrungen bei der Anwendung des Arbeitnehmerüberlassungsgesetzes - AÜG - sowie über die Auswirkungen des Gesetzes zur Bekämpfung der illegalen Beschäftigung - BillBG'. Drucksache I4/4220.

DGB Bildungswerk (2002), 'Rechte aus dem Arbeitsverhältnis: Arbeitnehmer und Arbeitnehmerinnen ohne Aufenthalts- und/oder Arbeitserlaubnis', Schriftenreihe Migration \& Arbeitswelt. 
Doeringer, P. B. \& M. Piore (I97I), Internal Labor Markets and Manpower Analysis. Lanham, MD: Lexington Books.

Data, Service and Information (DSI). <www.dsidata.com $>$.

EIRO (2003), 'Migration and industrial relations', EIRO Observer 3, supplement, European Industrial Relations Observatory.

Ehrenberg, R. G. \& R. S. Smith (2000), Modern labor economics: Theory and public policy. Boston: Addison-Wesley.

Fassmann, H., Kohlbacher J. \& U. Reeger (I995), Die 'neue Zuwanderung' aus Ostmitteleuropa - eine empirische Analyse am Beispiel der Polen in Österreich. Wien: ISR.

Fassmann, H., R. Münz \& W. Seifert (I997), 'Die Arbeitsmarktposition ausländischer Arbeitskräfte in Deutschland (West) und Österreich', Mitteilungen aus dem Arbeitsmarkt 4 .

Frey, M. \& U. Mammey (I996), Impact of migration in the receiving countries: Germany. Geneva: IOM, CICRED.

Grossman, J. B. (I982), 'The substitutability of natives and immigrants in production', Journal of Economics and Statistics 64 (4): 596-604.

Harris, N. (I995), The new untouchables: Immigration and the New World worker. London, New York: I. B. Tauris Publishers.

Hönekopp, E. (I999), Central and East Europeans in the member countries of the European Union since 1990: Development and structure of migration, population and employment. Background Report. Nuremberg: Institute for Employment Research.

Hönekopp, E. (200I), 'Labor migration to Germany from Central and Eastern Europe. Old and new trends', in: E. Hönekopp, S. Golinowska, \& M. Horálek (eds.), 'Economic and labor market development and international migration - Czech Republic, Poland, Germany - results of an international research project', Beiträge zur Arbeitsmarkt und Berufsforschung 244: 53-82.

Jahn, A. \& T. Straubhaar (I998), 'A survey of the economics of illegal migration', South European Society and Politics 3: 16-42.

Jaźwińska, E. \& M. Okólski (eds.) (200I), Ludzie na huśtawce: Migracje między peryferiami Polski i Zachodu. Warsaw: Scholar.

Kaczmarczyk, P. (2004), 'Popytowe uwarunkowania migracji zarobkowych - przypadek migracji sezonowych’, in P. Kaczmarczyk \& W. Lukowski (eds.), Polscy pracownicy na rynku Unii Europejskiej, 38-77. Warsaw: Scholar.

Kaczmarczyk, P. (2005), Migracje zarobkowe Polaków w dobie przemian. Warsaw: WUW.

Krikorian, M. (2004), 'Jobs Americans won't do: Voodoo economics from the White House', National Review Online, 7 January. <www.nationalreview.com/comment/krikorian20040I070923.asp>.

Martin, P. (2004), Promise unfulfilled: Why didn't collective bargaining transform California's farm labor market?. Center for Immigration Studies. <www.cis.org/articles/2004/backio4.html>.

Okólski, M. (2004), 'Seasonal labour migration in the light of the German-Polish bilateral agreement', in Migration for employment: Bilateral agreements at a crossroad, 2032I4. Paris: OEDC.

Piore, M. J. (I979), Birds of passage: Migrant labor and industrial societies. Cambridge: Cambridge University Press.

Radu, D. (2003), 'Skills and performance of CEE-employees in Germany: Lessons of the ' 90 s for post-enlargement migration?'. Hamburg: HWWA.

Rhoades, R. (I978), 'Foreign labor and German industrial capitalism I87I-I978: The evolution of a migratory system', American Ethnologist 5 (3): 553-573.

Richmond, A. (I992), 'Immigration and structural change: The Canadian experience, I97I-I986', International Migration Review 26 (4): I200-I22I. 
Rivera-Batiz, F. (1998), 'Undocumented workers in the labor market: An analysis of the earnings of legal and illegal Mexican immigrants in the United States', Journal of Population Economics I2(I): 9I-II6.

Ruhs, M. (2003), 'Temporary foreign worker programmes: Policies, adverse consequences, and the need to make them work', Perspectives on Labor Migration 6. Geneva: International Migration Branch, International Labor Office (ILO).

Sarig, Y., J. F. Thompson \& G. K Brown (2000), Alternatives to immigrant labor? The status of fruit and vegetable harvest mechanization in the United States. Center for Immigration Studies. <www.cis.org/articles/2000/backı200.html>.

Seifert, W. (I995), Die Mobilität der Migranten. Die berufliche, ökonomische und soziale Stellung ausländischer Arbeitnehmer in der Bundesrepublik. Eine Laengschnittanalyse mit dem Sozio-Ökonomischen Panel, 1984-1989. Berlin: edition sigma.

Seifert, W. (I996a), '\&PHgr;Alte\&PHgr; und \&PHgr;neue\&PHgr; Zuwanderungsgruppen auf dem Arbeitsmarkt, I990-I995', in T. Faist, F. Hillman \& K. Zuehlke-Robinet (eds.), Neue Migrationsprozesse: politisch-institutionelle Regulierung und Wechselbeziehung zum Arbeitsmarkt, ZeS-Arbeitspapier 6. Bremen: Zentrum für Sozialpolitik.

Seifert, W. (I996b), 'Neue Zuwanderungsgruppen auf dem westdeutschen Arbeitsmarkt', Soziale Welt 2.

Spahn, A. (I999), 'Saisonarbeit in der Landwirtschaft, in: Dokumentation, Migration und prekäre Beschäftigung', Tagung des Bildungswerkes des DGB. Düsseldorf: DGB.

Stalker, P. (2000), Workers without frontiers: The impact of globalisation on international migration. London: Rienner.

Szydlik, M. (1991), Die Segmentierung des Arbeitsmarktes in der Bundesrepublik Deutschland: Eine empirische Analyse mit Daten des Sozio-ökonomischen Panels, 1984-1988. Berlin: Sigma.

Velling, J. (I997), Immigration und Arbeitsmarkt: Eine empirische Analyse für die Bundesrepublik Deutschland. Baden-Baden: Nomos.

Wallerstein, I. (I997), The capitalist world-economy. Cambridge: Cambridge University Press.

Werner, H. (1996), 'Integration ausländischen Arbeitnehmer', in T. Faist, F. Hillman \& K. Zuehlke-Robinet (eds.), Neue Migrationsprozesse: Politisch-institutionelle Regulierung und Wechselbeziehung zum Arbeitsmarkt, ZeS-Arbeitspapier 6. Bremen: Zentrum für Sozialpolitik. 


\title{
4 Migrant smuggling and trafficking in Portugal: Immigrants, networks, policies and labour markets since the 1990 s
}

\author{
João Peixoto
}

\subsection{Introduction}

This chapter is based on a research project funded by the Foundation for Science and Technology (FCT) and the High Commissioner for Immigration and Ethnic Minorities (ACIME), Portugal, 'Migrants trafficking in Portugal: sociological, juridical and political perspectives', a project carried out from January through December 2004. ${ }^{1}$ First, the chapter will deal with the main conceptual questions involved in this issue. The theoretical difference between the trafficking and smuggling of migrants will be the axis of the discussion. Second, some of the research project aims and methodology will be presented, since they inevitably constrained the empirical evidence produced. Third, some of the projects' main results will be presented. Attention will be focused on the forms of smuggling of and trafficking in migrants into Portugal since the late 1990s, including irregular labour flows targeted for several segments of the labour market and, in particular, trafficking in women for sexual exploitation. Fourth, the results will be discussed in terms of their main theoretical implications. The issues under consideration will be the interlinking between forms of trafficking, smuggling and 'regular' migration; the causes of these phenomena; and the dynamic interaction between the agents.

\subsection{Conceptual questions}

The theoretical framework of this project was built around the main concepts and the existing literature on the study of migrant trafficking and smuggling, including the relevant evidence already collected. Despite the difficulty of empirically examining migrant trafficking and smuggling, given its illegal and informal ways of functioning, a considerable body of literature is already available on the subject, providing some good insights in this area (for a recent state of the art, see Peixo- 
to et al. 2005). For the purpose of this chapter, only the main conceptual debates will be highlighted.

Generally speaking, different types of human movements are usually conceived under the broad label of 'trafficking'. The most important distinction in this field separates smuggling from trafficking. Theoretical definitions of both phenomena are not always equivalent, and empirical descriptions frequently use the expression indistinctively (IOM 2000; Salt 2000; Aronowitz 200I). However, there are important theoretical differences between the two terms. The international definitions produced recently by the United Nations reflect the main issues at stake. Two recent UN protocols - both produced in 2000 - clarify the concepts: the UN Protocol to Prevent, Suppress and Punish Trafficking in Persons, Especially Women and Children; and the UN Protocol Against the Smuggling of Migrants by Land, Sea and Air.

For the UN, smuggling must be understood as 'the procurement, in order to obtain, directly or indirectly, a financial or other material benefit, of the illegal entry of a person into a State Party of which the person is not a national or a permanent resident (...) Smuggling, contrary to trafficking, does not require an element of exploitation, coercion, or violation of human rights.' Alternatively, trafficking is understood as 'the recruitment, transportation, transfer, harbouring or receipt of persons, by means of the threat or use of force or other forms of coercion, of abduction, of fraud, of deception, of the abuse of power or of a position of vulnerability or of the giving or receiving of payments or benefits to achieve the consent of a person having control over another person, for the purpose of exploitation' (see IOM 2004).

Observing these definitions, it may be accepted that, in the first place, some variables differentiate 'regular' migration from various forms of smuggling and/or trafficking. These include the 'irregularity' of the movement or the stay of migrants and the presence of a specific type of external agent (smuggler or trafficker) intermediating the flows, obtaining an economic profit. In the second place, the main variables differentiating smuggling from trafficking appear to be forms of exploitation, coercion and fraud. Again, the UN may be consulted in order to define what is at stake. According to the UN, exploitation must be considered as 'the act of taking advantage of something or someone, in particular the act of taking unjust advantage of another for one's own benefit (e.g. sexual exploitation, forced labour or services, slavery or practices similar to slavery, servitude or the removal of organs)' (IOM 2004).

These international definitions emerge directly from the available knowledge existing in the field. In general terms, international flows usually considered as smuggling and/or trafficking, to which these concepts are directed, are of a different kind. They include irregular 
movements of migrant labour, flows of women for the purpose of sexual exploitation and trafficking in children. It can be argued that these flows often overlap with each other and with other migration flows, and also transform into one another (e.g. smuggling into trafficking), questioning the apparent clarity of the theoretical trafficking/smuggling divide. As mentioned above, trafficking and/or smuggling of migrant labour often overlaps with 'regular' labour migrations, whenever a voluntary intention of economic migration is present; the main difference consists in the irregularity of the flow and the presence of a specific type of external agent (smuggler or trafficker) intermediating the flow. Also trafficking in women for sexual exploitation often overlaps with a motivation for labour migration on the part of many women, targeting a particular niche in the labour market (prostitution as a form of informal activity). Indeed, trafficking in children displays a sharper distinction, as it reflects the fact that victims are unable to develop a proper will.

It can be argued that one of the more central and difficult questions in this field is the evaluation of the degree of victimisation or, in other words, the problem of consent. A distinction must be acknowledged between the free choice of migrating and, in contrast, the conditioning of the will. It is one thing to admit, on the basis of many smuggled and/or trafficked flows, that these are typical economic migrants asking intermediaries for assistance of this type because of the lack of legal channels to migrate. Another completely different situation is the existence of forced labour in diverse niches of the labour market, including the sex and entertainment industries. However, in practical terms, it is difficult to assess what is free will and what is forced behaviour (Kyle \& Koslowski 200I; Okólski 200I). This is due to the intertwining of situations (based, for example, on fraudulent promises from the intermediaries) and the practical difficulties of research. Overall, there seems to be a large continuum of situations involving 'regular' migration, smuggling and trafficking (Salt 2000). It is this continuum that was placed as the background of the situations addressed in this chapter.

\subsection{Research aims and methodology}

The empirical basis of the research project from which this chapter draws was the study of trafficking in and smuggling of immigrants into Portugal, in the context of the international movements that occurred since the late ig9os. Several points were taken into consideration: the characteristics of migrant trafficking and smuggling networks; the characteristics of the victims; the causes and modalities of move- 
ments; and the political framework in the period concerned. The flows under study were those of irregular labour migrants targeting diverse niches of the (mainly) informal labour market and, particularly, women targeting the sex industry. ${ }^{2}$ The project also kept in mind the presentation of political solutions to these problems.

The rationale behind the project was the fact that, between the final years of the I990s and the beginning of the new century, Portugal witnessed significant processes of trafficking and/or smuggling. These were responsible for the large increase of irregular immigration flows into Portugal and for the launching of innovative ways of regularising these migrants. The figures on immigration in this period are impressive. In 2000, there were 207,607 legal foreigners (possessing residence permits) registered in the country, constituting around 2 per cent of the total population. In 2002, there were already 4I3,304 legal foreigners (possessing residence permits and permits to stay - a new status granted in 200I), about double the 2000 figure, constituting around 4 per cent of the total population and nearly 6 per cent of the total labour force. The process of regularisation begun in 200I, leading to the granting of permits to stay, did not conceal the endemic character of irregular migration, which immediately resumed. The main flows involved in trafficking and/or smuggling were those coming from Eastern Europe and, to a lesser degree, Brazil. In the particular case of women targeted for the sex industry, these flows originated mainly from Brazil and, to a lesser degree, Eastern Europe (on recent foreign immigration in Portugal, see Malheiros \& Baganha 2000; Peixoto 2002; Pires 2003; Baganha \& Fonseca 2004; Fonseca, Malheiros \& Silva 2005).

The research methodology in a theme such as this is always problematic, given the illegal and informal types of action. More than in any other kind of social research, the methodology adopted allows us to unveil only one part of the picture. In this case, the characteristics of the phenomenon, the previous lack of knowledge about it in Portugal and the time available for the research (only one year) explained why this project was just a first and preliminary step. The complexity and previous ignorance about the theme called for a pluralist research methodology. The main research steps undertaken were theoretical and documentary analysis, including the analysis of the scientific literature, the media and legislation; research into judicial cases concerning trafficking, smuggling and related activities (cases already decided or still sub judice in the courts); consultation of several governmental and non-governmental institutions related to the topic (semi-directive interviews to institutional representatives); and collection, when possible, of some life histories of traffickers/smugglers and their victims. Given the complexity of the theme and the time constraints existing to carry out field- 
work, the project opted for a mainly 'indirect' approach. The gathering of evidence resulting from the observation of documents (mainly media reports), judicial cases and interviews to institutional actors was preferred to direct contact with the agents involved, which requires time and reciprocal trust. ${ }^{3}$ At a disciplinary level, the project brought together contributions from sociology, law and political science.

\subsection{Smuggling and trafficking of migrant labour}

In this section and the next, some of the main results of the research project will be presented. In this section, the cases under scrutiny will be those regarding trafficking in and smuggling of irregular migrant labour targeting (mainly) the informal segments of the labour market. As previously mentioned, its major expressions were flows coming from Eastern Europe and, to a lesser degree, Brazil. In the next section, attention will be drawn to flows of women targeting the sex industry, mainly coming from Brazil and, to a lesser degree, Eastern Europe. Further details on the research results are displayed in Peixoto et al. (2005).

\subsubsection{The case of smuggling and trafficking from Eastern Europe}

Eastern European immigration is a completely new kind of migration to Portugal. The main flows date from the late I990s, with a peak being attained in 200I. Previously to these dates, only marginal flows coming from this region existed in the country, which makes the dramatic surge in numbers attained in only a few years even more surprising. In total, the flows coming from Eastern Europe went from a few hundred individuals in 1999 (legal foreigners with residence permits) to almost 100,000 in 2002 (legal foreigners with permits to stay). Most of these immigrants entered Portugal in an irregular way. However, the new administrative status for foreigners that was launched in early $200 \mathrm{I}$ - the permits to stay - allowed the regularisation of many. The new status was requested particularly by Eastern European immigrants, who came to represent more than half its numbers. ${ }^{4}$ This process did not eliminate the problem of undocumented immigrants, who remained a significant proportion, due to lack of conditions for regularisation in 2001 and to new arrivals. The main countries of origin involved in these flows were Ukraine (most migrants), Moldova, Romania and Russia. In 2002, Ukrainians amounted to more than 62,000 individuals, making them one of the three main foreign nationalities in Portugal, along with Cape Verdeans and Brazilians, countries with much longer ties with Portugal. 
Besides the push factors in sending countries and the activities of the trafficking and/or smuggling networks, this new immigration wave has been clearly tied to labour market dynamics in Portugal. The vast majority of Eastern European immigrants rapidly found work in the labour market, mainly in segments of the informal economy. Sometimes immigrants could get a short-term contract, even with an irregular status in the country. The prevalent mode of employment was in lowskilled jobs in sectors such as civil construction (given the great importance of subcontracting chains in the sector), cleaning, restaurants and commerce, not to mention the sex industry (which will be dealt with in the next section). The poor regulation or the precarious type of work contracts existing in these segments, together with rapid economic expansion, explained the easy absorption of many immigrants. The aim of the 200 I law on permits to stay was, simultaneously, to concede a regular status to new immigrants and to bring to the surface large segments of the informal economy (on Eastern European immigration in Portugal, see Peixoto 2002; Pires 2003; Baganha \& Fonseca 2004; Baganha, Marques \& Góis 2004).

The main routes for Eastern European immigration to Portugal are already known from some sparse evidence and from police reports (see Malheiros \& Baganha 2000; Baganha et al. 2004), and were confirmed in the research. Portugal's joining the Schengen area in 1995 was a first crucial step for the beginning of this migration wave. In fact, after this date, Eastern European immigrants could enter the Schengen area from a nearby country (for example Germany) with a tourist visa and then freely travel to other Schengen countries, including Portugal. There is evidence of abundant granting of tourist visas to some Schengen countries (such as Germany), and some sources admitted that there was a less rigorous vigilance by border police in those countries regarding the reasons for travel. The fact that these visas were granted by other EU countries prevented Portugal from using one of the classic means of border control, since the land borders became unguarded.

After entering the Schengen space, a bus or minibus brought the migrants through several European countries, usually Germany, France and Spain. Some of the migrants left the bus in one of these countries, whilst others continued their journey to Portugal. During the journey, changes of bus or minibus occasionally occurred. This suggests the existence of a broad international circuit of migrant routes and a complex operation of smuggling networks. Evidence was also collected about the existence of some attacks and robberies during the journey, leaving the immigrants without money or documents. These assaults were often planned by the smugglers/traffickers, in order to increase their earnings or to increase the vulnerability of immigrants. 
The 'migration package' bought by the migrants in the origin country was often wide-ranging. It usually included a tourist visa (shortterm) to a Schengen country, most often Germany, travel and a contact person in Portugal. The total cost of visa and travel amounted to between 750 and I,500 euros. The indication of a contact person, responsible for finding work in Portugal, might vary from 200 to 400 euros.

Once in Portugal, contact people provided housing for immigrants or helped with finding a job. However, sometimes these contact people did not show up or migrants did not obtain the promised job. Moreover, groups operating in well-defined areas of the territory were responsible for extorting money from migrants. They demanded protection money (regular, usually monthly, payments that generally amounted to between ro and 50 euros). It must be noted that this payment appeared to be quite independent of the debt contracted by immigrants to pay for their journey. Usually, this debt is repaid to people or institutions in the origin country through remittances.

Regardless, for the moment, of the distinction between trafficking and smuggling, the networks of traffickers/smugglers include contacts (network members) in the sending country, usually including a travel agency, responsible for advertising 'trips' to the host country; transport personnel; contacts in transit countries; and contacts in the host country. This latter group is responsible for receiving immigrants, finding accommodation and work and/or, at the same time, for extorting money from immigrants, i.e. demanding money with menaces, sometimes using violent means. Whenever work is effectively provided by these networks, it generally results from informal contacts in the labour market, including Portuguese employers. The work provided is usually in low-skilled jobs in the informal economy and therefore with no contract or any other form of protection.

Looking in detail at the structure of these networks, different types are evident. On the one hand, some networks seem quite loose; they consist of not much more than a travel agency and some scattered contacts, and are often not very effective. They break their ties with immigrants almost immediately following arrival in Portugal. They constitute typical smuggling networks, since they limit their activity to the transport of irregular immigrants to the country (the possession of a tourist visa to a Schengen country does not allow them the possibility of getting a job, and they usually overstay the limit). In contrast, other networks are well organised, displaying a formal hierarchy and job division, and they have ties with other criminal activities in the sending country (mainly Eastern mafias). ${ }^{5}$ They continue their interaction with immigrants, usually by extortion, even after arrival. The latter constitute fully fledged trafficking networks, since they threaten and exploit immigrants against their will. 
Moreover, trafficking networks, in a stricter sense, may reveal a dual character. They may display a complete set of actions in the sending, transit and host countries, in order to assist and profit from irregular immigration. In this sense, they act across the full range of the migration process. In other situations, they may act autonomously in the host country, extorting money from immigrants brought by other networks. In other terms, they may super-impose their own activities on 'regular' and smuggled immigrants. This latter modus operandi came up very often in the research. Interestingly, despite the larger presence of Ukrainian immigrants in Portugal, most of the violent extortion groups are controlled by Moldovans. ${ }^{6}$ It is mainly in the case of these groups that the term 'trafficking' is appropriate, since the presence of exploitation, violence and fraud is evident - although some of them only act in the final stages of the migration process (after the arrival of immigrants).

Even taking into consideration the 'indirect' approach of this project (as referred to in the methodological section), some notes may be added concerning the characteristics of the victims. First of all, although no rigorous evidence is available on this issue, it can be hypothesised that most Eastern European immigrants in Portugal have been involved in some form of smuggling and/or trafficking. This may be deduced from several facts: the previous ignorance about the country on the part of migrants; the non-existence, at the time of the main flows, of active informal support networks (family, friends and countrymen); and the legal difficulties of migrating (despite the opportunity that was conceded in $200 \mathrm{I}$ for regularisation in the host country). ${ }^{7} \mathrm{Gi}-$ ven this framework, to talk about victims of smuggling and trafficking is often the same as talking about the general characteristics of this inflow. Recent studies about this new migration wave (Baganha et al. 2004) and our sparse evidence indicate that these migrants were mostly men targeted for low-skilled jobs in civil construction (although generally over-qualified for these jobs) and, to a lesser degree, women targeted for domestic service and, occasionally, forced into the sex industry.

The operation of smuggling and trafficking networks from Eastern Europe is decreasing over time. This can be deduced from the fact that there is less immigration from Eastern European countries and apparently less exploitation and violence involving these immigrants in Portugal. Some reasons may be added to explain these facts: they include the decrease in job offers (mainly in construction) and the overall downturn of the Portuguese economy in recent years; the difficulties in acquiring legal status, particularly after the end of the 200I regularisation (conceding permits to stay); stronger police control, which led to the eradication of several trafficking networks and better control over 
their activities; some return migration; and better integration of immigrants, including the acquisition of legal status (mainly the permits to stay), and the spread of information and social support networks. This latter cause is of the utmost importance, since informal networks tend to substitute 'formal' and organised networks (although smuggling is still often required, for example for family reunion - possible in legal terms, but slow and expensive in practice). However, a change in the modes of operation of trafficking networks may be occurring, with a larger diversification of activities (for example trafficking in women and drug smuggling) or more subtle forms of exploitation (using less violence).

\subsubsection{The case of smuggling from Brazil}

Contrary to what occurs in the Eastern European case, Brazilian immigration has very deep roots in Portugal. Historically, it started as a typical counterflow of the Portuguese emigration to Brazil, flows mainly visible at the end of the nineteenth century and first decades of the twentieth century. Since the mid-I980s, there has been a significant inflow of skilled and middle-class Brazilians. They fled from insecurity and economic problems in Brazil and were attracted by the new status of Portugal as part of the EU. The use of the same language, the existence of informal networks active in the sending and host countries and effective job opportunities in Portugal explained this inflow. More recently, i.e. since the late I990s, there has been a 'second wave' of Brazilian immigration. This new inflow was characterised by larger numbers, was more irregular in character and the immigrants were of different social extraction: they were less skilled and more middle-lower class than the former, targeting other job opportunities in Portugal, including civil construction, domestic service, restaurants and commerce. Only this most recent inflow has possibly been involved with smuggling and/or trafficking networks (on recent Brazilian immigration, see Casa do Brasil de Lisboa 2004; Machado 2005; Padilla 2005).

A few cases of smuggled and/or trafficked Brazilians were detected in our research (in this section reference is made only to economic migrants other than migrant women employed in the sex industry). The main routes for migration were air travel from Brazil to Lisbon or, increasingly, to Madrid or Paris, and then bus or train to Portugal. Police checks at the Portuguese external air borders, particularly for some nationalities such as Brazilians, have become stricter in the last few years, explaining why diverse routes are sought for irregular immigration. Although visas are not required for Brazilian citizens entering Portugal (visas are only required for medium- and long-term stays), checks on Brazilian travellers at the Portuguese external borders (airports) is rig- 
orous. This is due to the fact that they are considered a 'risk' nationality, in the sense that they are potential immigrants to the country. Whenever they are unable to convince the authorities that they are real tourists (no return tickets, hotel reservations and means of subsistence), they can be stopped at the border. The Spanish and French borders seem more porous for this nationality, since the risk of immigration to these countries is less.

A 'migration package' also exists for these migrants. The package bought in Brazil usually includes air travel and a contact person in Portugal. Total travel costs may amount to between 750 and I,500 euros. The indication of a contact person may vary from 200 to 400 euros. These contact people, who help in providing housing and finding jobs, are not always effective. Often the contact does not exist or does not provide the promised job. Again, the jobs provided are usually in the low-skilled segments of the informal labour market, resulting from informal contacts with employers or from other forms of search by the smuggler (such as looking at advertisements in the newspapers).

Observing the networks involved in this migration, they include contacts (network members) in the sending country, often including a travel agency; and contacts in the host country, responsible for receiving immigrants and finding accommodation and jobs for them. Regarding the networks' structure, different types of networks exist. Most networks are loosely organised, sometimes having a family basis (members belonging to the same family). In contrast, more organised networks can be found, mainly operating into countries like the US. The difficulty of entering the US after 9/II explains precisely why some of these networks moved their attention to the European continent (Machado 2005), as a final target or an intermediate step to access the US.

Not much evidence exists to characterise the victims of these networks. It would seem that a significant (but unknown) fraction of recent Brazilian immigration became involved with these smugglers. In this case, it was probably the immigrants themselves who looked for help from the smugglers since they lacked informal social support networks in Portugal. A broad description of the 'second wave' of Brazilian immigration may help to identify these migrants. From the existing surveys (Casa do Brasil de Lisboa 2004), it is known that, in respect of previous Brazilian inflows, recent migrants are often less skilled, poor, and come from rural regions. In our research, it was observed that victims were mostly men targeted for low-skilled jobs in civil construction, with diverse sending areas in Brazil. Many of them lack previous informal support in Portugal.

Smuggling operations from Brazil seem to be considerable since the late I990s, due to several factors. These include some push factors in the country of origin, effective job offers in Portugal (construction, ser- 
vices, domestic cleaning), the increasing difficulty of illegal access to the US since September 200I, and the fact that Brazilians continue to be able to acquire legal status. In fact, after the 200I regularisation, a special legalisation process for Brazilians was launched in 2003, although its results are still not effective. ${ }^{8}$ These processes do not preclude the continued presence of many undocumented Brazilian immigrants in the country. As previously stated, the presence of strong informal networks among Brazilians in Portugal, together with the cultural proximity with the host country, enabling faster integration, make the operation of organised networks less relevant than in other cases.

To sum up, comparing the characteristics of smuggling and trafficking networks from Eastern Europe and from Brazil, they seem to be very different. On the one hand, the Eastern European networks are usually more organised, with formal hierarchies and job division among their members. They often look for the exploitation of immigrants and are also more violent. A case of trafficking may be witnessed here. On the other hand, the Brazilian networks (and a small part of the Eastern European ones) are more informal and loosely structured; they do not look for a systematic exploitation of immigrants and are less violent. They represent a case of smuggling. The fact that Eastern European immigration was a new kind of immigration to the country, while the Brazilians had both greater presence and cultural proximity, explains some differences, given the very different level of immigrants' social integration after arrival.

\subsection{Trafficking in women for sexual exploitation}

\subsubsection{The case of trafficking in women from Brazil}

Little is known about the international movement of women coming to work in the sex and entertainment industry in Portugal. From the sparse evidence, including mass media coverage, it is known that the vast majority of foreign women working in this sector are Brazilians. It is also known that these inflows grew in the late I990s, accompanying the growth of the sex and entertainment industry all over the country (urban and non-urban locations) - night bars, strip clubs, etc. The absolute numbers involved in this flow are, however, unknown. Those broad traits were confirmed by the evidence collected in the research project on which this chapter is based. This research also led to some clues regarding the operation of networks.

Similarly to Brazilian smuggled immigrants (see last section), the main routes for migration seem to be air travel from Brazil to Lisbon or Oporto or, increasingly, to Madrid or Paris, and then private car, taxi, bus or train to Portugal. The deviation from the Portuguese external 
borders is a result of the strict checks on Brazilian citizens, particularly women, at airports. Trafficking and/or smuggling networks involve: Portuguese owners of night bars; contacts in Brazil, often women (with or without previous experience of prostitution or of Portugal); and other contacts in Portugal, usually related to the sex business and owners of apartments. In general, the networks structure seems rather loose and flexible. Many small networks came to light in the research, made up of single businessmen and a few contacts in Brazil. However, this does not preclude the presence of other more organised and dense networks in the sending and in diverse host countries, including European ones (Leal \& Leal 2002).

Some regularity was found in the modes of operation of these networks. Contact people in Brazil are responsible for finding women interested in working as dancers or prostitutes in Portugal. An important fact is that there may not always be a reference to prostitution, but the indication of work in the sex and entertainment industry (dancers and strippers, for example) seems regular. However, the degree of 'fraud' in the first contacts is a matter of dispute (to work as a 'dancer' is not equivalent to working as a prostitute). Portuguese owners in the sex business often travel to Brazil to supervise operations; they loan money for air travel and give cash to be presented at the airport by the trafficked women (money intended to prove the 'tourism' purpose of the trip - usually around 2,000 USD). Women are then advised to be discreet and wear modest clothes during the journey. Contact people in Portugal (nightclub owners and personnel or other individuals) provide housing and indicate a work place. Some of the houses belong to network members.

Mixed evidence was found regarding operations in Portugal. Some evidence collected suggests that sex work in the night bars is not always compulsory; women must mainly act as 'escorts', receiving a percentage of the clients' consumption. As a result, sex work outside the night bars with the clients may sometimes be their choice, practised in their private apartments, even when, in some cases, the apartment's owner receives a percentage. In other cases, some coercion is visible (for example through threats and retention of documents) and sex work implies the payment of a fixed share of the income to the trafficker, demonstrating an explicit situation of sexual exploitation. Rotation between night bars is a common practice, being either the initiative of the owner (to 'renew' the club or to be protected against police checks) or at the initiative of the women themselves. Evidence of the imprisonment of women or strict checks on their movements was rarely found, at least in the medium- and long-term after their arrival, when repayment of the initial debt had been made. 
Regarding victims, it seems that most women come from the lower and lower-middle classes and from poor regions in Brazil, which confirms their vulnerability. Sending areas are diverse, with an apparent predominance of the North-East (Nordeste), Minas Gerais and Goiás. Previous experience in the sex and entertainment industry varies. Some women have previous experience in prostitution, others have experience as 'escorts', others have no experience in these fields. However, as already stated, women often seem to know broadly what kind of work they will do in Portugal. Moreover, despite some contradictory evidence, women seem to display a considerable amount of control over their destiny along the migration path, mainly after the repayment of the initial debt to the trafficker. This control is reflected in the decision to migrate to Portugal; the decision to do sex work after 'regular' work in night bars when this applies (the income earned from the sex work may be totally or partially for themselves); and the decision to leave the business or to 'rotate' between night bars.

Trafficking in women from Brazil seems to be considerable since the late I990s. This can be explained by push factors in the country of origin (poverty in many urban and rural areas of Brazil), the demand for sex work in Portugal, the unregulated character of the industry and the high incomes earned in this activity. However, the negative aspects associated with this activity and the restrictions now operating in Portugal may keep this inflow at a low level, quantitatively speaking. A recent strengthening of police control over illegal stays of women and sexual exploitation by night-bar owners, partially in response to some civil unrest, may help to restrict larger movements of this type. Some mass media coverage, as occurred in the case of the 'Bragança mothers' (a report on Brazilian prostitution in a peripheral town of the country published in Time magazine), turned attention to these inflows and partly explains the restrictions.

As discussed by the literature in the field, it is not always easy to distinguish trafficking in women from other forms of sex work carried out by immigrant women. Trafficking in women supposes depriving a woman of her free will and profiting economically from her involuntary work; however, it is often difficult to evaluate these conditions in practice (Okólski 200I: I40). The evidence gathered in this project - resulting, as mentioned before, from media reports, judicial cases and interviews with the authorities - is often mixed, displaying, on the one hand, cases of voluntary migration to the sex and entertainment industry and, on the other hand, situations of fraud and coercion. As a result, the only certain conclusion is that there are some organised networks bringing in vulnerable women from Brazil to engage in the sex business in Portugal. Trafficking in women does indeed exist, although the real size of the problem remains an open question. 


\subsubsection{Other cases of trafficking in women}

There is still less information available about other cases of trafficking in women for sexual exploitation although, compared to trafficking from Brazil, the volume seems to be much less. The main inflow comes from Eastern Europe. In this case, trafficking in women seems to be a by-product of other forms of smuggling and trafficking related broadly to economic migrants. Regarding absolute numbers, there was a major increase after the late I990s, but still a limited number of cases. Some evidence suggests that whenever a job is hard to find for a female regular economic migrant, or whenever she faces economic difficulties making it difficult for her to save or pay protection money, traffickers suggest she access the sex and entertainment industry (night bars, strip clubs, etc.). In fact, the amount of money earned in the industry may constitute a pull factor for some regular migrant women.

Still, as regards the Eastern European case, recent indications suggest that job trafficking networks are entering the sex business, as a way of diversifying sources of income, due to decreasing immigration and major difficulties in extorting money from migrants. The fact that trafficking in women was not, until now, a main activity of these networks may be explained since Portugal, as a peripheral market, is not sufficiently attractive for the major Eastern trafficking networks.

\subsection{Discussion and theoretical implications}

\subsubsection{Trafficking or smuggling?}

In conceptual terms, there are clear differences between trafficking and smuggling. As stated above, these differences result from the levels of exploitation, coercion and fraud. Taking these concepts in their strictest sense, a vast presence of ill-defined situations is apparent in Portugal. The project results seem to suggest that there are many forms of intertwining between trafficking, smuggling and 'regular' economic migration, including coercion and violence against voluntarily smuggled migrants, which must be added to some of the more clearcut trafficking situations.

Looking in detail at labour migration flows related to trafficking and/or smuggling, evidence of economic migrants moving under their own free will was most often found. This is the case as regards the Eastern European and the Brazilian flows, as well as in other cases not considered in this chapter. In this sense, no evidence of 'forced labour' was ever found. However, particular situations exist, mainly in the Eastern European case, which drives these migrations farther away 
from a typical labour flow or even from smuggling. As previously argued, migrants sometimes suffer extortion (in a proportion impossible to determine) from organised groups of the same or other Eastern European nationalities. This extortion consists of robberies or the regular demand of protection money. Here, coercion, violence and exploitation are present, involving migrants who may or may not have been smuggled in by these particular groups. These situations arise, in a significant part, due to the stringent rules allowing legal migration and the weak social integration of these migrants. In a sense, coercion, violence and exploitation may be understood as a side effect of irregular migration. The acquisition of legal status, together with better social integration, have clearly led to a decrease in these forms of coercion.

Regarding trafficking in women for sexual exploitation, there is also evidence of the exercise of free will for economic migration and work in the sex and entertainment industry among many women. The sex industry appears to be a form of work targeted by some women, due to strong demand and the low level of regulation in the host countries. Its main advantage is the high income to be earned, whilst its main disadvantage is the low social status and the weak social integration of migrants. Moreover, some evidence of at least partial control over their own destiny was found among many women. However, sexual exploitation of women is found in many cases - either considering prostitution or other types of work in the sex industry. As a result, a situation that, at the beginning, could be very similar to a case of 'regular' labour migration may turn into one where the migrant loses more than expected - or, in more dramatic cases, may become an unwanted nightmare (Anderson \& Davidson 2003).

It may be argued that smuggled labour immigration and the sexual exploitation of immigrant women, among other problems, correspond initially to regular economic migration. In most cases, a matching of interests between labour supply (migrants' ambitions) and demand (the employers' need for cheap and fresh labour) may be found. Portugal's need for economic migration does not show up in legal and nonproblematic forms of migration since legal channels for immigration scarcely exist. At most, migrants benefit from amnesties, although sometimes these only grant temporary statuses, as was the case in 200I. The diffusion of the informal economy and poorly regulated activities combines well with fragile forms of employment, attracting migrant labour. Indeed, among the main reasons for smuggling/trafficking, the existence of restrictive immigration policies, the informal economy and the character of prostitution as a non-regulated activity must be cited.

In addition, it should be said that many of these migrants - smuggled labour immigrants and women targeting the sex business - are not 
really 'victims' of external networks. In fact, they are often active connivers or, in other terms, accountable for their migrant condition. Indeed, they may even be satisfied with their immigrant condition, given the effectiveness of the service provided by the smugglers and the scarcity of legal channels to migrate (Koser 2006). One of the consequences is the difficulty in combatting trafficking and smuggling networks, due to the lack of cooperation on the part of the victims. Even if this low level of cooperation may also result partly from the fear of violence from smugglers/traffickers, it is also due to the migrants' responsibility for the situation.

The main analytical consequence of these observations is the presence of unclear boundaries between regular labour migration, smuggling and trafficking. Instead of clear-cut and well-defined phenomena, to be understood and regulated with different lenses and mechanisms, a large continuum of mixed situations may be found - as has been referred to above. Research and regulation must therefore be conducted with the aim of operating with unclear and ambiguous situations in these fields.

\subsubsection{Causes of trafficking and smuggling}

Multiple causes are active in the various modes of smuggling and trafficking found in Portugal, both considering all labour migration flows and the particular case involving the sex and entertainment industry. First, strong push factors for emigration prevail in the case of Eastern European countries, Brazil and others. Second, EU regulations became significant. In Portugal, this was mainly due to the Schengen Agreement, under which only the external air and maritime borders were controlled, giving place to an uncontrolled land frontier easily crossed by irregular migrants. Third, pull factors for immigration were important. These mainly result from the sizeable number of job offers in low-skilled and poorly regulated jobs between the late I990s and the early 2000 , in sectors such as civil construction, cleaning, restaurants and commerce, as well as in the sex and entertainment industry.

Fourth, Portuguese immigration policy explains many of the recent immigration traits. The scarcity and slowness of legal channels for regular immigration (for example family reunion) has been evident for a long time. Ever since the pressure for migration increased from the late I970s, the legal mechanisms have not been sufficient to deal with all the migrants, giving rise to an endemic problem of irregular migration. Consequently, various legalisation processes for irregular migrants were set up. 'Classical' legalisation processes were launched in I992 and I993 and in I996. More recently, the granting of 'permits to stay' (in practice, work visas granted in Portugal) was established in 
200I, allowing the regularisation of a large mass of recent migrants, mainly from Eastern Europe. Afterwards, in 2003, a special legalisation process for Brazilians was launched. ${ }^{9}$ All these regularisation processes have in common the retrospective acceptance of irregular and smuggled immigration. At the same time, the Portuguese government is increasingly imposing more severe immigration control at the external borders, combatting smuggling networks and the organised extortion of immigrants. Although the results of these initiatives have been partly effective, they have not completely contained the side effects mentioned above.

To sum up, the economic and institutional context has been favourable to the creation and strengthening of organised support networks for irregular migration and, sometimes, to the exploitation of migrants, or in other terms, to smuggling and trafficking networks (Salt \& Stein I997). These may be called 'formal' networks, in contrast to the more widely studied 'informal' connections of immigrants (Kritz, Lim \& Zlotnik I992; Portes I995). On the one hand, these 'formal' networks support individual migrants in their legitimate migratory strategy but, on the other hand, they may set in action mechanisms of exploitation as a form of taking advantage of migrants' vulnerability.

The main analytical consequence of this has already been stated. Migrant trafficking, as a form of exploitation, coercion and fraud, is often a perverse effect of smuggling activities and restrictive policies. In the Portuguese case, active smuggling of Eastern European immigrants gave rise to extortion. Organised networks took advantage of migrants on account of their initial irregular status, absence of informal support networks, and lack of cultural similarities and knowledge about the country.

\subsubsection{Dynamic interaction between agents}

One of the most interesting features that may be found in the empirical research on smuggling and/or trafficking is the number of agents involved and their dynamic interaction (Kyle \& Koslowski 200I). Several agents are involved in these processes: migrants and potential migrants (the so-called victims of the process); intermediary agents more-or-less organised smuggling and trafficking networks; employers (in sectors such as civil construction, domestic cleaning, the sex and entertainment industry, etc.); non-governmental associations; and the government and public authorities of the host country. Regular and dynamic interaction between these agents takes place. In other words, there is a permanent creation and (re)adaptation of strategies between individuals and groups. It may be argued that it is this interaction and 
its dynamics that lead to variations in the type of smuggling/trafficking, the quantitative volume of the flows and modes of operation.

The admission of agency among smuggled and trafficked individual migrants, in the sense of considered and intentional behaviour, albeit in the framework of social structures (Giddens I984), complicates the explanation for these flows. In fact, we may say that smuggled and trafficked migrants are often accountable in their migratory destiny, voluntarily becoming involved with smuggling/trafficking networks. Whenever this agency occurs, they are not passive victims, but active agents - even if the future contexts may become harsher than initially thought. Indeed, the agency and control over their own destiny on the part of migrants is usual in the more basic situations of smuggling, and problematic when real trafficking occurs. In any case, fraud, coercion and exploitation often occur as a perverse side effect of the available migration channels. The harsher traits of trafficking may appear as an unintended consequence of other forms of migration.

In the Portuguese case, the permanent adaptation of agent strategies in relation to each other has led to a profound change in immigration patterns in the last ten years. New sending countries are present outside the Portuguese-speaking area that was the traditional Portuguese migratory system. A very strong increase of immigration was witnessed in a short time span: between 2000 and 2002 tens of thousands of Eastern Europeans immigrated and spread all over the country. Many of the smuggling/trafficking networks activities resulted from shortterm economic and policy changes: job opportunities in civil construction; opportunities for legalisation (mainly in 200I); and the comparatively weak control of irregular immigration compared to other countries.

It may be argued that this dynamic interaction between the different agents involved - migrants, intermediary networks, employers and the state - creates a very changeable profile for immigration, regarding its rhythms and characteristics. The presence of active and organised intermediary agents has produced a situation that is very different from the traditional channels of migration, namely planned government-led international labour recruitment and the slow operation of informal social networks.

\subsection{Conclusion}

Smuggling and trafficking of migrants is a relatively new phenomenon in Portugal. Foreign immigration, per se, only began in significant numbers in the late i970s. Only in the late I980s did frequent situations of irregular and illegal migration begin to arise and only in the 
late I990s did smuggling and/or trafficking become a major concern of the general population and the public authorities. The most recent waves of foreign immigration to the country, namely those coming from Eastern Europe and the 'second wave' of Brazilian immigration, were the ones to become involved with irregular forms of channelling migrants. Research about these new waves of migration is still scarce. For a variety of reasons, research about forms of smuggling and/or the trafficking related to them is still rarer, due to the irregular and illegal status of these phenomena.

In this work, some of the main results of a project about migrants' trafficking and smuggling in Portugal have been presented. Two types of flows have been considered: movements of labour migrants targeting low-skilled segments of the (mainly) informal labour market, coming from Eastern Europe and, to a lesser degree, Brazil; and movements of women targeting the sex industry, mainly coming from Brazil and, to a lesser degree, Eastern Europe. The main characteristics of the smuggling and/or trafficking networks have been described, together with some of the victims' characteristics. The main contrast detected was between more organised and violent networks of smuggling/trafficking from Eastern Europe, and more loose and less violent smuggling networks from Brazil. Mixed characteristics are evident in the case of women involved in sexual exploitation, since some degree of choice and control among women is combined with coercion and exploitation.

The main conclusions are the following. First, smuggling and trafficking do not appear as clear-cut and distinct phenomena. Instead, they are connected with each other and with 'regular' labour migrations. The argument is that it is mainly the context that creates harsher forms of trafficking, instead of smooth paths of labour migration. Second, causes for smuggling and trafficking are multiple, and relate to all the agents involved in migration. Push and pull factors, which may be analysed through a micro or macro lens (individuals or societies), combine with institutional regulations to produce concrete ways of channelling irregular migrants. Third, dynamic interaction between agents is visible. The agents involved are migrants, smugglers and/or traffickers, employers and institutions (the government and non-governmental organisations), all of them active in this field. It is their concrete mode of interaction that leads to the concrete and changeable ways of smuggling and trafficking in a country. 


\section{Notes}

I I would like to acknowledge the financial support of FCT and ACIME, as well as the participation of the other members of the research team - António Goucha Soares, Paulo Costa, Susana Murteira, Sónia Pereira and Catarina Sabino - in the discussions leading to this chapter. All errors and shortcomings are my own responsibility.

2 The research also dealt with trafficking in children. However, since scarce evidence was found about this flow, no reference will be made in this chapter to the theme.

3 Only very few interviews were made with traffickers and/or smugglers. The ones that were carried out resulted from the willing cooperation of convicted individuals. No interviews were carried out with victims. Some contacts with migrants were requested from non-governmental organisations dealing with the problem, but they were not provided in order to protect victims from any form of observation. The life histories that were collected resulted from the observation of media reports, judicial cases and analyses of interviews.

4 Portuguese immigration policy has dealt tentatively with the issue of irregular immigration. In 1992 and 1996 , 'classical' legalisation processes of irregular migrants were set, granting immigrants a stable residence permit. In 200I, given the volume of new irregular inflows, a new status of 'permit to stay' was created, allowing immigrants a temporary stay (one year, renewable for five years). This status corresponded to the granting of work visas in the country, being based on the possession of a work contract (simultaneously, the law criminalised the hiring of illegal immigrants). The results of this initiative, equivalent to a legalisation process, led to the regularisation of a large mass of immigrants, mainly from Eastern Europe. This temporary status was only granted during $200 \mathrm{I}$ and was definitively abolished in 2003. Although many of the Eastern European immigrants were able to obtain a legal (albeit temporary) status, a significant number (mainly those arriving after 200I) remain undocumented.

5 Evidence collected during the fieldwork showed links between groups operating in the Portuguese territory, mainly the better organised and the more violent ones, with criminal groups in sending countries. This was mostly seen in the case of Moldova. Criminal activities of parent organisations ranged from trafficking in immigrants to other activities such as drug smuggling.

6 It may be admitted, as a hypothesis for future research, that Portugal's peripheral geographical position makes the country less attractive for Ukrainian and Russian criminal organisations, giving space to the stronger operation of Moldovan groups.

7 Some evidence on this issue has been collected by other authors, based on surveys of Eastern European immigrants. Although only a minority admitted to have been involved with smugglers and/or traffickers, most said they had entered Portugal in a regular way. Complementary evidence indicates that their visas were granted by other Schengen countries and that they obtained jobs without the necessary legal conditions to do so (Baganha, Marques \& Góis 2004). Given the difficulty of getting visas in the sending countries and the absence of former informal connections with Portugal, this suggests an organised smuggling network supporting irregular immigration.

8 Differently from other nationalities, Brazilians have benefited from a special regularisation arrangement agreed in 2003. This followed a visit to Portugal by Brazilian President Lula da Silva. Among several initiatives, explained by the privileged ties between both nations, a period of legalisation of irregular immigrants, based on the possession of work contracts, was launched. The high volume of 
candidates, the red tape and the slowness of the process would explain why few immigrants have already been granted a residence permit.

9 In 2004, a special legalisation process for immigrants who proved to have contributed to the public finances (e.g. social security contributions) also began. The numbers involved in this process are still low.

\section{References}

Anderson, B. \& J. Davidson (2003), Is trafficking in human beings demand driven? A multicountry pilot study. Geneva: IOM.

Aronowitz, A. A. (200I), 'Smuggling and trafficking in human beings: The phenomenon, the markets that drive it and the organizations that promote it', European Journal on Criminal Policy and Research 9 (2): I63-195.

Baganha, M. I., J. C. Marques \& P. Góis (2004), 'The unforeseen wave: Migration from Eastern Europe to Portugal', in M. I. Baganha \& M. L. Fonseca (eds.), New waves. Migration from Eastern to Southern Europe, 23-39. Lisbon: Luso-American Foundation.

Baganha, M. I. \& M. L. Fonseca (eds.) (2004), New waves: Migration from Eastern to Southern Europe. Lisbon: Luso-American Foundation.

Casa do Brasil de Lisboa (2004), A 'segunda vaga' de imigração brasileira para Portugal (1998-2003). Lisbon: Casa do Brasil de Lisboa.

Fonseca, M. L., J. M. Malheiros \& S. Silva (2005), 'Portugal', in J. Niessen, Y. Schibel \& C. Thompson (eds.), Current immigration debates in Europe: A publication of the European Migration Dialogue. Brussels/Lisbon: Migration Policy Group.

Giddens, A. (I984), The constitution of society: Outline of the theory of structuration. Cambridge: Polity Press.

IOM (International Organization for Migration) (2000), Migrant trafficking and human smuggling in Europe: A review of the evidence with case studies from Hungary, Poland and Ukraine. Geneva: IOM.

IOM (International Organization for Migration) (2004), Glossary on migration. Geneva: IOM.

Koser, K. (2006), 'Human smuggling: Theoretical and empirical perspectives from Pakistan, Afghanistan and the UK', paper presented at the seminar 'Mobility, ethnicity and society', Bristol, I6-17 March 2006.

Kritz, M. M., L. L. Lim \& H. Zlotnik (eds.) (1992), International migration systems: A global approach. Oxford: Clarendon Press.

Kyle, D. \& R. Koslowski (eds.) (200I), Global human smuggling: Comparative perspectives. Baltimore: The John Hopkins University Press.

Leal, M. F. \& M. L. Leal (2002), Pesquisa sobre tráfico de mulheres, crianças e adolescentes para fins de exploração sexual comercial no Brasil. Brasília: CECREA.

Machado, I. (2005), 'Implicações da imigração estimulada por redes ilegais de aliciamento - o caso dos brasileiros em Portugal', SOCIUS Working Papers 3/2005.

Malheiros, J. M. \& M. I. Baganha (2000), 'Imigração ilegal em Portugal: padrões emergentes em inícios do século XXI', in Janus 2001 - Anuário de relações exteriores, I9OI9I. Lisbon: Público and Universidade Autónoma de Lisboa.

Okólski, M. (200I), 'Trafficking in women in the Baltic States: Sociological module', in IOM (International Organization for Migration, Trafficking in women and prostitution in the Baltic States: Social and legal aspects, 95-I54. Geneva: IOM.

Padilla, B. (2005), 'Integration of Brazilian immigrants in Portuguese society: Problems and possibilities', SOCIUS Working Papers I/2005.

Peixoto, J. (2002), 'Strong market and weak state: The case of foreign immigration in Portugal', Journal of Ethnic and Migration Studies 28 (3): 483-497. 
Peixoto, J., A. G. Soares, P. Costa, S. Murteira, S. Pereira \& C. Sabino (2005), O tráfico de migrantes em Portugal: Perspectivas sociológicas, jurídicas e políticas. Lisbon: ACIME.

Pires, R. P. (2003), Migrações e integração: Teoria e aplicações à sociedade portuguesa. Oeiras: Celta Editora.

Portes, A. (ed.) (1995), The economic sociology of immigration: Essays on networks, ethnicity and entrepreneurship. New York: Russel Sage Foundation.

Salt, J. (2000), 'Trafficking and human smuggling: A European perspective', International Migration 38 (3): 3I-56.

Salt, J. \& J. Stein (I997), 'Migration as a business: The case of trafficking', International Migration 35 (4): 467-494. 


\title{
5 Romanian migration movements: Networks as informal transnational organisations
}

\author{
Swanie Potot
}

Since the fall of the Iron Curtain, the European continent has become, as it used to be, a vast area of exchange in which human migrations take diverse forms, from virtually permanent emigration to a variety of short-term movements, such as study programmes or seasonal jobs (Okólski 200I). The kind of migration this text deals with consists of constant mobility between the native country and several places abroad where migrants work on a temporary basis. This started at the beginning of the I990s and demonstrates how middle-class people from Eastern European countries have played a role, without waiting for international agreements, in the construction of a large transnational area across Europe.

\subsection{Introduction}

The cases studied here concentrate on movements between Romania and several other countries in the European Union. Even if some aspects are similar to other Eastern European countries, as regards migration, the Romanian situation is quite specific. First of all, it should be noted that unlike Poland, Hungary or Slovenia, Romanians had to apply for a visa to visit any other EU country throughout the I990s, in fact until 2002. For years, one of the big issues delaying the entry of the country into the EU was its migratory potential and the supposed permeability of its frontiers (Michalon 2005). Indeed, the possible numbers of Romanian migrants were frightening Western societies because of the supposed consequent burglary rate. Prior to entry into the EU, Romanians could not stay in EU countries for more than three months at a time and, apart from rare instances regulated by special bilateral agreements, were not allowed to work. Even though accession to the EU occurred in 2007, during the preceding sixteen years Romania had been marginalised within the international European area, a fact which strongly restricted, but did not stop, migrations.

The country's recent past and the way the transition to capitalism was driven after the collapse of the communist regime strongly weakened the national economy and subsequently reduced the standard of 
living of the entire population. Having become a communist country after World War II, from I965 to I989 Romania was in the grip of a powerful dictatorship, harshly conducted by Nicolae Ceausescu. Thus, when in I989 democracy was imposed, the economic situation was extremely bad and national industry very weak, outdated and unprepared for international competition. In such a context, the period of transition lasted more than ten years, although many sectors are still being restructured and privatised, and had a very high social cost (Lhomel 200I).

As a result, the option of temporarily working abroad has become a solution to the difficulties encountered at home. The wealth gap between Romania and Western countries allows migrants to make the most of their earnings by working in the West while spending in Romania. Thus, for most Romanian migrants, migration does not mean permanent departure; they are actually 'intermittently on the move', their life divided between several places, but their one real 'home' remaining their country of origin (Morokvasic et al. 2003). At the beginning of the I990s, as the possibilities for travel towards the West were very few, informal movements (i.e. not legally organised) involved mainly young males in search of adventure as well as prosperity. They went for a few months to Germany, France or other countries on tourist visas (often bought on the black market in Romania) and found jobs there, mostly in construction or tourism (hotels and restaurants), where there are numerous undeclared jobs (Diminescu 2003). These first experiences encouraged others to leave and eventually, with the growing number of candidates, migrating has become easier, thanks in particular to a large black market in Romania selling visas, information and opportunities to work abroad.

Acknowledging this situation, the research presented below, based on fieldwork conducted in Romania, France, Spain and Great Britain, has two main aims: first of all, to understand how a population that had had no chance to travel for decades managed to create transnational areas in which people can move and find opportunities to work on a European scale. It would seem that interpersonal links and a degree of mutual support have gradually created large social networks of economic migration, very well adapted to the globalisation of the European economy. Second, it is important to highlight the impact of these numerous micro-strategies on Romanian society as a whole. It seems clear that migrants, as transnational actors, are bridging Eastern and Western Europe and are actively participating in the 'Romanian transition towards a Western model. 


\subsection{An ethnographic approach}

The study began in 1998 and lasted for over five years (Potot 2003). Information and observations were gathered in France on a regular basis for the period 1999-2003: in Romania, for around five months over several stays between I999 and 2003; in the south of Spain, where two investigations were conducted in August 2000 and February-March 200I; and in London during fieldwork conducted over two months in 200I. Overall, the fieldwork covered two independent migration networks.

The first network had been expanding since 1995 between Târgoviste, a town of 100,000 inhabitants in the vicinity of Bucharest, and Nice in the south of France. During this period, around 300 migrants travelled once or more between both places. Their main occupation in France was selling newspapers on the street, an activity aimed at helping indigent people by giving them the opportunity to become streetsellers. When this opportunity was withdrawn when France tightened its law ${ }^{1}$ on asylum seekers (Benattig \& Brachet 1998), the model evolved into something much less synchronised. During the transition period, many little groups spread out towards Italy, Spain, Belgium, etc., in order to find more favourable conditions for temporary migration.

Eventually, in a third phase, another model emerged, notably reducing the number of destinations chosen by migrants from Târgoviste. In fact, only migration to London had important consequences for the network formerly established in Nice. The popularity of this destination relied on some significant advantages: first of all, although getting into the country could be difficult, the British authorities did not follow undocumented people very tenaciously and also, in such a situation, finding a place to work or renting a flat were quite easy compared with France; second, the job market was very dynamic and very open to foreigners. Additionally, wages were clearly higher than in Southern Europe and, although everyday life was expensive, migrants managed to send more money back home. Still the main problem was entry since Great Britain was not part of the Schengen area ${ }^{2}$ and subsequently Romanians were obliged to apply for a British visa, which was (and still is) difficult to obtain. A few migrants rapidly found a way around this barrier and, within a few months, the information being sold from one person to another had spread through the entire network. Then, as travel became easier and the quality of life began to improve, the migrant profile began to change as older people and women increasingly entered the migration process (Potot 2005).

The fieldwork showed how the network reconstructed itself and expanded as job opportunities became more numerous and better than selling newspapers on the street. The survey also highlighted the influ- 
ence of legal, social and economic status upon migrants' collective behaviour. Following the observations made on both sites, fieldwork was conducted in the homeland, not only to observe living conditions before and after migration but also to compare the ideas and attitudes of migrants when they are abroad and when they are at home.

The second migration network studied was totally independent from the first. It emerged between a region called Teleorman, in the south of Romania, and the province of Almeria, more precisely in the area of El Ejido, in Spanish Andalusia. This area is famous for developing its agricultural economy by harshly exploiting the labour of many foreign workers, often without documents. Many nationalities are represented there (Filipinos, South Americans, sub-Saharan Africans) but the largest and oldest group comes from Morocco, ${ }^{3}$ and is subject to considerable racism. In such a context, for three days in February 2000, racial tensions exploded into riots against Moroccan workers. Following these riots, all Moroccan workers went on strike, paralysing farming activities. At the time, employers reacted by immediately hiring some Eastern European migrants, mostly Romanians, to replace the Moroccan strikers. ${ }^{4}$

As a result of the fieldwork, it was possible to conclude that, even if the environment was different from the Târgoviste-Nice-London network, the presence of Romanians in this Spanish province was part of the same migration phenomenon, which is developing in different European economic and spatial areas. Its principal feature is that it involves people originating from the same area in Romania, connected either directly or through third persons and thus sharing local knowhow, who then find sectors of employment where their presence is accepted. Because of the poor wages and job conditions offered, they are not in direct competition with national workers. Moreover, being 'strike breakers', as the media put it, allowed them to enter a niche area of employment (Waldinger 1994) that was previously occupied by other foreigners.

Compared with the migrant population from Târgoviste, migrants from Teleorman were more diversified; composed of younger people as well as older ones who, following retirement, had come to Spain to build on the small pensions they received in Romania. Some migrants were unemployed in Romania, as is often the case for young and educated people, but others had left their rural or urban jobs to earn much more money in a few months, working hard in Spanish agriculture. In the greenhouses, the presence of some Romanian girls was also noticeable as they were virtually the only women hired.

Lastly, fieldwork in the Romanian region of origin was conducted in cities and small villages. ${ }^{5}$ Vast amounts of information were gathered through interviews with migrants and their families and with town 
councillors, priests and local government officials. The importance of individual connections for migrating was obvious: those who wanted to leave and did not attain their goal or those who had returned without having earned any money in Spain always blamed the lack of acquaintances. In contrast, flourishing families, who were constructing big houses, had often sent several members of the family who could rely on each other and replace each other in the Spanish province or elsewhere. Thus, it was possible to see traces of these migrations in the landscape: many houses erected in small villages showed how wealthy the region had suddenly become.

The aim here is not to compare both networks in every aspect but to pinpoint recurrent aspects occurring in both in order to understand, from an anthropological point of view how Romanian migrants, who prior to I989 did not migrate, have been able within a few years to develop original collective strategies and new forms of emigration.

\subsection{Transnational migration networks: a social form adapted to a 'globalised' Europe}

These two case studies analyse informal migrant networks. The point is to show how these informal organisations are being constructed through migrant practices on the basis of diverse links, and how throughout Europe they find a way to penetrate niches open to illegal workers which have spread across the western part of the continent. An analysis of Romanian movements brings to the fore the capacity of these transnational organisations that deal with the paradox of a rigid legislative framework regulating conditions of entry into the European area and the needs of an economy that go beyond any notion of state borders. With many social links - even if they are sometimes weak (Granovetter I973) - maintained over very large areas, migrants manage to bypass border controls and policies restricting migration and to spread within areas of very different geographic, social and economic characteristics. In fact, as the fieldwork shows, each migration destination is specific, and migrants continue to adapt themselves to each one individually, as variations in the economic and political situation in Europe regularly cause them to leave one place and find a new one where they might be accepted as workers. Thus, the uprooting these migrants experience goes hand-in-hand with the continuous recomposition of circulation areas, subject to an international situation simultaneously driven by the global economy and the internal workings of the different states. 


\subsubsection{Network sociability and structural constraints}

The success of migrant networks relies on the kind of sociability in these organisations. Links between migrants may be strong within very small groups so the social constraint experienced by migrants is minimal. Thus, during their migration, they usually feel free not to conform to the model used by others. In Nice, for example, a few people refused to sell newspapers on the street as they did not find it worthwhile, others chose to rent flats far away from the inner city hotels where most of their compatriots lived, but they maintained close connections with other migrants from Târgoviste and could request their collaboration or assistance if needed. ${ }^{6}$ On this point, these networks differ from other migrant communities who exercise strict control on their members' activities abroad, for example, migrant Mourid communities (Salem 1981). Here, members' participation in collective activities is variable and fluctuating. People can be integrated into the network to differing degrees, participate irregularly and even sometimes dissociate from other members before joining in once again. As long as they do not act against the network, for example by undermining relations with an important employer or by misbehaving in a hotel where many people from the same area are accommodated, the network remains open to its members, even occasional ones.

Consequently, migrants attempting to find original migratory destinations do not experience new migratory paths collectively, but individually or in very small groups. They sometimes take risks, but this does not challenge the position set up by the entire network. Meanwhile, failures or discoveries that cannot be shared with many people may still be exploited by the few. Thus, two young men who were formerly in Nice decided to go to Madrid to work. After a few months and many difficulties, they managed to find jobs in a restaurant and to settle down but they were not able to help their compatriots in reaching the place or in being hired. So, they added a destination outside their network's area, and it never became a collective migration spot. However, these two young men keep contact with their counterparts living in France or in England and so become a resource that could be exploited in the future. The possibilities of finding new opportunities are thus multiplied by attempting new strategies. After such a discovery, the most useful pieces of information spread little by little, first between men close to the 'discoverer', and then among an increasingly larger population, until most members of the network are informed. To sum up, the fact that individuals are connected by loose links makes it possible for each person to take initiatives that, when successful, will then be used by the whole group. Indeed, the strength of a migrant network comes from combining individual initiatives and sharing re- 
sources. Therefore, the amount of knowledge and abilities shared in a network is constantly increasing, allowing migrants to discover how to filter collectively into societies where they do not have any legal means of access.

The Romanian migrant network may then be thought of as a loose form of social organisation, especially tailored for transnational mobility. We therefore observe that the transnational movements of these migrants rely on the interpretation of each state's activities as regards border and immigration controls (Portes 200I). Laws are not the only aspect taken into account by migrants; they also consider how each state's institutions and authorities act in the face of illegal migration. With the same legal situation, a state, or a special area within a state, might be more tolerant towards undocumented workers if their labour is required by a particular sector of the economy, as in the province of Almeria where the police leave undocumented people in peace if they can prove that they regularly work in the local greenhouses. This kind of information is very precious as it determines the possibility of identifying a suitable destination for a group. But the only way to learn about it is through oral knowledge passing from one migrant to another, even if he/she is not member of the network. In this sense, one can say that the migrant network adapts to the way in which international migration is treated by the states. In particular, the degree to which states implement controls but also aspects that go beyond the law, namely the demand for labour.

Consequently, in order to find new migration channels and destinations, migrants do not study international law to find out where they might work legally, but rather they deal with their future employers on the basis of what they have heard or what they believe. Nevertheless, the cases studied tend to show that this trend towards ignoring the legal framework is limited in that mobility practices tend to harmonise, to a certain extent, with decisions taken at the international level. For example, Târgoviste's network reorientation from Nice to London happened just after the law concerning the asylum process in France was tightened. Their departure was therefore in response to new national legislation; yet migrants did not try to obtain legal status, nor did they stop travelling. Rather, they looked for another place where they would be tolerated and could remain unnoticed. It appears clearly here that, although those people do not directly conform to national or European policies, their movements partly depend on the enforcement of the law. In concrete terms, these statements show that what is important in migrant orientation is neither national or EU laws or policies on the movements of people, but institutional and employers' practices. The cases studied in Spain are examples of this tendency: Romanian migrants found a socioeconomic niche welcoming them as workers, in a 
place where they would not be very strictly controlled by the police, in spite of the fact that this country is part of the Schengen area, and therefore subject to strict legislation concerning immigration. Consequently, even if official policies managing flows do not weigh heavily upon transnational migration, what the state actually does in practice will influence transnational migration routes. Thus, states influence transnational migrant activities through the implementation of public policies.

Moreover, it was observed that despite the efforts of the EU to harmonise policies concerning migration and asylum within its boundaries, local disparities in the way migration is dealt with are maintained. As national borders inside the European area are progressively fading, measures taken in the face of migration are multiple and depend very much on the place where the migrants are. With the same legal framework, different authorities have different attitudes towards foreign workers, sometimes even within national areas. For example, in contrast with the tolerance shown by authorities in southern Spain, provinces very close to Almeria apply the law strictly, preventing any illegal work and expelling undocumented people. So, migrants do not dare travel through Spain, as they know that they cannot count on the tolerance of the police in the province of Almeria and they might be caught and expelled. Thus, by their various attitudes, local authorities delineate new territorial borders, inside the national territory.

Yet, if networks manage to submit to these implicit directives without erring, it is above all a result of how well the networks are functioning. Actually, nobody knows precisely how the situation evolves in Europe overall; there has been no analysis of the evolution of zones of tolerance. The ability to adapt and to move on from one place to another is, from this point of view, a collective competence. Individuals inside networks explore several migration possibilities among which only a small number is collectively useful. Only the most favourable situations, that is to say the ones providing improvement, are collectively invested in. The situation of each migrant trying a new destination is known by the other members of the network, and they will move to that place only if it offers better prospects than the previous one. However, the suitability of an option does not depend only on the economic benefits migrants may expect; living conditions and notably the fear of being expelled at any moment are very important too. Sharing information inside networks more or less allows the migrant group to choose between possible migration situations, but at the expense of strong social and/or institutional pressure, and situations in which undocumented workers are economically coveted and tolerated by the local society. For example, when migrants from Nice were looking for a new place to go, two of them went to Madrid, where they stayed, but the numer- 
ous difficulties they encountered there discouraged others from joining them. In this sense, the network helps in orientating migrants towards areas in which states unofficially authorise immigration.

Hence, this kind of organisation increases the flexibility imposed on undocumented workers while the transnational network makes it possible to be more flexible. When a network is spread over more than a single working niche, migrant workers are more flexible when dealing with employers. Inside a network, several activities and destinations are often exploited; this makes it possible for its members to move from one job to another, or from one destination to another, at a low cost in financial, time and psychological terms. Thus, when farmers try to lay off some of their workers, for example during the low seasons, or if the tourist industry slumps, collective organisation on the part of migrants makes it easier to move on to a new place of work. The same applies when, due to political decisions, the government appears to be less tolerant of illegal migrants. In this case, migrants maintain their social invisibility by leaving a destination or a work niche when their presence is not wanted anymore. This suits employers who require a very flexible working population and who do not want to spark a conflict when, in the case of difficulties, they decide to reduce their manpower or to cut wages. For the migrants studied, the way to prevent a deterioration of their working conditions is to keep moving, just as they first left home when their standards of living worsened.

\subsubsection{Weak collective identification}

The trend to submit to or even to anticipate constraints of invisibility and flexibility can be connected with another aspect of migrant networks. Differently from communities who clearly identify their members through traits thought to be commonly shared, in the networks studied, a collective identity never clearly appeared. When individuals use an identifying ' $u s$ ', it is never an intrinsic definition but is used simply to differentiate themselves from other groups encountered in the area of migration (Barth I969). The fact of belonging to a 'Romanian group' or to 'a Romanian migrant group of workers' is claimed only when migrants clearly identify a population category they want to be distinguished from. For example, Romanian Roma, greatly stigmatised by the main population in Romania, represent a real threat to the other Romanian migrants' identity. This is because Western societies often think of Romanian migrations as being a Roma activity, as a result of which middle-class Romanians might then be regarded abroad as being Roma. The violent racism towards this minority in Romania is even stronger in migration situations. 
However, we observe that this xenophobia, which sprang up in Romania concerning a specific ethnic group, the Roma, has been transferred abroad as it is, and concerns new ethnic categories. Dirtiness and treachery, which in the xenophobic discourse are characteristics of Roma, have become traits distinguishing North Africans in Spain or Pakistanis and Indians in London from Romanian migrants. Surprisingly, during the surveys Romanian migrants explained that Moroccans would always remain on the margins as they had been nomadic before their arrival in Spain, like the Roma were in Romania, while this interpretation was erroneous and previously unheard of. This assertion shows how a stigma can apply to one population and then to another without being reconsidered by those using it. When Romanians live abroad, they consider themselves as middle-class Europeans and claim their proximity to the dominant national population of their destination by differentiating themselves from socially lower foreign workers, often coming from former colonies or Southern countries. The reference to the 'Romanian nation' has only one aim, to distinguish themselves from any 'racial' categories, definitely seen as socially inferior. Thus, rejecting the 'others' is the main foundation of a collective 'us' used by migrants.

Moreover, in the various studies, references to the 'community' of migrants were almost non-existent. Although migrants were bonded by links and met each other occasionally, there were no places, such as churches, or special events that would gather all Romanians present in the area. In addition, although a few people were more popular than others, there was no figure representing authority or centralising information and demands in the network. During interviews, Romanian migrants would always reject the idea of a community, each one making it clear that they did not know all their compatriots there and felt no obligation of solidarity towards them.

Nevertheless, even if no claims of belonging to a national group are made during migration abroad, when back in Romania, migrants give another, much closer and more unified, image of their group. Former migrants regularly meet in bars or discotheques and are proud to show people that they have come back from the West where they have had the privilege to work. At home, this loose organisation becomes a social group that plays an important but discreet part in the Romanian transformation process.

\subsection{Migrants in the transition process}

As said before, these movements cannot be considered simply as emigration. Most migrants divide their time between some periods abroad and some in Romania, where they maintain their social links and parti- 
cipate in economic and social life. These migrants can be seen as a bond between Eastern and Western Europe. To some extent, migrants play a special role in Romania as transnational actors. They participate in the reshaping of the economic and social post-communist environment. It seems that repeated contacts with other countries are encouraging the emergence of a new state of mind, due to the partial acculturation to a Western capitalist model that Romania intends to adopt.

\subsubsection{Upon returning, Western consumerism}

It is noticeable that when migrants return to Romania, they do not live in the same way as they did before they left: whatever individual plans may be, migration aims at improving living conditions in Romania. Exceptionally, insufficiently skilled migrants, or those who cannot rely on acquaintances to facilitate their period abroad, return home without any savings, meaning that they have failed. In order to demonstrate to everybody that this is not their case, most of the people who return from abroad show off their wealth; improved social status has to be shown. This is why, in departure zones, migration is above all a visible phenomenon, in clear contrast with the habits of the stay-at-home people (i.e. those who have never left the country). Upon return, consumption becomes ostentatious and one can notice in the streets young men dressed as Westerners (Levis, Nike trainers, etc.) or driving elegant French or German cars. Also, they do not hesitate to buy all kinds of food, even in expensive shops, and to throw it away if they do not want it any more. This behaviour of endless spending - which is not specific to the Romanian migration case (Sayad I99I), is therefore very different from the thrifty habits which have been developing for a long time in Romania in the face of a difficult economic situation.

In town, the most visible aspect of migrants spending their money is, without a doubt, their presence in the many fashionable bars and discos where people coming back from abroad meet each other. Migrants' 'headquarters' are the most westernised locations. Of course, they are not the only people patronising these establishments, but the presence of migrants is noticeable in that they are regular customers and they specifically prefer to consume expensive imported items: Belgian or French beers, American cigarettes, crisps and so on. During a party, members of the group will pay for everybody at least once or twice, without counting the cost, as if their resources were unlimited. Their earnings abroad partly explain this, but they are often much lower than migrants claim and these parties make a substantial hole in the budgets of these young people. However, they must spend lavishly in order to create a special image for the group and precisely, to mark 
the difference from the stay-at-home people who often reduce leisure expenses and concentrate on more important needs.

In this sense, migrants use consumption to win social points: a migrant does not spend in order to live comfortably; he consumes leisure in order to provide evidence of his new social status. This phenomenon is obvious in the attitude of urban migrants, who cannot easily build themselves a house and yet invest heavily in ephemera: they spend their money on leisure, clothes and food - all items that are not so precious in themselves but which give prestige to those who buy them.

In the same way, goods distribution networks also play a part in the creation of a social image. As explained above, the Romanian black market is very important and many households rely on it for everyday supplies of food and clothes (Duchêne, Albu \& Kim 2002). Even if they do not completely abandon it when they return, migrants want to show that they do not need the black market to live. For example, most of them avoid purchasing any items in the market squares because they are too 'folksy' for them. Very often, when they come back, they prefer to buy items in a 'Western way', in modern self-service stores rather than in little shops in their area. During the observations conducted in Târgoviste, the BP petrol station that had replaced the old Peco station (the former national petroleum company) had opened a mini-market, which had become an important place for migrants to shop and even to meet. Of course, the mini-market attracted many onlookers too; but no one consumed as much as migrants who, thinking they would find the Western-quality items they were accustomed to there, considered the store as their main shop. Later on, the Carrefour supermarket that opened in Bucharest also became a major point of reference in the migrant universe. To visit these places is a way of appropriating the Western consumer's way of life, and consequently, to make it visible that one belongs not only to a relatively rich social class, but to a Western culture too. It is clear that this behaviour is conscious: the point in acting in this way is not mainly to preserve habits acquired in the West, as their standard of living was by no means as high while they were abroad, but to achieve a higher social status in Romania.

Nevertheless, the introduction of a consumption pattern favouring the formal market to the detriment of the black market contributes to changing Romania into a country where consumption follows the Western pattern. While the black market has been constantly reinforced for several decades, within the middle class migrants introduce new habits of consumption that invert the trend. Undoubtedly, the fact that an important part of migration income is put back into the official economy supports the economic and official development of the country. In this sense, migration contributes to the emergence of new attitude leading 
to the development of a consumption model typical of capitalist middle classes.

Although the most visible aspect of migration in Romania is high consumption, migrants contribute to the transition in other ways as well.

\subsubsection{Migrants and delocalisation}

Experience abroad allowed migrants to be part, even if in a marginal way, of a productive model quite distant from the one developed during the decades of the so-called communist dictatorship. During those times, many factories used to run very slowly, there was a shortage of raw materials and, as unemployment was forbidden, there were too many workers in relation to the work to be done. Moreover, stealing from the factories was quite common; it was a way of compensating for low wages and the absence of items in shops. After the collapse of the communist regime, these habits remained in many places and contributed to slowing down the transition process. So, working in the Western economy required a very different attitude to work. In the diverse sectors where they found jobs in the West, Romanian workers had to be especially productive if they wanted to keep their jobs in the face of competition from other migrants. Compared with previous earnings in Romania, the high wages they could expect for their jobs encouraged migrants to accept hard working conditions, and they rapidly understood that involvement in the success of the firm they worked in was required of them. They then learned to manage relations with their employers and with their supervisors in order to conform to the image of the foreign worker as pliable and not very vindictive.

Since then, migrants' experience abroad has allowed them to contribute, in an efficient way, to the shaping of new behaviour at work. This becomes very clear in the part they play in Western firms wanting to relocate in Romania to find less expensive workers. For example, a young woman who used to work as an employee in a shoe factory in Milan was hired to manage human resources in a factory of the same firm that had opened in Timisoara. Her duty was to liaise between the Italian owners and the Romanian employees. She was there to make it clear that the payment of high wages was in return for a constructive attitude towards the company, being on time, not stealing and more generally, being 'productive' at work. Here, familiarity with another operating mode helps to transform 'communist' workers into 'capitalist' workers.

In other cases, migrants recruited by these foreign firms help them in their dealings with Romanian institutions: not only do they often 
speak foreign languages, but also the Romanian administration is still quite complicated and foreign employers require help. Thus, migrants who both understand Western employers' expectations and know how to deal with Romanian state officials can sell their services to these foreign enterprises. In a certain way, their transnational culture may allow migrants to be a link between the two worlds, and hence to transfer foreign requirements to the post-communist environment.

\subsubsection{Migrant contractors}

In Romania, another way of participating in the transition consists in developing a capitalist spirit geared towards entrepreneurship. Some migrants take advantage of their - relative - wealth and of their migration know-how in order to start small businesses in their homeland.

Often they are in the import-export trade and make direct use of migrants' travels abroad. This is the case, for example, of many secondhand clothes shops, with stock imported from Germany or from France. The migrant often has a partner - usually a family member who takes care of the store in Romania while he deals with sellers abroad. These businesses represent a second investment in migration: in most cases migrants did not go abroad with the aim of making business contacts, it is only when they return that they decide to utilise their connections. Then, a few migrants become specialised in the import business and will, in a second phase, travel especially for this purpose. The procedure is the same for small export firms: a former casual farm worker in Spanish greenhouses, for example, started making terracotta pots in Romania, which he sells to his Spanish former employer.

But migration earnings may be invested in firms that focus only on Romania. In the city of Târgoviste, the most fashionable bars belong to former migrants now settled in Romania. The Western style of their establishment attracts many migrants during their visits to Romania. Others start photocopy service shops, for example. In all of these cases, the migration experience clearly appears as a way of financing these enterprises. But one can suppose as well that the energy and resourcefulness developed during migration are also reinvested in these small firms. During their migratory experiences, migrants learn to take risks, find information about places they could go, negotiate with state authorities and use every opportunity to find a place in the West in spite of difficulties due to their status. Hence it seems that the powers of persuasion and good planning skills developed when facing economic difficulties at home may turn into a useful business skill, thanks to experience abroad. 
Moreover, the migratory experience and the fact of belonging to a migrant group in Romania help businessmen as they can rely on their fellow migrants for a partnership. As has already been pointed out, being a migrant implies participating, in Romania as well, in a network of former and future migrants. Hence, returning migrants may expect cooperation from their peers with whom they share this 'migration culture' and an amount of capital to be invested. Thus, in their social group in Romania, they may find possible partners in order to launch into business. It appears clearly here that migration provides more than economic capital: it makes social capital available for former migrants (Bourdieu I985), allowing them to participate more actively in local economic life. In a way, even if many of these small enterprises often have a short lifespan, this small-scale economy, sustained by small investors, contributes to the improvement of Romanians' standard of living.

\subsection{Conclusion}

Transnational migrants therefore take part in the creation of a new social stratum in Romania, which both materially and culturally tends to move away from the ancient 'communist' habitus (Bourdieu i980) to move closer to the Western middle-class state of mind. Having experience of different European countries gives them a special position both in the West and in their homeland. Through transnational networks, migrants simultaneously participate in two different economic processes: one in Western Europe and the other in their homeland. In the West, their role as underpaid workers contributes to organising new forms of global capitalism (Réa 2002) while, in their own country, these migrants are directly involved in the so-called transition process which aims to put Romania into the spectrum of the industrialised countries.

Therefore, networks are vital to migration. As Waldinger (I994) puts it, information concerning a particular destination circulates inside this organisation, thus favouring the repetition of a first experience. However, for the migration movements studied here, the fundamental role of the network lies in the fact that more experienced peers teach their migration 'skills' to new migrants who can thus rapidly learn migration know-how, allowing them to become self-sufficient and to participate personally in developing new occupations in the network. The main asset is the ambivalence of these abilities, improved by each individual and transferable to different migration situations. As the working opportunities that these migrants exploit in the West are very fragile, resources provided by migrant networks do not consist mainly in 
reinforcing their position in niches in which they do not have any power. What is usually passed on inside these fluctuating informal organisations is the ability to move around inside the European area and to re-orientate and adapt to a new environment. Hence, not only do these organisations favour the enlargement of a group in a specific place, but they also contribute to the improvement of the transnational circulation itself.

In such a context, close attention paid to this transnational migration reveals these networks to be 'informal organisations' which have their own ways of working. Relying on diverse interests and types of social links, they are flexible, dynamic and spread over a large area. These patterns fit very well with the requirements of the globalisation process: migrants can move from one place to another adapting to the work available at the time and, by doing so, avoid entering into conflict with their employers or local populations when their presence is not required any more.

\section{Notes}

I Following the 'Chevènement' law, from II June I998, Romanian asylum seekers obtained a response to their application within a few days, so they could not use the administrative delay as a right to remain in French territory for some months as they had formerly done.

2 The Schengen agreements, which allow the free movement of persons within its area, were signed by Germany, Belgium, the Netherlands, Luxembourg, Spain, France, Portugal, Italy, Greece, Austria, Denmark, Norway, Finland, Sweden and Iceland. Several more countries joined in December 2007.

3 In 200I, it was estimated that there were around 25,000 Moroccan workers (legally present) in the province of Almeria, while others nationalities were practically absent from official data.

4 See the article by Juan Goytisolo and Sami Naïr, 'Racisme en Espagne' in Le Monde, I5 February 2000; and 'El revelo de magrebies por europeos del Este reaviva la tension en El Ejido' in El País, Io February 2000.

5 This study was conducted by a team from the University of Bucharest, under the guidance of Professor D. Sandu.

6 For example, migrants could collectively buy a car to be used at different times during the week or they could work together on construction projects that could not be done by one individual. Migrants also assist each other by giving administrative information or translating documents.

\section{References}

Barth, F. (I969), Ethnic groups and boundaries: The social organization of culture difference. Oslo: Universitetsforlaget.

Benattig, R. \& O. Brachet (I998), Les dynamiques migratoires roumaines: Le cas des demandeurs d'asile en France. Paris: Direction Population et Migrations. 
Bourdieu, P. (1980), Le sens pratique. Paris: Les éditions de minuit.

Bourdieu, P. (1985), 'The forms of capital' in J. G. Richardson (ed.), Handbook of Theory and Research for the Sociology of Education, 24I-258. New York: Greenwood.

Diminescu, D. (ed.) (2003), Visibles mais peu nombreux: Les circulations migratoires roumaines. Paris: Maison des Sciences de l'Homme.

Duchêne, G., L. L. Albu, \& B.Y. Kim (2002), 'An attempt to estimate the size of informal economy based on household behaviour modeling'. Romanian Journal of Economic forecasting I: I7-24.

Granovetter, M. (I973), 'The strength of weak ties', American Journal of Sociology 78: 1360I380.

Lhomel, E. (200I), 'Roumanie 2000-200I : Un nouveau départ?' Le courrier des pays de l'Est IоI6: I64-I77.

Marcus, G. E. (I995) 'Ethnography in/of the world system: The emergence of multi-sited ethnography', Annual Review of Anthropology 24: 95-II7.

Michalon, B. (2005), 'Dynamiques frontalières et nouvelles migrations internationales en roumanie', Revue d'études comparatives Est-Ouest 36: 43-69.

Morokvasic, M., U. Erel, K. Shinozaki \& I. Lenz (2003), Crossing borders and shifting boundaries. Opladen: Leske + Budrich.

Okólski, M. (200I), 'The transformation of spatial mobility and new forms of international population movements: Incomplete migration in Central and Eastern Europe', in J. W. Dacyl (ed.), Challenges of cultural diversity in Europe, 57-IO9. Stockholm: CEIFO.

Portes, A. (200I), 'Introduction: The debates and significance of immigrant transnationalism', Global Networks I: I8I-I94.

Potot, S. (2003), 'Circulation et réseaux de migrants roumains: Une contribution à l'étude des nouvelles mobilités', doctoral thesis. Nice: Université de Nice Sopia Antipolis.

Potot, S. (2005), 'La place des femmes dans les réseaux migrants roumains', Revue européenne des migrations internationales 2I: 243-257.

Réa, A. (2002), 'Le travail des sans-papiers et la citoyenneté domestique' in M.Péraldi (ed.) La fin des norias? Réseaux migrants dans les économies marchandes en Méditerranée, 450-478. Paris: Maisonneuve et Larose, MMSH.

Salem, G. (I98I), 'De la brousse au Boul'Mich: Le système commercial des mourides en France', Cahiers d'Études Africaines, XXI: 267-288.

Sayad, A. (I99I), 'Elghorba. Le mécanisme de reproduction de l'émigration' in A. Sayad (ed.), L'immigration ou les paradoxes de l'altérité, 23-48. Bruxelles: De Boeck-Wesmael.

Waldinger, R. D. (I994), 'The making of an immigrant niche', International Migration Review 8: 3-30. 



\section{PART II}

EVOLUTION OF REGIONAL PATTERNS OF INTERNATIONAL MIGRATION IN EUROPE 



\title{
6 Evolution of regional patterns of international migration in Europe
}

\author{
Corrado Bonifazi
}

\subsection{Introduction}

International migration trends are the result of many elements. Demographic contexts, economic and social conditions, political choices, international links, historical ties, and cultural factors play, at different levels, an important role in determining the size and directions of migration flows. Globalisation processes and the end of the Iron Curtain have been powerful factors in promoting human mobility and in accelerating the evolution of migration. The result is the increasingly complex and changeable picture that has characterised world migration in the last twenty years. During this period, some countries and regions have suddenly changed their role in migration systems. New destinations have unexpectedly emerged, whilst unforeseen connections have appeared.

The recent evolution of European international migration has been marked by the general and gradual enlargement of the migration system centred on the EU countries. This process was clearly encouraged, if not largely determined, by the enlargement of the EU. Six members originally signed the Treaty of Rome in I957 but between 1973 and I995 another nine countries joined so that almost all of Western Europe was covered. With the ten new members of May 2004 and the further two in January 2007, we now have an area of free circulation that covers a large part of the continent, thus enlarging further the size of a supranational entity that increasingly assigns an important role to migration policies.

There have also been important changes in the migration scenario in these years, for example, the former emigration countries of Southern Europe have increasingly become targets for immigration flows, radically changing their position in migration dynamics. Another development has been the way in which some of the new members of the EU are already becoming destination countries. Notwithstanding these processes, differences persist and contribute to the heterogeneity of trends, patterns and prospects within Europe. 
This chapter analyses the evolution of the regional patterns that have characterised European international migrations since World War II. This is a way of interpreting migration trends that can be very useful, above all given the fact that the different steps in the evolution of international migration experienced by a region or a country are a useful point of reference from which to analyse the trends and patterns of another area and to infer possible future scenarios (Salt 1989). Especially in periods like the current one, marked by important changes, knowledge of past patterns can be extremely helpful in understanding the present and trying to predict the future.

This kind of analysis is made more difficult by the well-known lack of reliable international migration statistics, making it very difficult to compare trends across time and space. Notwithstanding some important recent improvements and the remarkable efforts of international organisations (Poulain, Perrin \& Singleton 2006), the comparability of migration statistics is still a goal far from being satisfactorily reached (Bonifazi \& Strozza 2006). Even trying to assess migration size at the European level is difficult and questionable. Sometimes, it is even problematic to establish if net migration is positive or negative in a country, with diverging results if different measurement methods are employed or different data sets are considered. Although the measurement of European migration trends is still to be considered as work in progress, much research has described the main patterns and characteristics of international migration in our continent (Salt \& Clout I976; King I993a,b; Münz I995; Bonifazi \& Strozza 2002; Garson \& Loizillon 2003).

We have taken our starting point from these studies and available statistics to examine the migration patterns that have characterised the European scene since 1945. For reasons of clarity, we first outline the overall framework of the situation, mainly using the few comparable data sets available. The period under examination is then divided into four main stages that partially overlap but are nevertheless clearly differentiated considering the main flows and political context. This analysis allows us to identify some interesting aspects of the evolution of regional migration trends across the continent, which could also characterise future developments. Finally, the usefulness of the concept of migration systems has been considered as a way of analysing regional patterns within a consistent explanatory framework. 


\subsection{Migration patterns in Europe}

\subsubsection{Long-period trends over the last 60 years}

Until World War II, 'the predominant movement was out of rather than into Europe as millions crossed the ocean to settle in the New World: an estimated 55 to 60 million during I820-I940, of whom 38 million went to the United States' (King I993a: 209). Despite the fact that during this long period emigration out of the continent prevailed, intraEuropean flows were also important. Polish and Ukrainian workers went to the mines and steelworks of France and Germany, while Italians left in search of work in France or Switzerland and Irish emigrants moved to British industrial cities (King I993a). By way of example, in France foreigners already numbered more than a million in I886 and 2.7 million by I93I, equal to 7 per cent of the total population. In Switzerland the stock of foreign population had already exceeded the level of I5 per cent of the total population before World War I.

This situation of migration losses in relation to the rest of the world and strong movements within the continent from economically depressed regions to more developed ones characterised, as is explained below, the European scenario until the end of the ig6os. One way to evaluate the long-period trends is to look at net migration, calculated as a residual from United Nations population estimates ${ }^{1}$ (2005). Although net migration remains only a very rough indicator of international migration trends, it is one of the few ways available to compare the development of the phenomenon in all the countries of the continent for all the decades of the second half of the last century.

Until the end of the I96os, Europe continued to be an emigration area with a negative migration balance (table 6.I). According to these data, prior to the I970s only Western Europe had positive net migration, but this was insufficient to compensate the migration losses of the other macro-regions. In the I950s, total losses for the continent were 4.8 million people: the result of 2.I million more in Western Europe, one million less in Northern Europe, 2.7 million less in Southern Europe and 3.I million less in Central and Eastern Europe (CEE). In the I960s, the negative migration balance of the continent $(-644,000)$ as a whole largely decreased because of the doubling of the positive value for Western Europe. In the same period the other three regions still recorded negative net migration. Values in relation to the preceding decade declined in Northern Europe (only -II9,000 people over the decade) and CEE (-I.7 million), but increased in Southern Europe (-3.I million).

Since the I970s, all the regions of the continent have experienced positive net migration. For the continent as a whole, the migration gain has increased from the three million people of the I970s to 4.8 million 
Table 6.1 Net migration in European geographical areas, 1950-2000 (absolute values in thousands and annual average rates per thousand)

\begin{tabular}{|c|c|c|c|c|c|}
\hline \multirow[b]{2}{*}{ Geographical areas } & \multicolumn{5}{|l|}{ Years } \\
\hline & $1950-1960$ & $1960-1970$ & $1970-1980$ & $1980-1990$ & $1990-2000$ \\
\hline & \multicolumn{5}{|c|}{ Absolute values in thousands } \\
\hline Central Eastern Europe ${ }^{a}$ & $-3,145$ & $-1,702$ & 21 & 1,340 & 993 \\
\hline of which: Poland & -306 & -214 & -425 & -313 & -147 \\
\hline Russian Federation & -1331 & $-1,339$ & 318 & 2,080 & 4,160 \\
\hline Ukraine & -355 & 594 & 252 & 222 & -105 \\
\hline Northern Europe ${ }^{b}$ & $-1,033$ & -119 & 63 & 189 & 1,571 \\
\hline of which: UK & -544 & -15 & -182 & 96 & 959 \\
\hline Southern Europe ${ }^{d}$ & $-2,677$ & $-3,147$ & 627 & 96 & 3,304 \\
\hline of which: Italy & $-1,009$ & -828 & -33 & -135 & 1,176 \\
\hline Spain & -779 & -601 & 153 & 186 & 1,179 \\
\hline Western Europe ${ }^{c}$ & 2,065 & 4,296 & 2,296 & 3,123 & 5,504 \\
\hline of which: France & 960 & 1,983 & 663 & 530 & 643 \\
\hline Germany & 994 & 1,699 & 1,220 & 1,844 & 3,826 \\
\hline Europe $^{e}$ & $-4,804$ & -644 & 3,043 & 4,790 & 11,393 \\
\hline
\end{tabular}

\begin{tabular}{|c|c|c|c|c|c|}
\hline \multirow[b]{2}{*}{ Central Eastern Europe ${ }^{a}$} & & & & & \\
\hline & -1.2 & -0.6 & 0.0 & 0.4 & 0.3 \\
\hline of which: Poland & -1.1 & -0.7 & -1.2 & -0.8 & -0.4 \\
\hline Russian Federation & -1.2 & -1.1 & 0.2 & 1.5 & 2.8 \\
\hline Ukraine & -0.9 & 1.3 & 0.5 & 0.4 & -0.2 \\
\hline Northern Europe ${ }^{b}$ & -1.4 & -0.2 & 0.1 & 0.2 & 1.8 \\
\hline of which: $\quad$ UK & -1.1 & 0.0 & -0.3 & 0.2 & 1.7 \\
\hline Southern Europe ${ }^{d}$ & -2.8 & -3.1 & 0.6 & 0.1 & 2.8 \\
\hline of which: Italy & -2.1 & -1.6 & -0.1 & -0.2 & 2.1 \\
\hline Spain & -2.7 & -1.9 & 0.4 & 0.5 & 3.0 \\
\hline Western Europe ${ }^{c}$ & 1.4 & 2.7 & 1.4 & 1.8 & 3.0 \\
\hline of which: France & 2.2 & 4.1 & 1.3 & 1.0 & 1.1 \\
\hline Germany & 1.4 & 2.2 & 1.6 & 2.4 & 4.7 \\
\hline Europe $^{e}$ & -0.8 & -0.1 & 0.5 & 0.7 & 1.6 \\
\hline
\end{tabular}

Notes: (a) Albania, Bulgaria, Czech Republic, Slovakia, Hungary, Poland, Romania, former Yugoslavia countries (Bosnia-Herzegovina, Croatia, Republic of Macedonia, Slovenia and Yugoslavian Federation) and European countries of former Soviet Union (Belarus, Estonia, Latvia, Lithuania, Republic of Moldova, Russian Federation and Ukraine); (b) Denmark, Finland, Iceland, Ireland, Norway, Sweden and the UK; (c) Austria, Belgium, France, Germany (Federal Republic and Democratic Republic), Luxembourg, the Netherlands and Switzerland; (d) Greece, Italy, Malta, Portugal and Spain; (e) includes countries with a population of less than 100,000 in 2005

Source: elaboration of United Nations data (2005)

in the I980s and II.4 million in the I990s. Over those three decades, Western Europe has gained the most. Apart from the dip in the I970s, its net migration balance has been 5.5 million over the last decade. In that period, there were also very high migration gains in the other re- 
gions: I.6 million in Northern Europe, one million in CEE and 3.3 million in Southern Europe. In relative terms, Southern Europe has registered a net migration rate very close to that of Western Europe.

The figures for these large regional areas may reflect very different national situations, as was the case, for example, in CEE where the particularly high migration gains registered in the I980s (I.3 million) and I990 (one million) were the result of the positive balances estimated for the Russian Federation (2.I in the first decade and 4.2 million in the second one), that more than compensated for the losses registered in most of the countries of the area. The ethnic migrations from the other new states of the former Soviet Union greatly contributed to these results, but estimating methods could also have affected the data.

The limitations of this method of calculation have surely contributed to making the decline in the positive net migration balance seen in Southern Europe in the I980s much more evident. This decline was obviously the result of a greater intensity of nationals returning from emigrating abroad in the I970s in relation to foreign arrivals in the I980s. Nevertheless, at least in part, the decline was also the result of Italy's negative net migration, and attributed more to problems of 'miscounting' in the I99I census than to the actual migration patterns of the period.

A second means of evaluating long period trends uses another UN source. In fact, the UN has recently estimated the number of international migrants for all the countries of the world (United Nations 2006), generally referring to data on country of birth. According to these estimates (table 6.2), international migrants in Europe numbered I7.2 million in I960 increasing to 64 million in 2005, going from 4.7 per cent of the total population to 8.8 per cent. The most dramatic increase was recorded between 1975 and 1990 in CEE, when the stock of immigration rose from six to 25 million. As a matter of fact, this huge increase 'stems from the reclassification of persons who had moved inside the USSR [Soviet Union] before 1990 as internal migrants and who became international migrants at the time of disintegration' (United Nations 2006: I).

Although the strong growth in the numbers of international migrants in CEE is mostly the result of the reclassification of migrants after the birth of new countries following the disintegration of the USSR, growth in other geographical areas clearly shows that in recent decades Europe has become an area of immigration. Between ig60 and 2005, the number of international migrants grew 3.2 times in Western Europe, exceeding 22 million migrants in 2005 , and 3.6 times in Northern Europe, rising from 2.3 to 8.I million. But the most extraordinary growth was clearly to be found in Southern Europe. In the new countries of immigration, the number of migrants increased 8.3 
Table 6.2 International migrants in European geographical areas, 1960-2005

\begin{tabular}{|c|c|c|c|c|c|}
\hline \multirow[b]{2}{*}{ Geographical areas ${ }^{\mathrm{a}}$} & \multicolumn{5}{|l|}{ Years } \\
\hline & 1960 & 1975 & 1990 & 2000 & 2005 \\
\hline & \multicolumn{5}{|c|}{ Absolute values in thousands } \\
\hline Central Eastern Europe ${ }^{b}$ & $6,824.1$ & $6,087.5$ & $25,113.4$ & $25,304.3$ & $24,780.2$ \\
\hline Northern Europe & $2,267.6$ & $4,305.9$ & $5,317.4$ & $6,998.5$ & $8,133.4$ \\
\hline Southern Europe & $1,099.7$ & $1,638.3$ & $3,021.8$ & $4,706.3$ & $9,127.0$ \\
\hline Western Europe & $6,995.1$ & $11,309.5$ & $15,928.5$ & $21,207.6$ & $22,075.3$ \\
\hline \multirow[t]{2}{*}{ Europe $^{c}$} & $17,186.5$ & $23,341.2$ & $49,381.1$ & $58,216.7$ & $64,115.8$ \\
\hline & \multicolumn{5}{|c|}{ Percentages of total population } \\
\hline Central Eastern Europe ${ }^{b}$ & 2.2 & 1.7 & $7.3^{\circ}$ & 7.5 & 7.5 \\
\hline Northern Europe & 3.0 & 5.3 & 6.4 & 8.1 & 9.2 \\
\hline Southern Europe & 1.1 & 1.5 & 2.6 & 3.9 & 7.4 \\
\hline Western Europe & 4.6 & 6.7 & 9.0 & 11.6 & 11.9 \\
\hline Europe $^{c}$ & 2.7 & 3.2 & 6.8 & 8.0 & 8.8 \\
\hline
\end{tabular}

Notes: (a) for composition of geographical areas, see notes to table 6.1; (b) in 1960 and 1975 includes GDR and all former USSR; (c) in 1960 and 1975 includes all former USSR Source: United Nations (2006)

times in 45 years: rising from I.I million in 1960 to 4.7 million in 2000 and to 9.I million in 2005. Despite, this impressive growth in immigration in Southern Europe, which almost doubled in size from 2000 to 2005 , the highest numbers of migrants as a percentage of total population continue to be in Western Europe (II.9 per cent in 2005).

The two UN estimates, despite their limitations, provide some pointers for identifying the main stages of migration movements. In the first place, the data clearly show a period of strong migration to Western Europe and migration losses in the rest of the continent, which came to an end during the I970s. There followed a period when migration to Western Europe slowed down, while the rest of the continent improved its migration balance. With the fall of the Berlin Wall, a new stage began that was characterised by a steady and fast reintegration of the central-eastern region into the continental migration pattern and by a strong growth in migration to Southern Europe. We will now look in greater detail at what happened in the four periods of our analysis.

\subsubsection{The forced migration at the end of World War II}

The first period we considered is only partly covered by the UN data analysed above, in that it began just after World War II and ended in the early I950s. The main European flow of the period was forced mi- 
gration as a result of the direct and indirect effects of the peace treaties. The most dramatic ethnic cleansing in recent European history was probably recorded in this period. Whole populations were obliged to leave their homes; ethnic minorities were forced to move to ensure homogeneity within the new boundaries. This flow was concentrated in time, but it remains one of the most important after World War II. It is estimated that between I945 and I950, I5.4 million people moved from East to West; 4.7 million moved in the opposite direction and if we also consider the flows within countries, we would probably reach an overall figure of 30 million people (Fassmann \& Münz I995). From a geographical point of view, the origins of the flows were mainly in CEE and generally moved from East to West, with the predominance of Germany and the German-speaking population (King r993a). Among these flows, the most important were those from Poland to East and West Germany (7 million) and from the former Czechoslovakia to the two Germanys and Austria (3.2 million), while an estimated I.5 million people travelled from the former Soviet Union to the two Germanys and from the Soviet Union to Poland (Fassmann \& Münz I995).

\subsubsection{The golden period of European labour migration}

The second period was characterised by labour migration and recruitment of foreign workers. It began with the first bilateral agreements in the late I940s between Italy and Belgium and France and ended with the stop policies of the early i970s. The reconstruction period and the long phase of generalised and intense economic growth that, with only a few limited interruptions, lasted right through until the end of the I96os created the conditions necessary for a growing number of foreign workers to join the labour force in Western Europe. Some countries recruited from their former colonies, others first from Southern Europe, initially Italy and then Spain, Portugal, Greece and Yugoslavia. Later, this circle was extended to include the entire Mediterranean basin, when Turkey and North African countries entered the mechanism by which the labour force moved from the outer boundaries to the centre of the European migration system.

It is possible to obtain a general picture of these processes considering the data on foreign citizens resident in Western European countries (table 6.3). On the one hand, these data underestimate the overall intensity of the migrations because they do not count those who have returned home or died in the meantime, or the movements of nationals. On the other hand, however, the data overestimate the intensity of the migration flows because they include all the children born to im- 
Table 6.3 Foreign population in some European countries around some dates, 1950-2004 (absolute values in thousands; percentages of total population)

\begin{tabular}{|c|c|c|c|c|c|c|c|c|c|c|}
\hline \multirow[b]{3}{*}{ Countries } & \multicolumn{10}{|l|}{ Years } \\
\hline & \multicolumn{2}{|l|}{1950} & \multicolumn{2}{|l|}{1975} & \multicolumn{2}{|l|}{1990} & \multicolumn{2}{|l|}{2000} & \multicolumn{2}{|l|}{2004} \\
\hline & a. v. & $\%$ & a. v. & $\%$ & a. v. & $\%$ & a. v. & $\%$ & a. v. & $\%$ \\
\hline Germany $^{a}$ & 532 & 1.1 & 4,090 & 6.6 & 5,242 & 8.2 & 7,297 & 8.9 & 6,717 & 8.1 \\
\hline France & 1,737 & 4.2 & 3,442 & 6.5 & 3,608 & 6.3 & 3,263 & 5.6 & - & - \\
\hline UK & 392 & 0.8 & 1,436 & 2.6 & 1,875 & 3.2 & 2,301 & 3.9 & 2,857 & 4.7 \\
\hline Spain & 93 & 0.3 & 165 & 0.5 & 408 & 1.0 & 896 & 2.2 & 2,772 & 6.5 \\
\hline Italy & 47 & 0.1 & 186 & 0.3 & 781 & 1.4 & 1,380 & 2.4 & 2,320 & 4.0 \\
\hline Switzerland ${ }^{\mathrm{b}}$ & 285 & 6.1 & 1,039 & 16.4 & 1,100 & 16.3 & 1,384 & 19.3 & 1,495 & 20.7 \\
\hline Greece & 31 & 0.4 & - & - & 229 & 2.3 & 797 & 7.3 & $950^{c}$ & 8.5 \\
\hline Belgium & 368 & 4.3 & 835 & 8.5 & 905 & 9.1 & 862 & 8.4 & 850 & 8.2 \\
\hline Austria & 323 & 4.7 & 271 & 3.6 & 456 & 5.9 & 699 & 8.7 & 776 & 9.4 \\
\hline The Netherlands & 104 & 1.0 & 350 & 2.6 & 692 & 4.6 & 668 & 4.2 & 699 & 4.3 \\
\hline Sweden & 124 & 1.8 & 411 & 5.0 & 484 & 5.6 & 477 & 5.4 & 481 & 5.3 \\
\hline Denmark & - & - & 91 & 1.8 & 161 & 3.1 & 259 & 4.9 & 268 & 5.0 \\
\hline Ireland & - & - & 69 & 2.2 & 81 & 2.3 & 127 & 3.3 & 259 & 6.4 \\
\hline Portugal & 21 & 0.2 & - & - & 108 & 1.1 & 208 & 2.0 & 251 & 2.4 \\
\hline Norway & 16 & 0.5 & 71 & 1.8 & 143 & 3.4 & 184 & 4.1 & 213 & 4.5 \\
\hline Luxembourg & 29 & 9.8 & 86 & 23.9 & 110 & 28.6 & 159 & 36.8 & 174 & 38.6 \\
\hline Finland & 11 & 0.3 & 13 & 0.3 & 26 & 0.5 & 91 & 1.8 & 108 & 2.0 \\
\hline Total $^{c}$ & 4,113 & 1.5 & 12,555 & 3.9 & 16,409 & 4.6 & 21,052 & 5.4 & 24,453 & 6.2 \\
\hline
\end{tabular}

- not available

Notes: (a) Until 1990, only West Germany; the decrease in 2004 is the result of cross-checking the population registers and the alien registers; (b) seasonal and frontier workers excluded; (c) estimate; (d) in 2004 includes the value of France in 2000

Sources: 1950 and 1975, different national and international sources from Bonifazi and Strozza (2002); 1990-2004, Salt (2001, 2006), except Italy (national sources) and Greece 2004 (National Migration Observatory 2004)

migrants in the receiving country but who have not obtained citizenship.

Therefore, while the data reflect the different national laws on naturalisation, they do allow us to follow the evolution of migration processes. In I950 the resident foreign population in the countries under consideration numbered 4.I million, whereas 25 years later, at the end of the phase of active recruitment of immigrant workers, this number had risen to I2.6 million, equal to 3.9 per cent of the total population in these countries. Germany, France, the United Kingdom and Switzerland accounted together for 80 per cent of total foreign stock in I975. In relative terms, the foreign population at the end of the recruitment period was equal to 25 per cent of the total population in the small 
country of Luxembourg, greater than I6 per cent in Switzerland, 8 per cent in Belgium and 6 per cent in France and Germany.

The geographical divides were very clear, even if areas of arrival and departure expanded during the period along with the extraordinary growth of the economies of the European receiving countries. A dividing line was drawn along the Iron Curtain, completely separating East and West. In fact, among the socialist countries, only Yugoslavia participated in the mechanisms of labour movement from relatively underdeveloped areas of the continent to the wealthiest ones. The only other exchanges of population between the two blocs, in the period under consideration, were caused by the invasions of Hungary in 1956 and Czechoslovakia in I968. Within the Western bloc, countries of emigration included Southern European countries, Ireland and Finland, while the immigration area incorporated the remaining countries of Northern and Western Europe.

In this period, regional patterns could easily be singled out. Migration flows mainly worked on a European scale, and countries had a clear role in the migration system. The strict ties between some origins and destinations helped define some specific subsystems, like those linking the UK and Ireland, or Sweden and Finland (King I993a). The area of attraction enlarged to include Turkey and North Africa, but it essentially remained Mediterranean, the main exception being the flows coming from the colonies.

Decolonialisation led to the return of a large proportion of the European settlers to their countries of origin. The most numerous of these flows, numbering more than a million people, was probably from Algeria back to France; but equally important, even if on a smaller scale numerically, were flows back to France (from other former colonies), the UK, the Netherlands, Belgium, Portugal and Italy, as the various colonial possessions achieved independence. Colonial links then became the basis for flows from the 'native' populations of these countries to the European mother countries and, in particular, to the UK, France and the Netherlands. At least initially, these were movements that encountered a tolerant regulatory framework, partly due to the fact that the colonial powers that did not want to lose their links with their former colonies. This colonial heritage enriched European migration connections with important implications for the following decades (Münz I995). It was also the first arrival on a large scale of immigrants coming from non-European and non-Mediterranean countries, definitively showing the transformation of Europe into a continent of arrival.

The golden period of European labour migration was characterised by a favourable political climate towards international migration. Governments of receiving and sending countries usually had an active role in promoting the flows. They signed bilateral agreements for the re- 
cruitment of workers through official channels and well defined procedures. Besides, immigration countries were, on the whole, ready to regularise ex-post the position of foreign workers who had used unofficial channels of entry (Barbagli, Colombo \& Sciortino 2004). In I957 the Treaty of Rome introduced the principle of the free circulation of workers within the European Economic Community (EEC). In this regard, it is interesting to note that the position of the Italian government in favour of free circulation received the strong support of the German government during the preparatory discussions for the Treaty. This harmony of intentions made it possible to surmount the opposition of France and Belgium, worried about losing control over the domestic labour market. From a political point of view, the introduction of the principle of free circulation demonstrated the interest of receiving countries in promoting immigration in order to respond to the growing demand for labour on the part of their economies.

\subsubsection{The stop policies and the end of recruitment of foreign labour}

This favourable situation for migration flows was completely reversed with the two oil shocks of the I970s and the beginning of the third phase. The stop policies during I973-1974 signalled the end of the stage of expanding immigration and the passage to the stage of stabilisation: the immigrant communities, by means of family reunions, gradually normalised their demographic structure, while the tightening of regulations and the economic crisis led many immigrant workers to opt for permanent settlement rather than temporary migration or circular migration with periodic returns. Receiving countries stopped active recruitment and tried to encourage return migration. In this way, they wanted to export unemployment back to the sending countries and to address the problems of a migration that had clearly changed its nature from temporary to permanent. It was the beginning of increasingly strict control by states over entries, and of the growing importance of migration issues in national political debates. At the same time, economic pull factors rapidly moved from the core industrial sectors to services. In this period, the segmentation of labour markets and the restructuring of Western economies heavily affected international migration trends and characteristics.

The growth of the immigrant population in this period took place in a radically changed context, where the prevalence of push factors and economic globalisation led to an enlargement of the area of attraction and the types of flows. As a result, labour migration in this stage was often masked by other forms of immigration or happened outside regular channels or, at best, took place in particular sectors of the labour market. 
Despite strong control over the flows, the foreign population stock continued to grow, reaching I6.4 million in I990, equal to 4.6 per cent of the population (table 6.3). The increase is more marked in the countries where naturalisation procedures are more difficult and is the result, in many cases, of family reunions and the stabilisation of immigrant communities. In fact, a third of the total growth was recorded in Germany, where family reunion and the strict rules on naturalisation led to the foreign population increasing by I.I million. There was also significant growth in Italy, the UK, the Netherlands, Spain and Austria.

To a large extent Central and Eastern Europe continued to remain isolated behind the Iron Curtain, even if there was a resurgence of ethnic flows promoted by the political openings in the rg8os. The most important change in European regional patterns of international migration was recorded at the end of the I970s with the beginning of immigration flows towards the traditional emigration countries of Southern and Northern Europe. These flows reflected the more general changes in the economic and social contexts and the new characteristics of international migration (Salt i989). Irregular migration became more important than it had been in the previous decades and more immigrants entered the 'informal' or 'black' employment sectors. These changes have promoted a large debate on the existence and the characteristics of the Mediterranean model of immigration since the start of flows towards the southern shores of the EU (King \& Rybaczuk I993; Pugliese I993; King 2000; Boffo 2002; Arango 2003).

It was in this period that the enlargement and homogenisation of the European migration system began, reaching full maturity in the next period. It was in this third stage that the EU began its process of enlargement with the entry of Denmark, Ireland and the UK in I973, and Greece, Portugal and Spain in the I980s. At the beginning of the I970s, the differentiating factors were still widely prevalent within the countries of the Western bloc as well. The European migration scenario was definitely more fragmented and divided than it appears today. In the first place, at the start of this period, there was still a clear division between receiving and sending countries. Italy, Spain, Greece, Portugal, Finland and Ireland were, in fact, the main sources of supply to the labour markets of North-Central Europe. In the second place, there was still a sharp differentiation between the immigration policies of countries wanting to strengthen the temporary character of the flows, more or less openly discouraging the stabilisation of immigrants and the arrival of their families, and other countries more willing to utilise these immigrants for work purposes in order to encourage demographic rebalancing. In the third place, the areas of origin were closely linked to the particular experiences of each destination, with colonial 
links and geographical proximity being the decisive factors for the start-up and maintenance of flows.

All three elements changed profoundly in the following decades. The countries of emigration of Southern and Northern Europe became receiving countries to all effects and, in some cases and at some moments, they experienced foreign population growth rates similar to and sometimes greater than those of the traditional host countries. Migration policies became more standardised, as a result of the efforts to achieve effective integration at the Community level. Together with these processes, the area of attraction extended considerably, so that the composition by country of origin of new immigration was increasingly less dependent on the country of arrival and not always linked to geographical proximity and past colonial ties.

\subsubsection{The fall of the Berlin Wall and the enlargement of the European migration system}

In the last twenty years, the whole migration scenario at the global level has been characterised by deep changes, in parallel with the transformations of an increasingly globalised world that, with the fall of the Berlin Wall, witnessed the end of a polarised East and West, sanctioned by the Yalta conference and replaced by a not completely explained and defined 'new world order' (Gould \& Findlay i994). According to Castles and Miller (2003), the basic trends in this period can be found: in the changes in investment strategies, with more exporting of capital from the developed countries and the creation of manufacturing industry in previously underdeveloped areas; in the microelectronics revolution that reduced the need for manual labour in industry; in the expansion of the service sector, with demand concentrated on jobs requiring high and low qualifications; in the growth of the informal sectors of developed economies; in the growth of labour flexibility, with an increase in part-time work and employment instability; and in the growing differentiation of the labour force along lines of gender, age and ethnicity.

This set of factors has meant an overall redrawing of the map of international migrations and profound changes in the push and pull factors within the framework of the growing globalisation of the economy, leading in effect to a reduction in the distances and an increase of the ties between different territorial areas. The economic, political and demographic crisis that has hit a large part of the developing world has had the effect of increasing the supply of emigrants, as has the fall of socialism in Eastern Europe. At the same time, the function of the immigrant labour force in the receiving countries changed so that it no longer played the role of 'quantitative' rebalancing in the labour market, supporting the growth of labour supply; rather it took on a 'qualita- 
tive' role, filling the gaps that can occur in specific employment sectors, even in situations far from full employment.

The fourth stage began with the fall of the Berlin Wall in I989. With the end of the Cold War, political barriers to emigration were removed and CEE countries once again had the opportunity to participate in migration movements. It was a radical change for the geography of continental flows, even if Western countries rapidly established strict controls on immigration, not least to counteract the effects of the forced migrations caused by the ethnic conflicts in the former Yugoslavia and Soviet Union. This was a significant change of attitude compared with the more sympathetic response to the crises in Hungary in 1956 , Czechoslovakia in I968 and Poland in the I980s. Flows of refugees, asylum seekers and internally displaced persons from war zones played an important part in the migration movements of this period.

The most surprising example of the new CEE involvement in migration flows is probably Albania, a country that was completely isolated for more than 40 years and has become one of the most important emigration countries in Europe in an extraordinarily short period of time. During the I990s, on the basis of the UN data used in table I the total migratory loss in CEE countries was estimated at 687,000 people from Albania, surpassed only by Romania $(880,000)$ and followed by Bosnia $(651,000)$, Bulgaria $(361,000)$, Latvia $(225,000)$ and Lithuania $(208,000)$.

In this period, the role of the EU in the field of migration became increasingly active. This was a decisive factor in the development of a cohesive EU migration system, clearly demonstrated by the importance placed on the various aspects of migration management in the negotiations for the entry of new member countries. It should also be borne in mind that at this time there was a sharp acceleration in the process of building a united Europe, not only from the economic but also from the political point of view. In 1995, Austria, Finland and Sweden joined the EU. The single currency began to circulate in 2002 and ten new members joined in 2004, eight of which had previously been part of the Eastern bloc. Finally, Romania and Bulgaria became members at the start of 2007.

The period was also characterised by the strong growth in labour migration towards Southern European countries. The lack of adequate official recruitment channels meant that these flows were basically spontaneous and irregular and repeated regularisations were necessary, from a legal point of view, to resolve the position of immigrants who were already working. In effect, the most striking feature of this period was precisely the increase of foreign immigration into Southern Europe, by then one of the most important areas of attraction in the continent. 
Furthermore, this growth (only partly described by the data in table 6.3, given that for Italy and Spain the figures have risen further since 2004) has brought the foreign population close to the three million mark in the case of Italy and in excess of 3.5 million in that of Spain. However, in 2004, the total number of foreign residents in the countries under consideration was 24.5 million, equal to 6.2 per cent of the population, and only Germany, France and UK had a foreign population larger than Spain and Italy. In the first half of the current decade, the weight of foreigners in the total population was higher in Spain (6.5 per cent) and Ireland (6.4 per cent) than in the UK (4.7 per cent) and France (5.6 per cent); it was higher in Greece (8.5 per cent) than in Germany (8.I per cent); while in Italy (4 per cent) it was approaching UK levels (4.7 per cent).

During the I990s, political considerations became more important in EU countries along with the fear of an invasion of migrants from the former socialist countries. Notwithstanding these fears, the size of the actual flows from East to West has largely been below the levels feared. The same evolution of migration trends in CEE countries has indicated the beginnings of immigration flows and the achievement of positive net migration in more than one case (Okólski I998; Bonifazi 2003; Salt 2006). New forms of mobility have developed, even for noneconomic reasons, helping to make European migration much more diverse (King 2002).

From the point of view of the regional patterns, it is clearly significant that in the I990s, for the first time since the end of the conflict, net migration in all the countries of Northern, Western and Southern Europe was positive, showing how this part of the continent had become a well-defined area of immigration. The situation was different in CEE, where some countries such as Russia made quite large migration gains, while others recorded losses that were greater comparatively speaking. ${ }^{2}$ On the other hand, CEE countries, especially the ones that are now EU members, are undergoing very rapid migration changes, as shown by the positive net migration balances recorded in the last decade in Hungary, the Czech Republic, Slovakia and Slovenia. The most recent enlargements have brought into the EU some countries such as Poland, Romania and Bulgaria with a history of strong emigration, thus recreating a situation absent in the EU since the end of the 1970s. There is no doubt that this will tend to encourage emigration from these countries, as is happening today and, indeed, as was already happening in the years preceding their entry into the EU.

A new phase probably began to emerge at the turn of the new century (Garson \& Loizillon 2003). In fact, some EU countries started paying much greater attention to the promotion of skilled migrations, and employment-related migration is generally increasing. Moreover, the fi- 
nal document from the Tampere Conference of I999 contained the basis for a new approach to migration issues at a European level. In this framework, more attention is being devoted to the general contexts of international migration and to considering the positive effects of the flows on the economic development of the sending countries and on the economies and demography of the countries of arrival (European Commission 2005). The 'zero option', introduced in migration policies in the I970s, is perhaps coming to an end, even if strong resistance is emerging at the political level in both national and international contexts.

\subsection{Main aspects of regional trends in Europe}

Recent analyses of European migration trends have confirmed the difficulties in finding general and common patterns. As Salt (2003: 20) notes:

There are marked differences in the migration fields of individual countries, reflecting a range of historical (such as post-colonial links) and geographical (especially proximity) processes. Finally, the patterns depicted reinforce the diversity of migration experience across Europe.

Notwithstanding this diversity, some important aspects of regional patterns at the European level can be highlighted.

Emigration countries of Southern and Northern Europe during the I950s and I960s have now completed their transformation into immigration countries. From this point of view, the European panorama is now certainly more homogenous than it was 30 or 40 years ago. Old members of the EU (plus Switzerland and Norway) are currently sharing interests and fears; they substantially stay on the same side in the migration arena. To a large extent the heritage of past history continues to determine national policies, attitudes and trends but the general context has now become an important structural element of homogenisation. These changes in the scenario have definitely had an important function in making the role of the EU more powerful in the field of migration. Attempts to achieve a common policy, beyond the results already obtained, have become a strong factor in reinforcing a distinct migration system centred on the EU. The migration issue has played an important role in negotiations with the new member states, during which the EU has acted as a single interlocutor.

Political contexts and interests have always been a crucial factor in designing migration patterns. The clearest example is the division of 
Europe into two separate migration areas during the Cold War, with the strong limitation of flows between East and West. Migration policies have also reflected the more specific economic and social interests of the receiving countries. Support for immigration until the beginning of the I970s fostered the enlargement of the sending area and the establishment of migration relations with former colonies. In some respects, the stop policies paradoxically reinforced the role of pre-existing migration connections and networks. In fact, preventing the circulation of workers promoted the stabilisation of immigration, encouraging family reunions and the growth of already-settled foreign communities. The acquisition of important rights (long-term or permanent residence, family reunion and naturalisation) gave these networks a more favourable position than new potential immigration flows. In the traditional destination countries, this situation probably delayed or limited the development of flows coming from other sending areas.

The CEE countries have acquired an important role in migration trends since the fall of the Berlin Wall. Current trends in the area have developed along totally new and unexpected lines, such as transit migration, incomplete migration and flows within the region. Some countries in the region have also experienced immigration flows from their neighbours, Western countries and developing countries. These changes could herald, at least in some cases, an evolution similar to that characterising the countries of Southern Europe, especially if the improvement of the economic and social conditions were to lead to the stabilisation and growth of the pull factors.

At the beginning of the I980s, foreigners of European origin were the large majority in almost all the most important receiving countries, with the important exceptions of France and the UK. In I98I immigrants of European origin constituted 47.6 per cent of the total in France and 38.3 per cent in the UK, while in the same year they accounted for 86.6 per cent in Germany and reached 94 per cent in Switzerland (Wanner 2002; Golini, Strozza \& Gallo 200I). The importance of intra-European migration decreased in the following decades along with the growth of flows originating in other continents. The area of attraction has expanded. This has been particularly evident in Italy, Spain and Portugal, countries that have received significant flows from Latin America, the Far East and sub-Saharan Africa. In the case of Italy, this has occurred in the absence of any significant past colonial links. In the last few years flows from some Eastern European countries (Romania, Ukraine and Moldova) have gained importance, especially in Southern Europe, and have contributed to the reduction in the weight of non-European immigration.

These developments have been favoured by the EU's enlargement process and by a general softening of visa policies towards CEE coun- 
tries. This is an important change of direction, highlighted in Cangiano and Strozza's contribution to this volume, once again confirming how important the political factor can be in directing migration flows. In this instance, the entry into the EU of some of the emigration countries is leading to greater self-containment in the area and also to a greater autonomy vis-à-vis other geographical sending areas.

\subsection{A migration system approach in the analysis of regional patterns}

The study of the evolution of migration patterns has attracted the attention of many scholars. It is difficult to make generalisations in migration studies because of the specificity and particularity of many situations. The changes in national and regional patterns reflect a wide range of factors related to the particular situations of the countries involved and to the flows being considered. Furthermore, international migrations are the result of the behaviour of different actors (individuals, families, governments, etc.) that come into play at different geographical levels (community, local, national and international). Interactions between actors and geographical levels all make it very difficult to distinguish the different components of the migration process. A useful tool to address this complexity of relations is the concept of the migration system. Originally proposed by Mabogunje (I970) to analyse rural-urban migration in Africa, the concept was generalised for international migration (Kritz, Lim \& Zlotnik I992). A migration system was defined as 'a network of countries linked by migration interactions whose dynamics are largely shaped by the functioning of a variety of networks linking migration actors at different levels of aggregation' (Kritz \& Zlotnik I992: I5).

The identification of a migration system is a really hard task, considering the complexity of the existing economic, social and political interactions (Zlotnik 1992). General criteria have been proposed but the scarcity of data does not help the analysis, given the large gap between theoretical needs and the available statistics. Referring to the situation in the I980s, Salt (1989) considers Western Europe a single system, while Zlotnik (I992) identified three migration systems in Western Europe: (i) the first system included the continental part of the region; (ii) the second was centred on the UK and Ireland, with strong ties with former UK colonies; and (iii) the last system included the Nordic countries. A few years later, Massey et al. (I998: IIo) found, despite the persisting differences, 'sufficient similarities among the nations of Western Europe to consider them as a single international migration system organised under the Treaty of Rome and united in a common 
economic and political order that now embraces twelve core countries.' In the three proposals, the political dimension played an important role and Eastern Europe was mainly considered as a sending area.

More recent research is not limited to Western Europe but considers the entire continent. Salt (200I) has identified three different subsystems in the European scenario, closely related but characterised by flows of different types and sizes. In particular, Salt suggests one migration system focused on the countries of Western Europe, one centred on the countries of the former Commonwealth of Independent States (CIS) and another based on the region between these two geographical areas.

Despite the fact that Salt's proposal is recent, it already seems to have been overtaken by events. The entry of most of the previously 'planned economies' into the EU has effectively expanded a migration system previously centred on Western European countries, making it more self-sufficient than in the past. The borders of the system have moved eastwards so that the countries of the former CIS now form a buffer zone - in the I990s it had been created by the countries that are now EU members to protect their borders with the older members (Collinson 1996). This development has also led to increasing immigration flows towards the EU from countries of the former USSR, such as Ukraine and Moldova.

In the analysis of the evolution of regional migration patterns, the systems approach has the important advantage of already being based on large geographical areas where similarities tend to prevail over dissimilarities. Nevertheless, as with all generalisations, there is a risk of losing, in a broader context, the specific evolutionary patterns of the single flows. In this respect, the Castles and Miller (I993) model offers a sound frame of reference to explain the stages of the evolution of a migration flow. Their model considers four stages: (i) temporary labour migration of young workers with strong links with the sending country; (ii) prolonging of stay and development of social networks; (iii) family reunion with increasing orientation towards the receiving country; and (iii) permanent settlement. The final product of this process can differ greatly according to the policy and attitudes towards immigration of the receiving country. However, Western democratic societies have always granted some basic rights to immigrants, allowing de facto permanent settlement even when the aim of official policy was the promotion of temporary migration.

In order to make a correct analysis, the point of reference should really be the evolution of the single flows rather than the migration dynamics of a whole country. The evolution of any single migration flow is the result of complex interactions between internal dynamics and external conditions leading each immigrant group to adapt to the realities 
of the specific receiving society. Each migratory process tends to follow an evolutionary trend, but the nature of the specific context involved plays an important role in enhancing or delaying the development of the various stages and influencing their characteristics (White 1993). In this respect, two dimensions are worth considering: the stage of the migration flow and time. In demographic terms, the stage can be considered the age of the flow, while time includes the period effects that each generation experiences during its life (Arango 2004). Only by considering these two different dimensions together can we have a clear idea of the evolutionary processes of current trends. In fact, these are the products of the single migration flow, whose patterns are related to its 'ageing' process and to the specific constraining or promoting factors experienced since it began. By and large, the analysis of national and regional patterns tends to deal with the general lines and focuses on the main factors, partly due to the lack of detailed data. In this regard, making use of a 'demographic' perspective in research on regional migration patterns could help to improve our understanding of them.

\subsection{Conclusions}

Many questions are on the agenda in this specific field of migration studies. First, it is necessary to find a suitable balance between two opposing needs: to generalise and yet also to bear in mind the peculiarities of each national situation. In this respect, a better definition of European migration systems could help to improve our knowledge of regional patterns. The improvement of the comparability of migration data is a key condition for achieving these aims and producing analyses to satisfy the specific demands of policymakers. From this point of view, a good assessment of past trends and past evolution at the regional level could be an important analytical tool to explain current changes at the European borders. In fact, the changing nature of international migration is accelerating the evolution in some traditional sending areas (notably North Africa and Turkey), where important changes have already emerged. In this context, transit migration and the presence of large numbers of migrants waiting to move on to the EU could herald more substantial changes in the role of these countries in migration dynamics.

Lessons drawn from the analysis of past regional patterns may also be a useful tool in predicting the future evolution of these areas. This is the approach taken by Bijak and colleagues in the next chapter and one which allows the authors to sketch far more credible future scenar- 
ios for migration than those obtained by mathematically extrapolating from past trends.

Past experience has shown how the political factor can be decisive in characterising migration flows. In this sense, the enlargement of the EU is already playing an important role in encouraging new entrants to develop in the same way as the Southern European countries did. This development is being fostered by both economic growth resulting from entry into a free trade area and by the population dynamics that, in the next few years, will witness a sharp reduction in the migration potential of countries that today experience the highest outflows. What is more difficult to predict is how migration will develop in areas of the continent that are not part of the EU. It would be very risky to make any forecasts in this regard, because much will depend on how relations develop between these countries and the EU over the next few years. We can only note that in the case of the Balkans, an area fairly small and geographically close, the context is favourable to growing integration with the EU; while as regards the larger countries of the former Soviet Union, relations with the EU could take a completely different direction.

\section{Notes}

I Calculating net migration as a residual with the demographic balance equation (total population growth minus natural growth), the result also incorporates all the mistakes of the counts of population stocks and flows.

2 In the I990s, the migration surplus gave a net migration rate in the Russian Federation of 2.8 per thousand, whereas there were losses of -2I.9 per thousand in Albania, -I9 per thousand in Bosnia and Herzegovina, and -II.2 per thousand in Estonia. Losses that were relatively much greater than the gains recorded in Russia were also recorded in Latvia ( -9 per thousand), Lithuania ( -5.7 per thousand), Moldova ( -4.5 per thousand), Bulgaria ( -4.4 per thousand) and Romania (-3.9 per thousand).

\section{References}

Arango, J. (2003), 'Is there a Southern European model of immigration?', paper presented at the 'European Population Conference', Warsaw, 26-30 August 2003.

Arango, J. (2004), 'Postwar migration in Southern European countries', paper presented at the conference 'Immigration Issues in EU-Turkish Relations', Istanbul, 9-Io October 2004 .

Barbagli, M., A. Colombo \& G. Sciortino (2004), 'Introduzione', in M. Barbagli, A. Colombo \& G. Sciortino (eds.), I sommersi e i sanati. Le regolarizzazioni degli immigrati in Italia, 7-I7. Bologna: Il Mulino.

Boffo, S. (2002), 'Il modello mediterraneo nel quadro delle nuove migrazioni internazionali', La Critica Sociologica I43-I44: 88-IO4. 
Bonifazi, C. (2003), 'Central and Eastern European Countries and the new reality of European international migration', in I. E. Kotowska \& J. Jóźwiak (eds.), Population of Central and Eastern Europe. Challenges and opportunities. European Population Conference 2003, Warsaw, 26-30 August 2003, 415-439. Warsaw: Statistical Publishing Establishment.

Bonifazi, C. \& S. Strozza (2002), 'International migration in Europe in the last fifty years', in C. Bonifazi, \& G. Gesano (eds.), Contributions to international migration studies, 33-I05. Rome: IRP-CNR.

Bonifazi, C. \& S. Strozza (2006), 'Conceptual framework and data collection in international migration', in G. Caselli, J. Vallin \& G. Wunsch (eds.), Demography. Analysis and synthesis, Vol. IV, 537-554. San Diego: Elsevier.

Castles, S. \& M. J. Miller (I993), The age of migration: International population movements in the modern world. Hong Kong: Macmillan.

Castles, S. \& M. J. Miller (2003), The age of migration: International population movements in the modern world. Third edition. New York: Palgrave Macmillan.

Collinson, S. (1996), "Visa requirements, carrier sanctions, "safe third countries" and "readmission": The development of an asylum "buffer zone" in Europe', Transactions of the Institute of British Geographer 2I (I): 76-90.

European Commission (2005), Confronting demographic change: A new solidarity between the generations. Green Paper. Luxembourg: Office for Official Publications of the European Communities.

Fassmann, H. \& R. Münz (I995), 'European East-West migration', in R. Cohen (ed.), The Cambridge survey of world migration. Cambridge: Cambridge University Press.

Garson, J.P. \& A. Loizillon (2003), 'Changes and challenges: Europe and migration from I950 to present', paper presented at the conference 'The Economic and Social Aspects of Migration', Brussels, 2I-22 January 2003.

Golini, A., S. Strozza \& G. Gallo (200I), 'Population trends and migratory pressure in the European Economic Area and the Euro-Middle East-Africa region', Studi Emigrazione 38 (I44): 754-786.

Gould, W. T. S. \& A. M. Findlay (eds.) (1994), Population migration and the changing world order. Chichester: John Wiley \& Sons.

King, R. (I993a), 'European international migration I945-90: A statistical and geographical overview', in R. King (ed.), Mass migration in Europe. The legacy and the future, I939. London: Belhaven.

King, R. (I993b), 'Why do people migrate? The geography of departure', in R. King (ed.), The new geography of European migrations, I7-46. London: Belhaven.

King, R. (2000), 'Southern Europe in the changing global map of migration', in R. King, G. Lazaridis \& C. Tsardanidis (eds.), Eldorado or fortress? Migration in Southern Europe, 3-26. London: Macmillan.

King, R. (2002), 'Towards a new map of European migration', in International Journal of Population Geography 8 (2): 89-106.

King, R. \& K. Rybaczuk (I993), 'Southern Europe and the international division of labour: From emigration to immigration', in R. King (ed.), The new geography of European migrations, I75-206. London: Belhaven.

Kritz, M. M. \& H. Zlotnik (I992), 'Global interactions: Migration systems, processes and policies', in M. M. Kritz, L. L. Lim \& H. Zlotnik (eds.), International migration systems. A global approach, I-I6. Oxford: Clarendon Press.

Kritz, M. M., L. L. Lim \& H. Zlotnik (eds.) (I992), International migration systems: A global approach. Oxford: Clarendon Press.

Mabogunje, A. L. (I970), 'Systems approach to a theory of rural-urban migration', in Geographical Analysis 2 (I): I-I7. 
Massey, D. S., J. Arango, G. Hugo, A. Kouaouci, A. Pellegrino \& J. E. Taylor (1998), Worlds in motion: Understanding international migration at the end of the millennium. Oxford: Clarendon Press.

Münz, R. (1995), 'Where did they all come from? Typology and geography of European mass migration in the twentieth century', in EAPS/IUSSP, Evolution or revolution in European population, European population conference, Milano, 1995, Vol. 1, Plenary sessions, 95-I54. Milan: F. Angeli.

National Migration Observatory (2004), Statistical data on immigrants in Greece: An analytic study of available data and recommendations for conformity with European Union standard. Athens: MMO.

Okólski, M. (1998), 'Regional dimension of international migration in Central and Eastern Europe', Genus 44 (I-2): II-36.

Poulain, M., N. Perrin \& A. Singleton (eds.) (2006), THESIM. Towards harmonised European statistics on international migration. Louvain-la-Neuve: Ucl Presses Universitaires de Louvain.

Pugliese, E. (1993), 'Restructuring of the labour market and the role of Third World migration in Europe', in Environment and Planning D: Society and Space II (5): 513-522.

Salt, J. (1989), 'A comparative overview of international trends and types 1950-80', International Migration Review 23 (3): 43I-456.

Salt, J. (200I), Current trends in international migration in Europe. Strasbourg: Council of Europe. Available on the web in February 2003. <www.coe.int/t/dg3/migration/ Documentation/Migration\%2omanagement/200I_Salt_report_en.pdf>.

Salt, J. (2003), Current trends in international migration in Europe. Strasbourg: Council of Europe. Available on the web in November 2004. <www.coe.int/t/dg3/migration/ Documentation/Migration\%2omanagement/2003_Salt_report_en.pdf>.

Salt, J. (2006), Current trends in international migration in Europe. Strasbourg: Council of Europe. Available on the web in October 2006. <www.coe.int/t/dg3/migration/ Documentation/Migration\%20management/2005_Salt_report_en.pdf>.

Salt, J. \& H. D. Clout (eds.) (I976), Migration in post-war Europe: Geographical essays. London: Oxford University Press.

United Nations (2005), World population prospects: The 2004 revision. New York: United Nations.

United Nations (2006), Trends in total migrant stock: The 2005 revision. CD-ROM documentation. New York: United Nations.

Wanner, P. (2002), Migration trends in Europe, European Population Papers Series 7. Strasbourg: Council of Europe.

White, P. (I993), 'The social geography of immigrants in European cities: The geography of arrival', in R. King (ed.), The new geography of European migrations, 47-66. London: Belhaven.

Zlotnik, H. (I992), 'Empirical identification of international migration systems', in M. M. Kritz et al. (eds.), International migration systems: A global approach, 19-40. Oxford: Clarendon Press. 


\title{
7 Long-term international migration scenarios for Europe, 2002-2052
}

\author{
Jakub Bijak, Anna Kicinger, Dorota Kupiszewska \\ and Marek Kupiszewski ${ }^{1}$
}

\subsection{Introduction}

The hypotheses regarding the future shape of international migration are not only demographic by nature, but also have to take into account various economic, political, sociological and ethnic factors. Moreover, migration is a phenomenon characterised by a much higher level of uncertainty and is much more controversial in terms of expectations for the future than fertility or mortality. For these reasons, predicting migration is very difficult and the results of various forecasts often prove to be unsuccessful, bearing very high prediction errors.

This article presents assumptions for the future development of long-term international migration in 27 European countries for the period 2002 to 2052 . The assumptions have been developed to serve as an input for forecasts and simulations of population and labour force dynamics in Europe. In geographic terms, the analysis covers the European Union excepting Cyprus and Malta, plus Norway, Switzerland, as well as two EU accession countries - Bulgaria and Romania. ${ }^{2}$ With due respect to the demographic dispute about distinguishing between 'forecasts' and 'projections', we have used the term 'forecast' throughout the study to stress that the outcome reflects our beliefs about what we expect to be the possible future migration and population development paths (see Ahlburg \& Lutz 1998).

The article starts with a description of legal and political developments concerning freedom of movement in Europe, as well as assumptions of the forecasts in that respect, which are shown in section 7.2. In two subsequent sections (7.3 and 7.4), qualitative migration scenarios are presented, respectively for movements among the countries under study and for population exchange with the rest of the world. These scenarios describing our knowledge-based expectations of future changes in international population flows are quantified using the algorithms described in detail in section 7.5. The results of the analysis, including the impact of the assumed scenarios on population forecasts for the selected European countries, are summarised in brief in the 
sixth section of the article. Finally, section 7.7 presents a synopsis of the outcomes, as well as the major conclusions of the study.

\subsection{Freedom of movement in Europe: status quo and assumptions}

The high profile of migration policy in the public debate in recent years in the old EU-I5 countries has greatly influenced negotiations on EU enlargement. Fears arising from the growing migratory pressure from the South were further fuelled by sometimes contradictory and exacerbated forecasts about the possible flood of workers from new member states (NMS). Such forecasts, offered both by researchers and journalists, greatly influenced public opinion. Negotiations in the area of free flow of people were delicate and sometimes tense (Duszczyk 2002), but finally the respective negotiations chapters were closed.

The definite conditions of accession of the ten new states to the EU were laid down in the Treaty on Accession and in the Act on Accession, signed on I6 April 2004 (European Communities 2003a,b). Following the results of negotiations, the Treaty provided for transitional periods in the area of the free flow of workers for the citizens of NMS (excluding Malta and Cyprus). According to the Treaty, the old EU-I5 countries were given the right to introduce transitory provisions for two, five or a maximum of seven years in order to limit access to their labour markets for workers from the new member states. The key element of the transitory provisions was the opportunity to apply national measures and those resulting from the previous bilateral agreements in lieu of Community law, which normally would have to be applied.

The decision whether to introduce transitional periods was left to the respective member states. According to the agreed schedule, in 2006, after the first two years following accession, the Commission prepared a review of the situation (European Commission 2007), but the decision whether to discard or to maintain the restrictions was again left to the states. Only in 2009 , after the five-year period, should all restrictions on the free flow of workers be lifted, with the exception of countries declaring serious disturbances in the labour market or a threat thereof. Such countries would be eligible to extend the application of the transitory measures for the following two years.

According to the Accession Treaty, the new member states were given the chance to introduce similar restrictions against EU-I5 nationals on the principle of reciprocity. Nevertheless, only Poland, Hungary and Slovenia used this opportunity, ${ }^{3}$ while the Czech Republic, Estonia, Latvia, Lithuania and the Slovak Republic accepted this asymmetry in their relations with the EU-15. 
The first decisions whether to impose the transitional periods were announced by I May 2004. According to them, only three countries Ireland, Sweden and the United Kingdom - did not introduce any transitional measures; however the UK imposed some obligations not stipulated in the Community law, such as the Workers Registration Scheme. The rest of the EU-I5 decided to introduce a two-year transitional period in order to protect their labour markets and to calm public opinion. Thus, for the purpose of this study, we set up a scenario of the probable future dates for the opening of these labour markets to NMS nationals. ${ }^{4}$ We assumed that Denmark, Finland and the Benelux countries were likely to open their labour markets to the nationals of the new EU member states in 2006, whereas Southern and Mediterranean EU members i.e. Italy, France, Spain, Portugal and Greece were more likely to open their labour markets only in 2009. Germany and Austria, according to the often-repeated statements of politicians, were almost sure to extend restrictions on access to their labour markets for the maximum period, i.e. for seven years.

Our forecasts include two non-EU countries: Norway and Switzerland. Norway belongs to the European Economic Area (EEA) where the principle of the free flow of workers is equally secured. We assumed that it would discard the restrictions by 2006. Switzerland does not participate in the free movement of workers in Europe as it does not belong to the EU nor to the EEA. According to the Agreement between the EU and Switzerland on the free movement of people by 2014 , providing the positive outcome of the Swiss referendum in 2009, the regulation of the free flow of people between Switzerland and the extended EU is supposed to be entirely in place (European Communities 2002; BMF 2004).

According to the treaty on the accession of Bulgaria and Romania to the EU signed in April 2005, they joined the EU in 2007 (European Communities 2005). Both countries accepted the transitional periods in the free flow of people identical to those provided by the Accession Treaty for the eight NMS that joined the EU in 2004. The reasons for imposing such restrictions comprised, among others things, economic disparities between Bulgaria and Romania and the EU countries, unsolved problems with the Roma and other ethnic minorities in these two countries, the experience of Bulgarian and Romanian irregular immigration to the EU countries, as well as the developed migratory networks of these countries' nationals in Western, Central and Southern Europe. For the purpose of the current study it was therefore assumed that the schedule for opening EU labour markets for Bulgarian and Romanian workers would follow the schedule for opening Western European labour markets for the citizens of the eight NMS that accessed the EU in 2004, albeit with a three-year time delay. 


\subsection{Intra-European migration scenarios after EU enlargement}

International migration flows can be described in terms of push (unfavourable) and pull (attracting) factors. The current study focuses on the two types of such variables: economic determinants and those related to migration policies. There are also other important factors (political disturbances, wars, etc.) that to a large extent shape international population flows, as for example the fall of the socialist system or the I990s armed conflicts in the former Yugoslavia. Nevertheless, due to the unpredictability of such events, they have not been considered in setting the scenarios.

There have been numerous attempts to predict migration from Central and Eastern Europe to the EU-I5 countries following the enlargement of the EU, presented here as a background reference for the current scenarios of intra-European migration (see Layard et al. I992; Franzmeyer \& Brücker 1997; Fassmann \& Hintermann 1997; Lundborg 1998; Fertig 1999; Orłowski \& Zienkowski 1999; Bauer \& Zimmermann 1999; Salt et al. I999; Fertig \& Schmidt 2000; Orłowski 2000; Sinn et al. 200I; Brücker \& Boeri 200I; Hille \& Straubhaar 200I; Alvarez-Plata, Brücker \& Siliverstovs 2003). These studies, published during the I990s mainly by Western European researchers, focus on East-West migration, not analysing population flows in the opposite direction. Regrettably, many studies refer to the 'migration potential' of Central and Eastern Europe, a term lacking precision and not really applicable as a predictor of actual migration streams (Kupiszewski $2002 \mathrm{~b}$ ). The existing studies cover European origin and destination countries either in whole, or only partially, the latter focusing mainly on a group of the then candidate countries, or on Germany as the main destination.

A comprehensive study by Alvarez-Plata et al. (2003) shows that in most of the previous studies the forecasted numbers of migrants to Western Europe were overestimated, including the study of Franzmeyer \& Brücker (I997) in the highest extreme, forecasting up to I.I8 million migrants yearly from Central and Eastern Europe to Western Europe. The study of Alvarez-Plata et al. (2003) additionally takes into consideration policy issues in the form of different possible dates of opening of the labour markets of the EU-I5 countries. Several possible years are assumed, from 2004 to $20 \mathrm{II}$, according to the ' $2+3+2$ years' scheme of transition periods. Although this proposition assumes the one-off opening of labour markets of the whole EU-I5, the conclusion is that regardless of the date of full freedom of movement, the migration patterns are very similar, only observed with a time delay.

Most of the mentioned forecasts are based on the econometric models with purely economic explanatory variables. As has been noted by 
Kupiszewski (2002b), such an approach lacks certain features that would be desired from the methodological point of view. First of all, the demographic, social or policy constraints of migration are not considered in such models, which seems to be a serious material omission. Secondly, the economic variables used as predictors, like GDP (gross domestic product) or unemployment, are difficult to forecast themselves and thus increase the uncertainty of migration forecasts to a very significant degree. Therefore, the results of all the studies mentioned will be used only as a background reference for the forecast outcome in the current study, applying the methodology of knowledgebased scenarios.

In the current forecasts, three different scenarios of intra-European migration developments are considered: base (the primary one), low, and high - the two latter expressing an expected range of possible deviations from the base, according to the authors' judgement. The scenarios differ primarily with respect to the assumptions on the expected economic performance of particular countries. The developments of intra-European migration policies are assumed the same for all scenarios, with the gradual opening of Western European labour markets for the citizens of Central and South-Eastern European countries following the outline described in section 7.2.

In general, the presence of an overall trend of migration intensity is assumed in all scenarios, with the gradual implementation of the freedom of movement policy marking temporary deviations from the global tendency. This allows us to distinguish three phases of migration developments:

- Pre-opening period, with migration following the overall trend starting from the initial values observed for 2002 .

- Post-opening period, following the full implementation of the freedom of movement policy, with increased migratory movements from Central and Eastern to Western European countries, yet systematically declining over time.

- Period of long-term stabilisation, with migration flows returning to their overall trends, which continue until the end of the forecast period.

Especially in the first period following the full implementation of the freedom of movement provisions, the scope and direction of migratory flows is going to depend heavily on the disparities between origin and destination countries. For the purpose of the current analysis, the 27 countries under study have been clustered into three groups, according to their socioeconomic situation: Western Europe, consisting of the EU-I5 countries, Norway and Switzerland; Central Europe, composed 
of the eight new member countries from 2004, as well as South-Eastern Europe (Bulgaria and Romania).

We assume that the gradual opening of labour markets will have no impact on migration within Western Europe, as well as on the SouthEastern cluster. In the latter case we envisage that the excess migration streams from Bulgaria and Romania will be directed predominantly to Western and to a lesser extent to Central Europe. Disparities of income between the clusters are expected to be the only source of additional migration pressure in that case. Conversely, within Central Europe one can expect a slight increase of population movements, due to the opening of diversified labour market opportunities in various countries.

Naturally, the most important changes can be expected with respect to population flows from Central and South-Eastern to Western Europe, as well as to a lesser extent from South-Eastern to Central Europe. Their magnitude would depend on income disparities between particular clusters, as well as on the scenario type (highest migration pressure in the low variant, assuming a continuation of the income gap in Europe, and lowest in the high). With respect to eastward migration we assume that there will be an increase in population flows, but the scope of this phenomenon will be rather limited in all forecast variants. We also foresee that labour movements between the old and new EU member states can increasingly become two-way flows, as more demand for specific types of labour in the new EU member countries may be generated, including for highly skilled professionals. Nevertheless, the returns of former emigrants are likely to be the primary source of eastward migration.

The base scenario reflects an assumption of the stable socioeconomic development of Europe, most importantly sustainable economic growth and thus convergence of income levels in all European countries in the long term. In terms of a general trend, this would mean an overall increase in the mobility of Europeans, following the emergence of new job opportunities in all countries. These possibilities are probably going to be of key importance for East-West migration, where the gradual opening of Western European labour markets is expected to constitute a strong pull factor for the citizens of Central and Eastern Europe. On the other hand, these phenomena are expected to be limited in time, and as the positive effects of European integration are assumed to prevail, migration levels are ultimately going to return to their long-term trends.

The low scenario assumes that Europe is going to face economic stagnation, resulting in high unemployment and structural problems in labour markets. Especially in the pre-opening and post-opening periods, some economic disturbances may be observed in the countries of Central and Eastern Europe, similar to those witnessed in East Ger- 
many in the I990s after German reunification. As very slow income growth is expected to prevail, resulting in few new job opportunities, overall spatial mobility is hardly going to increase. In this scenario, the major factor determining population movements in Europe is going to be the pressure on migration from Central and Eastern to Western Europe after full implementation of the freedom of movement policy. In this variant, the disparities between different parts of Europe are going to relate to unfavourable economic conditions, which would generate substantial migration streams in the medium term. Therefore, the post-opening wave of migration in the low variant is assumed to be higher and to last longer than under the 'regular' conditions assumed in the base scenario.

In the high scenario, all European countries are expected to be characterised by substantial economic growth and a relatively rapid convergence of income levels. On the one hand, this is going to significantly increase the overall mobility of people within Europe, as new employment possibilities emerge across the continent. On the other hand, the push factors to emigrate from Central and Eastern Europe to the West are going to be substantially reduced. In this scenario, the post-opening increase of East-West population flows is expected to be a short-term phenomenon, rather moderate in size.

The assumptions of the low and high scenarios are meant to provide the expected lower and upper bounds of possible migration developments for the period 2002 to 2052 according to the judgement of the authors. It seems implausible to believe that the conditions for either high net migration losses or gains would be so long lasting. A belief in the existence of the long-term economic 'equilibrium' path of growth may contribute an additional argument in that respect.

Following the liberalisation of population movements within Europe, one may also expect the occurrence of a short-term phenomenon of 'migration without migrating'. In Western European countries, many of the so far irregular migrants and illegal workers from Central and Eastern Europe are likely to regularise their status once they have such an opportunity. Therefore, shortly after liberalisation takes place, an increase in the numbers of migrants will likely be observed in statistical registration, but not in reality. This hypothesis has been substantiated by the British government Home Office report (2004) stating that in May 2004 as many as 6I per cent of those who registered under the Working Registration Scheme arrived before I May 2004. By September 2004 , the share decreased to I2 per cent. This is exactly as was predicted by Kupiszewski (2002a). 


\subsection{Net migration scenarios from the other parts of the world}

In setting the scenarios of net international migration from the remaining countries of the world (hereafter 'external' migration), in the first place the economic and political situation at the fringes of an enlarged EU has to be considered. The other post-socialist countries, including the former Soviet Union, as well as the countries of former Yugoslavia, are potential sources of large population inflows. A very important way in which the situation in these countries can have an impact on migration to their European neighbours is through the presence of established migrant networks. The situation in the countries of the former Soviet Union will most likely have an impact on migration flows to Poland, the Baltic States and the Czech Republic, as well as to the rest of Central Europe. One also cannot completely ignore the ethnic migration of Poles and Germans from the former USSR, etc., although this migration source is already almost extinguished. The countries of former Yugoslavia may in turn generate substantial population movements to Slovenia and Hungary, following the strong historical and cultural ties in that region. Another potential important source country of migration is Albania, with significant numbers of migrants (both of regular and irregular status) already present, especially in neighbouring Italy and Greece. Due to Albania's low level of socioeconomic development on the one hand, and to migrant network effects on the other, this direction of migration is expected to prevail in the future.

The flows pointed out above depend heavily on the further political and economic development of the countries mentioned, and especially on their chances of joining the EU. This factor, however, remains hardly predictable, especially with respect to post-Soviet states, Albania, Bosnia and Herzegovina, Macedonia (FYROM), or Serbia, Montenegro and Kosovo. Especially with respect to the latter, due to the uncertain political and economic future of the new country, a possibility that subsequent developments would generate a wave of politically motivated or humanitarian migration, cannot be excluded. In the current study, however, due to the fact that political events are totally unpredictable over a span of 50 years, we assume that migration from these countries will be primarily economically driven.

The second group of potential large sources of population inflows comprises the countries with historically large migrations into Western and Southern Europe, mainly Turkey and the Northern African countries. In general, it can be envisaged that these population inflows to Europe will continue, to some extent regardless of the pace of socioeconomic development in the origin countries. In general, existing disparities in income and living conditions between European countries and 
most of the outside world will no doubt constitute a strong push factor to migrate. This will influence the possible magnitude of migration into Europe, particularly taking into account large countries like China, especially as there are already significant Chinese migrant networks in Europe.

On the other hand, policy measures aimed at limiting migration or shaping it in a desired way, like admitting highly skilled professionals, are almost certain to be in place. Hence, although migration potential outside Europe is very large, its impact is likely to be offset by these policies. The policies are also likely to depend on economic development on the global scale: both in the highly developed as well as in the developing countries. For the purpose of setting the scenarios of net migration to Europe from the rest of the world, again three variants of global socioeconomic developments are assumed:

- Base scenario, with a moderate, yet sustained improvement in the economic, political and social situation worldwide, resulting in a moderate overall population inflow to Europe and a gradual shift in places of origin from the neighbouring countries to the other developing regions of the world. In this scenario, policy measures are not assumed to be very restrictive, due to a relatively good and stable socioeconomic situation in Europe.

- Low scenario, assuming economic stagnation both in Europe and in the rest of the world, resulting in strong migration pressure on developed countries. The strong push factors are in this scenario offset by restrictive migration policies, having an impact on the decline of registered migration at least. Migration policies are primarily aimed at the protection of European labour markets and reducing the possible social tensions related to the inflow of large numbers of immigrants.

- High scenario, assuming dynamic economic growth and social development, resulting in a need for an inflow of foreign labour and thus leading to relatively liberal immigration policies. Economic growth in the developing regions is assumed to be a factor contributing to the increased mobility of people worldwide.

In terms of overall assumptions, comprehensive scenarios of overall net migration for a majority of European countries have been presented by De Beer and Van Wissen (I999). In their work, countries have been clustered into five groups: Eastern (Bulgaria, Romania and the former USSR without the Baltic states), Central (remaining post-socialist countries including the Baltic states, Croatia and Slovenia), Northern (Nordic countries), Southern (Greece, Italy, Portugal and Spain) and Western (the remaining countries of Western Europe). 
Two scenarios of population developments have been presented: one of 'uniformity', assuming the convergence of demographic pattern trends within Europe; and the other of 'diversity', preserving the current differences between countries. In the 'uniformity' scenario it was assumed that by 2050 , net migration rates in all European countries would reach levels of +2.5 per I, ○०o population, with the exception of Southern European countries, with target rates of +3.5 per I,000. In the 'diversity' scenario, the assumed target net migration rates were correlated to the level of socioeconomic development in particular clusters, ranging from -0.5 per I,O०O in Eastern Europe, through -I.O in Central Europe, +I.5 in Western and Northern Europe, to +3.5 in Southern Europe. Although these scenarios are not directly comparable with the current study, as they relate to the overall net migration of particular countries, they form a valid point of reference in the scenario setting.

The major shortcoming of the forecasts of De Beer and Van Wissen (I999) is that they do not take into account migration policy issues, and especially EU enlargement. Moreover, as their forecast is based on data up to I995, they do not take into account recent population developments, which seem to be crucial for the understanding of the dynamics of migration processes, not only in Central Europe, but also in countries like Ireland or Spain. What seems worthwhile in their study is the clustering of European countries according to similar demographic patterns. In the current work, an analogous grouping is therefore applied, with only three exceptions:

- The Czech Republic and Hungary have been assigned to the West cluster, not to the Central, due to their recent migratory developments with positive net migration in the second half of the I990s, as well as due to the high level of socioeconomic development;

- Slovenia has been attached to the South cluster, not only due to recent migration history and geographic location, but also due to very good economic performance, the best among the former European socialist countries.

Given the above, it is envisaged that in all European countries, the net migration from the rest of the world will eventually be positive, regardless of the forecast variant. The lowest 'external' net migration rates are expected for Eastern Europe, the highest for Southern Europe, with Central, Northern and Western clusters in between. The Northern countries have been assigned lower target 'external' net migration rates in comparison with Western Europe due to their slightly more peripheral position in the European migratory system. The highest values for Southern Europe reflect their recent migration history, post-colonial ties and the related migrant networks, as well as their proximity to im- 
portant sending areas like Turkey and North Africa. The targets for the low and high variants need to be specified allowing for reasonable deviations from the base scenario, given the assumptions on the global socioeconomic situation mentioned before. The quantification of the assumptions is discussed in detail in the next section.

\subsection{Quantification of the forecast assumptions}

With regard to the intra-European migration scenarios for the period 2002 to 2052 , the forecasted variable is migration volume between particular countries. Following the proposition of Kupiszewski (2002a: Io6), initial migration figures for 2002 have been taken as greater than the values registered by sending and receiving countries, according to the data of the Council of Europe (2003: country specific tables 7.6) and Eurostat (NewCronos). In the MULTIPOLES forecasting model applied in this study (Kupiszewski \& Kupiszewska I998; Kupiszewska \& Kupiszewski 2005), the total number of migrants from country $i$ to $j$ is divided by the mid-year population of the sending country (i) in order to obtain origin-destination specific migration rates $\left(M R_{i, j}\right)$. The scenarios are made on the basis of $M R_{i, j}$ multipliers for subsequent periods $t$ $\left(m_{i, j, t}\right)$, satisfying the condition $M R_{i, j, t}=M R_{i, j, t}-\mathrm{I} \cdot m_{i, j, t} \cdot$

In the current study the multipliers $m_{i, j, t}$ are comprised of two multiplicative components: the overall trend $(T R)$ for a given scenario, constant for the whole forecast period, and the post-accession deviation. The latter component is assumed to occur at the moment of introducing a free-flow policy between particular countries, and gradually diminishes within an assumed period of time. The post-accession deviation is calculated in such a way that the difference between the current $M R_{i, j, t}$ and its trend follows a logistic curve, diminishing from the postaccession level to zero. In terms of multipliers $m_{i, j, t}$, the relevant formula for flows from country $i$ to country $j$ in the year $t$ is:

$M_{i, j, t}=T R \cdot \frac{P A I_{i, j}+\left(T R-P A I_{i, j}\right) /\left(\mathrm{I}+\exp \left(-r \cdot\left(t-Y F_{i, j}\right)-0.5 \cdot Y S\right)\right)}{P A I_{i, j}+\left(T R-P A I_{i, j}\right) /\left(\mathrm{I}+\exp \left(-r \cdot\left(t-Y F_{i, j}\right)-0.5 \cdot Y S-\mathrm{I}\right)\right)}$

where $r$ denotes a growth rate of the logistic curve, $t$ - year (where $Y F_{i, j}$ $\left.<t<Y F_{i, j}+Y S\right), P A I_{i, j}$ - assumed post-accession increase in migration rates, expressed as a multiplier; $Y F_{i, j}$ - year of introducing freedom of movement from country $i$ to $j$, and $Y S$ - number of years needed to return to the trend. Specific assumptions have been made for:

$-m_{i, i, t}=\mathrm{I}$

for the default zero flows from country $i$ to country $i$; 
- $m_{i, j, t}=T R$

for both $i, j$ denoting Western European countries;

- $m_{i, j, t}=T R$

- $m_{i, j, t}=T R \cdot P A I_{i, j} \quad$ for $t=Y F_{i, j}$.

Assumptions for $P A I_{i, j}$ have been established for three clusters of European countries: Western, Central and South-Eastern. The low scenario is based on the assumption of a difficult economic situation in Europe, resulting in slow convergence in the development levels of the countries and thus in strong westward mobility. The base scenario depicts the situation of modest yet sustainable economic growth across Europe, having effects of moderate convergence and a moderate increase in mobility. Finally, the high scenario assumes relatively fast economic growth, convergence and the intensification of unification processes, resulting in overall high mobility, with less importance of westward population movements.

In terms of numbers, the overall trend $T R$ in the low scenario is assumed to be equal to I, reflecting constant mobility throughout the forecast period $(T R=\mathrm{I})$; in the base scenario the moderate mobility increase by 0.5 per cent yearly is assumed $(T R=1.005)$; and in the high scenario, a significant increase by I per cent per annum ( $T R=\mathrm{I}$.OI). In the case of westward movements from South-Eastern to the Central and Western clusters, as well as from the Central to the Western cluster, the $T R$ trend multipliers for the high and low variants have been swapped to ensure consistency of the assumptions (see figure 7.I).

The time needed for the migration flows to stabilise and return to the trend after liberalisation of the population movements (YS) is assumed to equal twenty, fifteen and ten years, respectively, in the low, base and high scenarios. In all cases, the annual growth rate for the logistic curve $r$ is assumed to amount to 0.5 . The hypotheses regarding the size of post-accession increase of migration from country $i$ to $j$ $\left(P A I_{i, j}\right)$ are presented in table 7.I.

The results in terms of 'hypothetical' trajectories of migration rate developments, in relation to the values observed for the period prior to the introduction of the freedom of movement policy, are presented in figure 7.I. It has to be noted that in reality, the schedules will be postponed, according to the policy-related assumptions presented in section 7.2 influencing the delay in mutual opening of labour markets by particular countries $(Y F)$.

Separate assumptions have been made with respect to the sex and age distributions of migrants within Europe. Distribution by gender has been assumed to be the one observed in 2002, remaining constant throughout the forecast period. The age-specific migration rates have been calculated for the following four groups of countries: 
Table 7.1 Initial post-accession increase (PAI $i, j$ ) for clusters of countries

\begin{tabular}{lccc}
\hline & Western Europe & Central Europe & $\begin{array}{c}\text { South-Eastern } \\
\text { Europe }\end{array}$ \\
\hline & & Low scenario, from/to \\
Western Europe & 1.00 & 1.00 & 1.00 \\
Central Europe & 1.50 & 1.00 & 1.00 \\
South-Eastern Europe & 2.00 & 1.50 & 1.00 \\
& & & \\
Western Europe & 1.00 & Base scenario, from/to & 1.05 \\
Central Europe & 1.35 & 1.05 & 1.05 \\
South-Eastern Europe & 1.60 & 1.10 & 1.00 \\
& & 1.35 & \\
Western Europe & 1.00 & High scenario, from/to & 1.10 \\
Central Europe & 1.20 & 1.10 & 1.10 \\
South-Eastern Europe & 1.20 & 1.20 & 1.00 \\
\hline
\end{tabular}

Source: own elaboration

- Germany, separated due to its key position in the European migration system;

- Western Europe: Austria, Belgium, Denmark, Finland, Ireland, Luxembourg, the Netherlands, Norway, Sweden, Switzerland and the UK;

- Southern and Mediterranean Europe: France, Greece, Italy, Portugal and Spain;

- Central and Eastern Europe: Bulgaria, the Czech Republic, Estonia, Hungary, Latvia, Lithuania, Poland, Romania, Slovakia and Slovenia.

It is worth noting that this grouping has been made specifically for the purpose of defining age patterns of migration intensity, and differs from the two clustering schemes concerning the magnitude of intraEuropean and 'external' flows, respectively presented in sections 7.3 and 7.4. For example, France is considered as a Western country with respect to the overall migration volume, but a Southern/Mediterranean country with regard to the age structure of migration.

In most cases, German data on migrants by five-year age groups and by citizenship have been used, as the best available proxy of age distributions by origin and destination countries. The only exceptions were flows from Western to Southern and Mediterranean Europe, where the data of destination countries have been applied due to suspected local specificities in age structures, namely the presence of visible post-retirement migration peaks. Their presence turned out to be true for all 

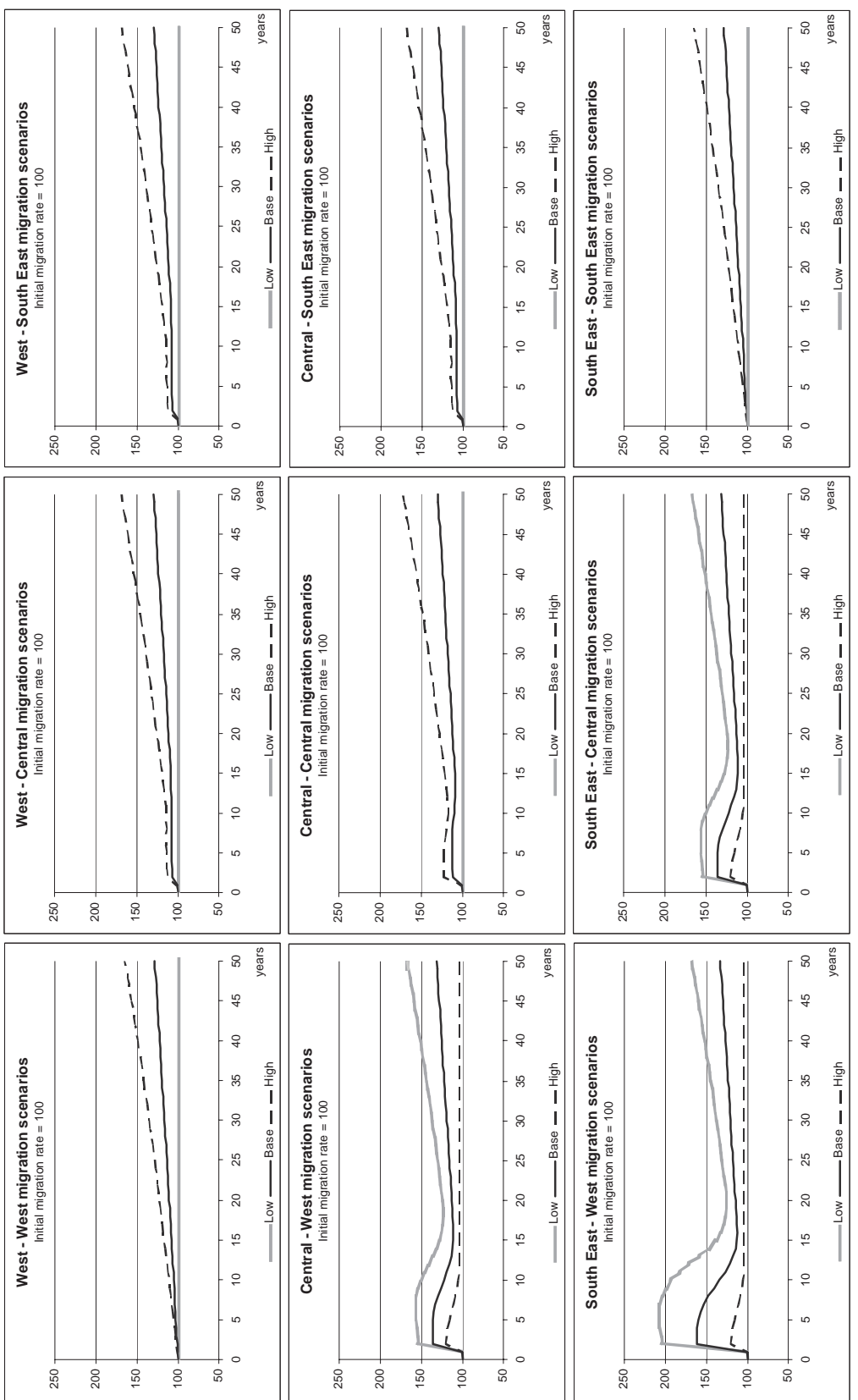

Figure 7.1 Overview of assumed post-accession intra-European migration developments: low, base and high scenarios

Source: own elaboration 
Southern/Mediterranean countries but France. Nevertheless, as the difference of the age schedules of migration to France between the French and German data was rather small, in this case we decided to retain the data of the receiving country, assuming it to be more complete and accurate.

The input has been taken from Eurostat (NewCronos), except for France, where the figures have been estimated on the basis of the study of INED (I999). In all cases, age distributions of migrants have been assumed constant throughout the forecast span, i.e. until 2052.

With regard to population exchange with the rest of the world, assumptions on net migration for each of the 27 countries under study have been made in terms of crude numbers of migrants. The forecasted variable is thus the 'external' net migration (ENM). The initial values for 2002 have been estimated as total net migration reported by the countries themselves, less net migration among the 27 European countries under study.

The assumptions on target values of net migration from the outside world are also by necessity judgmental due to the higher uncertainty over predictions of international migration on a global scale. As proposed in the previous section of this article, for the purpose of scenario-setting the countries have been grouped into five clusters, according to similar levels of socioeconomic development and common migration history as well as geographic and cultural proximity. The cluster-specific target 'external' net migration rates (ENMR) per I,ooo population preliminarily assumed for three forecast variants are presented in table 7.2 .

Table 7.2 Target 'external' net migration rates (ENMR) per 1,000 population for 2052

\begin{tabular}{|c|c|c|c|c|c|}
\hline \multirow[t]{2}{*}{ No. } & \multirow[t]{2}{*}{ Cluster } & \multirow[t]{2}{*}{ Countries } & \multicolumn{3}{|c|}{$\begin{array}{l}\text { Target ENMR per } \\
\text { 1,000 population }\end{array}$} \\
\hline & & & Low & Base & High \\
\hline 1 & South-Eastern Europe & Bulgaria, Romania & 0.0 & 1.0 & 2.0 \\
\hline 2 & Central Europe & $\begin{array}{l}\text { Estonia, Latvia, Lithuania, } \\
\text { Poland, Slovak Republic }\end{array}$ & 0.25 & 1.5 & 3.0 \\
\hline 3 & Northern Europe & $\begin{array}{l}\text { Denmark, Finland, Norway, } \\
\text { Sweden }\end{array}$ & 0.5 & 2.0 & 4.0 \\
\hline 4 & Western Europe & $\begin{array}{l}\text { Austria, Belgium, Czech } \\
\text { Republic, France, Germany, } \\
\text { Hungary, Ireland, Luxembourg, } \\
\text { the Netherlands, Switzerland, UK } \\
\text { Greece, Italy, Portugal, Slovenia, }\end{array}$ & 1.0 & 2.5 & 5.0 \\
\hline & & Spain & 1.5 & 3.0 & 6.0 \\
\hline
\end{tabular}

Source: own elaboration 
The ENMR rates have been further transformed into crude target ENM numbers multiplied by the 2002 population size of particular countries. The results have been taken as target values for 2052 $\left(E N M_{2052}\right)$. The initial and target ENM values have been bridged by means of an exponential interpolation, according to the formula:

$$
E N M_{t}=E N M 2052+\left(E N M 2002-E N M_{2052}\right) \cdot \exp (-r \cdot(t-2002))
$$

where $t$ denotes year $(t<2052)$ and $r$ the growth rate, assumed to equal o.I per annum. Such a curve ensures a smooth passage from $E N M_{2002}$ to $E N M_{205_{2}}$ and the stabilisation of the ENM in the long term.

With respect to the sex and age distributions of the 'external' migrants, cluster-specific assumptions have been made on the basis of clustering presented in section 7.4. For Western, Northern and Southern Europe, three countries have been chosen as typical: Germany, Sweden and Spain. Due to unavailability of similar data for Central and South-Eastern Europe, the schedules have been estimated on the basis of Czech statistics. The gender-specific age distributions of 'net migrants' from outside the system of 27 countries under study have been calculated in the form of fractions of the overall total, as shown in figure 7.2 .

The proposed distributions reflect a slight tendency among people migrating to Western Europe to return to the country of origin, especially among males above 60 years of age. For the remaining clusters, net migration remains positive for almost all age groups, with only very minor exceptions.

\subsection{Impact of migration assumptions on population forecasts}

The impact of different migration scenarios on population size and structure of the 27 countries under study in the period 2002 to 2052 has been assessed by running the MULTIPOLES forecasting model (Kupiszewski \& Kupiszewska I998; Kupiszewska \& Kupiszewski 2005), with fairly standard assumptions on key demographic variables: fertility and mortality (Bijak 2004). As a result, it appears that although higher immigration generally contributes to maintaining the population size, it does not stop or reverse the ageing processes. A summary of the basic forecast results is presented in table 7.3, showing countryspecific changes in population size and in old-age dependency ratio (ODR, calculated as a ratio of population aged 65 years or more to the population of the age of fifteen to 64 years) between 2002 and 2052 . For the end of the forecast span (2052), the impact of three different scenarios of international migration is shown. It can clearly be seen 

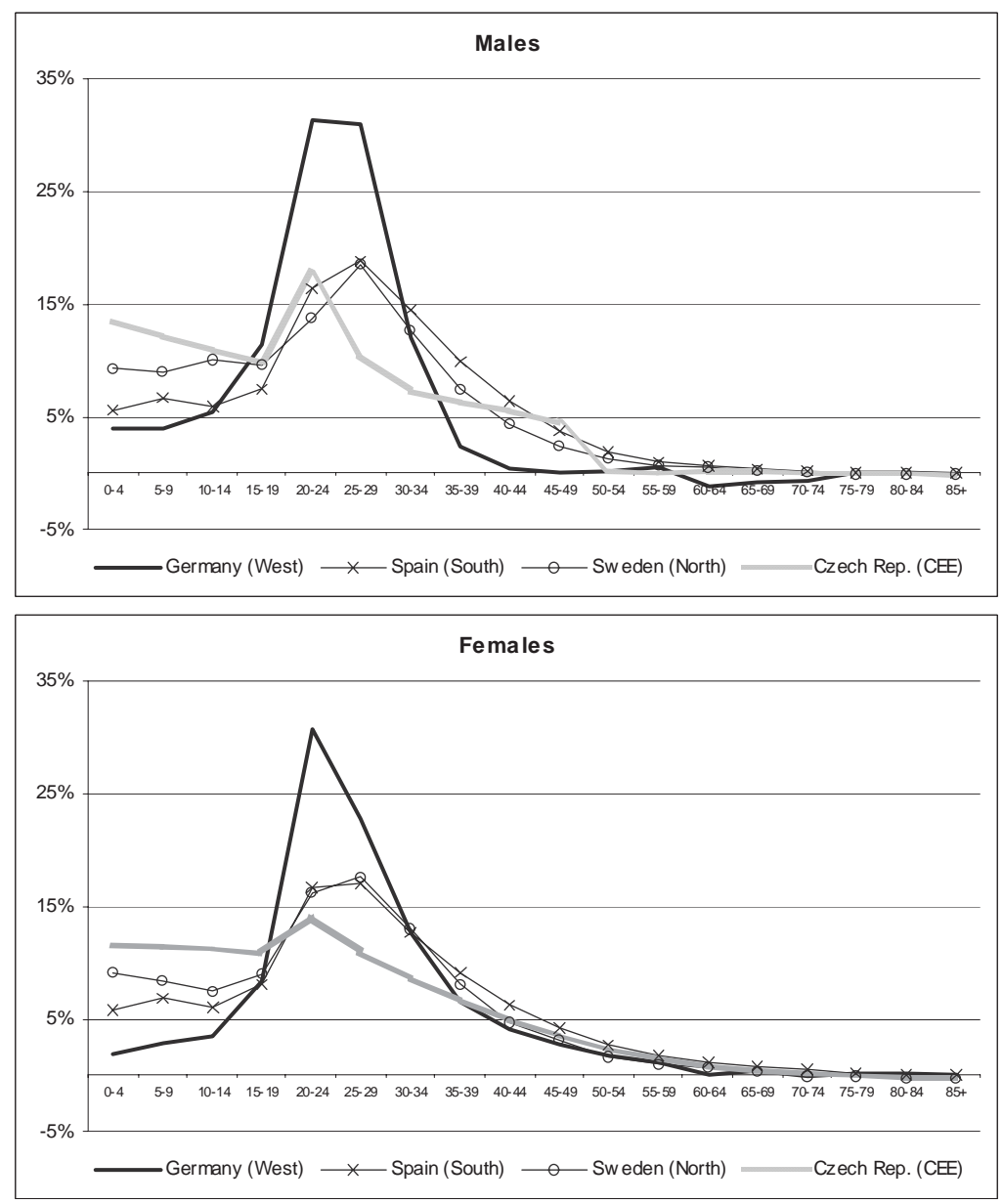

Figure 7.2 Age schedules of net 'external' migration, fractions of the total Note: negative numbers indicate age-specific migration in opposite direction than the total Source: Eurostat / NewCronos, own calculations

that for all the countries under study, although hardly any change in the overall population size is forecasted under the base migration scenario, the average ODR nearly doubles from 0.24 in 2002 to 0.55 by 2052.

It is worth noting that the expected contribution of post-2002 migrants to the population size of all countries in the study forecast for 2052 is very substantial. In comparison with the base scenario, a simulation using a zero-migration assumption yields a forecast overall population size of the 27 countries that is smaller by 80.4 million people in 


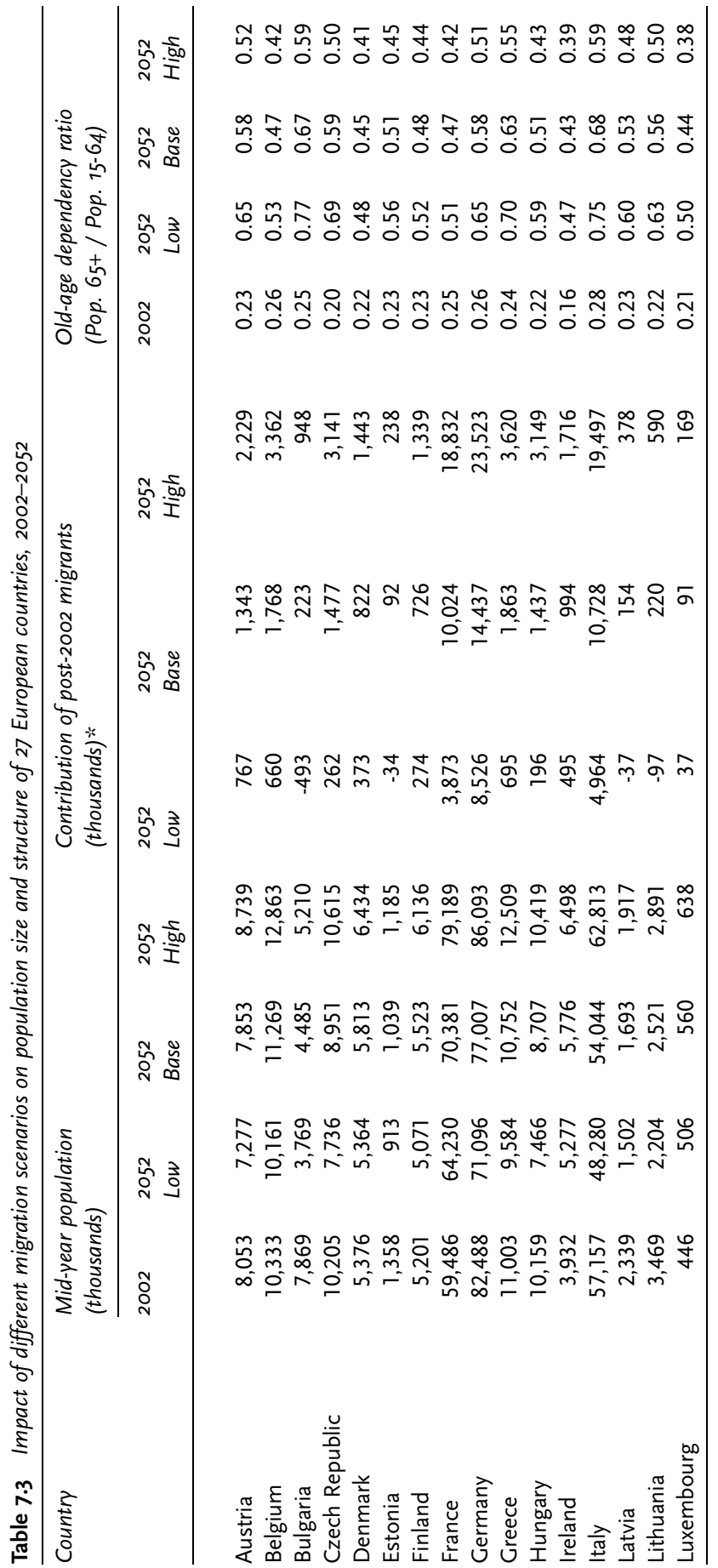




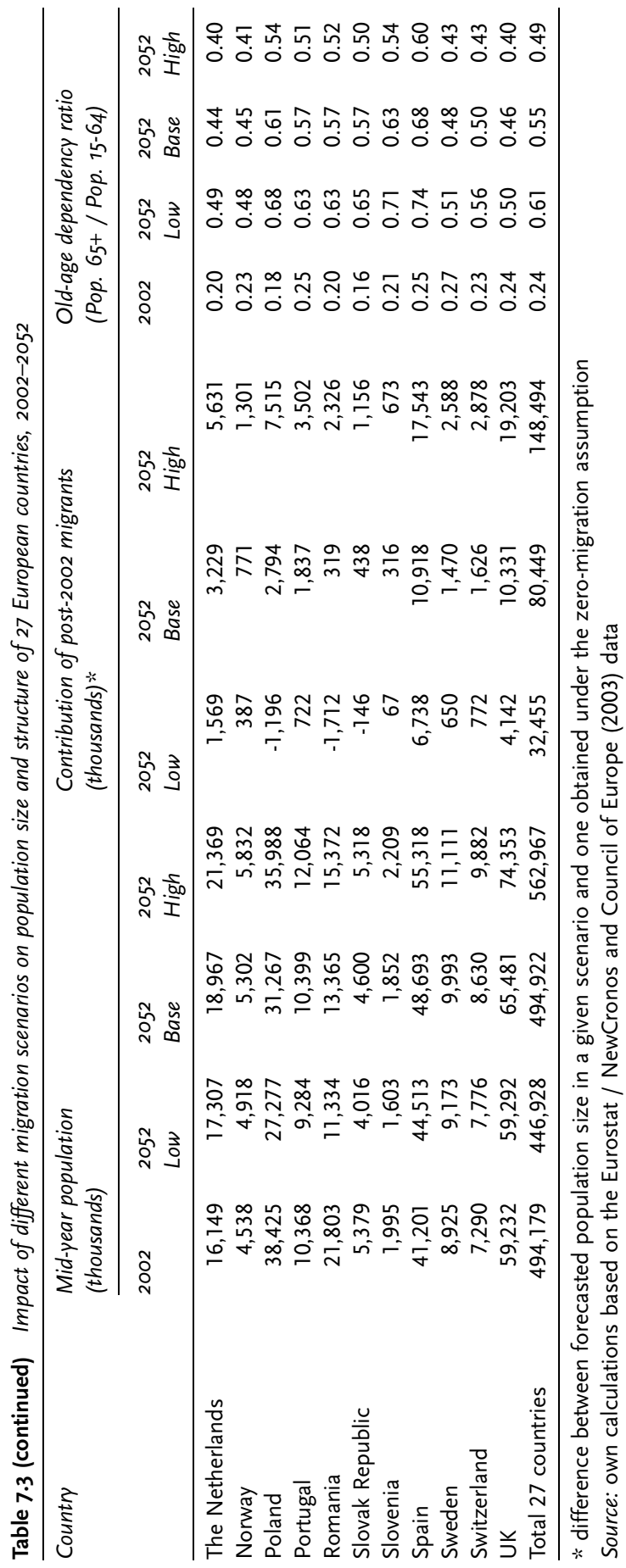


2052 (table 7.3). The contribution of migrants to the overall population size of the 27 countries totals in the low and high variants 32.5 and I48.5 million people, respectively, over five decades. Especially in the countries with assumed low fertility levels (Southern Europe, Central and South-Eastern Europe, German-speaking countries; details in Bijak 2004), the impact of international migration on overall population dynamics is thus clearly visible.

A comprehensive discussion of the results of population and labour force forecasts and simulations summarised above, as well as their implication for the population and social policymaking are presented in Bijak et al. (2005) and Bijak et al. (2006).

\subsection{Summary and conclusions}

Forecasting international migration is a very difficult task, due to the high level of uncertainty associated with this phenomenon. As migration is highly sensitive to two unpredictable factors, migration policies and political developments, the results of the forecasts are usually uncertain. Therefore, we created and quantified the knowledge-based scenarios, applying a methodology widely used in demographic forecasting, in order to accommodate the possible impact of economic factors and migration policies. Still, we did not consider the consequences of possible future political disruptions, in particular, armed conflicts.

The presented analysis assumes that the increase of emigration from new EU member and accession countries to Western Europe is going to be temporary and thus in the long run a declining trend of this phenomenon can be anticipated. To a lesser extent, an increase of population movements in the opposite direction can also be expected. In the long run, the stabilisation of intra-European migratory phenomena is envisaged, with an increasing impact of migration from outside Europe as the whole continent is expected to become more and more attractive to immigrants from less-developed regions of the world. Notably, this will increasingly be the case for Central and South-Eastern European countries, being both migration destinations and possible ways of transit to the West.

It is expected that in the base scenario all new EU members will eventually become immigration countries by 2020 , except for Bulgaria and Romania, for which net migration is envisaged to remain negative throughout the forecast period. In the high scenario, the change of the dominant direction of migration flows is expected to happen earlier, and to include the two Eastern Balkan EU accession countries. In the low scenario, negative net migration is expected to prevail in all Central 
and South-Eastern European countries but the Czech Republic, Hungary and Slovenia.

Coleman (I992) observed that the need for immigration in the developed countries in the context of population ageing is usually motivated by three main factors: a need for care of the elderly; a mismatch between demand and supply of labour in domestic labour markets; and a need to rejuvenate working populations, which is beneficial for productivity. Although international migration may be helpful in filling labour force shortages in certain sectors of the economy, it does not seem to be the solution for sustaining, for example, the pension systems, given the decline of the labour force and of cohorts of working age. Summing up, in none of the scenarios presented above, under fairly standard demographic assumptions for the future, is international migration going to offset the demographic impact of population ageing.

\section{Notes}

I The views presented in this article are the ones of the authors and do not necessarily reflect the opinions of the founding organisations of the CEFMR. This study has been prepared within the framework of the research project 'Impact of international migration on population dynamics and labour force resources in Europe', financed by the Foundation for Population, Migration and Environment (BMU-PME) of Zurich. Jakub Bijak gratefully acknowledges the Foundation for Polish Science (FNP) Annual Stipend for Young Scientists received at the time of preparing this study.

2 An extended version of the study is available in Bijak, Kicinger and Kupiszewski (2004) at www.cefmr.pan.pl.

3 Poland until January 2007, Slovenia until May 2006.

4 The following migration scenarios were made according to the politicians' statements available in 2004, when the study was conducted (Bijak et al. 2004). Some of the assumptions became reality, whereas some others turned out be outdated. Nonetheless, the schedule for opening EU labour markets does not significantly affect the migration scenarios in the long run, which is the main focus of the chapter.

\section{References}

Ahlburg, D. A. \& W. Lutz (1998), 'The need to rethink approaches to population forecasts', Population and Development Review 24 (Suppl.): I-I4.

Alvarez-Plata, P., H. Brücker \& B. Siliverstovs (2003), Potential migration from central and Eastern Europe into the EU-15: An update, report for the European Commission, DG Employment and Social Affairs. Berlin: Deutsches Institut für Wirtschaftsforschung.

Bauer, T., \& K. F. Zimmermann (I999), Assessment of possible migration pressure and its labour market impact following EU enlargement to Central and Eastern Europe. Bonn: Institut zur Zukunft der Arbeit, and London: Centre for Economic Policy Research.

BFM [Bundesamt für Migration] (2004), The EU extension and the extension of the Agreement on the Free Movement of Persons. Bern: BFM. <www.bfm.admin.ch>. 
Bijak, J. (2004), Fertility and mortality scenarios for 27 European countries, 2002-2052. CEFMR Working Paper 3/2004. Warsaw: CEFMR.

Bijak, J., A. Kicinger \& M. Kupiszewski (2004), International migration scenarios for 27 European countries, 2002-2052. CEFMR Working Paper 4/2004. Warsaw: CEFMR.

Bijak, J., D. Kupiszewska, M. Kupiszewski \& K. Saczuk (2005), Impact of international migration on population dynamics and labour force resources in Europe, CEFMR Working Paper I/2005. Warsaw: CEFMR.

Bijak, J., D. Kupiszewska, M. Kupiszewski, K. Saczuk \& A. Kicinger (2006), 'Population and labour force projections for 27 European countries, 2002-2052: Impact of international migration on population ageing', European Journal of Population 23 (I): I-3I.

Brücker, H. \& T. Boeri (2000), The impact of Eastern enlargement on employment and labour markets in the EU member states. Berlin: Deutsches Institut für Wirtschafts-forschung, and Milan: Innocenzo Gasparini Institute for Economic Research.

Coleman, D. A. (1992), 'Does Europe need immigrants? Population and work force projections', International Migration Review 26 (98): 4I3-46I.

Council of Europe (2003), Demographic yearbook 2003: Recent demographic developments in Europe. Strasbourg: Council of Europe.

CPB (Centraal Planbureau) (2004), Arbeidsmigratie uit de Midden- en Oost-Europese toetredingslanden. CPB Notitie aan de Ministerie van SZW. The Hague: CPB.

De Beer, J. \& L. van Wissen (eds.) (I999), Europe: One continent, different worlds. Population scenarios for the 21st century. Dordrecht: Kluwer.

Duszczyk, M. (2002), Swobodny przepływ pracowników w negocjacjach o członkostwo Polskiw Unii Europejskiej. Warsaw: Institute of Social Policy, Warsaw University.

European Commission (2004), Free movement for persons: A practical guide for an enlarged European Union. Brussels: European Commission. <europa.eu.int> (as of 30 September 2004).

European Commission (2007), Communication from the Commission to the Council, the European Parliament, the European Economic and Social Committee and the Committee of the Regions: Report on the functioning of the Transitional Arrangements set out in the 2003 Accession Treaty (period 1 May 2004-30 April 2006). COM (2006) 48 final.

European Communities (2002), Agreement between the European Community and its Member States, of the one part, and the Swiss Confederation, of the other, on the free movement of persons, official journal L II4, 30 April.

European Communities (2003a), Act concerning the conditions of accession of the Czech Republic, the Republic of Estonia, the Republic of Cyprus, the Republic of Latvia, the Republic of Lithuania, the Republic of Hungary, the Republic of Malta, the Republic of Poland, the Republic of Slovenia and the Slovak Republic and the adjustments to the Treaties on which the European Union is founded, official journal C 227E, 23 September.

European Communities (2003b), Treaty concerning the accession of the Czech Republic, the Republic of Estonia, the Republic of Cyprus, the Republic of Latvia, the Republic of Lithuania, the Republic of Hungary, the Republic of Malta, the Republic of Poland, the Republic of Slovenia and the Slovak Republic to the European Union, official journal C 227E, 23 September.

European Communities (2005), Treaty concerning the accession of the Republic of Bulgaria and Romania to the European Union, official journal L 157, 2I June.

Fassmann, H. \& Ch. Hintermann (1997), Migrationspotential Ostmitteleuropa, ISR-Forschungsberichte 15. Vienna: Institut für Stadt-und Regionalforschung.

Fertig, M. (1999), Potential migration from the East to Germany: Time series analysis and scenario. Background report. Heidelberg: Mimeo.

Fertig, M. \& C. M. Schmidt (2000), Aggregate-level migration studies as a tool for forecasting future migration streams, IZA Discussion Paper I83. Bonn: Institut zur Zukunft der Arbeit. 
Franzmeyer, F. \& H. Brücker (1997), Europäische Union: Osterweiterung und Arbeits-kräftemigration, DIW Wochenbericht 5/97, 89-96. Berlin: Deutsches Institut für Wirtschafts-forschung.

Hille, W. \& T. Straubhaar (200I), 'The impact of EU-enlargement on migration movements and economic integration, results and recent studies', in OECD, Migration policies and EU enlargement. The case of Central and Eastern Europe, 79-IOO. Paris: OECD.

Home Office (2004), Accession monitoring report, May-September 2004. London: Home Office.

INED (Institut National d'Études Démographiques) (I999), Statistiques des flux d’immigration en France. Année 1999. Paris: INED.

Kupiszewska, D. \& M. Kupiszewski (2005), A revision of traditional multiregional model to better capture international migration: The MULTIPOLES model and its application, CEFMR Working Paper 10/2005. Warsaw: CEFMR.

Kupiszewski, M. (2002a), Modelowanie dynamiki przemian ludności w warunkach wzrostu znaczenia migracji międzynarodowych. Warsaw: Institute of Geography and Spatial Organization, Polish Academy of Sciences.

Kupiszewski, M. (2002 b), 'How trustworthy are forecasts of international migration between Poland and the European Union?', Journal of Ethnic and Migration Studies 28 (4): 627-645.

Kupiszewski, M. \& D. Kupiszewska (I998), 'Projection of Central and East European populations. Models, data, preliminary results', in J. Fleischhacker \& R. Münz (eds.), Gesellschaft und Bevölkerung in Mittel-und Osteuropa im Umbruch, 22-40, Demographie Aktuell I3. Berlin: Humboldt Universität.

Layard, R., O. Blanchard, R. Dornbusch \& P. Krugman (1992), East-West migration: The alternatives. Cambridge, MA/London: MIT Press.

Lundborg, P. (1998), 'The free movement of labour between Sweden and the new EU members', in A bigger and better Europe? Final report. Stockholm: Committee on the Economic Effects of EU Enlargement.

Orłowski, W. M. (2000), 'Migration from Central and Eastern European countries after the accession: Effects for regions, labour markets, and social security systems'. Research Bulletin 2 (9): 7-2I. Warsaw: Central Statistical Office.

Orłowski, W. M. \& L. Zienkowski (1998), 'Skala potencjalnych emigracji z Polski po przystąpieniu do Unii Europejskiej: próba prognozy', in P. Korcelli (ed.), Przemiany w zakresie migracji ludności jako konsekwencja przystapienia Polski do Unii Europejskiej, 55-66.Warsaw: Committee of the Spatial Organization, Polish Academy of Sciences, Bulletin no. I84.

Salt, J., J. A. Clarke, S. Schmidt, J. Hogarth, P. J. Densham \& P. Compton (I999), Assessment of possible migration pressure and its labour market impact following EU enlargement to Central and Eastern Europe. Final report. London: Migration Research Unit, University College London.

Sinn, H.W., G. Flaig, M. Werding, S. Munz, N. Duell \& H. Hofmann (200I), EU-Erweiterung und Arbeitskräftemigration, Wege zu einer schrittweisen Annäherung der Arbeitsmärkte. Munich: IFO-Institut für Wirtschaftsforschung. 



\title{
8 Foreign immigration in Southern European receiving countries: New evidence from national data sources
}

\author{
Alessio Cangiano and Salvatore Strozza
}

\subsection{Introduction}

The measurement of both the dimensions and main features of the foreign population in Southern European host countries (Italy, Spain, Greece and Portugal) is not an easy task. In addition to the typical problems of statistics on migration flows and migrant population stocks, the presence of a sizeable and dynamic irregular component is a major hindrance. Even for the estimation of the legal presence, administrative sources are often not exhaustive, either because they capture different subsets of the whole universe of regular foreigners (as in the case of Italy) or because of very restrictive immigration policies preventing migrants from keeping legal status for long (Greece).

Moving within this context, this work sets out to highlight some new evidence on the recent evolution of foreign populations in Southern Europe. ${ }^{1}$ The approach is based on the comparison and integration of several data sources, jointly used to draw the quantitative evolution of the stock of foreigners living in the four countries in the last ten to fifteen years. Although the bulk of the analysis is focused on regular foreign presence, data from the periodic regularisation programmes are also used to stress the role of illegal migration and to emphasise the impact of such policies on the size and characteristics of the foreign population.

A strong focus of this paper is on the changes in the geographical origins of recent immigrants. Some patterns shared by all Southern European countries as well as some features specific to national contexts are pointed out. By analysing the changing structures by nationality, we try to understand how the role of the Southern European host countries has changed in the European migration scenario, making them increasingly attractive destinations especially for migrants leaving Latin America, Eastern Europe and the Balkans. 


\subsection{From national data sources to the measurement of the stock of foreigners}

In this section, the evolution of the foreign population in Southern European host countries from the beginning of the I99os is reconstructed. The most recent trends are considered with particular attention. Since the different national data sources capture diverse subsets of the foreign population and are characterised by a variable quality of registrations, our approach strives to draw a picture as comprehensive as possible by comparing and integrating the available information.

\subsubsection{Italy}

To trace the evolution of the foreign population in Italy, three main sources of data are available:

- Permits to stay, which provide reliable information on the stock of legal foreigners aged eighteen and over since the National Statistical Institute (Istat) annually revises the figures issued by the Ministry of the Interior. Minors are underestimated by this source since those depending on their parents are not granted their own permits.

- Population register (anagrafe), in which usual residents are recorded. The main advantage of this source is that minors are enumerated. As far as the adult population is concerned, foreigners recorded in the population register can be roughly considered as a subset of documented foreigners because holding a permit to stay is a precondition for registration in a municipality. However, this source is possibly affected by problems of overestimation, especially because migrants do not always de-register when they leave the country.

- Censuses, which provide the most detailed information on the whole population at the beginning of every decade. Census data can be biased especially because of the well-known problems of under-coverage. Foreigners are more likely than nationals to escape census registration, particularly if they are residing or working illegally.

In Italy, migratory inflows from non-EU countries became important in the late ig8os. Since then, the evolution of the legal foreign population has been strongly affected by the chronology of the regularisation programmes. Following the first two regularisations carried out in I986 and I990, the number of valid permits to stay in I99I was already above 600,000 (see figure 8.I). The I99I census managed to count only the most 'visible' part of the resident immigrant population. After a moderate increase in the early I990s, more than 250,000 applications were presented at the I995 regularisation. A similar situation 


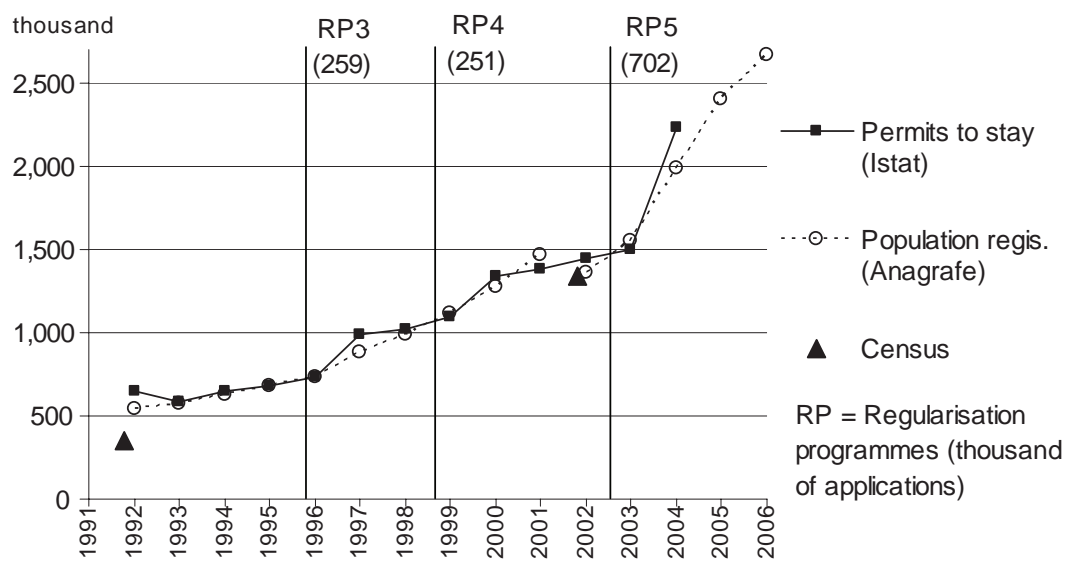

Figure 8.1 Foreign population in Italy according to different sources, 1991-2006 (absolute values in thousands at the beginning of the year)

occurred three years later, with another 253,000 applications for the fourth regularisation programme and the subsequent increase in permits to stay. This trend is also reflected by municipal register records although this line is smoother - and by the 200I census, which this time probably succeeded in counting at least the usual foreign residents (over I. 3 million). However, the real turning point in the dimension of the legal foreign population in Italy has taken place with the most recent regularisation programme, which followed a new immigration law enacted in 2002. More than 700,000 applications were submitted and about 647,000 new permits were issued, implying a 50 per cent increase in the number of legal foreign residents. By I January 2004 , the number of valid permits to stay were 2.2 million.

The striking results of the 2002 regularisation confirmed that over the last decade only a few migrants entered Italy holding a permit to stay, owing to a very restrictive quota system. The prevailing role of migrations occurring outside the official channels can be shown by comparing the cumulative number of new permits issued as a consequence of the 1995, 1998 and 2002 regularisations (I.I million) with the growth of valid permits to stay between I99I and 2004 (I.5 million). This comparison is, of course, only indicative - since some migrants may have availed themselves of more than one regularisation scheme ${ }^{2}$ and no figures on returns are available - but the result is so clear-cut as to be unquestionable.

Even referring to a different subset of the foreign population (i.e. only those who registered with their local municipality, but including minors) the stock of foreign residents reflects the evolution of the 
number of permits to stay - with a smoother trend due to the fact that registration with the municipality is not compulsory and takes a longer period than the issue of a permit to stay. The decrease observed in $200 \mathrm{I}$ is mainly due to the revision of the municipal records that followed the census operations.

According to recent figures issued by Istat, the number of foreigners recorded in the population register reached 2.7 million by I January 2006 , more than 585,000 of whom were less than eighteen years old. After the dramatic increase that occurred as a consequence of the 2002 regularisation, foreign residents are continuing to grow in number, especially because of an increasingly high number of births (over 50,000 in 2005) and of more generous quotas for legal entry. Combining the information on permit to stay holders with that on minors registered in the anagrafe one can easily assume that the whole number of foreigners with a legal status comes to more than 2.8 million people.

\subsubsection{Spain}

For Spain, too, there are three main sources that enable us to draw the evolution of the foreign population: the I991 and 2001 censuses, the register of foreigners legally resident in Spain elaborated from the files supplied by Ministry of the Interior (permits to stay) and the population register (Padron Municipal), of which statistical exploitation has been handled since I996 by the Spanish National Statistics Institute (INE). Unlike Italy, the possession of a permit to stay is not necessary for registration in the municipal register. Even irregular migrants must register - and they are likely to do so because registration allows them to take advantage of some welfare benefits (health, education). Therefore, this source should record the whole foreign population living in Spain and enable us to obtain estimates of the number of undocumented immigrants from the difference with the stock of legal residents. However, the number of foreigners recorded in the municipal registers (Empadronados) could be slightly overestimated because of the administrative nature of this source - municipalities have interest in swelling their populations to raise more funds - and because of the high mobility of foreigners, especially of recent immigrants.

The number of legal foreigners in Spain started to increase in the mid-I980s, when a first regularisation programme took place. After the second amnesty in I99I, with more than II0,000 immigrants applying for legal status, we observe a more or less constant growth of the permits to stay - the trend being much smoother than for Italy (figure 8.2). As a matter of fact, from I994 to I999 (excluding I996) a separate quota system for foreigners already working illegally in the country served basically as a de facto permanent regularisation (Rey- 


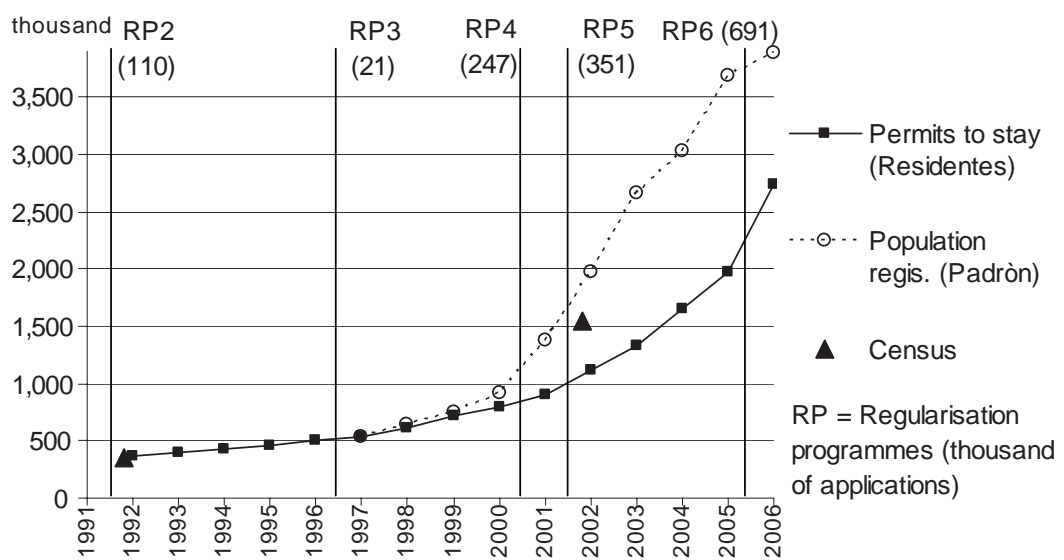

Figure 8.2 Foreign population in Spain according to different sources, 1991-2006 (absolute values in thousands at the beginning of the year)

neri 2003). Despite substantial success in reducing illegal presence in this period, the number of migrants not holding a valid residence authorisation increased significantly by the end of the decade. Thus, as of January 2000, when a new immigration act was passed providing for another regularisation scheme, almost 250,000 people applied. Even greater $(35 \mathrm{I}, 000)$ was the number of applications presented in 200I during the fifth amnesty, in which employment as well as strong social ties with Spain had to be proved. These two campaigns marked the beginning of a sustained growth in the stock of legal foreign residents. Consistent with this trend, the 200I census recorded more than I.5 million foreign nationals - 300-400,000 of whom were probably undocumented. The series of data obtained from the Padròn Municipal shows an even more pronounced growth in the overall foreign population since the beginning of the decade.

Despite the considerable participation in the 2000 and 200I regularisation programmes, massive unauthorised migration flows gave rise to the formation of a new huge pool of undocumented foreign residents. The difference between empadronados and permits to stay came to I.7 million on I January 2005. Leaving aside minors and the citizens of other industrialised countries, the presence of I.2 million undocumented immigrants could be assumed (Arango \& Jachimowicz 2005). Hence, the need to reduce the pool of irregularity to a more manageable number led to a new regularisation programme, for which applications could be submitted from 7 February to 7 May 2005. Intended only for workers who had been residing in Spain at least since August 2004 and with a job offer for at least six months, the programme at- 
tracted more than 690,000 applications, almost equalling the Italian 'big regularisation'. Considering that the programme requirements left out a significant proportion of undocumented residents - children, spouses, students, the self-employed and other ineligible workers - this figure is substantially coherent with the estimated illegal presence before the implementation of the procedure. As a result of this new amnesty the stock of legal foreigners has undergone a further sudden rise reaching 2.7 million as of I January 2006. According to the most recent figures the difference between empadronados and permit holders has now decreased but is still high (I.I million).

In conclusion, even more than in Italy, the size of the immigrant population living in Spain has increased dramatically over a very short time period. Until the mid-I99os some half a million foreigners resided legally in the country, while only ten years later this number had multiplied by five. As we shall see below, such a large increase occurred with marked consequences on the structure by nationality of the foreign population.

\subsubsection{Portugal}

Like for Italy and Spain, information on the dimensions and features of the foreign population in Portugal can be obtained both from demographic sources (censuses) and from administrative data. Census statistics on foreigners basically suffer from the usual problems affecting such data - in particular the likely under-registration of people not entitled to the right to reside in the country. However, it is worth mentioning that the Portuguese Statistical Institute (INE) adopted a restrictive definition of the status of resident, including only foreigners who had been living in Portugal for at least one year (Rosa, Seabra \& Santos 2003).

As far as regular foreigners are concerned, two different sorts of legal status are currently allowed by the authority in charge (Serviço de Estrangeiros e Fronteiras -SEF): the permit to stay (autorização de residência - AR) and the 'permanence' permit (autorização de permanência - AP). The latter was introduced in January 200I, creating a new category of legal temporary worker. The main requirement that applicants had to fulfil was to prove availability of a work contract. In practice, this new law prompted a policy of direct labour recruitment, the new permits being a sort of labour visa obtained at destination (Peixoto 2002). This new status was conferred for one year, with the possibility of renewal for the next four years before applying for permanent residence. The law was repealed in February 2003.

On the basis of the I99I census data and on the number of permits to stay - at that time the only administrative condition for legal foreign- 
ers - the size of the foreign population at the beginning of the past decade can be estimated at around IIO-I20,000 people (figure 8.3). Apart from some 40,000 other European nationals, foreign residents living in Portugal at that time were basically people who moved from the former colonies as a consequence of the economic and political instability following the process of decolonisation. As a matter of fact, in the mid-I970s alongside the retornados - people born in Portugal and their descendants, who were automatically granted Portuguese citizenship - a number of Africans, especially from Cape Verde and Angola, moved to Portugal and established important migratory chains (Malheiros 2002).

After joining the European Union (I986) Portugal became more attractive for non-EU migrants both as a destination and as a transit country. The origins of people arriving in Portugal from overseas became more varied. As a result of the growing inflows of African and, to a lesser extent, Brazilian migrants, the stock of foreign residents started to increase. The Portuguese government soon realised that a significant part of the phenomenon was occurring through illegal channels and implemented its first regularisation programme (I992). Almost 40,000 undocumented foreigners legalised their status under the programme, 72 per cent of them coming from the PALOP states (African Countries with Portuguese as the Official Language) (Rosa, De Seabra \& Santos 2003). A second regularisation was carried out in I996, with 35,000 applicants (6I per cent from the PALOP countries). Given the considerable bureaucratic delays that affected both procedures, their impact on the size of the legal foreign population is observable only some years later (figure 8.3). The 200I census substantially confirmed the significant increase in immigrants, recording 233,000

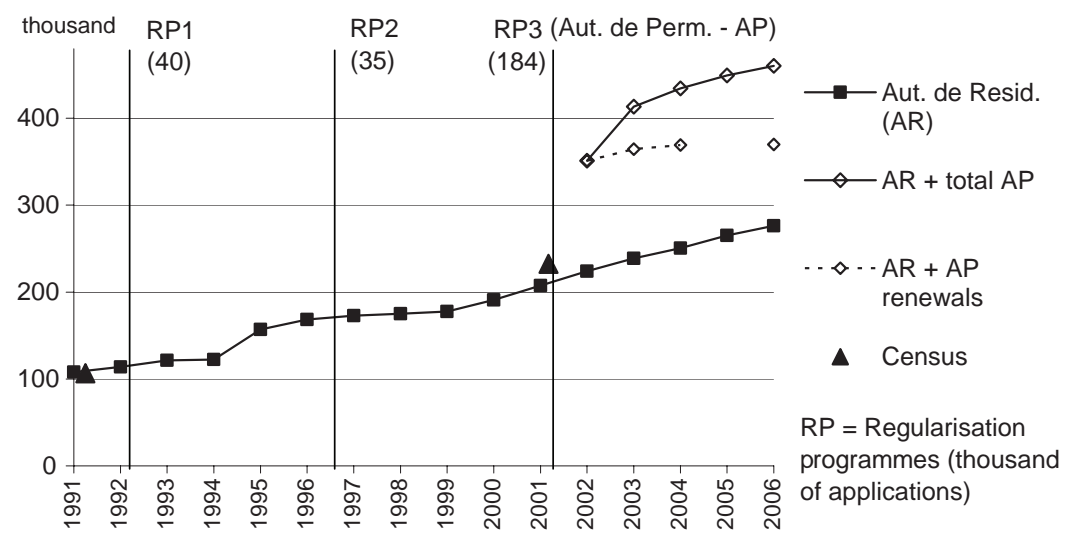

Figure 8.3 Foreign population in Portugal according to different sources, 1991-2006 (absolute values in thousands at the beginning of the year) 
foreign nationals - a figure that in all probability underestimated the actual amount of foreigners. ${ }^{3}$

An important turning point in the size of the recorded immigrant population in Portugal has been the $200 \mathrm{I}-2003$ programme, which granted a temporary legal status (permanence permit) to undocumented foreigners already working in the country. The opportunity for migrant workers to regularise their status whenever engaged by an employer had the explicit purpose of allowing them to fulfil the specific needs of some economic sectors or local labour markets (Peixoto 2002). Almost 184,000 permits were issued during this period, ${ }^{4}$ the majority of them to Ukrainians $(64,300)$ and Brazilians $(37,700)$.

Since statistics on the autorização de permanência only record the flow of permits issued or renewed in a calendar year and not the stock of permits valid at a given date, we cannot determine the total amount of foreigners legally residing in the country - i.e. with either a residence or a permanence permit - after 200I. A range within which this amount should fall can be obtained adding to the stock of valid autori$z a c ̧ a \tilde{o}$ de residência either the total amount of permanence permits issued during the regularisation ('AR + total AP' in figure 8.3) or the number of permanence permits renewed in a given year ('AR + AP renewals' in figure 8.3). The former operation is a maximum estimate since it assumes that all people granted a permanence permit were still legally residing in the country in a given year. The latter is a minimum estimate because only people who renewed their AP in that year are counted. ${ }^{5}$ Both estimates are to some extent unreliable: the former because some people who regularised through the AP scheme might have left the country or fallen back into a condition of irregularity, the latter because of administrative delays. ${ }^{6}$ Given this premise, we can plausibly assume that the number of legal foreign residents in Portugal on 1 January 2006 ranged from 370 to 460,000 (figure 8.3).

\subsubsection{Greece}

Migration statistics in Greece are particularly poor and often unreliable. In the early I990s, when both policymakers and society became aware of the massive number of migrants entering Greece from neighbouring countries, an adverse attitude towards the new phenomenon led to the enactment of a very restrictive immigration law making little provision for legal entries and stays. Therefore, permits to stay are unsuitable for drawing the evolution of the foreign population living in Greece during the I990s because documented migrants were only a minority and because most granted authorisations were of short duration and were affected by bureaucratic inefficiencies. Information on migrants in Greece is then provided mainly by censuses and regulari- 
sation data (Duquenne \& Kaklamani 2004). Besides, data comparability is often hindered by discrepancy in definitions - mainly because ethnic Greeks are classified in different ways. ${ }^{7}$

Although there had been a small number of immigrants in Greece throughout the I980s, the phenomenon became significant only after the collapse of Albania's communist government. The size of the initial mass immigration from I99I onwards is largely unknown. The I99I census registered 167,000 foreigners in a total population of 10.26 million - although it probably under-recorded the foreign residents, finding only EU nationals and those with legal status. Similarly, foreigners with a valid permit to stay in the early I990s numbered 250,000, but 60,000 of them were ethnic Greeks and another 80,000 were EU or North American citizens, so that 'real' authorisations came to only I00,000. Figures for the middle of the I990s even display a decrease of legal residents (figure 8.4), confirming the unreliability of this source in measuring a phenomenon that was rapidly expanding despite the efforts of the governments in charge to limit its impact. ${ }^{8}$

By the mid-I990s it became clear that a large number of immigrants were residing illegally in Greece. Thus, in 1998 the Greek government adopted its first regularisation programme. Over 370,000 non-EU citizens - 65 per cent of whom were Albanian - applied for and received a certificate (the 'white card') entitling them to reside legally in Greece for some months. ${ }^{9}$ Applications were processed very slowly, so that by February 2000 only 107,000 cards had been awarded (Fakiolas 2003). Ultimately over 90 per cent of applications were approved, but most of them were issued late and for one year only. Also, the renewal acceptance rate was only 54 per cent (Baldwin-Edwards 2004a). Even after the

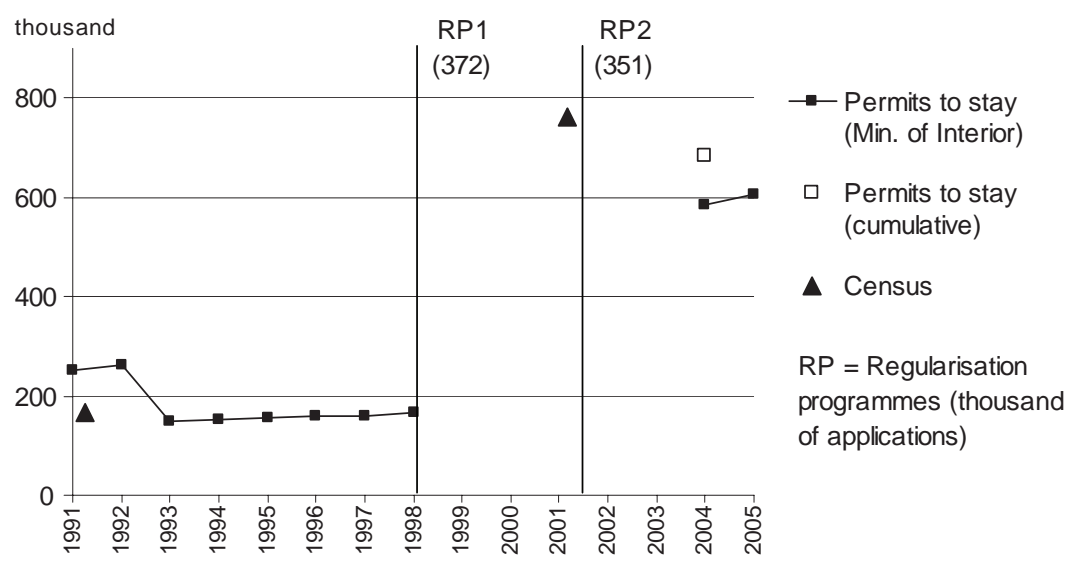

Figure 8.4 Foreign population in Greece according to different sources, 1991-2005 (absolute values in thousands at the beginning of the year) 
regularisation, no statistics on the number of valid permits were issued by the authority in charge of the process (OAED, Greek Manpower Employment Organisation, a branch of the Ministry of Labour). However, it is likely that in addition to the unauthorised immigrants who applied for legal status, there were approximately another 200,000-250,000 illegal residents who did not apply (Cavounidis 2002). Therefore, the overall foreign presence at the time of the 1998 regularisation could be estimated at more than 600,000 people.

The first reliable information on the actual dimensions of the foreign population in Greece was provided by the 200 I census. Thanks to advertising campaigns and public assurances of the confidentiality of the data, the Statistical Service substantially succeeded in recording the immigrant population (legal and undocumented): 762,000 'usual' residents with non-Greek citizenship were found. According to some recent estimates, I50,000-200,000 ethnic Greeks from Russia, Turkey and Albania - who were recorded as Greek nationals - and some I००,००० people not participating in the census should be added to the recorded foreigners to complete the foreign population (Baldwin-Edwards $2004 \mathrm{~b}$ ). Important information was provided by the self-declared length of stay: almost half of the foreigners declared they have been residing for at least five years.

In 200I, the need for an actual immigration policy - rather than the exclusionary approach of the I99I law - led to the enactment of a new immigration act with a last minute amendment for a new regularisation procedure ('Green Card II'). The 200I regularisation was similar to the previous one, the only difference being that the work permit became a prerequisite for obtaining a permit to stay. Over 350,000 immigrants applied to OAED, but only 220,000 met the eligibility criteria. Even this time, no data on the permits to stay issued by the procedure were made available.

Recent estimates and data indicate a further increase of the immigrant population in the period following the census. Baldwin-Edwards $(2004 \mathrm{~b})$ - using the cumulative number of permits to stay issued in 2003 and early $2004(683,000$, see figure 8.4) and adding the number of schoolchildren, EU nationals and a conservative estimate of the illegal stock - estimates a total of 950,000 foreign residents in 2004 (excluding ethnic Greeks with homogeneis cards). Finally, the Greek statistical office started to produce official statistics on the legal foreign population based on the permits to stay issued by the Ministry of Interior and by the Ministry of Public Order (for EU citizens). Minors are meant to be included in these statistics. Apart from the substantial under-coverage of EU nationals - Cypriots in particular - who may not need a permit to stay - if they do not work, for example - and the obvious non-registration of undocumented migrants, these data seem to 
be consistent with the census figures, recording 604,000 legal foreigners at I January 2005 .

\subsubsection{The role of Southern Europe in the European migration scenario}

In order to understand whether and to what extent this considerable increase in the foreign population in Southern Europe mirrors a growing power of attraction of these countries within the European migration scenario, table 8.I compares the stock of foreign residents in Italy, Spain, Portugal and Greece and in the rest of the EU-I5 over a fifteenyear period. When we look at these figures it must be borne in mind that in most Northern and Western European countries a significant number of foreigners acquired the host country's nationality, 'disappearing' from the statistics based on citizenship. While in Southern Europe there is still a large overlap between the foreign and the migrant populations, this is not the case in the rest of the EU-I5. ${ }^{10}$ This important difference needs to be taken into account not to overestimate the magnitude of our results.

Over the last fifteen years, the foreign population in Southern Europe has increased by 5.7 million people, which is over half the total growth observed in the EU-I5 (IO.I million). In relative terms the number of foreigners living in New Immigration Countries (NICs) in 2006 is almost six times that found in I99I, while in the rest of the EU-I5 it has risen by only a third. The largest increase is found in Spain (2.4 million) and in Italy (2.3 million). ${ }^{11}$

Table 8.1 Foreign population in Southern Europe and in the rest of the EU-15 in 1991 and 2006 (absolute values and variations in thousands, percentages of total population and percentages of all foreigners living in the EU-15)

\begin{tabular}{|c|c|c|c|c|c|c|c|c|}
\hline \multirow[t]{2}{*}{$\begin{array}{l}\text { Countries } \\
\text { and areas }\end{array}$} & \multicolumn{2}{|c|}{$\begin{array}{l}\text { Foreign } \\
\text { population }\end{array}$} & \multicolumn{2}{|c|}{$\begin{array}{l}\text { Increase } \\
1991-2006\end{array}$} & \multicolumn{2}{|c|}{$\begin{array}{l}\% \text { of total } \\
\text { population }\end{array}$} & \multicolumn{2}{|c|}{$\begin{array}{l}\% \text { of foreigners in } \\
E U-15\end{array}$} \\
\hline & 1991 & 2006 & $\begin{array}{l}\text { Abso- } \\
\text { lute } \\
\text { values }\end{array}$ & $\begin{array}{l}\text { Ind. } \\
\text { num. } \\
\text { (1991= } \\
100)\end{array}$ & 1991 & 2006 & 1991 & 2006 \\
\hline Italy & 356 & 2,671 & 2,315 & 750 & 0.6 & 4.5 & 2.5 & 11.0 \\
\hline Spain & 361 & 2,739 & 2,378 & 759 & 0.9 & 6.2 & 2.5 & 11.2 \\
\hline Greece $^{b}$ & 167 & 950 & 783 & 569 & 1.6 & 8.6 & 1.2 & 3.9 \\
\hline Portugal & 107 & 370 & 263 & 347 & 1.1 & 3.5 & 0.7 & 1.5 \\
\hline \multicolumn{9}{|l|}{ Total Southern } \\
\hline Europe $^{a}$ & 990 & 6,729 & 5,739 & 680 & 0.9 & 5.4 & 6.9 & 27.6 \\
\hline Rest of EU-15 & 13,285 & 17,617 & 4,332 & 133 & 5.6 & 7.2 & 93.1 & 72.4 \\
\hline
\end{tabular}

Notes: (a) Italy, Spain Greece and Portugal; (b) 2006 data are Eurostat estimates referred to 2004

Sources: own elaboration on national statistical data 
The consequences of this considerable growth are mirrored in the rising weight of the foreign population in Southern Europe both on the host country populations and within the overall number of foreigners living in the EU-I5. As a matter of fact, the percentage of foreigners out of the total population of Southern European countries has substantially increased over the last fifteen years (from 0.9 per cent to 5.4 per cent), though remaining lower than the average in the rest of the EU-I5 (7.2 per cent) in all NICs but Greece (8.6 per cent). Nowadays, over one in four ( 28 per cent) foreign nationals residing in the EU-I5 live either in Italy, Spain, Greece or Portugal - this share was only 7 per cent in I99I. Despite the limits discussed above, these figures clearly show the growing importance of Southern Europe as a destination area in the European migration system. The increasing power of attraction of the NICs is confirmed by the statistics on migration flows (Salt 2006).

\subsection{New countries of origin: from South-North to East-West migration}

\subsubsection{Foreigners in Italy: from North Africans to Central and Eastern Europeans}

Over the last four or five years, the considerable increase in the foreign population in Italy (from I.34 to 2.67 million) ${ }^{12}$ has concerned only migrants coming from developing countries and from Central and Eastern Europe, producing a notable variation in the foreign population structure by nationality (table 8.2). The increase in Africans, from both the Mediterranean coast and the sub-Saharan region, has been lower than the average total growth; in fact, despite an increase of 220,000 people, their share in the foreign population has decreased from 29 per cent to 26 per cent. In particular, the proportion of migrants coming from the Mediterranean coast - who represent the largest and more established African groups - has decreased from 20.1 per cent to 18.2 per cent. Moroccans, although increasing by 140,000 units, have lost their over ten years of supremacy, being outnumbered by Albanians and almost equalled by Romanians. Between the 2001 census and the beginning of 2006, Asians have grown from 210,000 to a little under 450,0000 (16.7 per cent of the overall foreign population) with an absolute increase (about 240,000) that is surpassed only by that of Eastern Europeans. The Filipino community, one of the first groups settling in Italy (earliest arrivals date back to the end of the 1970s), has been outnumbered by the Chinese community: between 2001 and 2006 the number of Chinese immigrants has almost tripled (from 47,000 to 128,000, 5 per cent of foreigners). Migration from the Indian subcontinent has also grown 
Table 8.2 Usual foreign residents by area and main countries of citizenship. Italy, 21 October 2001 and 1 January 2006 (absolute values and differences in thousands, percentages and index numbers [2001=100])

\begin{tabular}{|c|c|c|c|c|c|c|c|}
\hline \multirow{2}{*}{$\begin{array}{l}\text { Area and } \\
\text { countries } \\
\text { of citizenship }\end{array}$} & \multicolumn{3}{|c|}{$\begin{array}{l}\text { Absolute values } \\
\text { (in thousands) }\end{array}$} & \multicolumn{3}{|c|}{$\begin{array}{l}\% \text { by area / country } \\
\text { of citizenship }\end{array}$} & \multirow{2}{*}{$\begin{array}{l}\text { Index numbers } \\
2006 / 2001\end{array}$} \\
\hline & 2001 & 2006 & Difference & 2001 & 2006 & Difference & \\
\hline Total & 1,335 & 2,671 & 1,336 & 100.0 & 100.0 & 100.0 & 200 \\
\hline MDCs & 180 & 184 & 4 & 13.5 & 6.9 & 0.3 & 102 \\
\hline LDCs and CEE & 1,155 & 2,486 & 1,332 & 86.5 & 93.1 & 99.7 & 215 \\
\hline European Union & 132 & 143 & 11 & 9.9 & 5.3 & 0.8 & 108 \\
\hline Other MDCs & 48 & 41 & -7 & 3.6 & 1.5 & $\ldots$ & 86 \\
\hline CEE & 437 & 1,106 & 669 & 32.7 & 41.4 & 50.1 & 253 \\
\hline Northern Africa & 268 & 485 & 217 & 20.1 & 18.2 & 16.3 & 181 \\
\hline Rest of Africa & 119 & 210 & 91 & 8.9 & 7.9 & 6.8 & 177 \\
\hline Asia & 209 & 446 & 238 & 15.6 & 16.7 & 17.8 & 214 \\
\hline Latin America & 122 & 239 & 117 & 9.2 & 8.9 & 8.7 & 196 \\
\hline Albania & 173 & 349 & 176 & 13.0 & 13.1 & 13.2 & 202 \\
\hline Morocco & 180 & 320 & 139 & 13.5 & 12.0 & 10.4 & 177 \\
\hline Romania & 75 & 298 & 223 & 5.6 & 11.1 & 16.7 & 397 \\
\hline China & 47 & 128 & 81 & 3.5 & 4.8 & 6.1 & 273 \\
\hline Ukraine & 9 & 107 & 98 & 0.6 & 4.0 & 7.4 & 1239 \\
\hline The Philippines & 54 & 90 & 36 & 4.0 & 3.4 & 2.7 & 166 \\
\hline Tunisia & 48 & 84 & 36 & 3.6 & 3.1 & 2.7 & 175 \\
\hline Serbia \& Montenegro & 49 & 64 & 15 & 3.7 & 2.4 & 1.1 & 130 \\
\hline
\end{tabular}

Note: (a) More Developed Countries (MDCs) comprise EU15, the other non-former Communist Countries of Europe, North America, Oceania, Israel and Japan; Less Developed Countries (LDCs) include all Africa, Asia (excludes Israel and Japan) and Latin America; Central and Eastern Europe (CEE) includes all European countries of the former Communist bloc; Asia excludes Israel and Japan

Source: elaboration of Istat data from fourteenth population census and from population register

significantly - Indians in particular, followed by Pakistanis and Bangladeshis, but also by the long-established Sinhalese group. Among Latin Americans, the traditional areas of origin (Brazil and Argentina and, since the mid-1990s, Peru) have been outnumbered by Ecuador (from $14,000$ to 62,000$)$.

However, the sending region that contributed most to the spectacular growth in the number of foreigners in Italy is by far Central and Eastern Europe. Although this is not a new phenomenon, ${ }^{13}$ recent trends have marked a significant 'Europeanisation' of the immigrant population in Italy. Comparing the size of these migrant communities as it appeared in the 2001 census and at the beginning of 2006, Central 
and Eastern Europeans have grown from less than 440,000 (32.7 per cent of the total) to 1.1 million (41.4 per cent), with an absolute increase of about 670,000 units - almost half the overall growth of the foreign population over the same period. In absolute terms, the largest increase is recorded for the Romanian community (from 75,000 to over 350,000 residents). However, Ukrainians were the group experiencing the highest growth rate: this community has increased by over 100,000 - they numbered less than 10,000 in 2001 - achieving fifth place in the nationality chart. More in general, there is evidence of migration flows reaching Italy from some former Soviet countries (for example Moldova) that were outside the former East-West migration routes until a few years ago. Migration from Poland - which started in the 1980s due the refugees fleeing Jaruzelski's regime - also increased constantly from the mid-1990s acquiring completely different features in comparison with earlier flows. This huge expansion of the Central and Eastern European presence in the Italian migration scenario seems to be confirmed by recent evaluations of the irregular presence after the 2002 regularisation (Blangiardo \& Tanturri 2006). According to these estimates, referring to mid-2005, migrants from CEE countries represent more than half (precisely 53 per cent) of irregular foreigners currently living in Italy - with Romanians (17 per cent) and Albanians (12 per cent) at the top of the list, a large share of Ukrainians (8 per cent) and a significant irregular presence also from Poland and the nearby Slavic republics (in particular, Serbia and Montenegro and the Former Yugoslavian Republic of Macedonia).

To sum up, two main trends seem to characterise the recent evolution of the foreign population in Italy. The first is a growing diversification of migratory routes, shown by 'new' migrant groups reaching a significant size especially as a consequence of larger inter-continental migration flows. This is a clear sign of the globalisation process that has concerned the European migration system since the rg8os. The second is an equally clear sign that has emerged in recent years: the gradual growth and current supremacy of East-West migratory flows as opposed to South-North ones (Carella \& Pace 200I; Bonifazi \& Strozza 2002), with a consequent 'Europeanisation' of the immigrant population.

\subsubsection{Foreigners in Spain: Latin Americans but also Eastern Europeans}

In Spain international migration flows have also intensified over the past fifteen years. The number of foreigners who held a permit to stay at the beginning of 200I has tripled in five years: from less than 900,000 to over 2.7 million at the beginning of $2006^{14}$ (table 8.3). Stronger migratory flows and the occurrence of new areas of origin 
have also significantly affected the structure by nationality of the foreign population. At the beginning of the 1990s, more than half of legal foreign residents were either EU nationals or came from other economically developed regions (North America, Oceania, Japan, etc.). Nowadays, this share has dropped to 20 per cent - which is in any case higher in comparison with the rest of Southern Europe.

This change of the structure by nationality has been following distinct patterns over time. During the second half of the I990s the increase in legal foreigners was mostly due to the considerable inflows of Moroccans, so that the share of Northern Africans rose significantly (from I5 per cent to 24 per cent between I997 and 200I). From 200I onwards, although the stock of Moroccans has continued to increase by $50-60,000$ per year (more than doubling in five years and reaching nearly 500,000 regular immigrants), their share in the foreign population has been decreasing (table 8.3). Latin America has suddenly become the most important sending region for Spain. Latin Americans have grown from 185,000 to about one million and they now represent over a third of legal foreign nationals. This dramatic growth occurred especially thanks to the massive inflow of Ecuadorians $(326,000$, I8 per cent of the total increase) and Colombians (I80,000, Io per cent of the total increase). The growth of Argentinean, Peruvian and Bolivian communities has also been significant $(66,000,55,000$ and 49,000, respectively).

However, the most important change in the Spanish migration scenario is the beginning and strengthening of migratory flows from Central and Eastern Europe (CEE). The number of CEE nationals has increased by 350,000 people in only five years - nine times larger than at the beginning of $200 \mathrm{I}-$ and they account now for I4.3 per cent of the legal foreign population. Romanians are largely responsible for this growth $(\mathrm{I} 8 \mathrm{I}, 000)$ and are currently the fourth largest foreign group in Spain (I92,000 people, 7 per cent of the total). Bulgarian and Ukrainian communities have also reached considerable sizes $(56,000$ and 50,000 people, respectively). ${ }^{15}$

These figures clearly stress the growing importance of Spain as a major European destination. The economic crisis that troubled several Latin American countries determined a worsening of the population's living conditions in many countries, spurring a number of people to leave Ecuador, Colombia, Argentina, Bolivia, Peru and Venezuela - just to mention the most important areas. The tightening of US immigration policies after 9/II probably contributed to redirecting these flows to Europe (Pellegrino 2004). Linguistic and cultural bonds due to the Spanish colonial past in the region are probably the main factors that explain why Spain has been chosen as a preferred destination - Italy also experienced a rise in Latin American migration but with much 
Table 8.3 Foreigners with permits to stay by area and main countries of citizenship, Spain, 2001 and 2006 (at the beginning of the year absolute values and differences in thousands, percentages and index numbers [2001=100])

\begin{tabular}{|c|c|c|c|c|c|c|c|}
\hline \multirow{2}{*}{$\begin{array}{l}\text { Area and } \\
\text { countries } \\
\text { of citizenship }\end{array}$} & \multicolumn{3}{|c|}{$\begin{array}{l}\text { Absolute values } \\
\text { (in thousands) }\end{array}$} & \multicolumn{3}{|c|}{$\begin{array}{l}\text { \% by area/country } \\
\text { of citizenship }\end{array}$} & \multirow{2}{*}{$\begin{array}{l}\text { Index numbers } \\
2006 / 2001\end{array}$} \\
\hline & 2001 & 2006 & Difference & 2001 & 2006 & Difference & \\
\hline Total & 896 & 2,739 & 1,843 & 100.0 & 100.0 & 100.0 & 306 \\
\hline MDCs & 338 & 538 & 200 & 37.7 & 19.6 & 10.9 & 159 \\
\hline LDCs and CEE & 558 & 2,201 & 1,643 & 62.3 & 80.4 & 89.1 & 394 \\
\hline European Union & 306 & 494 & 188 & 34.2 & 18.0 & 10.2 & 161 \\
\hline Other MDCs & 31 & 43 & 12 & 3.5 & 1.6 & 0.7 & 138 \\
\hline CEE & 42 & 392 & 350 & 4.7 & 14.3 & 19.0 & 938 \\
\hline Northern Africa ${ }^{b}$ & 215 & 532 & 317 & 24.0 & 19.4 & 17.2 & 247 \\
\hline Rest of Africa ${ }^{\mathrm{C}}$ & 46 & 117 & 71 & 5.2 & 4.3 & 3.9 & 255 \\
\hline Asia & 69 & 173 & 104 & 7.7 & 6.3 & 5.6 & 251 \\
\hline Latin America & 185 & 986 & 801 & 20.6 & 36.0 & 43.5 & 533 \\
\hline Morocco & 200 & 493 & 293 & 22.3 & 18.0 & 15.9 & 247 \\
\hline Ecuador & 31 & 357 & 326 & 3.4 & 13.0 & 17.7 & 1,156 \\
\hline Colombia & 25 & 204 & 180 & 2.8 & 7.5 & 9.7 & 827 \\
\hline Romania & 11 & 192 & 181 & 1.2 & 7.0 & 9.8 & 1,749 \\
\hline UK & 74 & 149 & 75 & 8.3 & 5.4 & 4.1 & 201 \\
\hline China & 29 & 86 & 57 & 3.2 & 3.1 & 3.1 & 299 \\
\hline Italy & 31 & 85 & 54 & 3.4 & 3.1 & 2.9 & 275 \\
\hline Peru & 28 & 83 & 55 & 3.1 & 3.0 & 3.0 & 296 \\
\hline
\end{tabular}

Notes: (a) see table 8.2; (b) excludes Libya and Sudan; (c) includes Libya and Sudan Source: elaboration of Ministry of Interior data

more limited consequences. On the other hand, South-North migration to Spain, which includes a huge number of people moving from the nearby African coast, has been crossed by the growing East-West flow. As happened in Italy, this flow did not start right after the fall of the communist regimes and the Soviet Union's break-up but only in more recent years. The fact that several countries of origin are involved seems to confirm that a strong emigration pressure is more and more a generalised phenomenon in the Eastern European region.

\subsubsection{Foreigners in Portugal: Ukrainians more than PALOP}

In Portugal the effects of the above-mentioned migration trends are evident in the changing composition of the foreign population by area of citizenship and even more in the size of the main immigrant groups 
(table 8.4). Until the late I990s the composition of the legal foreign presence still reflected Portugal's colonial past. Almost half of the regular immigrants were citizens of Portuguese-speaking African countries (PALOP), with Cape Verdeans being the most sizeable group (around 40,000 people) and other large communities coming from Angola, Guinea-Bissau, Mozambique and São Tomé and Principe. Among Latin Americans, Brazilians were by far the most numerous $(20,000)$. One out of four foreigners (27 per cent) was a citizen of another EU country.

In the early 2000s, the Portuguese migration scenario experienced a considerable geographical shift in migrant origins with a significant inflow of Eastern Europeans. Currently, Central and Eastern Europeans represent I7 per cent of the legal foreign presence - even considering the conservative estimate obtained adding only the permanence permits renewed in 2005 to the permits to stay. The clear predominance

Table 8.4 Legal foreign residents by area and main countries of citizenship, Portugal, 1 January 2001 and 1 January 2006 (absolute values and differences in thousands, percentages and index numbers [2001=100]).

\begin{tabular}{|c|c|c|c|c|c|c|c|}
\hline \multirow{2}{*}{$\begin{array}{l}\text { Area and } \\
\text { countries } \\
\text { of citizenship }\end{array}$} & \multicolumn{3}{|c|}{$\begin{array}{l}\text { Absolute values } \\
\text { (in thousands) }\end{array}$} & \multicolumn{3}{|c|}{$\%$ by area/country of citizenship } & \multirow{2}{*}{$\begin{array}{l}\text { Index numbers } \\
2006 / 2001\end{array}$} \\
\hline & 2001 & 2006 & Difference & 2001 & 2006 & Difference & \\
\hline Total & 208 & 370 & 162 & 100.0 & 100.0 & 100.0 & 178 \\
\hline MDCs & 70 & 90 & 20 & 33.8 & 24.4 & 12.4 & 129 \\
\hline LDCs and CEE & 137 & 280 & 142 & 66.2 & 75.6 & 87.6 & 203 \\
\hline European Union & 57 & 76 & 20 & 27.4 & 20.7 & 12.1 & 134 \\
\hline Other MDCs & 13 & 14 & 1 & 6.4 & 3.7 & 0.3 & 104 \\
\hline CEE & 3 & 62 & 59 & 1.4 & 16.7 & 36.4 & 2,137 \\
\hline Northern Africa & 1 & 2 & 1 & 0.3 & 0.5 & 0.8 & 299 \\
\hline Rest of Africa & 98 & 140 & 42 & 47.2 & 37.9 & 25.9 & 143 \\
\hline Asia & 8 & 19 & 11 & 3.8 & 5.0 & 6.6 & 237 \\
\hline Latin America & 28 & 56 & 29 & 13.3 & 15.2 & 17.6 & 204 \\
\hline Cape Verde & 47 & 62 & 15 & 22.7 & 16.8 & 9.3 & 132 \\
\hline Brazil & 22 & 49 & 27 & 10.7 & 13.4 & 16.8 & 223 \\
\hline Ukraine & 0 & 35 & 35 & 0.1 & 9.6 & 21.7 & - \\
\hline Angola & 20 & 31 & 11 & 9.8 & 8.5 & 6.7 & 154 \\
\hline Guinea-Bissau & 16 & 24 & 8 & 7.7 & 6.5 & 5.0 & 150 \\
\hline UK & 14 & 19 & 5 & 6.8 & 5.1 & 3.0 & 134 \\
\hline Spain & 12 & 16 & 4 & 5.9 & 4.4 & 2.5 & 134 \\
\hline Germany & 10 & 14 & 3 & 5.0 & 3.7 & 1.9 & 130 \\
\hline
\end{tabular}

Note: (a) see table 8.2

Source: elaboration of Ministry of Interior data (Serviço de Estrangeiros e Fronteiras) 
of Ukrainians among the new temporary workers - followed at some distance by Moldavians, Romanians and Russians - determined a marked shift in the composition of the foreign population. The traditional migrant groups originating from the Portuguese-speaking African colonies are still important, but with a lesser weight than before owing to a relatively small number of applications for temporary legal status. Ukrainians quickly became the third largest immigrant community in Portugal, just smaller than Cape Verdeans and Brazilians - who participated massively in the 200I-2003 regularisation anyway.

These recent inflows have induced a marked change in Portugal's immigration history, until recently strictly linked to its colonial past and developing within a specific migration system united by the Portuguese language. The reasons for this 'Eastern revolution' are probably related to Portugal's EU membership and more generally to its inclusion in a new worldwide migration scenario. The dismantling of the former socialist regimes and the resulting employment crisis have determined a well-known push effect, while the characteristics of the Portuguese labour market - most of which are similar to the other Southern European host countries - have been responsible for its power of attraction.

\subsubsection{Foreigners in Greece: Albanians and other Balkan people}

Compared with the other Southern European countries, in terms of migration flows Greece has experienced in advance the consequences of the collapse of communist regimes in Central and Eastern Europe. Evidence of this fact was first provided by the results of the I998 regularisation. Not only 65 per cent of all immigrants participating in the amnesty were Albanians, but six of the seven countries with the largest number of applicants belonged to the former Eastern bloc. The dominance of Central and Eastern Europeans in the Greek immigration scenario was confirmed by the 200 I census. Besides an overwhelming majority of Albanians, the presence of Bulgarians, Georgians, Romanians and Ukrainians - just to mention the largest groups - was recorded (table 8.5). Furthermore, recent data on permits to stay suggest that the share of Eastern European nationals might have increased in the last few years, given that these data refer only to legal residents. For instance, the number of Albanian legal residents at the beginning of $2005(448,000)$ was higher than the total Albanian population (including a number of undocumented residents) recorded in 200 I.

Some basic facts distinguish recent migratory trends to Greece from those observed in the rest of Southern Europe. First, the dramatic increase in the immigrant population has occurred despite the great number of 'administrative deportations' (2.2 million from 1992 to 
Table 8.5 Foreigners usually resident in Greece in 1991 and 2001 (absolute values in thousands, percentages and index numbers [1991=100])

\begin{tabular}{|c|c|c|c|c|c|}
\hline \multirow{2}{*}{$\begin{array}{l}\text { Area and } \\
\text { countries } \\
\text { of citizenship }\end{array}$} & \multicolumn{2}{|c|}{$\begin{array}{l}\text { Absolute values } \\
\text { (in thousands) }\end{array}$} & \multicolumn{2}{|c|}{$\begin{array}{l}\% \text { by area/country } \\
\text { of citizenship }\end{array}$} & \multirow{2}{*}{$\begin{array}{l}\begin{array}{l}\text { Index } \\
\text { numbers }\end{array} \\
\qquad(1991=100)\end{array}$} \\
\hline & 1991 & 2001 & 1991 & 2001 & \\
\hline Total & 167 & 762 & 100.0 & 100.0 & 456 \\
\hline MDCs & 69 & 83 & 41.1 & 10.9 & 121 \\
\hline LDCs and CEE & 99 & 679 & 58.9 & 89.1 & 690 \\
\hline European Union & 35 & 47 & 21.1 & 6.2 & 133 \\
\hline Other MDCs & 33 & 36 & 20.0 & 4.7 & 107 \\
\hline CEE & 69 & 577 & 41.5 & 75.8 & 832 \\
\hline North Africa & 5 & 8 & 2.8 & 1.1 & 180 \\
\hline Rest of Africa & 4 & 7 & 2.4 & 0.9 & 179 \\
\hline Asia & 17 & 82 & 10.1 & 10.8 & 487 \\
\hline Latin America & 2 & 3 & 1.3 & 0.4 & 138 \\
\hline Albania & 21 & 438 & 12.3 & 57.5 & 2,131 \\
\hline Former USSR & 13 & 40 & 7.7 & 5.3 & 312 \\
\hline Bulgaria & 2 & 35 & 1.4 & 4.6 & 1,455 \\
\hline Romania & 2 & 22 & 1.1 & 2.9 & 1,144 \\
\hline Cyprus & 15 & 17 & 8.8 & 2.3 & 119 \\
\hline Poland & 10 & 13 & 5.8 & 1.7 & 133 \\
\hline
\end{tabular}

Note: (a) see table 8.2

Source: Census data

200I) carried out with the intention of dissuading immigrant settlement (see note 9). Forced circular migration was a common pattern for Albanians. Second, one national group (Albanians) represents about 60 per cent of the whole foreign presence. No similar level of dominance of a single source country is found in the other three countries considered here. More generally, the proximity of the sending countries distinguishes the Greek migration experience, as even other important immigrant groups (Bulgarians) come from neighbouring countries (Cavounidis 2002). Finally, Greece is the Southern European country most often sought by refugees (especially Iraqis and Afghans arriving from Turkey). Initially considered only as a country of transit, Greece has become more and more attractive to asylum seekers as long as other EU countries restrict asylum policies. Forced migrants overstaying their visa began to resemble economic migrants - although not entitled to the right to work - creating networks for other people willing to migrate. 


\subsubsection{A general overview: the effects of crises in CEE and Latin America}

For an overview of the major immigrants' areas of origin that shows the most significant changes occurring over the last few years, data on foreigners recorded in Southern European host countries around three dates (I99I, 200I and 2006) are reported in table 8.6. Due to the uncertain reliability of Greek data on the foreign presence after the last census, only Italy, Spain and Portugal were included. Despite some problems of data homogeneity ${ }^{16}$ the table is useful to summarise the latest evolution of the foreign population in Southern Europe and its characterisation by area of origin.

As a consequence of the globalisation of international migration movements, all major world regions have significantly contributed to the increase of the foreign population in Southern Europe. However, the contribution of the different regions varies. The increase of foreigners from More Developed Countries (MDCs) has been small - especially for non-EU citizens - if compared with the huge growth in the stock of foreigners coming from Less Developed Countries (LDCs) and Central and Eastern Europe. Therefore, the relative size of the former group has dramatically reduced: if at the beginning of the I990s foreigners from MDCs constituted over a third of the foreign presence, today they only account for I2 per cent of the total.

Table 8.6 Foreign population by area of citizenship. Italy, Spain and Portugal around 1991, 2001 and 2006 (absolute values and differences in thousands, index numbers [2001=100] and percentages)

\begin{tabular}{|c|c|c|c|c|c|c|c|c|c|c|}
\hline \multirow[t]{2}{*}{$\begin{array}{l}\text { Areas of } \\
\text { citizenship }^{\text {a }}\end{array}$} & \multicolumn{3}{|c|}{$\begin{array}{l}\text { Absolute values } \\
\text { (in thousands) }\end{array}$} & \multicolumn{2}{|c|}{$\begin{array}{l}\text { Difference } \\
\text { (in thousands) }\end{array}$} & \multicolumn{3}{|c|}{ Index numbers } & \multicolumn{2}{|c|}{$\begin{array}{l}\text { \% by area } \\
\text { of citizenship }\end{array}$} \\
\hline & 1991 & 2001 & 2006 & 1991-01 & $2001-06$ & 1991 & 2006 & 1991 & 2001 & 2006 \\
\hline Total & 823 & 2,438 & 5,779 & 1,615 & 3,341 & 34 & 237 & 100,0 & 100,0 & 100,0 \\
\hline MDCs & 351 & 588 & 812 & 237 & 224 & 60 & 138 & 42,6 & 24,1 & 14,1 \\
\hline LDCs and CEE & 472 & 1,850 & 4,967 & 1,378 & 3,117 & 26 & 268 & 57,4 & 75,9 & 85,9 \\
\hline European Union & 282 & 495 & 714 & 213 & 218 & 57 & 144 & 34,2 & 20,3 & 12,3 \\
\hline Other MDCs & 69 & 93 & 99 & 24 & 6 & 75 & 106 & 8,4 & 3,8 & 1,7 \\
\hline CEE & 62 & 481 & 1,560 & 419 & 1,078 & 13 & 324 & 7,6 & 19,7 & 27,0 \\
\hline Northern Africa & 122 & 484 & 1,019 & 362 & 535 & 25 & 211 & 14,8 & 19,8 & 17,6 \\
\hline Rest of Africa & 83 & 263 & 468 & 180 & 205 & 32 & 178 & 10,1 & 10,8 & 8,1 \\
\hline Asia & 80 & 285 & 637 & 205 & 352 & 28 & 223 & 9,7 & 11,7 & 11,0 \\
\hline Latin America & 123 & 335 & 1,281 & 212 & 947 & 37 & 383 & 15,0 & 13,7 & 22,2 \\
\hline
\end{tabular}

Note: (a) see table 8.2

Source: own elaboration of national data 
At the beginning of the I990s, Africans were already a quarter of the overall foreign presence (in absolute terms, over 200,000 people) and, following the growth that occurred over that decade, they represented the largest migrant group in Southern Europe at the beginning of the new millennium (nearly 750,000s, over 30 per cent of the total). More recently, African immigration experienced a much lower growth in comparison with immigration coming from other areas, so that Africans have lost their numerical supremacy (they have reached nearly I.5 million, but their proportion has decreased to 26 per cent).

Among the South-North flows, those from Latin America have been growing significantly in the three countries considered here (this does not apply to Greece), especially in Spain because of its colonial links. A vast number of people came during the 2000 s, in particular. By consequence, the number of Latin Americans increased by almost one million since the beginning of the decade and their proportion on the overall foreign population shifted from I4 per cent to 22 per cent.

However, the new and most important element is certainly the birth and the dramatic growth of westbound migratory flows originating in the former socialist countries. In I99I only 62,000 Eastern Europeans (7.6 per cent of the total) lived either in Italy, Spain or Portugal; after a decade there were about 500,000 (I9.7 per cent); most recently they have topped the I.5 million mark (27 per cent). The latter figure jumps to two to 2.5 million if Greece is also considered. Overall, the recent prevalence of East-West flows has determined the regionalization of migrations directed towards Southern Europe and the Europeanisation of the foreign populations.

\subsection{Concluding remarks}

Over the last few years, the statistical information available to researchers for the study of international migrations in Southern Europe has significantly improved. The substantial success of the 2000 round censuses in capturing foreign populations (especially in Greece and Spain), the availability of new sources able to quantify the whole universe of foreigners (Spain), the issue of extensive datasets on regularisation procedures (Italy), have all contributed to a better understanding of the migratory phenomena in these countries. Nevertheless, significant limits still remain, and further efforts to fill in some serious gaps in information are needed. The most urgent is certainly the arrangement of an efficient database able to provide updated information on valid permits to stay in Greece.

Alarmist predictions spread right after the fall of the Berlin Wall about a great and unmanageable wave of people from the East (be- 
tween thirteen and fifteen million people in thirteen years) have proved to be overestimated. Nevertheless, the significance of East-West migration, both recorded and unrecorded, has grown considerably compared to the past (Frejka I996; Okólski I998). Wars in the Balkans characterised population movements over the last decade of the twentieth century with forced, sudden and massive displacements (Salt 2003). The areas of origin of migratory flows have widened with the emergence of new emigration countries (for instance Albania and Ukraine); displacements among CEE countries have been considerable (these can be compared to migrations between former Soviet Union countries); and the arrival of foreign immigrants, often only transiting, in some countries in the region has become significant. Patterns of international migrations also changed suddenly and unexpectedly after i989 (Okólski I998): in a number of countries, long-term migrations have been gradually surpassed by short-term ones; forms of mobility that can hardly be defined as 'migrations' (described as incomplete migrations) have gained importance; irregular and clandestine movements have become more relevant too due to the spread of criminal organisations that manage illegal migratory networks (Muus 200I; Conti, Orchidea \& Arigoni 2003; Holzmann \& Münz 2004). The issue of a large number of entry visas for short stays (not to be considered actual migrations) to citizens mainly from Central and Eastern Europe has determined a strong circulation within the Schengen area of so-called overstayers (Baganha, Marques \& Gois 2006), who took advantage of the latest regularisation programmes to obtain a permit to stay.

The latter kind of immigration has concerned Southern Europe in particular, where Eastern Europeans have acquired a growing and prevailing weight out of the overall foreign population. Among the different reasons for such a territorial concentration and of Southern Europe's power of attraction, there are both the presence in these countries of a wider irregular economy and the opportunity of periodical regularisation programmes and more permissive regulations towards illegal foreigners (see observations in previous paragraphs). The origin of migratory flows is a further element that supports the hypothesis of a Mediterranean migratory model that pools the four analysed countries (De Filippo \& Carchedi I999; Bonifazi, Conti \& Gesano 2000; King, Lazaridis \& Tsardanidis 2000; Boffo 2002; Pugliese 2006). The other supporting elements are: a) the common past of emigration countries that has not yet ended given the definite outflow of citizens, though this is lower than in the past; b) a migration policy that has been deregulated for many years and which has turned to be restrictive and unable to manage incoming flows, unless through a posteriori periodical regularisation programmes; c) an economic structure based on small and medium enterprises and on the dynamism of the informal 
sector; d) a labour market segmented according to sectors, territories and occupations that places immigrants at the bottom of the economic ladder and traps them in the irregular economy (mainly seasonal jobs in agriculture, tourism, building, caring and lower service industry); and e) a wide 'feminisation' of migratory flows arising from a large demand for domestic work and elderly care coming from families, which, unlike in other countries, are not sufficiently safeguarded by the welfare system. Moreover, immigration to these countries features a relatively geographical proximity, colonial bonds (for Iberian countries) and flows connected to the globalisation of international migrations. All these specific features draw a picture that shows how Southern Europe can be considered a specific migratory region.

\section{Notes}

I This work was carried out within the research project 'Euro-Mediterranean immigration to the new receiving countries of Southern Europe. Empirical evidence for Italy' [L'immigrazione euro-mediterranea nei nuovi paesi di accoglimento dell'Europa meridionale: evidenze empiriche per l'Italia], funded by the Department of Statistical Sciences of the University of Naples Federico II and co-financed by the Italian Ministry of Education, Universities and Scientific Research (MIUR) as part of the national project 'Demographic dynamics, migrations and their economic impact' [Dinamiche demografiche, migrazioni e loro impatto economico] (PRIN 2005-2005I3I55_004). We are grateful to Sergio Carfagna and Domenico Gabrielli for providing some useful data and their valuable comments.

2 Actually, some studies pointed out that the overwhelming majority (80-90 per cent) of migrants participating in the I990s regularisations had not applied for a previous programme (Carfagna 2002). This is consistent with the finding that those who are granted a permit are unlikely to fall back into illegality (Blangiardo 2005).

3 The census operations probably failed to capture the real extent of some immigrant groups, recording a number of individuals lower than the amount of valid permits to stay. This is especially the case for Cape Verdeans and most EU nationals (except the French). Besides, comparing the census results with the number of permanence permits issued in 200I, the suspicion arises that many Eastern Europeans also escaped the registration.

4 A government decree in April 2004 included an article that opened the possibility of a further regularisation of non-EU foreign workers who could prove they were present in the Portuguese labour market before March 2003. There were around 40,000 applications but only about 3,000 foreigners had received work permits by the spring of 2005 .

5 AP renewal can be claimed within two months of the expiry date. Moreover, delays in processing applications are not infrequent, so people sometimes wait several months before their permit is renewed.

6 The maximum estimate was probably more reliable in the period when the regularisation law was in place, or just after it. The minimum estimate is likely to be closer to the real amount of legal foreign residents in most recent years.

7 Immigrants of Greek descent with foreign nationality come mainly from the former Soviet Union and from Albania. The former are 'Pontians' whose ancestors migrated 
in the nineteenth and early twentieth centuries from the Pontos region to the Caucasus and to the northern coast of the Black Sea, but were dispersed to various republics of the former Soviet Union during Stalin's dictatorship. According to a special census carried out in 2000, some 150,000 descendants of these Greek emigrants had repatriated, mainly from Georgia $(79,000)$, Kazakhstan $(3 \mathrm{I}, 000)$ and Russia (23,000). Ethnic Greeks with Albanian nationality come from the south of Albania - the region known to Greeks as 'Northern Epirus' - and were estimated at I00,000 individuals (Cavounidis 2002).

8 The restrictive immigration law approved in I99I created the institution of 'administrative deportation' for all immigrants found without the appropriate authorisation of legal stay. This mechanism was used extensively throughout the I990s. Around 2.2 million people were expelled to neighbouring Balkan countries from I992 to 200 I $-85-89$ per cent of whom were Albanians. No other European country has been able to carry out such a massive numbers of expulsions (about 250,000 per annum in 1992-1996, with a new peak in 2000), even in presence of bilateral agreements on repatriation signed with the main sending countries. The legality of such treatments has also been questioned by the local Ombudsman Office (Baldwin-Edwards 2004a).

9 To get a work permit (the 'green card') immigrants had to make a second application, including proof of employment during their temporary stay. Because of the stricter requirements, only 220,000 could apply for the green card. About 150,000 migrants who received a white card but were unable to apply for the second legalisation phase quickly fell back into illegality (Reyneri 2003). Furthermore, immigrants who for various reasons (too recent entry, fear either of being fired by their employer or being identified by authorities) did not even apply for the 'white card' were estimated at over 150,000 (Cavounidis 2002; Fakiolas 2003).

Io In countries with a long migration history, with high naturalisation rates and/or ius soli prevailing in the citizenship law, the official number of legal foreign residents largely underestimates the immigrant population (Haug, Compton \& Courbage 2002). For instance, in the Netherlands the foreign-born population on I January 2006 amounted to I,604,300, while only 691,400 people were legal foreign residents.

II For the sake of homogeneity with the other countries we also used the I99I census data for Italy. As discussed in the previous paragraph, this figure possibly largely underestimates the actual size of the foreign population at the beginning of last decade.

I2 These data do not record the less stable component of the migrant population. In mid-2005, foreigners from LDCs and Central and Eastern Europe were estimated at 3.4 million adding about 320,000 regular immigrants and about 540,000 irregular immigrants to the 2.5 million residents (Blangiardo \& Tanturri 2006).

I3 The structure by nationality of the permits to stay shows that Central and Eastern Europeans were 13.3 per cent of permit holders at the beginning of 1992, they went up to 22.4 per cent after five years and to 29.8 per cent after five more years on the eve of the 2002 regularisation. This gradual growth has been determined especially by migrations from the Balkans: during the early I990s from Albania (due to the fall of the communist regime) and from former Yugoslavia (following the infamous war); during the second half of the I990s also from Romania.

I4 Actually, at the beginning of 2006 (provisional data) foreigners registered in the $\mathrm{Pa}$ dron Municipal stood at almost 3.9 million, 8.7 per cent of the overall population. This source is likely to record a substantial part of foreigners residing illegally but might be also subject to problems of overestimation for a number of reasons - for example misspelling of the name, foreigners who have left the country without cancelling their names from the lists, people registering in the lists their friends or relatives 
who are still outside the country, interest of municipalities in swelling their population for administrative purposes, etc. For this reason and in order to keep consistency with the other countries analysed, in this paragraph we prefer to use data on permits to stay.

I5 Data from the Padron Municipal give even a more clear-cut picture of the growing Eastern European presence, which features a larger share of irregular foreigners compared to other areas of origin. At the beginning of 2007 the overall number of Central and Eastern Europeans was about 900,000. Romanians (525,000) were the second largest group of foreign residents, preceded only by Moroccans $(576,000)$. These figures refer to the situation before the last EU enlargement, the consequences of which are still not captured by the available data.

I6 Even if selected data are as homogeneous as possible in order to survey the same segment of the foreign population (basically regular or regularised foreigners), there are certainly considerable differences related to specific national regulations (for example, the number and share of migrants who have acquired host country citizenship may vary), to the type of sources used and to the distance from the last regularisation programme that may significantly affect the size and share of the irregular presence.

\section{References}

Arango, J. \& M. Jachimowicz (2005), 'Regularizing immigrants in Spain. A new approach', MPI/Migration Information Source. <www.migrationinformation.org>.

Baganha, M. I., J. C. Marques \& P. Gois (2006), 'Imigrantes de Leste em Portugal', Revista de Estudos Demográficos 38: 3I-45.

Baldwin-Edwards, M. (2004a), 'Immigration into Greece, I990-2003. A Southern European paradigm?', paper presented at the UNECE European Population Forum, Geneva, I2-I4 January 2004.

Baldwin-Edwards, M. (ed.) (2004b), Statistical data on immigrants in Greece. An analytic study of available data and recommendations for conformity with European Union standards. Athens: Mediterranean Migration Observatory, Panteion University.

Blangiardo, G. C. (2005), 'I processi di immigrazione: dall'illegalità alla regolarizzazione', in M. Livi Bacci (ed.), L'incidenza economica dell'immigrazione, Quaderni Cesifin, n. 20. Turin: Giappichelli.

Blangiardo, G. C. \& M. L. Tanturri (2006), 'La presenza straniera in Italia', in G. C. Blangiardo \& P. Farina (eds.), Il Mezzogiorno dopo la grande regolarizzazione. Immagini e problematiche dell'immigrazione, 23-5. Milan: Franco Angeli.

Boffo, S. (2002), 'Il modello mediterraneo nel quadro delle nuove migrazioni internazionali, La Critica Sociologica I43-I44: 88-104.

Bonifazi, C. \& S. Strozza (2002), 'International migration in Europe in the fast fifty years', in Bonifazi C. \& G. Gesano (eds.), Contributions to international migration studies, 33-I05. Rome: Irp-Cnr.

Bonifazi, C., C. Conti \& G. Gesano (2000), 'Dinamica demografica e migrazioni nell'area del Mediterraneo', in G. Gomel \& M. Roccas (eds.), Le economie del Mediterraneo, I87205. Roma: Banca d'Italia.

Carella, M. \& R. Pace (200I), 'Some migration dynamics specific to Southern Europe. South-North and East-West axis', International Migration 39 (4): 63-98.

Carfagna, M. (2002), 'I sommersi e i sanati. Le regolarizzazioni degli immigrati in Italia', in G. Sciortino \& A. Colombo (eds.), Stranieri in Italia. Assimilati ed esclusi, 53-87. Bologna: Il Mulino. 
Cavounidis, J. (2002), 'Migration in Southern Europe and the case of Greece', International Migration 40 (I): 45-70.

Conti, C., A. Orchidea \& I. Arigoni (2003), 'Migrazioni post-moderne: il caso dei flussi Est-Ovest', in M. Natale \& E. Moretti (eds.), Siamo pochi o siamo troppi?, 303-336. Milan: Franco Angeli.

De Filippo, E. \& F. Carchedi (I999), 'I mercati del lavoro e la collocazione degli immigrati. Il modello mediterraneo', in F. Carchedi (ed.), La risorsa inaspettata. Lavoro e formazione degli immigrati nell'Europa mediterranea. Roma: Ediesse.

Duquenne, M. N. \& S. Kaklamani (2004), 'Dimensions et caractéristiques dominantes de l'immigration économique en Grèce', paper presented at the thirteenth AIDELF conference 'Les migrations internationales: observation, analyse et perspectives'. Budapest, 20-24 September 2004.

Fakiolas, R. (2003), 'Regularising undocumented immigrants in Greece. Procedures and effects', Journal of Ethnic and Migration Studies 29 (3): 535-56r.

Frejka, T. (ed.) (1996), International migration in Central and Eastern Europe and the Commonwealth of Independent States. New York and Geneva: United Nations.

Haug, W., P. Compton \& Y. Courbage (eds.) (2002), Les caractéristiques démographiques des populations immigrées, Etudes démographiques 38. Strasbourg: Council of Europe.

Holzmann, R. \& R. Münz (2004), Challenges and opportunities of international migration for the EU, its member states, neighboring countries and regions. A policy note, Social Protection Discussion Paper Series 04II. Washington, D.C.: World Bank.

Istat (2006), La popolazione straniera residente in Italia al $1^{\circ}$ gennaio 2006 , Statistiche in breve. <www.istat.it>.

King, R., G. Lazaridis \& C. Tsardanidis (eds.) (2000), Eldorado or fortress? Migration in Southern Europe. London: Macmillan.

Malheiros, J. (2002), 'Portugal seeks balance of emigration, immigration', MPI/Migration Information Source. <www.migrationinformation.org >.

Muus, P. (200I), 'International migration and the European Union. Trends and consequences', European Journal on Criminal Policy and Research 9 (I): 3I-49.

Okólski, M. (1998), 'Regional dimension of international migration in Central and Eastern Europe', Genus 44 (I-2): II-36.

Peixoto, J. (2002), 'Strong market, weak state. The case of recent foreign immigration in Portugal', Journal of Ethnic and Migration Studies 28 (3): 483-497.

Pellegrino, A. (2004), Migration from Latin America to Europe. Trends and policy challenges, Migration Research Series I6. Geneva: International Organization for Migration.

Pugliese, E. (2006), L'Italia tra migrazioni internazionali e migrazioni interne. Bologna: Il Mulino.

Reyneri, E. (2003), 'Immigration and the underground economy in new receiving South European countries. Manifold negative effects, manifold deep-rooted causes', International Review of Sociology I3 (I): II7-I43.

Rosa, M. J. V., H. de Seabra \& T. Santos (2003), Contributos dos 'imigrantes' na demografia portuguesa. O papel das populações de nacionalidade estrangeira, Acime. $<$ www.oi.acime.gov.pt>.

Salt, J. (2003), Current trends in international migration in Europe. Strasbourg: Council of Europe.

Salt, J. (2006), Current trends in international migration in Europe. Strasbourg: Council of Europe. 


\title{
9 The post-enlargement migration space
}

\author{
Paolo Ruspini ${ }^{1}$
}

Since its foundation the transnational experiment called the European Union has tried to provide a political form for the ancient idea of Europe. This has been attempted by establishing a set of rules opposing the entropy of the international system and setting up a common market, therefore continuing the process of political integration sanctioned by treaties. These rules have generated a dense network, which has grown up, surprisingly, beyond all proportions, entangling 'goods and persons' and at times delaying the overall growth of the system. The geopolitical space of the EU has expanded or decreased because of historical social factors and the political willingness, or not, of the ruling coalitions of its member states.

In more than 40 years of its recent history, Europe has been a divided entity reproducing variables of political thought and socioeconomic systems in contrast with each other: East and West, a planned economy against the free market, totalitarianism and democracy.

The collapse of the Soviet paradigm in I99I and the ensuing gradual reunification of the European continent have not only forever altered a vision of the world, but they have also sparked movements of populations long appeased, thus making migration regimes and the impermeability of European borders subjects for discussion.

The idea proposed in this paper is the need to look at the transformations of the EU migration space in the period that starts in the I980s, goes through the I990s, until the decisive appointment of I May 2004, the day that sanctioned the fifth and most imposing EU enlargement. The last date is actually a starting point for the continent to look further and try to identify the empirical form and political features within today's migration scenario in the enlarged EU.

\section{1 'Enlargements' and 'restrictions' in the European Union}

Social phenomena and political processes, often complementary, have fuelled the enlargement of the common European space: the processes of globalisation and economic interdependence on one side together 
with the evident impossibility of adopting national immigration policies without externalising the control of borders.

The I980s, the starting point of our discussion, saw an acceleration of the political union with the introduction of the concept of 'variable geometry' and the publication of the 'White Book' by the Delors Commission, which included detailed proposals for realising a common market. The accession of Greece in I98I, together with that of Spain and Portugal in 1986 gave us twelve EU member states. In the latter year the Single European Act was enacted. It modified the Treaty of Rome by introducing 'qualified majority voting' for the harmonisation of legislations. This act, fervently encouraged by Kohl and Mitterand, opened the road to the creation of a big common market without frontiers, expected for I January I993 (Motta 2003). The Delors Plan, adopted in 1989 , prepared the establishment in three stages of economic and monetary union, while the Schengen Convention, which includes the total abolition of border controls, was signed on I9 June I990. The last objective was only achieved in I993, after the signing of the Treaty of Maastricht (7 February 1992) that sanctioned the freedom of movement for people, goods, services and capital.

Historical reconstruction aside, the development of the European integration process was distinguished by two enlargements for three Southern European countries, only five years apart, and by the signing of the Schengen Convention that closed the I980s and smoothed the way for the important institutional turning points of the I99os.

It is interesting to note that the economic situation of Greece, Spain and Portugal at the time of their EU accession, compared with that of the member states was not so dissimilar to that between the EU-I5 and the new Central and Eastern European (CEE) members in 2004. Certainly, one should proceed with caution in making comparisons between socioeconomic models when taking into consideration their diverse historical experience. In the case of CEE countries, these models have been shaped over time by planning mechanisms historically absent in the West. It is worth noting, however, that calculations may be made with the purpose of raising distinctions and therefore restricting the freedom of movement of workers from the new member states, for subsequently renegotiable transitional arrangements, so as to avoid an imbalance in the labour markets of the old member states (Traser 2005). The scarce migratory flow, once the freedom of movement for workers of the three Mediterranean countries was sanctioned (Van Selm \& Tsolakis 2004), has proved these calculations to be groundless.

On a contemporary level, estimates on the potential of the new joining countries towards Western Europe have safely shown a sound growth in flow. The increase in the number of the EU-8 residents in the EU-I5 can be assessed at 200,000-250,000 people per annum 
since 2004 (Brücker 2007). Such growth especially concerned those countries that provided freedom of employment since I May 2004, namely Ireland, the United Kingdom and, to a lesser extent, Sweden (Traser 2005).

The publication of a European Commission (Commission of the European Communities - CEC) report on the functioning of transitional periods, quoting a series of administrative sources and surveys on the occupational power of the countries of the EU, denies any causal relationship between mobility from the new joining countries of Central and Eastern Europe and the periods of transition towards access to the labour market in force. According to the report of the European Commission, apart from Ireland, where intra-European migration is more complex, ${ }^{2}$ the flows towards the United Kingdom and Sweden are comparable if not lower than those towards those countries that have adopted restrictive measures, such as Austria (CEC 2006). It is not easy to evaluate the overall phenomenon statistically, because not all of these workers register in the UK, while after 1 May 2004 many took the opportunity to abandon a situation of past irregularity (CEC 2006). The report of the European Commission on the functioning of transitional periods estimates a growth of 0.4 per cent based on applications for residence and employment permits, requested in the UK from May 2004 to September 2005 by citizens of the new member states (CEC 2006). According to figures released on 27 February 2007 by the British government Home Office, almost two years after enlargement, Britain is still receiving an estimated 20,000 workers per month. Altogether, 579,000 workers from Central and Eastern Europe have entered the United Kingdom since 1 May 2004.

A depopulation of rural areas in the new member states is also reported (The Economist 2005) due to the fact that the search for better working and earning conditions drives many Latvians, for instance, to leave the countryside and to search for work in the fast-growing economy of the capital Riga, thus filling the places left vacant by Riga residents emigrating to Western Europe. Shortages of qualified labour also occur, not exclusively due to outward migration however, but also because of the very common phenomenon of a decrease in the population. Lithuanian employers are more and more often bound to hire their workforces from third countries, for example 78 per cent more in 2005 than in the year before (Traser 2005).

All in all, migration potential, which basically remains reasonable in Central and Eastern Europe, shows the positive and complementary effects that the arrival of skilled workers from the new joining countries have on the labour markets of the old member states (CEC 2006; Brücker 2007). A discussion took place at community level on the abolition of restrictions, as in Finland, or on their renewal for three more 
years, up to 30 April 2009, as in Germany and Austria. Further discussions took place during the accession of Bulgaria and Romania in 2007. The decision whether or not to establish transitional periods within the different member states diverted the migratory flows, influencing subsequent policy decisions. Of the EU-15 who chose restrictions in 2004, only Finland has decided upon free access in this second round of enlargement. Sweden, which achieved a liberal regime back in 2004, once more relaxed its restrictions towards labour migrants. Net migration from the EU-8 into that country was, however, negligible in the two years since enlargement (Brücker 2007). The UK and Ireland, which allowed free movement to EU-8 workers, have since announced further restrictive measures (Drew \& Sriskandarajah 2007).

In the EU member states that opened their labour markets, the new European citizens alleviated skills bottlenecks and filled the jobs that are done in the rest of Europe by irregular migrants, either from the new member states or non-EU countries (Weil 2005).

As for the twelve EU countries using transitional arrangements, evidence suggests that some of these may have experienced undesirable side-effects, such as higher levels of undeclared work and bogus selfemployed work (CEC 2006). In view of this, lifting the transitional arrangements might eventually contribute to the reduction of irregular workers coming from non-member states and thus deter irregular migration from outside the EU (Weil 2005).

In our opinion, it will be more interesting to look at the eventual reproduction of return migration scenarios, such those regarding Greece, Spain and Portugal, when the internal economic conditions became competitive compared with those of the destination countries. They are hypotheses to be verified on the grounds of the characteristics of the CEE migratory regimes and the logic of the pre- and post-enlargement scenario. Since the 2004 enlargement, labour market developments in the EU-8 have been positive with unemployment rates, though still high, dropping significantly in almost all of them, while the outlook for economic growth remains bright and the increased Structural and Rural Development Funds are starting to bear fruit in promoting economic growth and employment creation (CEC 2006).

One observation must be added regarding the evident contrast between the EU set of standards that advocate the freedom of movement for all workers who live and reside in the Union, and the distinctions exercised by the member states in proposing transitional arrangements. They seem to deny and contradict the freedom of movement in selective terms, i.e. where the Union has accepted countries whose economic development is inferior to the member states' average, and where the relative migratory potential was only 'apparently' increased by virtue of projections based on their history as emigration countries. 
It is actually worth remembering that, when in I995 Austria, Finland and Sweden joined the Union, the need to adopt restrictive measures was not apparent, and again in 2004 for Malta and Cyprus.

With these issues in mind, the partial negation of the Treaties' postulate, which has sanctioned the freedom of movement, throws a gloomy light on the EU Charter of Fundamental Rights and raises questions about the compatibility of any future political union with criteria of democratic inclusion typical of a federal structure. By adopting a theoretical model which correlates federation and democracy at the time of migration (Koslowski 2000), we might possibly ask whether 'when there is migration among states entering a federal political union and those states base complete free movement of people and labour on transitional arrangements for the included new members and on long-term objectives for the new excluded neighbours, is the political union compatible with inclusive democracy?'

\subsection{The 'permeability' and 'impermeability' of the enlarged EU borders}

A 'Copernican revolution' took place within the EU in the middle of the I990s, which would have soon transformed the global migration regime of the continent. In I995, for instance, the Schengen Convention came into force ten years after its signature, covering common external borders, common rules for visas and asylum, control of external borders and free movement of people. The Schengen Information System (SIS) has been established to counterbalance freedom and security. It is directed at the gathering and exchange of personal identification data and the description of lost and stolen objects. Limited to the five I985 founding states (France, Germany and Benelux), the Schengen space has progressively extended to nearly all EU member states (with the exceptions of the United Kingdom and Ireland). ${ }^{4}$ Furthermore, the Southern European member states, belonging to the Mediterranean model born at the beginning of the 1980s, grouping common migratory characteristics and experiences, anticipated paths similar to those of the CEE countries, adapting their mechanisms of border control. The reactive character of many of these laws has since been considered unsuitable for implementation, in its ignorance of historical contingencies and existing immigration policies ( $\mathrm{K} \square$ pi $\square$ ska \& Stola 2004).

The need to satisfy parameters established from above, at the EU level, without the advice of the directly interested countries, has led on several occasions to the postulating of policies that are often inadequate in taking into account the historical characteristics of the CEE region and the problems, as a consequence of population movements in the 
past century, which have arisen in the displacement of ethnic minorities outside their borders of origin. The management of CEE ethnic minorities therefore cannot be conceived on the basis of the Western European experience, because conditions are rarely analogous and the gaps between the range of rights which the minorities of these regions aspire to and those that the governments of their countries of origin would be willing to grant are much wider compared with Western European standards (Górny \& Ruspini 2004).

It may be that in the process of EU enlargement, ad hoc meetings and exchanges of experiences at the EU level among all the actors concerned with the policymaking process would have been useful, including those of immigrant communities and ethnic minorities from Eastern and Western Europe. This would have enabled migration experts from the candidate countries to be actively and effectively involved in the formation of immigration policy. Such active involvement would certainly have served as a stimulus to facilitating a search for solutions and compromises for the diplomatic controversies that arose during the enlargement process.

The above observations are not aimed at disclaiming the important role of the 'reactive' element in encouraging the formation and harmonisation of member and candidate countries' immigration policies. This is certainly an important first goal, though not definitive, when such diverse starting premises are considered. The alleged facts also testify to the influence that politics, and not only market rules, have on the importance of shaping the flow of migration and to the space of that singular model of supranational political integration that is the European Union. This (re)shaping has not always occurred in the right and desired direction, aimed at matching the general with the specific interests of immigrant groups and ethnic minorities. At any rate, the fact that the policymaking process has started is an important success in itself.

On the basis of what is set out above, the importance of the role that the Schengen acquis or convergence criteria play in shaping the EU borders is therefore self-evident. An unexpected freedom of movement for CEE citizens towards the West generated by the removal of exit controls in the I990s has been granted. Many have taken advantage of the concession of temporary permits, staying permanently in Western European countries, in particular where the geographic proximity, the historical and cultural ties and the economic attraction of the labour markets makes the stay reasonable and employment possibilities more advantageous. An absence of exit controls together with the adoption of liberal immigration policies by several Western European countries were responsible for a flow of migration towards the West and may have often even sparked this flow. 
Moreover, in the decade preceding the beginning of the I990s, the CEE migration space worked nearly exclusively according to internal rules; population movements were mainly restricted to the CEE region, as a direct consequence of the lack of exit controls and passport visas for accessing the West. These dynamics were functional to Western Europe. The region acted, in fact, as a 'buffer zone' between East and West and so it was until I May 2004. The Schengen barrier acted as a propeller for CEE migratory flows for a long time. Flows were circular, 'incomplete', triggered by the exploitation of wage differentials at the time of the transition of the CEE economies as well as the backwardness and progressive decline of the bordering former Soviet republics.

An 'epos' came about, made up of peddlers, small 'entrepreneurs', asylum seekers, ethnic networks and dubious legal trading between bordering regions of Eastern Europe. Thus what at first was temporary mobility slowly became a transformation towards settlement implying permanent stay. The rate of mixed marriages between Poles and Ukrainians, for instance, increased as a result of the prolonged stay and the new and continuing flows from the East, thus demonstrating the significance of a particular kind of flow within the overall character of migration originating in the former Soviet Union (Górny \& Kępińska 2004).

The CEE countries will soon show characteristics and profiles similar to Western Europe in their way of experiencing the migratory phenomenon. Castles \& Miller (I993) identified the constant factors associating countries that have reached the various stages of their immigration experience so as to include:

- A dynamic process of migration, which transforms the temporary entry of workers and refugees into permanent settlers who form distinct ethnic groups;

- The economic and social marginalisation of the immigrants;

- Community formation among immigrants;

- Increasing interaction between immigrant groups and the local population;

- The imperative for the state to react to immigration and ethnic diversity (Castles I995: 293).

These are stages that Castles and Miller have found, through different sources, in all the Western European countries and that global migratory dynamics are gradually exporting to the CEE region (Iglicka 2004). This hypothesis can be verified on the grounds of how the enlarged migration space is synthetically analysed herein. The territory is delimited by new borders, and diverse migratory experiences will increasingly tend to converge until the similarities as listed by Castles and Miller will prevail over the differences. 
The debate in question is not the next convergence on migration, but, rather, it is the question of the identity of the European migration space and its borders. The reshaping of this space and the eastward shift of the EU border has actually generated dynamics of inclusion and exclusion to be carefully observed.

In this regard, this research diverges from that which posits the superiority of market forces over politics, supporting the 'uninterrupted' porosity of the EU border without making any distinction between the time before and after the EU enlargement (Favell \& Hansen 2002). There is no objection as far as the porosity of the borders in the fifteen years before the enlargement is concerned. There is, rather, the conviction that migration dynamics and regional networks have suffered meaningful consequences because of EU enlargement, and they require political interventions to face the process of reshaping the borders and the ongoing mechanisms of enclosure.

In other words, I would argue that the factors of inclusion and exclusion generated by the 2004 enlargement created 'visible' borders, like the one between Poland and Ukraine, and equally 'invisible' borders, such as those generated by the simultaneous existence of wage differentials and the new boundaries of entry and mobility (Ruspini 2003). The differences in socioeconomic development, though inherent to the expansion processes, endanger the cohesion and social tissue of culturally and geographically similar communities and the well-established exchange and mobility practices between borders.

In order to face the consequences of EU enlargement, 40 regions on the EU's eastern border set up a network in Brussels on 8 December 2005. The Network of Eastern External Border Regions (NEEBOR) brought together regions from Finland, the Baltic states, Poland, Hungary, Slovakia, Romania and Greece, as well as some Russian, Ukrainian and Belarusian regions aiming at boosting cross-border labour markets, exchanging information about environmental projects or activities supporting good governance and democracy (Kubosova 2005).

As a matter of fact, it is not only a question of East-West borders, but of North-South geopolitical spaces, as was remarked some months before the eastward enlargement by some Maghreb colleagues who complained at the insufficient attention given to EU processes of 'inclusion' on the southern side of the Mediterranean. There is no doubt that the process of European integration is made of tight interdependent variables (Wallace 200I), but one should not forget that the meaningful, though not complete, solution of the East-West differences within the EU enlargement leaves the North-South difference unsolved.

Though mistrusting the porosity of the CEE borders, it is difficult to imagine Europe as a 'fortress'. More realistically, the Union should strive to re-establish an absent or 'forever lost' socioeconomic equili- 
brium. For example, the EU should aim at preventing an expansion of the bridge demarcating the border between Narva in Estonia and Ivangorod in Russia; two urban agglomerates which were a single city up until I May 2004 (Visetti 2004). This represents a deep division between Catholicism and Orthodoxy, the EU and Russia.

\subsection{The 'pendulum' of Helen Wallace and the 'pillar' of justice and home affairs}

The pendulum fluctuates, attracted, as it is, by two opposite magnetic fields. Helen Wallace (I996: I3) noticed very clearly the fluctuations resulting from the shifts in interests and loyalties in the process of policy coordination of the EU field of justice and home affairs. These fluctuations happen during the harmonisation of policy between the national and transnational/supranational dimensions. The European institutions on one side and the national level governance on the other (with the minor 'magnetic fields' of the regional and local dimensions) are two opposite poles in competition for the overall field of decisional spaces. The probability that one or the other dimension prevails and the policies adopted depend on the strength of the two magnetic fields: if both sides are weak, no coherent policy will emerge either at the supranational or the national level.

Helen Wallace's 'pendulum' is based on a series of premises, which we have indirectly pointed out, such as the political inadequacy of the national states, the impact of globalisation and the specific features of the European region (Apap 2004). The pendulum movements illustrate with precision the opposite tensions at work during the process of European integration: its progress at times regular, at others irregular, moving between fluctuations and immobility. Wallace's metaphor is also useful to illustrate the contrast, which has become more and more intense since the second half of the I99os, between the intergovernmental and supranational dimensions in the creation of EU immigration and asylum policy. A contrast which, in the light of the structural characteristics of the model, does not anticipate a definitive solution in favour of one or the other dimension, but rather a continuous fluctuation with sometimes the prevailing of one, sometimes of the other, depending on the historical circumstances and the political and economic interests at stake.

In this context, some more precise information is necessary in order to contextualise the fluctuations in this field of policy. After the Treaty of Maastricht came into force, the I990s saw the I996-I997 European intergovernmental conference that prepared the Treaty of Amsterdam. On 2 October I997, the treaty was signed and on I May I999 came 
into force. The EU became 'a space for freedom, security and justice'. Justice and home affairs acquired a wider field of action and more specific objectives; the European institutions a more balanced role and a more effective and democratic method of working had been planned. Moreover, the European Commission acquired wider prerogatives and a new Title (IV) included in the Treaty encompassed freedom of movement, immigration and asylum. The Schengen agreements were integrated into the legal framework of the acquis of the EU. Aims to be achieved are 'free movement of persons' (EU and third country residents) and 'security through the fight against crime and terrorism' (Article 2 of the Single European Act). The introduction of a scoreboard, the so-called 'Scoreboard to Review Progress on the Creation of an Area of Freedom, Security and Justice in the European Union' should guarantee the periodic control of the work in progress.

It is the beginning of the 'communitarisation' of immigration policies. The praxis of intergovernmental consultation however, seems to be fading over the horizon. In fact, in the five years following the entry into force of the Treaty of Amsterdam (2004), decisions on immigration and asylum will have to be adopted only with a qualified majority. Besides, the European Council will have to ensure the effective freedom of movement, the control of the borders and the implementation of all the other measures in the field of immigration and asylum (Geddes 2003).

In October I999, a special European Council gathered in Tampere with the aim of making the EU into 'an area of freedom, security and justice'. One of the priorities of the Tampere Council was the invitation to the EU member states to elaborate a common policy on asylum and immigration. The aim of the common policy in these specific fields implies the creation of 'a harmonised and common way for immigrants and asylum seekers to obtain entry to all EU States' (CEC 2002). The main intervention areas for reaching these goals have been carefully listed: I) a comprehensive approach to the management of migratory flows; 2) fair treatment of third-country nationals; 3) partnership with countries of origin; and 4) development of a common European asylum system (CEC 2000). The selection of intervention areas is a recognition by the European Commission that, given declining population and labour shortages in some sectors of a number of EU countries, 'the existing "zero" immigration policies, which have dominated thinking over the past 30 years, are no longer appropriate' (CEC 2000: 6).

In short, with the signing of the Treaty of Amsterdam and the subsequent meeting of the European Council in Tampere, a new institutional revolution seemed to shake the foundations of the European institutions and start an unprecedented acceleration in the EU process of 
decisional coordination in the field of asylum and immigration. Unfortunately, this is not exactly true of the current situation.

The subsequent European Councils in the years from 2001 to 2003 showed a deceleration (Laeken) in asylum and immigration policy, followed by the determination to go on (Seville) or again by the acknowledgement of the progresses made with the approval of such longawaited directives, such as the one on 'family reunification' (CEU 2003a) or 'the status of third-country nationals who are long-term residents' (Thessaloniki; see CEU 2003b). In fact, it is clear from the analysis of the documentation produced in these and other venues, that the member states are determined not to abdicate from their own prerogatives of national sovereignty by keeping control of such a sensitive field as immigration. The resounding declarations of principle included in these documents often clash with the daily practices of the national governments, urging the European Commission on more than one occasion, to invite the member states not to adopt legislation in the migratory field which might, to a certain extent, contrast or hinder the ongoing supranational harmonisation.

The metaphor of the Wallace 'pendulum' thus seems to find in these statements and in the contradictory results listed so far, a raison d'etre and a true confirmation. In spite of the efforts at harmonising it is, however, legitimate to argue that progress in this area is, at the end of the day, the result of a combination of intergovernmental and supranational political decisions (Jordan, Stråth \& Triandafyllidou 2003).

On I May 2004, the conclusion of the first imposing phase of the process of EU enlargement with the accession of ten new member states, took place at the same time as the entry into force of the Treaty of Amsterdam. The enlargement, with the revision of the borders and the external relations of the Union, had raised hopes for the setting aside of another aspect of member states' sovereignty and the intensification of efforts for common policy formation even in areas like immigration and asylum policy (Ruspini 2002). In fact, the number of directives adopted in this field is, all in all, scarce in comparison with the legislative proposals put forward since Tampere; while at the moment the decisional mechanisms have not been changed as originally expected. The inability of the European Convention to impose qualified majority voting on national states as a sine qua non in some sensitive decisional fields of the European Constitution ${ }^{6}$ meant unavoidable repercussions for the expected deadline for the entry into force of the Treaty of Amsterdam. The agreement reached by the European leaders on the so-called 'Hague Programme' during the European Council in Brussels of 4 and 5 November 2004 fixed the new deadline of 2010 for the adoption of common policy solutions in the field of asylum and immigration (CEU 2004). Furthermore, the European Council stressed the 
importance of the debate on the Green Paper as a tool for identifying possible options for a EU legislative framework on economic migration (CEC 2005c).

The approval of this new agenda has allowed the adoption of qualified majority decisions in the field of border controls, illegal immigration and asylum starting from 2005. The area of legal immigration remains instead subject to the unanimity rule and the right of veto until the European Constitution is approved. As a result of the rejection of the Constitutional Treaty by the French and Dutch constituencies in the 2005 referenda, there is a predominant feeling that counterbalances, deceleration and distinctions regarding principles will still influence future political choices, allowing the 'pendulum of Wallace' to fluctuate again.

\subsection{The post-enlargement migration space and its open questions}

Having witnessed the conclusion of the eastward expansion of the EU migration space, it is interesting to note the effectiveness of the postTampere agenda and its impact on the forming of a common immigration policy. I would limit suggestions to a few remarks regarding the migratory phenomenology of the enlarged EU and to the identification of variables while providing a view of the future scenario. For clarity's sake I would first focus on a series of points (Ruspini 2004):

- The EU migration space has been enlarged and it will be further increased to the south-east;

- The 'buffer zone' between East and West has moved further eastwards;

- The borders are not as porous as before, at least in the EU eastern border zone;

- Russia and the former Soviet republics still lack suitable laws and infrastructures for carrying out the role of 'buffer zone', long represented by the CEE countries before the EU enlargement;

- Migrants coming from the former Soviet republics and the extremities of the Asian continent travel in the huge geographic spaces of Russia and the former Soviet republics looking for a place to enter the West;

- Centrifugal migratory dynamics (towards the West) are added to centripetal dynamics (towards the 'core' of Russia) making the overall Eurasian migration space extremely mutable.

In this context, the demographic and economic differentials between border regions of the post-Soviet universe spark the migratory flows. 
The absence of controls on entry and strict controls on exit towards the West sometimes transform transit through the post-Soviet space into a stay of indefinite length. According to the most reliable estimations, 45 million immigrants are irregularly present in the territory of the Russian Federation (Ivakhniouk 2003). It is an area that attracts irregular immigrants on a scale that should raise greater interest from both the Russian Federation and the EU.

Until recently the approaches of the Russian state bodies and nongovernmental organisations towards how to improve the situation and tackle the phenomenon of large-scale irregular migration were antipodal. By the end of 2005 it seemed, however, that the position of the Federal Migration Service (FMS) had become more focused on legalisation for irregular migrants. The news of a forthcoming regularisation on a large scale in Russia - subject, however, to legislative checks and delays highlighted by the mini-regularisations promoted in the districts of Moscow, Krasnoyarsk, Irkutsk and Primorsky Kray - as well as the inclusion in the Russian criminal code starting from I5 January 2007 of an article on the responsibility of employers who irregularly hire immigrant workers, seems to be the first positive news for those who have to manage problems created by the proximity of new EU borders. However, the crackdown resulting from the governmental resolutions (682 and 683) setting immigration quotas and limiting the number of foreigners working in the marketplaces and in retail of alcoholic beverages and pharmaceuticals indicates tightening immigration policies (EU 2007).

At the southern borders of the European continent, the Mediterranean Sea separates opposite poles of economic development. The Maghreb presses for making closer ties with the countries of the north side of the Mediterranean, while migrants coming from sub-Saharan Africa try desperately to move towards the Schengen space (Barros et al. 2002). The Maghreb countries are therefore assuming transit characteristics typical of migratory phenomenology already seen in other geographic areas of the European continent.

What is the EU answer to these dynamics? The concession of 'facilitated transit' settles controversies like the one involving the Kaliningrad region, the enclave between East and West of the enlarged Union, and allows the Russians of Ivangorod to visit their neighbours of Narva, but these are only extemporaneous solutions for controversies of smallor medium-size intensity. These solutions certainly indicate the best practices in facing similar cases in other EU zones, but their complexity and their limited operational sphere undoubtedly have several limits.

The 'neighbourhood policy' prepared for EU expansion is still too vague. The Union has planned ad hoc budget lines for implementing 
these policies by taking advantage of experience gained with other financial instruments as in Phare, Tacis and Meda (CEC 2004). In any case, though important, the problem not only lies in identifying and displaying adequate financial instruments for policy implementation. Overall, the policies proposed by the European Commission, aimed at smoothing the way for the neighbourhood policy, still lack a real vision. They do not seem able to avoid the methodological superficiality and scientific vagueness of expressions like 'ring of friends' to define the countries bordering the EU. It is actually not always a question of 'friends', if one considers either the strongly authoritarian regime of Alexander Lukashenko in Belarus or the powerful lobby of the political technologists in Moscow who are aiming at regaining the influence of the Russian blizhneye zarubezehiye ('near abroad') (Kratsev 2005).'

The existence of an unstable and uncertain world on its doorstep should put pressure on the EU to take political action, as well as economic measures, in order to meet the challenges and problems of the 'neighbouring' areas. Closer to our immediate interests, i.e. immigration policy, one should be thinking now about multilateral solutions that can effectively involve all interested parties in the policymaking process. A solution could be to use the 'open method of coordination' (CEC 200I) for EU immigration policy, not only 'horizontally', i.e. by involving all the actors at national level in the setting up of immigration policy, but also 'vertically' by involving non-governmental and international organisations, migrant associations and ethnic minorities operating at the transnational level. This coordination should be established by encouraging participation in the process of harmonisation on the part of all actors in the interested countries, old and new EU members and those neighbouring countries whose membership is probably not imminent.

We are now facing new challenges in enlargement: the 2007 enlargement to encompass Romania and Bulgaria, and possibly an enlargement to include Croatia in 2009 and also Turkey, whose accession date has still to come. Turkey seems to create more problems, because of its demographic potential and, above all, its Muslim identity overlapping East and West. It is worth remembering that only a few years ago, the fear that some millions of Turkish citizens resident in Germany were able to acquire, over time, dual nationality and consequently significant electoral power, forced the adoption of a compromise model for reforming the citizenship law. The new law adopted some elements of jus soli, but the hypothesis of a double passport originally included in the reform supported by the red-green coalition was rejected (Ruspini 2000). In the following years a new debate started, advocated by the Christian Democratic and Christian Social parties concerning national identity and the concept of Leitkultur, a 'dominant culture' the roots of 
which date back, according to the exponents of the two parties, to the Christian tradition of Germany (Ruspini 200I).

The German case is only one example. Other Western countries are experiencing equally strong conflicts over issues of identity which the 9/II tragedy particularly exacerbated. The conditions of immigrant communities and ethnic minorities living in the EU have become harsher. Multicultural practices are constantly under discussion and face more and more difficulties in being really implemented (Rex 2004). In the autumn of 2005, in the Paris banlieues, violent ethnic fights flared up as evidence of the fact that second and third generations of Maghrebi immigrants are separated from the surrounding fabric of society and are far from being integrated in the imperishable French republican model.

The Turkish issue is added to this composite picture, forcing the EU to rethink itself, its identity and its borders (Ruspini 2006). The European Parliament, while reacting to the Commission's 2005 enlargement strategy paper, recalled that the Union's capacity for absorption, as set out at the I993 Copenhagen Summit, remains one of the conditions for the accession of new countries (EP 2006). The EU legislative body stressed the link between absorption capacity on one hand and the nature of the EU and its geographical borders on the other hand. It also requested the Commission to submit a report setting out the principles that underpin this concept. Finally, only when the debate on the identity of the EU is entirely exhausted will the practical problems of the national and supranational political spheres come to a suitable solution.

\section{Notes}

I This article first published in Italian, as Ruspini (2005), has also greatly benefited from the discussions and improvements originating from two conference versions published either in Romania or in Latvia.

2 Flows into Ireland are bigger, but the figures are not strictly comparable because the statistical indicators i.e. the Personal Public Service (PPS) numbers, are issued by Irish authorities to individuals not just for employment reasons.

3 Spain and Portugal were among the first countries following suit with Finland by announcing the removal of restrictions towards EU-8 workers. Italy announced on 20 July 2006 the decision to lift the restrictions in place since May 2004, soon after the government change that took place in Rome.

4 Denmark also maintains a unique position concerning Schengen since it can choose whether or not to apply any new decisions made under the Schengen agreements. Non-EU members Norway and Iceland joined the Schengen area in 1996, while Switzerland, following the positive outcome of a referendum held on 5 June 2005 , plans to implement the Schengen provisions by 2008. Eight new member states from Central and Eastern Europe plus Malta should also join the Schengen 
borderless area in 2008 by providing a functioning information system as well as a secure external border. A separate procedure still stands for Cyprus.

5 As a result of the EU summit at Hampton Court during the 2005 UK presidency, the European Commission seemed to acknowledge it, while starting a process to readdress its policy stance in the Mediterranean region (CEC 2005a).

6 Adopted from the intergovernmental conference of I8 June 2004, the European Constitution should have entered into force on I November 2006.

7 Kratsev stresses that the major aim of the political technologists' policy and their leader, Sergei Markov, is to develop an efficient non-governmental organisation network that can use the predictable crisis of the current Ukrainian orange-type regimes to regain influence on the Russian 'near abroad' area, not simply at government level but at society level as well.

\section{References}

Apap, J. (2004), 'Requirements for a more effective and enhanced JHA cooperation in an enlarged European Union. Towards closer partnerships', working paper for the ELISE Consortium. Brussels: Centre for European Policy Studies (CEPS). $<$ www.eliseconsortium.org/article.php3?id_article $=136>$.

Barros, L., M. Lahlou, C. Escoffier, P. Pumares \& P. Ruspini (2002), 'Limmigration irreguliere subsaharienne a travers et vers le Maroc', Cahiers de Migrations Internationales, 54 F. Geneva: Bureau International du Travail.

Brücker, H. (2007), 'Labor mobility after the European Union's eastern enlargement. Who wins, who loses?', report to the German Marshall Fund of the United States. Washington, D.C.: The German Marshall Fund of the United States.

Castles, S. \& M. J. Miller (1993), The age of migration. International population movements in the modern world. Basingstoke: Palgrave Macmillan.

Castles, S. (I995), 'How nation-states respond to immigration and ethnic diversity', New Community 2I (3): 293-308.

CEC (2000), 'On a Community immigration policy', communication from the Commission to the Council and the European Parliament, COM 757 final, 22 November. Brussels: European Commission.

CEC (200I), 'On an open method of coordination for the Community immigration policy', communication from the Commission to the Council and the European Parliament, COM 387 final, iI July. Brussels: European Commission.

CEC (2002), 'Tampere. Punto di partenza della politica dell'Unione europea nel settore della giustizia e degli affari interni', factsheet 3.I. Brussels: Direzione generale Giustizia e affari interni. <europa.eu.int/comm/justice_home/index_en.htm>.

CEC (2004), 'European neighbourhood policy. Strategy paper', communication from the Commission, COM 373 final, I2 May. Brussels: European Commission.

CEC (2005a), 'Priority actions for responding to the challenges of migration. First followup to Hampton Court', communication from the Commission to the Council and the European Parliament, COM 62I final, 30 November. Brussels: European Commission.

CEC (2005b), '2005 enlargement strategy paper', communication from the Commission, COM 56I, 9 November. Brussels: European Commission.

CEC (2005c), 'Green paper on an EU approach to managing economic migration', COM 8II final, II January. Brussels: European Commission.

CEC (2006), 'Report on the functioning of the transitional arrangements set out in the 2003 Accession Treaty (period I May 2004 - 30 April 2006)', communication from the Commission to the Council, the European Parliament, the European Economic 
and Social Committee and the Committee of the Regions, COM 48 final, 8 February. Brussels: European Commission.

CEU (2003a), 'Council Directive 2003/86/EC of 22 September 2003 on the right to family reunification', Official Journal of the European Union L 25I (3 October): I2-8.

CEU (2003b), 'Council Directive 2003/109/EC of 25 November 2003 concerning the status of third-country nationals who are long-term residents', Official Journal of the European Union L I6 (24 July): 44-53.

CEU (2004), 'Draft multiannual programme. The Hague Programme; strengthening freedom, security and justice in the European Union', note from the Presidency to the Council (General Affairs)/European Council, I3993/04, 27 October. Brussels: Council of the European Union.

Drew, C. \& D. Sriskandarajah (2007), 'EU enlargement in 2007. No warm welcome for labor migrants', Migration Information Source, I January. Washington, D.C.: Migration Policy Institute. <www.migrationinformation.org/Feature/display.cfm?ID $=568>$.

EP (2006), 'Report on the Commission's 2005 enlargement strategy paper', final A6$0025 / 2006$, 3 February. Brussels/Strasbourg: European Parliament.

EU Delegation of the European Commission to Russia (2007), 'Tacis programme 2004. Russian Federation. Support for institutional, legal and administrative reform. Annex II: Terms of reference. Development of immigration legislation', Publication Ref. EuropeAid/I24716/C/SER/RU.

Favell, A. \& R. Hansen (2002), 'Markets against politics. Migration, EU enlargement and the idea of Europe', Journal of Ethnic and Migration Studies 28 (4): 58I-6oI.

Geddes, A. (2003), 'The politics of migration in an integrating Europe', in A. Geddes (ed.), The politics of migration and immigration in Europe, I26-I48. London: SAGE Publications.

Górny, A. \& E. Kępińska (2004), 'Mixed marriages in migration from the Ukraine to Poland', Journal of Ethnic and Migration Studies 30 (2): 353-372.

Górny, A. \& P. Ruspini (2004), 'Forging a common immigration policy for the enlarging European Union. For diversity of harmonization', in A. Górny \& P. Ruspini (eds.), Migration in the new Europe. East-West revisited, 247-277. Basingstoke: Palgrave Macmillan.

Iglicka, K. (2004), 'The revival of ethnic consciousness. The case of Poland', in A. Górny \& P. Ruspini (eds.), Migration in the new Europe. East-West revisited, I3I-I56. Basingstoke: Palgrave Macmillan.

Ivakhniouk, I. (2003), 'Eastern Europe. Current and future migration trends', key paper for the fourth regional conference of the Council of Europe 'Migration policies on the eve of the EU enlargement. What challenges for future co-operation within the East European region', Kiev, 9-Io October.

Jordan, B., Stråth, B. \& A. Triandafyllidou (2003), 'Contextualizing immigration policy implementation in Europe', Journal of Ethnic and Migration Studies 29 (2): 195-224.

Kępińska, E. \& D. Stola (2004), 'Migration policy and politics in Poland', in A. Górny \& P. Ruspini (eds.), Migration in the new Europe. East-West revisited, I59-I76. Basingstoke: Palgrave Macmillan.

Koslowski, R. (2000), Migrants and citizens. Demographic change in the European state system. Ithaca and London: Cornell University Press.

Kratsev, I. (2005), 'Russia's post-orange empire', open Democracy, 20 October.

$<$ www.opendemocracy.net/node/2947>.

Kubosova, L. (2005), 'EU border regions join in bid to prevent new iron curtain', euobserver.com, 7 December.

Motta, G. (2003), 'Dal mercato alla politica: Le istituzioni europee dalla CECA al Trattato di Nizza', in L. Faccioli Pintozzi (ed.), Europa: il Nuovo Continente. Presente, Passato e Futuro dell'Unione Europea, 37-48. Rome: RelazionInternazionali. 
Rex, J. (2004), 'Multiculturalism and political integration in modern nation states', in A. Górny \& P. Ruspini (eds.), Migration in the new Europe: East-West revisited, 93-I08. Basingstoke: Palgrave Macmillan.

Ruspini, P. (2000), 'I paesi dell'Unione europea', in Fondazione Cariplo ISMU, Quinto Rapporto sulle Migrazioni 1999, 213-219. Milan: Franco Angeli.

Ruspini, P. (200I), 'I paesi dell'Unione europea', in Fondazione Cariplo ISMU, Sesto Rapporto sulle Migrazioni 2000, 225-233. Milan: Franco Angeli.

Ruspini, P. (2002), 'Larea dell'Unione europea', in Fondazione ISMU, Settimo Rapporto sulle migrazioni 2001, 263-270. Milan: Franco Angeli.

Ruspini, P. (2003), 'Migratory flows and policies in the new European space', in S. Giusti, L. Tajoli (eds.), Convergence in the enlarged European Union, 22I-24I. Milan: EgeaISPI.

Ruspini, P. (2004), 'Lo spazio migratorio della Ue allargata: Russia e repubbliche ex-sovietiche. Nuovi confini migratori', in Fondazione ISMU, Nono rapporto sulle migrazioni, 33I-34I. Milan: Franco Angeli.

Ruspini, P. (2005), 'Da dieci a venticinque: il nuovo spazio europeo', in Fondazione ISMU, Decimo Rapporto sulle migrazioni 2004. Dieci anni di immigrazione in Italia, 317-330. Milan: Franco Angeli.

Ruspini, P. (2006), 'Allargamento europeo e identità europea', in Fondazione ISMU, Undicesimo Rapporto sulle migrazioni 2005, 389-399. Milan: Franco Angeli.

The Economist (2005), 'The brain-drain cycle', Io December, 377 (8456): 33-34.

Traser, J. (2005) 'Who's afraid of EU enlargement?'. Brussels: European Citizen Action Service.

Van Selm, J. \& E. Tsolakis (2004), 'The enlargement of an \&PHgr;area of freedom, security and justice\&PHgr,. Managing migration in a European Union of 25 members', MPI policy brief 4. Washington, D.C.: Migration Policy Institute.

Visetti, G. (2004), 'Ai confini della Nuova Europa una città divisa tra Ue e Russia', La Repubblica (29 April): I7.

Wallace, H. (1996), 'The challenge of governance', in H. Wallace \& W. Wallace (eds.), Policy-making in the European Union ( ${ }^{\text {rd }}$ Edition). Oxford: Oxford University Press.

Wallace, H. (200I) 'Introduction. Rethinking European integration', in H. Wallace (ed.), Interlocking dimensions of European integration, I-22. Basingstoke: Palgrave Macmillan.

Weil, P. (2005), 'A flexible framework for a plural Europe', discussion paper prepared for the UK Presidency, October. <www.fco.gov.uk/Files/kfile/Weil-final.pdf>. 


\section{Part III}

MEASURING INTEGRATION:

IMMIGRANTS AND THE SECOND GENERATION 



\title{
10 The integration of migrants in the Netherlands monitored over time: Trend and cohort analyses
}

\author{
Rob V. Bijl, Aslan Zorlu, Roel P.W. Jennissen \\ and Martine Blom
}

\begin{abstract}
At the end of the twentieth century the political debate on the integration of ethnic minorities radically changed in the Netherlands. The country that had the image, and that fostered the image, of an open and tolerant society towards immigrant groups and minorities appeared to have changed within one year into a country where 'everyone' was against multiculturalism, which was more restrictive on immigration issues and that required almost full assimilation of its immigrant groups and minorities. The change was announced by the writer Paul Scheffer in his essay 'The multicultural drama' (Scheffer 2000). It was directly followed by $9 /$ II and Pim Fortuyn, both by his comet-like rise in Dutch politics in late $200 \mathrm{I}$ and early 2002, as well as his assassination in May 2002, ten days before the national elections.
\end{abstract}

As a reaction to these events, a parliamentary investigation committee was set up in December 2002. The Committee concluded (Tweede Kamer 2003, 2004a) that most immigrants, up to 70 per cent of them, have found their way towards integration, as measured by indicators such as self-sufficiency, linguistic competence and participation in society. It was, however, not the effect of national or local policies. The policies had an unclear or no impact. The conclusion of the Committee was that integration was much less of a problem than had been suggested in the election campaigns and in political debate since $200 \mathrm{I}$.

The government's reaction underlined, however, the great and undiminished need for clear and further immigration and integration policies, because a considerable number of immigrants and their descendants still seemed to be 'backward' on important integration indicators, such as education, language proficiency and labour market participation, while immigrants were over-represented on counter-indicators of integration, such as (violent) crime and bride-import (Tweede Kamer 2003,2004 b). Members of ethnic minorities, for their part, increasingly felt they were not fully accepted in the Netherlands. Media reports about radical Islamic groups, the concentrations of ethnic minorities in the major cities and the nuisance caused by groups of Moroccan 
and Antillean youths brought the darker side of the multi-ethnic society into sharp relief.

The findings of the Parliamentary Committee had proven that, in the past, there was not only a lack of information on the integration of minorities, but there was also a lack of awareness in Dutch society of the ongoing social changes related to ethnic minorities. It had become painfully clear that the aims and outcomes of integration policies had not consistently been followed and measured. Images, presuppositions and prejudices about the successes and failures of the integration of minorities and the role of policymaking were widely prevalent. It was widely accepted that empirical evidence was urgently needed and that evaluation instruments had to be developed.

In 2004, the Integration Monitor was developed (Van Rijn et al. 2004); in 2005 (Bijl et al. 2005) the first comprehensive monitor was published. The particular object of the Integration Monitor was to measure the progress of immigrant groups in different social fields. By analysing developments in the field of ethnic minority integration over time, a better understanding can be gained of the integration process. On the one hand, this occurs by describing trends over time, focusing on both oldcomers and newcomers. On the other hand, this is achieved by following cohorts of immigrants from their arrival in the Netherlands for a longer period of time, enabling us to gain an insight into the extent and rate of integration and the routes along which this process occurs.

\subsection{Definition of integration and actors in the integration process}

The Integration Monitor is not a 'data-driven' study. A theoretical framework has been developed, which is aimed at the inclusion of data to be analysed.

Integration predominantly involves the process leading towards the achievement of citizenship status and participation in the society in which migrants take up residence. By using this general description, we are emphasising the process-based nature of integration and indicating the absence of an objective minimum or desired end situation.

The achievement of citizenship and participation in society covers at least three dimensions or domains: legal/political, socioeconomic and socio-cultural (Penninx et al. 2004; Ager \& Strang 2004; Esser 2003; European Commission 2005; Entzinger \& Biezeveld 2003; Hagendoorn et al. 2003; Bauböck et al. 1996). The central question in relation to the legal/political dimension of participation and citizenship is the extent to which ethnic minorities are regarded and actually partici- 
pate as full members of the political community. To what extent do they have formal political rights and obligations, and are they able to achieve the positions enjoyed by the autochthonous Dutch population? The socioeconomic dimension refers to social and economic rights, obligations and performance. To what extent do ethnic minorities have the (equal) right and opportunity to accept work and to use institutional provisions to find it? Do they have access to work-related provisions, such as unemployment benefits and insurance and other social security provisions made by the government? The third dimension refers to the domain of the socio-cultural and religious rights of, and possibilities for, migrants. To what extent do they have the (equal) right and opportunity to organise and manifest themselves as cultural, ethnic or religious groups? Are they recognised, accepted and treated the same as similar groups and are they entitled to similar provisions? To what extent do ethnic minority groups form part of the host society, or do they continue to distinguish themselves from it? Does any form of rapprochement exist between migrants and the native-born Dutch population? The legal/political dimension is of special significance, since the other two dimensions are determined by it to an important extent. Viewed from the perspective of individual immigrants, their legal position and the rights granted to them may, in the first place, have important positive or negative consequences for their behaviour and their efforts to integrate. For example, a long period of uncertainty about the question of whether or not an immigrant will legally be permitted to stay may have a negative impact on his willingness to make the effort to integrate. Secondly, the exclusion of migrants living legally in the Netherlands from access to local or national political systems and decision-making does not promote participation or integration and may lead migrants to feel that they are not regarded as full citizens, but as outsiders. Again, this does not invite immigrants to play an active role in the socioeconomic and cultural domain. Generally, policy and attitudes of this nature will have a negative impact on migrant integration processes.

The actors involved in integration processes form a second aspect. In actual fact, there are two such parties: migrants and the host society. The interaction between these parties determines the direction and the outcomes of the integration process. Naturally, these partners are not equal in terms of (political) power and resources. The host society, its institutional structure and its response to newcomers are far more decisive for the outcome of the integration process. Integration policy is established via the political decision-making system and often encompasses the expectations and requirements held by society.

Thus, integration processes occur not only at the level of the individual immigrant, at which level integration is measured in terms of his 
housing, work and education, and his social and cultural adjustment to, and participation in, the new society. Integration also occurs at a collective level for an immigrant group or groups. Migrant organisations are the expression of mobilised resources and ambitions, and they may become an accepted part of society or may isolate themselves and even be excluded by society.

A third level at which integration processes occur is at the institutional level, both at a local and national level. General institutions, such as the education system, the labour market or the political system, are expected to serve all citizens in an equal manner. Laws, regulations, but also unwritten rules and practices form part of these institutions. However, these institutions can also impede access or equal outcomes for immigrants - whether formally or informally. This may occur, for example, where (informal) 'restriction to access' to institutions exists, or through forms of discrimination. Thus, at institutional level, social exclusion processes may also occur, with negative consequences for integration.

\subsection{Integration processes}

Although the processes and mechanisms underlying the achievement of citizenship and participation in society are different at each of the three levels, the outcomes at each level do influence the other levels (Penninx 2004). For example, institutional regulations (legislation, subsidy possibilities, etc.) also influence the opportunities and the scope or the development and orientation of immigrant organisations. Added to this, migrant organisations can use their activities (in the field of interest representation, for example) to help ensure that individual migrants are supported in terms of their participation in society.

Much literature on the subject of integration focuses on first-generation immigrants, and therefore on individuals who have actually already entered the host country. However, in the Netherlands, refugees (asylum seekers) form a relatively small group in comparison with other categories of immigrants. The great majority of immigrants are family reunification migrants, family formation migrants and migrant workers, and form important target groups for government policy. Added to this, second-generation migrants - individuals with an ethnic minority background (born in the Netherlands, into families in which at least one parent was born abroad) - are also one of the main aims of integration policy. In the strict sense of the word, these individuals are not migrants, but here too the question is whether and how they are able to fully participate as equal citizens in society. Intergenerational integration applies for second-generation migrants, i.e. the opportu- 


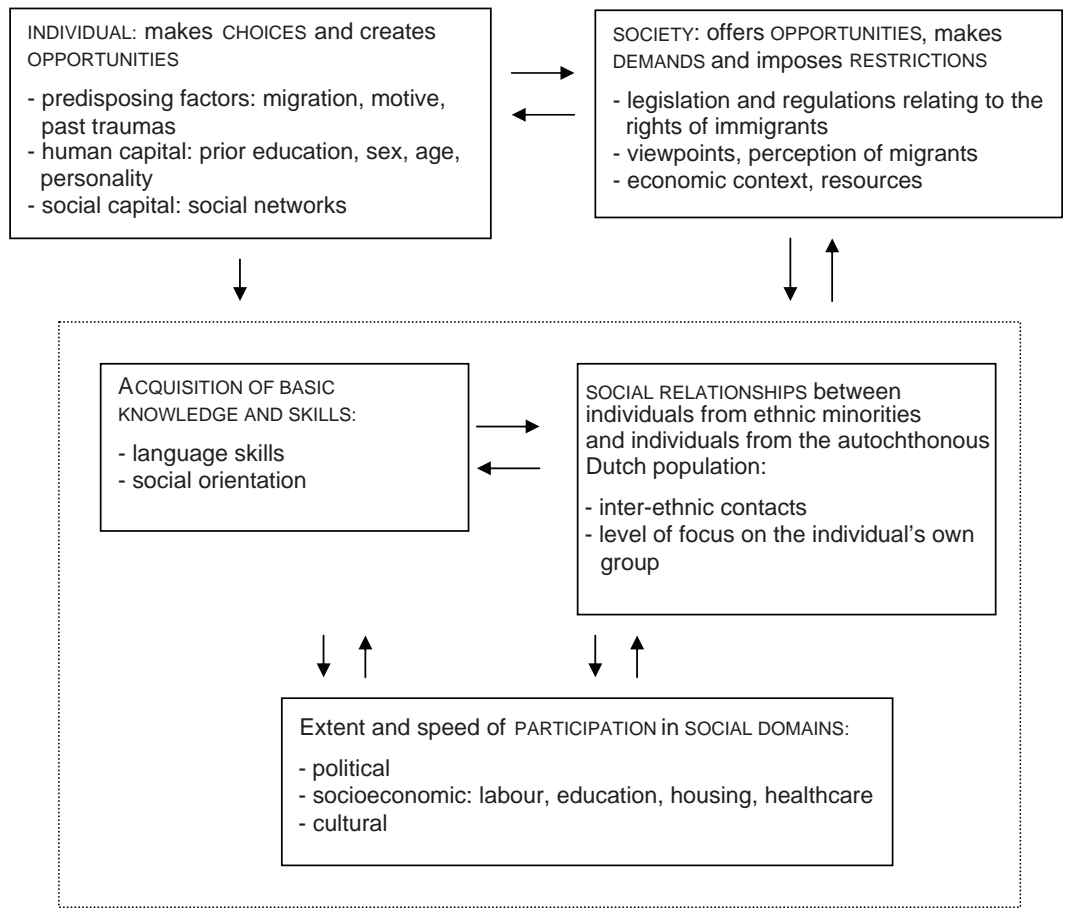

Figure 10.1 Integration processes

nities that second-generation children have to participate in society and the choices made by them to this end are determined (sometimes to a large extent) by the development of their parents' integration process. Traditional opinions on assimilation and adjustment mechanisms applicable to many migrant groups would no longer appear to be adequate in these situations (Esser 2003).

In order to gain an understanding of the question of which processes occur during migrant integration, it is important to highlight the distinction between the various groups targeted by integration policy. The migration motives, personal backgrounds, starting position and initial qualifications, expectations and ambitions of a highly educated employment migrant that comes to the Netherlands to work differ greatly from those of a traumatised refugee from a war zone, or those of a poorly educated partner who comes to the Netherlands in the context of family reunification, to join his or her partner who has already been living in the Netherlands for many years. Thus, the outcomes of integration processes will be very different.

Despite these differences, several basic principles can be distinguished, which can throw some light on the processes and mechan- 
isms applicable to migrant integration. In addition to the competencies ('human capital') that individuals possess (language proficiency, level of education, psychological characteristics, social skills, etc.) and which can be tapped, other important concepts are 'social networks' and 'social capital' (Li 2004; Woolcock I998).

As a first step towards a further theoretical substantiation of studies into integration processes, in which the interaction between the individual and his environment, and that between individual migrants (both first and second generations) and migrant organisations and social institutions (such as the labour market and the political system) is sufficiently recognised, the social capital factor is interesting. This term refers to the social connections and social networks that influence personal interactions and behaviour (Flap \& Völker 2004; Durlauf \& Fafchamps 2003). In many social domains (including voting behaviour, health, social integration (Lock Kunz \& Li 2004; Ager \& Strang 2004; Woolcock I998)), the notion of social capital has been used to gain a better understanding of and offer explanations for individual and group differences. Social links and connections and the shared knowledge, norms, rules and expectations present in them form the core of this approach. The notion of social capital suggests that people are able, by means of the social networks to which they belong and the shared values that are involved, to create advantages for themselves in the short or long term (Portes I998). By drawing from social networks and actively investing in them, they can achieve goals in life that could not otherwise have been achieved. By throwing light on the social bonds within the individual's own ethnic group, for example, the social bridges with members of other groups, and the social links with institutions such as government agencies (Ager \& Strang 2004), it becomes possible to clarify which people are successful or unsuccessful in different areas of life, and how this occurs. Who obtains paid work - and how did the social network help to achieve this? Who completes a course - and to what extent did the immediate social network play a role in this, in terms of mental or material support? And what effect does it have on an immigrant's integration process if he establishes social networks in the Netherlands, but at the same time continues to focus on his country of origin by maintaining a network there too and performing (economic) activities there, as well as culturally continuing to focus on his country of origin (transnationalism)? The choices that people ultimately make, and the extent to which they utilise their own social networks, can be clarified as part of the social capital approach.

It is also important to be able to clarify why the integration of certain groups - or of certain members of migrant groups - is not happening as well or as quickly as that of others, or better in certain social domains than in others. Networks can also lead to 'negative social capital'; 
not only solidarity but also, for example, social pressure to avoid getting too involved with the rest of society, which could lead to 'mobility entrapment' amongst other things, and a restriction on the possibility to progress in the labour market, for example (Li 2004).

\subsection{Operationalisation: social domains and indicators}

We have described integration as a process of acquiring citizenship and the participation of migrants in society in three domains (political, socioeconomic and cultural). In this process, interaction occurs between the migrant/individual from an ethnic minority and society. The migrant makes efforts and invests - in his social networks, amongst other things - with the object of creating opportunities for himself, which he will utilise to achieve a position for himself in society. The host society offers opportunities to this end, but also formulates a number of requirements and restrictions. Figure IO.I shows the factors relevant for the integration process for (groups of) migrants and the relationships between these factors.

The migrant uses his competencies and opportunities (human capital) and his social networks (social capital) to gain a position for himself in society. However, starting positions - and, as such, the opportunities that the various ethnic minority groups have to invest in social participation - vary. A traumatised refugee has a different starting position from a migrant worker with a strongly supportive network and who has enjoyed a good level of education in his country of origin. However, intergenerational effects between first and second-generation migrants form another example. The socioeconomic position of parents, for example, is an important predictor for the school level that their children will achieve (Gang \& Zimmermann 2000).

The motives for immigration are also relevant for the choices and efforts that a migrant can or wants to make. After all, differences in migration motives (for refugees, migrant workers, marriage migrants, etc.) impact on residential status, expectations for the future, ambitions and the focus on the 'new' country.

The efforts made by the migrant take place within a social context, in which legislation and regulations, but also opinions and (pre-)judgements about individuals from ethnic minorities partly determine the migrant's room for manoeuvre. Perceptions and inclusion and exclusion mechanisms related to this have a great impact on migrants' opportunities for participation (Van Tubergen 2004). The economic situation is also relevant: the possibilities that migrants/individuals from ethnic minorities have to find work and, in this manner, gain an inde- 
pendent social position for themselves fluctuate in line with economic developments.

The possession of a sufficient basic knowledge of society and language skills is generally regarded as a condition for full participation in society (Chiswick, Lee \& Miller 2004). This can mean that it becomes easier to establish contacts with the autochthonous Dutch population, for example, which in turn can mean that language proficiency and the knowledge of, and insight into, society further improves or that the immigrant establishes a relevant (new) social network. (Compulsory) integration, which is one of the spearheads of the current integration policy, presupposes the great relevance of sufficient language proficiency and knowledge of Dutch society for successful participation in society.

Thus, the extent to which and the rate at which participation in the relevant domains of politics, economy and culture will occur are interwoven with a complicated combination of individual-related and social factors that can reinforce each other, but also oppose each other. The level of participation or the rate at which the process develops may also vary for an individual or a group per social area. An example of this are the first-generation workers who did take part in the labour process, but generally had inadequate Dutch language proficiency and maintained little or no social contacts with the Dutch population, and also remained disengaged from a political point of view.

Finally, the model makes it clear that as a result of migrant integration, changes may also occur in the host society. Legislation and regulations can be amended in accordance with changed needs and issues in society, and public opinion on migration and migrants may also change. As a result of this, migrants will be able to base their choices and possibilities on the new situation.

\subsection{The development of an Integration Monitor in the Netherlands}

At the end of 2004 and 2005, the first two Integration Monitors (Van Rijn et al. 2004; Bijl et al. 2005) were published. These reports explore the possibility of following immigrant integration processes (in relation to both established immigrants and newcomers) over time. For the Integration Monitor, the Social Statistics Database (SSB), produced by the National Institute for Statistics, i.e. Statistics Netherlands, is the basis. In this database, a large number of registers (including those from the tax authorities, benefits agencies, police) are linked at an individual level to the municipal personal records database (the Gemeentelijke Basis Administratie - GBA). The Immigration and Naturalisation Service (Immigratie- en Naturalisatiedienst - IND) has agreed to allow its Cen- 
tral Aliens Register (Centrale Registratie Vreemdelingen - CRV) to be linked to the SSB too, enabling us to investigate the significance of immigration motives for the integration process. Thanks to these links, the SSB provides individual data on all inhabitants of the Netherlands, including demographic characteristics, employment, benefits, income, education and immigration motives. Because the different years are also interlinked, opportunities are created for the longitudinal monitoring of people in the various registers. In addition to these registrations, personal surveys are linked to the SSB, so that missing data are added on a random test basis (Arts \& Hoogteijling 2002).

The Integration Monitor represents a new approach to the monitoring of integration in the Netherlands in various respects:

- Through the use of the SSB with its data covering the entire population of the Netherlands it is, to an increased extent, possible to make a detailed breakdown of the groups according to their different countries of origin. In addition to describing the traditional 'big four' (the Turkish, Moroccan, Surinamese and Antillean origin groups), it can also be indicated how small immigrant populations that have arrived in the Netherlands in more recent years participate in this country.

- In addition, due to the availability of longitudinal data, an insight can be provided into the progress of integration for a number of groups over a longer period and in different domains of society. This is done by featuring both trends over time and by monitoring cohorts of newcomers that settled in the Netherlands in a certain year, in order to see how they have fared. In the years ahead, trend and cohort analyses will be possible over longer time frames and, moreover, it will then be possible to monitor cohorts in various social domains simultaneously.

- The Integration Monitor focuses on actual behaviour and actual social positions held by individuals, as opposed to attitudes, perceptions, subjective experience and opinions.

Basically, the Integration Monitor is an instrument to support the evaluation of integration policies in the Netherlands. The very first question then, is if the Dutch integration policy, the integration programs and the concrete interventions have been phrased in a sufficiently Specific, Measurable, Acceptable, Realistic and Time-related (SMART) way. With regard to the labour market participation of migrants, target figures have been agreed upon that should be realised within a determined period of time. This, however, is an exception. In many integration projects, aims are often implicit or vague, for example enhancing mutual understanding between migrants and the native population, or promotion of more social cohesion. These goals seem to be very sym- 
pathetic, but it is very difficult to have a concrete and reliable assessment of the outcome of these policies.

Monitoring how individuals and groups develop in different social domains generates the material needed to be able to answer the question of the extent to which developments to be observed over the years in relation to integration are connected to developments within (government) policy. The Integration Monitor makes no claim to measure policy effects, but does establish an important basis for sound effectiveness in its research.

\subsection{Time perspective: state of affairs, developments in generations, trends and cohorts}

A tool that can be used to indicate levels of integration requires a certain type of research. The possibilities are described briefly below.

First, the level of social integration by ethnic minorities can be described on the basis of data describing the situation at a certain moment in time. One disadvantage of this method is that all individuals from ethnic minorities are dealt with in the same manner, whether they have been living in the Netherlands for a short or long period of time, and whether they are first- or second-generation members of their group. Via a second method, i.e. a comparison of different generations of the same origin group, this disadvantage is compensated to some extent. These data can, for example, be used to answer the question of how many generations it takes before a certain origin group achieves a position in education or in the labour market that is comparable to that of the native-born Dutch population.

One problem encountered when comparing generations is the continuous renewal of the migrant population, as a consequence of which the first generation consists of migrants with a duration of stay spanning from several months to as long as 40 years. It would seem improbable that this first generation forms a homogeneous group consisting of individual members whose level of integration is comparable and achieved via a similar process. Account ought to be taken of a number of factors, including the specific economic situation applicable from the time of a migrant's arrival. Particularly in times of low economic activity, it is difficult for newcomers to the labour market to gain a position for themselves.

In order to achieve an understanding of (economic) developments, research is needed into developments over a longer period. For this reason, we also identify a third way of describing social integration, i.e. a comparison of the above statuses at different times. An autochthonous Dutch comparison group is vital for the demonstration of develop- 
ments. For example, research can be used to ascertain whether social integration increases or, instead, decreases over time. This method of research provides some insight into the integration process. However, a number of observations can also be made. If developments in integration are described on the basis of trends, these will partly be determined by the composition of the origin categories. Variables such as age, sex and duration of stay influence chances of social participation, and should therefore be taken into account. Added to this, the level of origin-group entry and exit is one of the factors that influences changes in time. As a consequence, a comparison of two moments in time will relate in part to different groups of individuals.

Therefore, the methods described above (statuses, statuses specified by generation, trends) provide insufficient information on the integration process.

\subsubsection{Cohorts of newcomers}

In order to understand the integration process, the longitudinal method was chosen. This requires that a fixed group of individuals (all ethnic-minority individuals residing in the Netherlands in I998, for example) be monitored over time, on the basis of the chosen indicators of integration. For example, it may be found that a certain origin group is increasingly participating in the labour market. With the exception of people that die or (re-) emigrate, the group being monitored consists of the same individuals.

A further concentration of this method on the development of the Integration Monitor is the monitoring of cohorts of newcomers. This provides a picture of the integration process of a group that arrived in the Netherlands at more or less the same time. In this manner, the integration process is identified from the time at which individuals arrive in the Netherlands, so that the starting positions are comparable in terms of familiarity with the new environment.

By monitoring a cohort of newcomers, it becomes possible to evaluate the integration process. A comparison with the development of average participation in various social domains provides an indication of how quickly the newcomer cohorts approach that average. What is more, if we standardise according to a number of relevant background variables (age and sex, for example), we are able to ascertain whether and if so, how quickly - a population is being approximated in the Netherlands that is equal in terms of these characteristics.

However, by studying just one newcomer cohort, it will not be possible to determine changes over time. This deficiency can be compensated for if various newcomer cohorts are compared with each other (for example, newcomers who immigrated in 1995 and I998). This 
provides an insight into whether the integration process is happening faster or, in contrast, more slowly for different newcomer cohorts.

All these analyses can be refined even further by controlling the outcomes obtained for a number of relevant background variables. This might, firstly, be age, sex and level of education. These controls provide an insight into the factors relating to differences in integration.

\subsection{Indicators of integration}

In order to actually be able to determine the level of integration achieved by different ethnic minority groups, specific social domains must be distinguished in which the level of participation - and changes in this level - is measurable. Labour market participation and educational participation are often regarded as the most relevant structural social domains for the integration process. Sometimes, housing and the use of (health-) care provisions are also included in the equation. As regards the socio-cultural and political domains, in most cases the creation and maintenance of inter-ethnic social relationships, the level of political participation and the level of orientation towards the host society and identification with it are considered relevant for integration.

Besides attention being focused on actual participation or successes in these various social domains, attention is often given to the enabling aspects. An example is the determination of the level of language proficiency in individuals from ethnic minorities. Although language proficiency is not a goal in itself for integration, it is regarded as an essential condition for success, in the labour market for example.

A definitive list of indicators cannot be given. The indicators chosen to determine the various aspects of integration depend, for instance, on the level of detail required and on policy priorities. Ideally, one would like to have one or more indicators for each of the areas described in the model. However, the limited availability of quantitative data compels us to be modest. In many areas, data that make it possible to reveal developments over time, or monitor the integration process of migrant/ethnic minority cohorts over the years are particularly absent.

On the basis of the integral data available at this point at individual level - in order to be able to reveal trends and developments over time - the following indicators for the Integration Monitor 2005 have been selected: performance in education, labour market position, social contacts, and crime. 


\subsubsection{Performance in education}

This section addresses success rates of secondary-school pupils in final examinations; extent of entry into higher education; choice of course of study in higher education; graduation from higher education.

Explanation: Important indicators for the extent to which ethnic minorities gain knowledge and skills are found in their performance in education. Various studies have shown that the performance of individuals from non-Western ethnic minorities in primary education lags behind that of pupils from the autochthonous Dutch population (see, for example, Gijsberts 2003). The intergenerational transfer of a language delay in individuals from non-Western ethnic minorities is probably the most important underlying cause of this. Despite the fact that some of the performance differences are eliminated during pupils' time in primary education, on average pupils from ethnic minorities receive lower recommendations from their primary schools in terms of their choice of secondary school than pupils from the autochthonous Dutch population do.

At a later age, school performance and choice of school are influenced less by the socioeconomic position of pupils' parents than they are at a younger age (Mare I98I). Despite this fact and the existence of schools at different levels, which is in contrast to the situation in primary education, pupils from ethnic minorities continue, on average, to perform less well in secondary education than their classmates from the autochthonous Dutch population. To illustrate this, school dropout rates in secondary education are considerably higher among pupils from ethnic minorities than they are among pupils from the autochthonous Dutch population (Herweijer 2003). This is particularly true for Turkish and Moroccan pupils. The Integration Monitor particularly focused on the performance of final-examination candidates in secondary education and on educational performance and participation in higher education.

Figure I0.2 shows an example of the information that cohort analyses can give. A cohort that entered higher education in 1995 was followed for eight years. The percentage of students that graduate from higher education differs considerably between men and women. On average, women graduate more often and faster than men. After eight years, 72 per cent of women from entry cohort 1995 had graduated from higher education as opposed to 63 per cent of men. Moroccan and Turkish women achieve percentages that are (to a certain extent) comparable with those for autochthonous Dutch men. Moroccan and Turkish men were found to lag far behind them. For example, less 


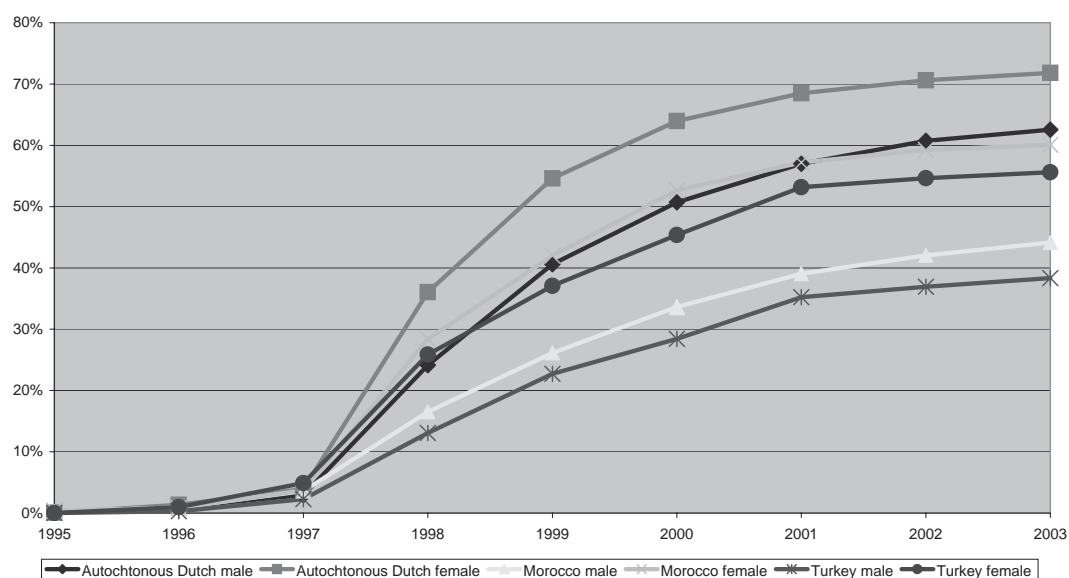

Figure 10.2 Percentage of students that graduate from higher education, based on origin and sex, entry cohort 1995

than 40 per cent of Turkish men who started higher professional education in I995 graduated before 2004 .

\subsubsection{Labour market position}

This section addresses level and rate of labour market participation (as an employee or as someone who is self-employed) and the use of social benefits by newcomer cohorts; trends in labour market participation.

Explanation: Together with educational position, the labour market and income position forms the core of the structural integration of ethnic minority individuals.

Therefore, trends in the labour market and income position of the potential working population were examined (i.e. all people aged from I5 to 64 inclusive) in the period I999 to 2003 , looking at the actual position of individuals (working as employees, or who are self-employed, recipients of assistance benefit, unemployment benefit (WW) or disability benefit (WAO)).

Various explanations may underlie the differences in positions and the differences in over-representation or under-representation of the various origin groups in the labour market or in terms of social benefits. For example, personal backgrounds - such as migration motives, initial qualifications upon arrival in the Netherlands, age, work motivation, sex and length of stay - may affect opportunities for social participation. However, institutional regulations and laws are also influential, 

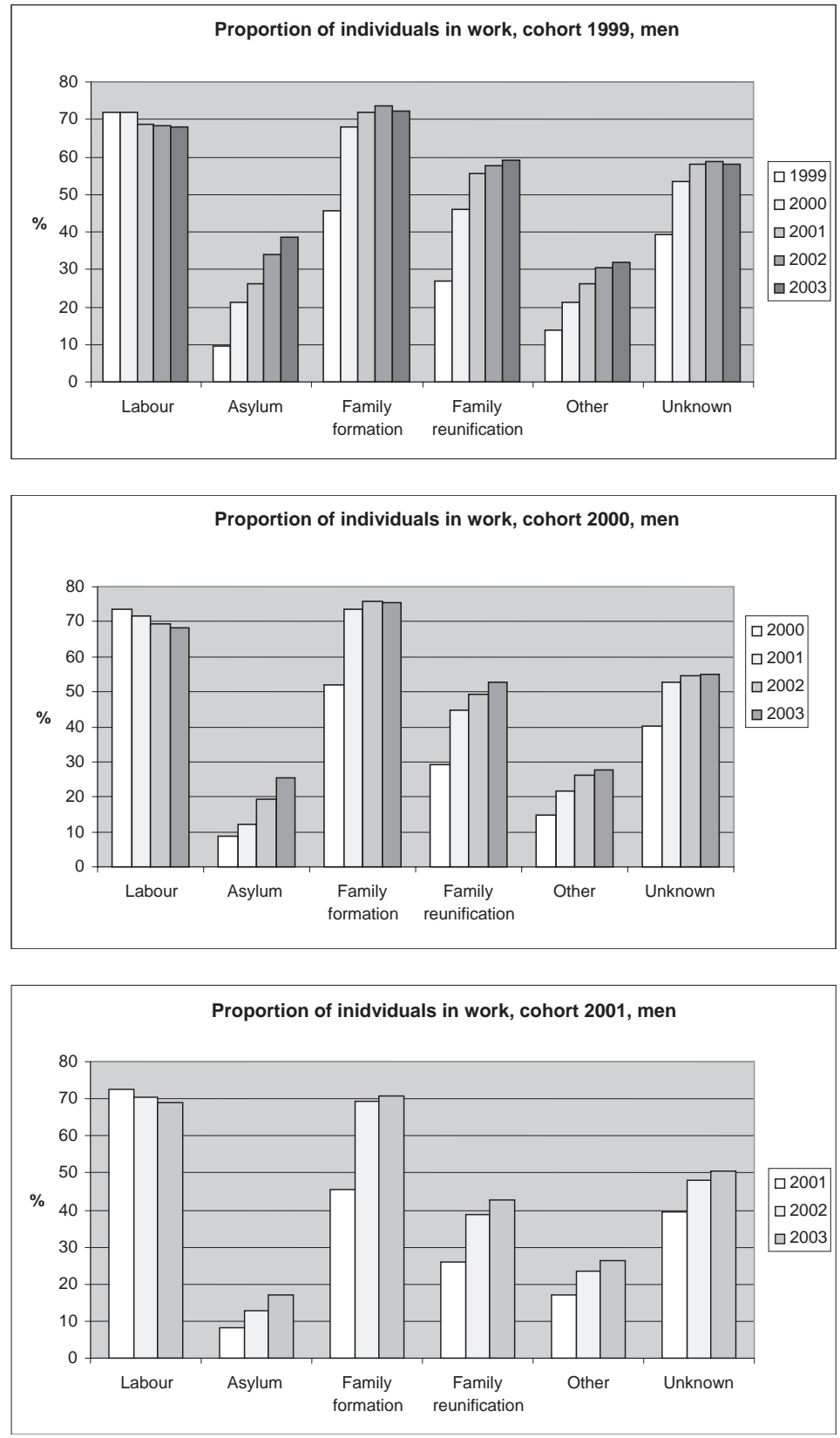

Figure 10.3 Percentage of individuals in work, by immigration cohort (1999, 2000 and 2001), migration motive and sex 

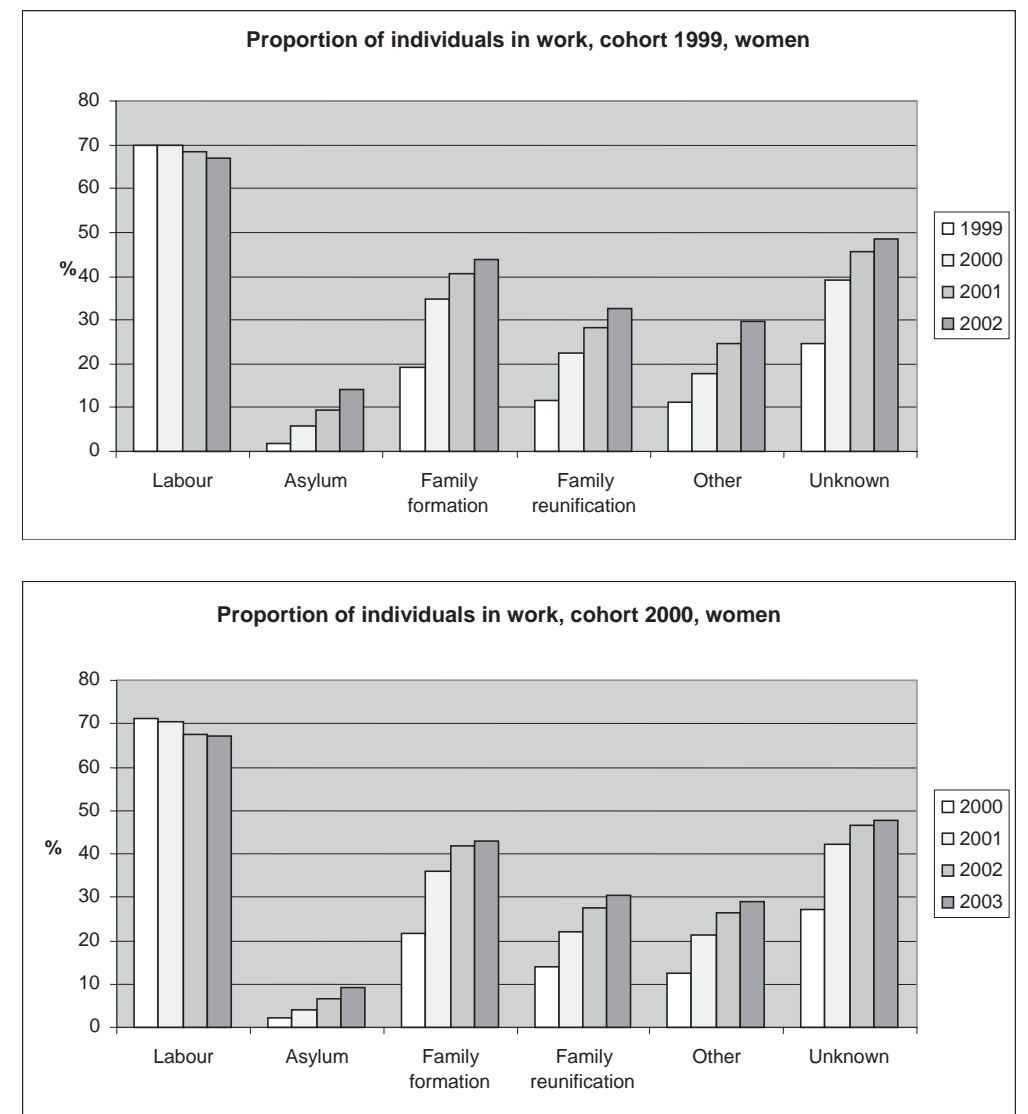

Figure 10.3 (continued)

such as restrictions preventing asylum seekers from entering the labour market.

In the Integration Monitor, a cohort of newcomers was monitored and it was analysed how these migrants with different migration motives fared in the labour market. All newcomers (aged fifteen to 60) who settled in the Netherlands between September I998 and September 1999 (which we will now refer to as the 1999 cohort, consisting of 72,797 individuals) were monitored in the period up to and including 2003. Adding to this, two new cohorts were created, respectively consisting of newcomers who settled in the Netherlands between September 1999 and September 2000 (which we will now refer to as the 2000 cohort, with 79,426 individuals) and between September 2000 and September 200I (the 200I cohort: 86,670 individuals). The 2000 cohort was monitored for a period of four years, while the $200 \mathrm{I}$ cohort 
was monitored for three years. All of the immigrants in these immigration cohorts were aged between fifteen and 60 during their first year in the Netherlands.

Per year, immigrants' labour market position on the last Friday of September was the point of reference. Three labour market positions have been distinguished. The first category comprises individuals working as employees or as independent entrepreneurs. The second category consists of individuals receiving social security benefits ${ }^{2}$ and who are not in work (referred to as 'benefit recipients'). The third category is a residual category consisting of labour market non-participants. These individuals are neither in work nor receiving benefits, but are, for example, in education or are housewives/husbands. By comparing the labour market position of the three cohorts through the years, it can be discovered how quickly immigrants find their way onto the Dutch labour market in a period in which a change occurred in the economic situation. Following a period of economic growth, stagnation occurred after 2001. The effect of this change in the economic climate on the labour market position of immigrants from various origin countries and with various migration motives (work, asylum, family formation, family reunification) can be revealed, as can the relationship between duration of stay and their incorporation process.

A comparison of the cohorts on the basis of migration motives shows that the labour market careers of migrant groups do not demonstrate any startling differences in this respect over time. In all three cohorts, a strong increase occurs among family migrants of the number of individuals in work in their second year in the Netherlands; subsequently, the proportion of individuals in work stabilises. As of the second year of their stay in the Netherlands, the proportion of male family formation migrants with a job is at approximately the same level as that applicable for male labour migrants. The situation is different for female family formation migrants. More of these women receive benefits and are less often in work than female labour migrants are.

Family reunification migrants are often in a less favourable position than family formation migrants are. This can, perhaps, in part be explained by the fact that family reunification migrants are young, on average, and not (yet) planning to find a job. In contrast, family formation migrants are often young adults who have already completed their education and are keen to enter the labour market.

In the individual asylum migrant asylum seekers cohorts, we see an ongoing increase among both the proportion of individuals in work and the proportion of benefit recipients. However, clear differences do exist between men and women. Women are less often in work and more often on benefits. When compared to migrants with other migration motives, the percentage of asylum seekers in work is the lowest, and the 
proportion of benefit recipients is the highest amongst this group. This is due to the legal position and immigration history of asylum seekers. The labour market participation of immigrants from asylum countries is very low in the entry year (up to approximately ro per cent for men and 2 per cent for women). This does increase in subsequent years, but remains low in comparison with other immigrants.

\subsubsection{Social contacts}

This section addresses the number of mixed marriages; marriages with partners from the country of origin; composition of residential areas according to the proportion of individuals from ethnic minorities within them.

Explanation: In addition to political and economic participation, integration also entails socio-cultural participation in society. Common to all definitions of socio-cultural integration (Dagevos 200I) is an emphasis on the extent to which contact exists between individuals from ethnic minorities and the autochthonous Dutch population. To what extent do ethnic minority groups form part of the host society, or to what extent do they remain separate to it? Is there any form of rapprochement between migrants and the autochthonous Dutch population?

The Integration Monitor did not focus on opinions and attitudes but on actual behaviour in the field of social contacts. We must realise that maintaining contact is just one small part of what is referred to as socio-cultural integration and, what is more, that there are several indicators to represent the concept of 'social contacts', which, incidentally, is a broad concept in itself.

With these limitations in mind, the Monitor reported on the results obtained on the extent to which the origin groups enter into marriages with autochthonous Dutch brides and bridegrooms. Building a relationship with someone of a different ethnic origin and confirming it by means of marriage can be considered a strong form of social contact. The authors addressed the question of whether differences exist between first- and second-generation individuals from ethnic minorities in terms of marriage patterns. After all, if this difference is considerable, it can be concluded that integration is progressing well in this respect. A relevant fact in this context is that first-generation individuals were often already married when they arrived in the Netherlands. Thus, they will (often) not marry an individual from the autochthonous Dutch population.

The second indicator is the extent to which individuals from ethnic minorities arrange for marriage partners to join them from their countries of origin. Amongst other things, these two indicators indicate the 
extent to which individuals from ethnic minorities (still) orient themselves towards the norms and values of their society of origin, whether or not influenced by family. The more migrants adapt to and become rooted in the society in which they settle, the more their choice of partner ought automatically to become directed at someone from their new country; this is a well-known proposition from migrant studies. If migrants - the second generation in particular - continue to marry within their own circles, this can be interpreted as a sign that they are continuing to feel different to, or are still being regarded as different by, the dominant group (Sterckx \& Bouw 2005; Hooghiemstra 2003).

Table IO.I shows trends in the percentage of marriages, per origin group and generation, in which individuals from Western and nonWestern ethnic minorities residing in the Netherlands marry partners from their country of origin.

Table 10.1 Proportion of individuals from ethnic minorities that are resident in the Netherlands and arrange for partners to join them from their countries of origin (by sex, origin and generation)

\begin{tabular}{lrrrrrrrr}
\hline & \multicolumn{1}{c}{ Men (\%) } & & \multicolumn{7}{c}{ Women (\%) } \\
\cline { 2 - 8 } Origin & 1999 & 2000 & 2001 & 2002 & 1999 & 2000 & 2001 & 2002 \\
\hline & & & & & & & & \\
Ethnic-minority total & 27.3 & 30.2 & 32.3 & 28.3 & 18.0 & 18.9 & 20.6 & 18.8 \\
$\quad$ First generation & 40.4 & 43.2 & 45.0 & 40.4 & 23.4 & 21.9 & 24.3 & 22.3 \\
$\quad$ Second generation & 8.6 & 10.2 & 12.5 & 11.7 & 12.1 & 15.5 & 16.5 & 15.0 \\
& & & & & & & & \\
Western ethnic minority & 5.3 & 7.2 & 7.9 & 7.2 & 1.5 & 2.1 & 2.0 & 1.9 \\
$\quad$ First generation & 14.0 & 19.0 & 19.8 & 18.2 & 3.4 & 4.2 & 4.0 & 3.9 \\
$\quad$ Second generation & 1.4 & 1.5 & 1.9 & 1.7 & 0.4 & 0.9 & 0.9 & 0.7 \\
Non-Western ethnic minority & 47.2 & 49.1 & 50.1 & 45.2 & 35.8 & 35.2 & 37.3 & 34.4 \\
$\quad$ First generation & 49.2 & 51.0 & 52.8 & 48.1 & 33.6 & 31.2 & 34.6 & 32.5 \\
$\quad$ Second generation & 36.5 & 39.5 & 39.2 & 35.4 & 41.2 & 44.2 & 42.6 & 37.9 \\
& & & & & & & & \\
Turkey & 62.5 & 65.5 & 64.1 & 61.1 & 62.8 & 64.1 & 62.7 & 61.9 \\
$\quad$ First generation & 63.9 & 67.7 & 68.6 & 65.6 & 66.1 & 63.4 & 64.5 & 69.0 \\
$\quad$ Second generation & 59.4 & 61.1 & 56.2 & 54.7 & 59.7 & 64.6 & 61.3 & 56.5 \\
Morocco & 66.7 & 65.1 & 65.5 & 55.9 & 63.7 & 59.7 & 58.0 & 52.7 \\
$\quad$ First generation & 68.1 & 66.5 & 67.5 & 59.1 & 65.9 & 61.2 & 62.1 & 56.7 \\
$\quad$ Second generation & 51.1 & 51.6 & 52.1 & 40.5 & 57.5 & 56.3 & 49.5 & 45.6 \\
Suriname & 19.8 & 18.7 & 20.3 & 17.3 & 10.6 & 10.0 & 8.4 & 9.6 \\
$\quad$ First generation & 22.9 & 21.0 & 24.1 & 20.7 & 11.8 & 10.8 & 9.4 & 11.3 \\
$\quad$ Second generation & 4.7 & 8.1 & 6.4 & 7.5 & 5.6 & 7.1 & 5.6 & 5.8 \\
Netherlands Antilles and Aruba & 2.8 & 1.8 & 1.1 & 2.1 & 2.5 & 3.6 & 3.1 & 3.9 \\
$\quad$ First generation & 3.4 & 2.5 & 1.1 & 2.7 & 3.4 & 4.2 & 4.5 & 5.5 \\
$\quad$ Second generation & 1.0 & 0.0 & 1.0 & 0.8 & 0.0 & 2.2 & 0.0 & 0.7 \\
\hline Sourc: WOD/CBS & & & & & & & &
\end{tabular}

Source: WODC/CBS (2006) 
In I999, almost two-thirds of Turkish and Moroccan marriages were migration marriages. This applies for both men and women. This is slightly lower amongst the second generations, but amongst these individuals too, the percentage applicable ranges from approximately 50 to 60 per cent. Few differences exist between I999 and 200I. But especially in Moroccans, we see a significant decrease in 2002, both in the first and second generations.

\subsubsection{Crime}

This section addresses suspects being questioned by the police; type of offence; recidivism.

Explanation: Over-representation of individuals from ethnic minorities in crime figures has been a focus of the government's attention for many years. Various studies point to this over-representation in the criminal justice system, such as the recently published WODC publication entitled Suspected of crime. A closer look at persons of foreign and Dutch heritage (Blom et al. 2005). The excessive involvement of individuals from ethnic minorities in crime can be regarded as an expression of limited bonding with society and, as such, as an expression of inadequate (socio-cultural) integration. A big difference between population groups would seem to result in the violation of prevailing norms (Dominguez Martinez, Groeneveld \& Kruisbergen 2002). The over-representation of individuals from ethnic minorities in crime figures may also be an indication of a socioeconomic integration that is lagging behind (Kromhout \& Van San 2003). Incidentally, the relationship between crime and integration cannot be interpreted very clearly (Bovenkerk 2003). Among other things, the relationship that exists between police deployment and the likelihood of being caught may mean that some origin groups become more known to police and the judiciary than others. The extent to which this says something about the degree of criminal behaviour amongst these origin groups and, as such, could also be an indication for their (non-)integration into society, is difficult to say.

The Integration Monitor reproduced the most recent indicators that have become available since the publication of Blom et al. (2005).

The above set of indicators - which, where possible, distinguished between origin group, generation, length of stay, sex and age - has not (yet) made it possible to cover all of the relevant areas in all the various domains of society. Added to this, these data only make it possible to demonstrate the two-sidedness of the integration process to a limited extent. As soon as more data become available, the number of indicators will be increased. 


\subsection{The value of the monitoring approach in integration policy evaluation}

Although data that make it possible to monitor integration over time are becoming available in increasingly more areas, we must realise that this information is still missing for a number of relevant areas.

The connection between efforts to integrate and (later) successes in the labour market and socio-cultural integration has not yet been made. Do immigrants that invest in the achievement of a social position and who are (extra) active in their acquisition of the Dutch language and their orientation towards Dutch society - via an integration programme or by other means - find work faster, or work at a higher level, and do they develop a bigger social network than migrants who are less active in this area?

The reciprocity of integration, the role played by the Dutch host society, has not been adequately identified. Possible indicators in this connection are data on the access that migrants have to important facilities, such as primary healthcare and social work. Are migrants equally able to gain access, to an equal extent? Another potential indicator - at macro level - are amendments to legislation and regulations that affect migrants, and how they turn out in practice.

The consequences of the economic situation and of social perceptions of the position of ethnic minorities can be identified better and more systematically. The Annual Report on Integration (SCP/WODC/ CBS 2005) provides relevant information on mutual perceptions of ethnic minority individuals and the autochthonous Dutch population, opinions on ethnic distance, etc. However, for this subject too it would be relevant to have access to actual behavioural data, such as data on reports of discrimination, reports of violence by individuals from the autochthonous Dutch population against individuals from ethnic minorities, and vice versa.

A difficult subject is the specific identification of social inter-ethnic contacts in day-to-day life and of the extent to which people focus or continue to focus on their countries of origin. However, data are still missing on developments in time as regards actual contacts at work, in clubs, in the residential area and in other contacts. This example makes clear that probably survey data must inevitably be added to register data, since not all domains that are relevant are covered by register data.

The absence of information about migrants' starting positions is a serious deficiency: what their actual background upon arrival in the Netherlands in terms of level of education is, knowledge of Dutch/Western society, physical and mental health, their social networks - if present - in the Netherlands and in their countries of origin. This sort of 
information about migrants' human and social capital is vital for the interpretation of successful and unsuccessful integration processes. This type of information - about their parents - is also important for second-generation individuals from ethnic minorities. What support, encouragement and socioeconomic opportunities have this second generation of young people received from their parents?

Ideally, the integration of origin groups in a number of social domains should be examined simultaneously. For local and national integration policy, it is vital to know how social stratification unfolds amongst origin groups; how and in which origin groups educational performance is accompanied by successful performance in the labour market, for example. Or, the extent to which the development of a social network consisting of individuals from ethnic minorities and from the autochthonous Dutch population promotes the extent or rate of social participation. By identifying integration processes in these various domains simultaneously for clearly defined groups of migrants, we will be able to clarify the mechanisms at play in these processes. This will prove invaluable when developing effective measures aimed at promoting integration.

We stressed that a monitor is an instrument to support policy evaluation. The Integration Monitor focuses on output of integration, for example the changes in labour market position or educational attainment over a specified period of time. The monitor does not give insight into the 'working mechanisms' of integration policy. The key question in policy evaluation is 'what works for whom in what circumstances?' Policy measures aimed at young Turkish second-generation migrants to enhance their opportunities to find a job, will not necessarily be effective - or might even have negative side-effects - in Moroccan first-generation migrants, due to differences in social and economic background and social capital, cultural values, or some other, still unknown, context. Because most available data are 'isolated', an integrated evaluative approach of integration policies in Dutch society is difficult to realise. Statistical data from national registers - however complete and reliable they may be - will never give a comprehensive picture of the integration processes in society. Additional data are needed that give insight into the specific contexts of distinct migrant groups.

Politicians and policymakers are primarily interested in the question if the measures they initiated are 'effective'. Apart from the issue that it is vital not to stick at an intervention or policy measure as a 'black box', but to try to clarify the working mechanisms, other complex questions can be raised. In evaluation research the experimental study design is the golden standard. This design allows with the most certainty conclusions about the causal relationship between an intervention and the effects that have been measured. In the well-known Maryland 
Scientific Methods Scale (Farrington et al. 2002) the highest level of assessment of effect is an experimental design with an assessment before and after the intervention, and an assessment of the effects both in the group that has experienced the intervention and in a control group. An additional condition is that the people have been included in both groups totally at random.

There is no doubt that this type of study design is inconceivable in the field of integration policy. Most often a policy measure is taken for the total population, and does not give any possibility to study on small scale - with the possibility of monitoring a control group - if the measure is effective, or the measure or intervention is aimed at a very specific group of migrants, making it impossible to find a comparable control group.

In integration research there is a need for a methodology combining quantitative and qualitative designs (Ager \& Strang 2004). Though there is an increasing amount of quantitative outcome data on a national level that describe the positions and the careers of migrants in different sectors of society, better knowledge of the cause-effect relationships between a policy measure and these social positions of migrants requires another type of information. The in-itself appropriate attention to 'hard' figures should not lead to a situation in which qualitative information gathered by in-depth interviews, focus groups and the like, as a source for evaluation, be ignored.

\section{Notes}

I The date of entry is the settlement date, thus the date of registration in the personal records database. In other words, this excludes the preceding period, which in the case of asylum migrants, for instance, may have been spent in an asylum seekers centre.

2 This includes all benefits: ABW (assistance benefits), WAO (disability benefits), WAZ (disability benefits for the self-employed, Wajong (benefits for young disabled people), WW (unemployment benefits), but also other benefits, such as Ziektewet (sickness benefits), IOAW (non-means tested welfare) and IOAZ (benefits for older individuals and the partially disabled, individuals formerly self-employed).

\section{References}

Ager, A. \& A. Strang (2004), 'Indicators of integration', Final report. London: Home Office.

Arts, C. H. \& E. M. J. Hoogteijling (2002), 'Het Sociaal Statistisch Bestand 1998 en I999', Sociaal-economische maandstatistiek I2: I3-2I. Voorburg/Heerlen: Statistics Netherlands. 
Bauböck, R., A. Heller \& A. R. Zollberg (eds.) (1996), The challenge of diversity. Integration and pluralism in societies of immigration. Aldershot: Avebury.

Bijl, R. V., A. Zorlu, A. S. van Rijn, R. P. W. Jennissen \& M. Blom (2005), 'Integration Monitor 2005. The social integration of migrants monitored over time: trend and cohort analyses'. The Hague: WODC.

Blom, M., J. Oudhof, R. V. Bijl \& B. F. M. Bakker (eds.) (2005), Verdacht van criminaliteit. Allochtonen en autochtonen nader bekeken. The Hague: WODC/CBS.

Bovenkerk, F. (2003), 'Over de oorzaken van allochtone misdaad', in F. Bovenkerk, M. Komen \& Y. Yesilgöz (ed.), Multiculturaliteit in de strafrechtspleging, 29-58. The Hague: Boom Juridische Uitgevers.

Chiswick, B. R., Y. L. Lee \& P. W. Miller (2004), 'Immigrants' language skills. The Australian experience in a longitudinal survey', International Migration Review 38 (2): 6II654 .

Dagevos, J. (200I), Perspectief op integratie. Over de sociaal-culturele en structurele integratie van ethnische minderheden in Nederland. The Hague: Netherlands Scientific Council for Government Policy/WRR.

Dominguez Martinez, S., S. Groeneveld \& E. Kruisbergen (2002), Integratiemonitor 2002. Rotterdam: ISEO.

Durlauf, S. N. \& M. Fafchamps (2003), 'Empirical studies of social capital: a critical survey', working paper no. I2. Madison: University of Wisconsin-Madison.

Entzinger, H. \& R. Biezeveld (2003), 'Benchmarking in immigrant integration', report to the European Commission. Rotterdam: Erasmus University/ERCOMER.

Esser, H. (2003), 'Does the new immigration require a new theory of intergenerational integration?’, working paper no. 7I. Mannheim: Universität Mannheim/Mannheimer Zenturm für Europäische Sozialforschung.

European Commission (2005), 'A common agenda for integration. Framework for the integration of third-country nationals in the European Union', $\operatorname{COM}(2005) 389 / \mathrm{F}$.

Farrington, D. P., D. C. Gottfredson, L. W. Sherman \& B. C. Welsh (2002), 'The Maryland scientific methods scale', in L. W. Sherman, D.P. Farrington, D. Layton MacKenzie \& B.C. Welsh (eds.), Evidence-based crime prevention. New York: Routledge.

Flap, H. \& B. Völker (eds.) (2004), Creation and returns of social capital. A new research program. London/New York: Routledge.

Gang, I. \& F. Zimmermann (2000), 'Is child like parent? Educational attainment and ethnic origin', Journal of Human Resources 35: 550-569.

Gijsberts, M. (2003), 'Minderheden in het basisonderwijs', in J. Dagevos, M. Gijsberts \& C. van Praag (eds.), Rapportage Minderheden 2003, 63-I09. The Hague: SCP.

Hagendoorn, L., J. Veenman \& W. Vollebergh (eds.) (2003), Integrating immigrants in the Netherlands. Cultural versus socio-economic integration. Aldershot: Ashgate.

Herweijer, L. (2003), 'Voortgezet onderwijs, beroepsonderwijs en hoger onderwijs', in J. Dagevos, M. Gijsberts \& C. van Praag (eds.), Rapportage Minderheden 2003, III-I42. The Hague: SCP.

Hooghiemstra, E. (2003), Trouwen over de grens. Achtergronden van partnerkeuze van Turken en Marokkanen in Nederland. The Hague: SCP.

Kromhout, M. \& M. van San (2003), Schimmige werelden. Nieuwe etnische groepen en jeugdcriminaliteit. The Hague: WODC.

Li, P.S. (2004), 'Social capital and economic outcomes for immigrants', Journal of International Migration and Integration 5: I7I-190.

Lock Kunz, J. \& P.S. Li (2004), 'Introduction to special issue. The role of social capital in immigrant integration', Journal of International Migration and Integration 5: I65-I69.

Mare, R. D. (I98I), 'Change and stability in educational stratification', American Sociological Review 46: 72-87. 
Pawson, R., T. Greenhalgh, G. Harvey \& K. Walshe (2005), 'Realist review. A new method of systematic review designed for complex policy interventions', Journal of Health Services Research and Policy IO, suppl I: 2I-34.

Penninx, R. (2004), 'Integration policies for Europe's immigrants. Performance, conditions and challenges', expert paper for the Sachverstängenrat für Zuwanderung und Integration. Gouda, 2004.

Penninx, R., K. Kraal, M. Martiniello \& S. Vertovec (2004), Citizenship in European cities. Aldershot: Ashgate.

Portes, A. (I998), 'Social capital. Its origins and applications in modern sociology', Annual Review of Sociology 24: I-24.

Rijn, A. S. van, A. Zorlu, R. V. Bijl \& B. F. M. Bakker (2004), De ontwikkeling van een Integratiekaart. The Hague: WODC/CBS.

Scheffer, P. (2000), 'Het multiculturele drama', NRC Handelsblad, 29 January.

SCP/WODC/CBS (2005), Annual Report on Integration 2005. The Hague: SCP/WODC/ CBS.

Sterckx, L. \& C. Bouw (2005), Trouwen van daar. Partnerkeuze van Turkse en marokkaanse Nederlanders. Amsterdam: SISWO.

Tweede Kamer (2003/2004a), Bruggen bouwen: Eindrapport Tijdelijke commissie onderzoek integratiebeleid. The Hague: Tweede Kamer (House of Representatives), conference year 2003/2004, 28689, no. 8-9.

Tweede Kamer (2003/2004b). Kabinetsreactie op het rapport Bruggen bouwen van de Tijdelijke commissie onderzoek integratiebeleid (commissie-Blok). The Hague: Tweede Kamer (House of Representatives), conference year 2003/2004, 28689, no. I7.

Tubergen, F. A. van (2004), The integration of immigrants in cross-national perspective. Utrecht: Utrecht University.

WODC/CBS (2006), 'Integration Monitor 2006'. The Hague: WODC / CBS.

Woolcock, M. (1998), 'Social capital and economic development: Towards a theoretical synthesis and policy framework', Theory and Society 27: 151-208. 



\title{
11 What integrates the second generation? Factors affecting family transitions to adulthood in Sweden
}

\author{
Calvin Goldscheider, Eva Bernhardt and Frances Goldscheider
}

\subsection{Introduction}

While there have been many studies of immigrant adaptation in the public spheres of work, school and politics and some on select family dimensions (for example fertility and divorce), few have focused on family relationships among immigrants, either generationally or between partners. Even fewer studies have investigated immigrant groups from a 'gendered' perspective, going beyond gender differences in labourforce participation and economic activities to investigate gender roles and attitudes of immigrants and their adult sons and daughters. Several major research reviews have highlighted the importance of studying family relationships and the critical role of gender relationships that characterise immigrants, and have called attention to these lacunae in the research literature (for reviews, see Hugo I997; Bjerén I997; Pedraza I99I).

Research in various countries has documented the important role of family relationships for the social and economic integration of immigrants. Families are a source of values conveyed across the generations and are also a resource for immigrants in their adaptation to their place of destination. Families normally assist in the initial settlement and the economic adjustment of immigrants, forming social and economic networks for immigrant integration. Over time, families assist in the socialisation of the next generation, the native-born of foreignborn parents, in learning how to adjust to the new society and in retaining or redefining the culture and values of their origins (see Brubaker 200I; Portes I995; Zhou 200I). Hence families are particularly important for those of foreign-born origins and are more problematic, providing many of the resources needed for success in the new society and a 'brake' on assimilation into the new society. The examination of the relative balance of these family processes has become a critical part of an assessment of the integration and inclusion of immigrants and their children. 
A focus on the 'private sphere' of the family directly raises the question of gender relationships. The roles of women and men in families are challenged by the potential family generational break brought about by the immigration process when gender roles differ in the new society. When these differences are reinforced at work and in school, relationships between husbands and wives and between parents and their sons and daughters are often strained. These generational tensions and strains are increased when the cultural differences and social expectations of the places of origin and destination are greater.

There are two central axes of family life: between parents and their children, and between men and women. Both are under conspicuous challenge among immigrants and their children in a society such as Sweden with its egalitarian family system and social policies reinforcing gender and generational equality (Bernhardt 1992). Living with others of similar national origin often provides networks of information and opportunities, given that the language barriers are low and the claims of kin and landsmen are still strong (Murdie \& Borgegard I996). But too close a residential or occupational connection with other immigrants can limit social integration into wider Swedish society and access to its opportunities. Immigrant and ethnic clustering may also intensify prejudice and discrimination against those who live and work separately from longer-term residents (Pred 2000). Thus, issues of gender and ethnic variation in immigrant adjustments are conspicuous features of countries with rapid increases in immigration from culturally diverse countries of origin.

We focus in this paper on indicators of gender and ethnic differences in selected areas of family life among the adult children of immigrants in Sweden. The particular history of immigration and family policy in Sweden places in context the general challenge of integration through the prism of family processes and gender relationships.

\subsection{Sweden's recent history of immigration and family policy}

Sweden experienced rapid increases in immigration in the last decades of the twentieth century and a new generation of Swedish-born children of recent immigrants is beginning the transition into adulthood in the twenty-first century. The new immigration is not only larger in volume than in earlier periods but also originates from more culturally distant areas, such as the Middle East, Asia and Africa, increasing the diversity of Sweden's population. The number of foreign-born people in Sweden increased from 538,000 in 1970 to almost a million in I999 (table II.I). While the total Swedish-born population increased by less than 5 per cent over these three decades, the foreign-born popula- 
Table 11.1 Changing Swedish society: more foreign-born, more non-European

\begin{tabular}{lrrr}
\hline & 1970 & 1999 & \% Change \\
\hline Swedish total population (thousands) & 8,077 & 8,861 & 9.7 \\
Swedish born population (thousands) & 7,539 & 7,880 & 4.5 \\
Foreign-born population (thousands) & 538 & 982 & 82.5 \\
& & & \\
\% of population foreign-born & 7.1 & 12.5 & - \\
Of foreign born: & & & - \\
\% from Nordic Countries & 59.7 & 28.5 & - \\
\% from other Europe & 32.7 & 32.9 & - \\
\% from non-Europe & 7.6 & 38.6 & \\
\hline
\end{tabular}

Source: Statistics Sweden

tion increased by 82 per cent. As a result, the proportion born outside of Sweden increased from about 7 per cent of the population to more than I2 per cent from I970-I999; about one in nine people living in Sweden at the end of the twentieth century was foreign-born. Furthermore, a quarter of children below seventeen years of age have one or both of their parents born outside of Sweden.

The impact of the recent immigration on Swedish society has been shaped even more by its changing composition. Not only was the proportion of the foreign-born much less in I970 than in the late I990s, but three out of five who were foreign-born in I970 were from other Nordic countries (59.7 per cent), primarily from Finland. Most of the rest (one-third) were from other European countries (32.7 per cent) and only 7.6 per cent of the I970 foreign-born population was from countries outside Europe. By I999, however, nearly 40 per cent of the foreign-born were from non-European countries, numbering almost 380,000 people. Among the foreign-born in I999 from the non-Nordic European countries, those from Poland $(40,000)$ and from Turkey (3I,O०O) are among the largest immigrant groups. Our analysis of the children of the foreign-born focuses on those of Polish and Turkish origins, targeting two of Sweden's largest immigrant groups. These two communities represent culturally and socially diverse populations and illustrate a range of adjustments among the new populations living in Sweden.

A new generation of Swedes with foreign-born parents is already emerging, because immigrants are normally young adults, most just beginning their family lives. Our analysis of family patterns among adult children of immigrants making the transition to adulthood focuses on those from Poland and Turkey, groups that are already substantial in size. By I998, there were more than 26,000 children of Polish-born parents growing up in Sweden, so that there were nearly 66,000 people in Sweden of Polish origins (those born abroad and 
their children). Swedish-born children are increasing the size of the Turkish community in Sweden even more rapidly. In 1998, there were nearly 26,000 children of Turkish-born parents growing up in Sweden which, combined with the 31,000 immigrants from Turkey, makes a total of 57,000 of Turkish origins in Sweden. Many of these, of course, are still children. Increasingly, Swedish society is gaining a new generation of workers, voters, and parents who were raised in Sweden, but in families in which at least one of the parents was born and raised abroad.

The increase in the numbers of Swedes from non-Western countries is a particular challenge because of Sweden's extensive social and family policy programs. These were established while Sweden was a culturally homogeneous country and were designed to reinforce individual choice and gender equality both at home and in the workplace. These values often contrast with the gender relationships and the marriage and work patterns that are common among immigrant families in Sweden. Many immigrant communities reinforce families over individualism by supporting early marriage and discouraging non-family living, cohabiting, out-of-wedlock parenthood and female employment (Lesthaeghe 1995). In many countries of origin, gender separation is normative; only men are expected to be employed and women are expected to focus on caring for their families. Male dominance and control are encouraged. Hence, we expect increased tensions between the generations, as the immigrants' native-born children struggle to shape their own family lives in the transition to adulthood. ${ }^{1}$

Do immigrants' children's family patterns change as they are exposed to new contexts of family-, gender- and child-based policies supported by the state and other non-family institutions? Sweden provides financial incentives that might motivate immigrants and their Swedish-born children to become 'Swedish', but are these incentives enough? What happens to the adult children of immigrants socialised in Sweden when their background, with its culture of gender segregation and familism, is at odds with the broader culture into which they are becoming adults? More specifically, we ask: what are the patterns among the adult children of immigrants, compared to those of Swedish origins, of leaving home, forming a family with a partner, and balancing work and family?

Our focus on the transition to adulthood highlights the tensions associated with young adulthood where there is a density of transitions (to work, school, partnering and new family formation) in a short period of the life course. The shifts in generational relationships during this period are likely to reveal the challenges of integration into Swedish society. Gender issues challenge the relationship of women to their families in the transition to adulthood and increase the tensions 
between young men and women as they seek to make new lives, perhaps together.

We review in this paper the analysis of a series of family indicators that illuminate choices and attitudes in young adulthood-leaving home, partnering and cohabitation, the ethnic origins of partners, and the preferred balance of work and family when there are young children. In the Swedish context, these family themes are central to understanding how these adult children of foreign-born parents differ from those of Swedish origins (for the larger study, see Bernhardt, Goldscheider \& Goldscheider 2007).

We selected a series of family dimensions that are critical to understanding the transition to adulthood of children of immigrants:

- The timing and route out of the home reveals intergenerational relationships for immigrant groups and their adult children where, unlike among the Sweden origin population, non-family living is rare;

- The level of cohabitation tells us both about intergenerational relationships (given that cohabitation was rare in the home country) and gender relationships (commitments between men and women);

- Inter-ethnic partnering is a profound indicator of the weakening of intergenerational ties and the social integration of ethnic groups;

- Similar to cohabitation and non-family living, the balance between work and family is an important dimension of 'new' Swedish family patterns, with a focus on gender equality.

Using survey data (see a brief description in the appendix), we examine these family transitions in young adulthood among young native-born Swedes of Polish, Turkish and Swedish origins. We start with non-family living.

\subsection{Generations of family living}

An often-overlooked dimension of family change is co-residence between parents and children in young adulthood. One form of family extension, in which a young couple lived with the husband's parents for a period of time, has largely vanished from Sweden, although it was never very prevalent. However, a new choice for young adults and their parents became increasingly important during the last half of the twentieth century - that of non-family living in young adulthood. Until the middle of the twentieth century, most young adults remained in the parental home until marriage. But with the growth of higher education, the increasing delay in marriage, and perhaps the cultural (and 
legal) redefinition of adulthood to younger ages (i.e. eighteen rather than 2I years old), increasing proportions of young adults now live independently from their parents even before establishing a co-residential partnership via marriage or cohabitation. By the end of the twentieth century, of course, even the parents of young adults have had this experience, and some may even have become concerned that their children remain at home too long.

How many young adults of Swedish origin are still living at home? Does the second generation of young adults of Polish and Turkish origins resemble Swedish patterns? Very few young adults of Swedish origins aged 22 and 26 were living with their parents. Specifically, this is the case for little more than one out of ten for young men and only 5 per cent among young women (table II.2). (For a detailed analysis of the leaving home patterns of the Swedish-born of Swedish parents, see Bernhardt, Gähler \& Goldscheider 2005). Young women of Polish origins closely resemble those of Swedish origins in this respect. However, considerably more Polish-origin men were living with their parents than was the case for men of Swedish origin, with nearly one in five living at home. The largest difference, however, was between those of Swedish and Turkish origins. About one-third of young men and women of Turkish origin were still living at home. As with those of Polish and Swedish origins, it is the men of Turkish origin who are most likely to live with parents. Among this group, the gender difference mostly reflects the later age at which males form a union.

There are many routes out of the parental home. Some leave to form unions, cohabiting or marrying; others form some non-family living arrangement, sometimes in conjunction with higher education. To what extent do these routes out of the home differ among the three groups? Do those of Turkish origins mostly leave to establish unions or have many adopted the 'new' pattern of non-family living?

A considerable majority of young adults from all groups experience non-family living in young adulthood. Even among women of Turkish

Table 11.2 Route out of the home by sex and origin (percentage)

\begin{tabular}{lcccccc}
\hline & \multicolumn{2}{l}{ Swedish } & \multicolumn{3}{c}{ Polish } & \multicolumn{3}{l}{ Turkish } \\
\cline { 2 - 7 } & Men & Women & Men & Women & Men & Women \\
\hline Still at home & 11.0 & 4.6 & 19.0 & 5.3 & 35.7 & 28.9 \\
For a partner & 19.3 & 32.8 & 15.6 & 20.7 & 21.4 & 32.2 \\
For non-family living & 69.7 & 62.6 & 65.3 & 74.0 & 42.9 & 38.8 \\
Total & 100.0 & 100.0 & 100.0 & 100.0 & 100.0 & 100.0 \\
Number surveyed & 716 & 824 & 147 & 169 & 84 & 121 \\
\hline
\end{tabular}

Source: 'Family and working life in the 21 st century' survey 1999 
origin, who are often considered to be under the strict control of their families (particularly of their fathers and brothers), slightly more than half of those who had left home had left for non-family living (55 per cent). Not quite half of the young adults took the more traditional route out of the home to move directly to live with a partner (figure II.I).

Nevertheless, for most of the other young adults in our study, non-family living was almost universal - about 80 per cent of young adults of both sexes of Polish origin and of men of Swedish origin left home to live outside a family altogether. The two 'intermediate' groups, interestingly, are men of Turkish origin and women of Swedish origin, among whom only about two-thirds left home for non-family living, indicating that fully one-third left home directly to live with a partner.

Another way to look at this information is to examine only those living outside a marital or cohabiting partnership who have the 'choice' of living with parents or living in some non-family situation. Living with parents is more common among young men and women of Turkish origins: over 40 per cent of the unpartnered young adults of Turkish origin were still living with their parents. Among the other two groups, there are much larger gender differences than among those of Turkish origins, and it is males who are more 'traditional' in this regard, with almost I5 per cent of unpartnered men of Swedish origin still living with parents and nearly a quarter among comparable men of Polish origin. Young women, perhaps, prefer greater privacy or benefit from fewer domestic services than their brothers do, and hence leave home at an earlier age than their brothers (figure II.2).

These data show that young adults born in Sweden of Turkish origins are more likely to live at home than those of Polish or Swedish

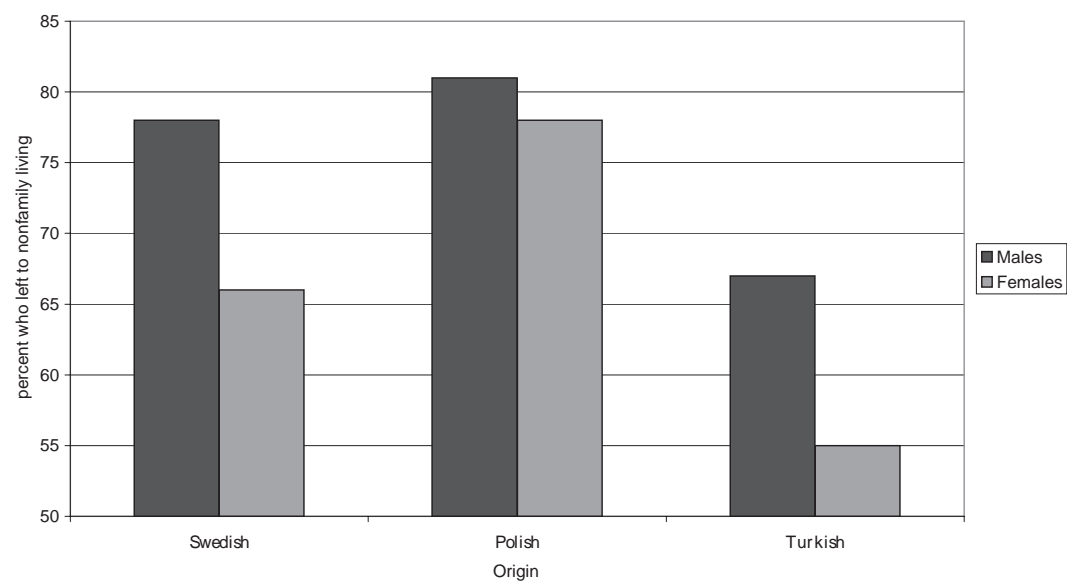

Figure 11.1 Leave to Family or 'Non-family'? 


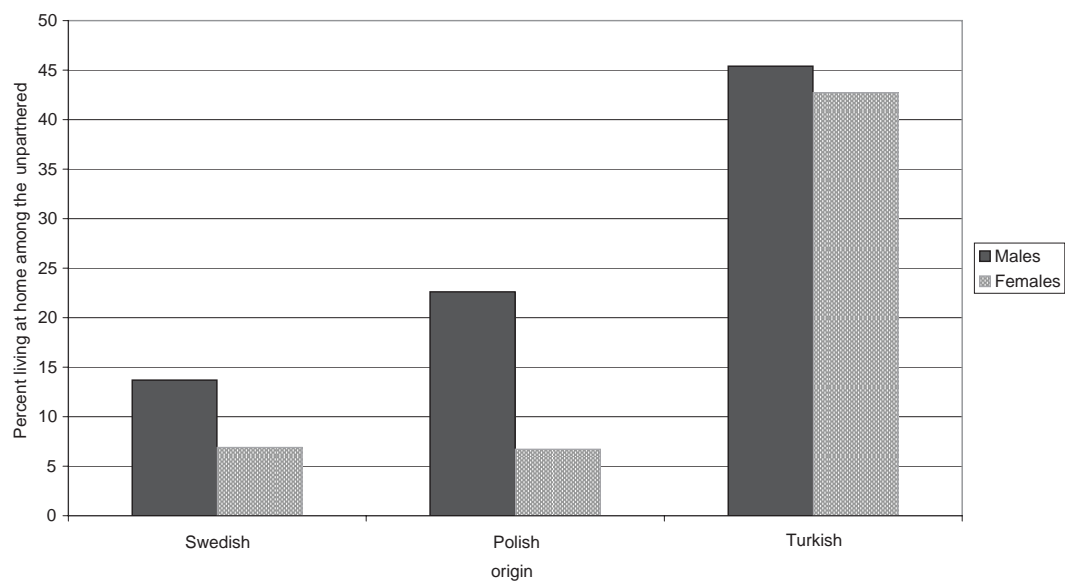

Figure 11.2 Only males and those of Turkish origin stay home if unpartnered

origins. There is a significant gender difference in leaving home as the Swedish-born young men of all origins, not the young women, are more likely to remain in the parental home. Most young adults leave home for non-family living, even those of Turkish origins, but those of Turkish origins are less likely to do so when compared to young adults of Polish or Swedish origins.

\subsection{Generations of partnering}

The decisions that young adults make as they begin their own family lives in the transition to adulthood are major indicators of intergenerational continuity or change for native-born Swedes. The timing and type of partnering are therefore critical themes in the transition to adulthood. Gender and generational relationships are forged in this stage of the life course. When young adults form a union, when they decide on its type (cohabitation or marriage), and particularly, when they choose a partner (from their own background or some other), will they follow the patterns of their parents or those of their peers of Swedish origins? Do their decisions primarily reflect their parents' national origins or their own particular characteristics, such as education? Are partnering decisions the same for young men and young women? Is the behaviour of young adults more constrained than their attitudes? This section begins to focus on these issues.

We first examine the timing of partnership formation for native-born young adults of Swedish, Polish, and Turkish backgrounds at age 22 and age 26 (table II.3). These data are arranged to show the progres- 
Table 11.3 Type of relationship among men and women by age and ancestry (percentage)

\begin{tabular}{lcccccr}
\hline & Swedish & \multicolumn{3}{c}{ Polish } & \multicolumn{3}{c}{ Turkish } \\
\cline { 2 - 6 } & 22 & 26 & 22 & 26 & 22 & 26 \\
\hline Men & & & & & & \\
No partner (single) & 44.0 & 31.9 & 34.7 & 34.4 & 42.6 & 30.0 \\
Non-resident partner & 29.7 & 19.3 & 41.7 & 23.4 & 31.5 & 10.0 \\
Cohabiting & 25.5 & 44.6 & 23.6 & 35.9 & 14.8 & 20.0 \\
Married & 0.8 & 4.2 & 0.0 & 6.3 & 11.1 & 40.0 \\
Total & 100.0 & 100.0 & 100.0 & 100.0 & 100.0 & 100.0 \\
Number surveyed & 361 & 336 & 72 & 64 & 54 & 30 \\
& & & & & & \\
Women & 23.9 & 19.1 & 28.3 & 22.5 & 45.4 & 9.1 \\
No partner (single) & 27.0 & 16.9 & 33.7 & 22.5 & 20.9 & 27.3 \\
Non-resident partner & 47.1 & 50.4 & 36.9 & 38.0 & 5.8 & 24.2 \\
Cohabiting & 2.0 & 13.6 & 1.1 & 16.9 & 27.9 & 39.4 \\
Married & 100.0 & 100.0 & 100.0 & 100.0 & 100.0 & 100.0 \\
Total & 397 & 403 & 92 & 71 & 86 & 33 \\
Number surveyed & & &
\end{tabular}

Source: 'Family and working life in the 21st century' survey 1999

sion of partnership commitment or intensity, from having no identifiable partner (single), to having a steady but not a co-residential partner, to having a cohabiting partner, and finally, to having a married partner. There are three basic patterns: I) women form partnerships of all kinds earlier than men; 2) there are small differences among these groups at each age in the proportions of men with no partner, but larger differences for women; and 3) the type of partnership differs considerably for both women and men among young adults of Swedish, Turkish and Polish origins. (Adding controls for other factors likely to affect partnering patterns does not affect these results. For a more detailed analysis of several aspects of partnering in this population, see Bernhardt et al. 2007).

The timing and type of partnering patterns show that about four out of ten men in each origin group has no serious partner at age 22 (i.e. are single). Among women, those of Swedish origin are the least likely not to have a serious partner (24 per cent) while those of Turkish origin are the most likely to have no serious partner (45 per cent). Clearly, women of Turkish origin are less likely to 'date' or have a serious partner early in adulthood than those of Polish origin, and particularly than those of Swedish origin. By age 26, however, the picture for women changes radically. At this age, those of Turkish origin have made the most rapid entry into romantic partnerships: fewer than one in ten does not have a serious relationship, compared with one in five among 
those of Swedish and Polish origin. So the timing of partner formation is more compressed among young women of Turkish origins.

The proportion cohabiting is much less among men and women of Turkish origin and the proportion married is much more. Almost none of the Swedish-origin men and women are married at age 22 and only 4 per cent of the men and I4 per cent of the women are married by age 26. Young adults of Polish background follow the Swedish pattern of marriage timing at slightly higher levels $(6$ per cent of men and 17 per cent of women of Polish background are married by age 26 ). The native-born Swedes of Turkish origin, however, marry much earlier. By age 26,40 per cent of both the men and women are married. Indeed, 28 per cent of the women of Turkish origins and II per cent of the men are married by age 22, higher than the men and women of Swedish or Polish origins at age 26 . This suggests that union formation is more tightly scripted in terms of age in the Turkish community, and more subject to individual vagaries for the other two groups. As with men, a substantial proportion of women of Turkish origins begin to behave like Swedes by age 26: about a quarter of the 26-year-old Turkish women are in cohabiting unions compared with about one-third for those of Polish origin and half for those of Swedish origin.

One question that the analysis of these data poses is how to assess the relative proportion cohabiting. A quarter to one-fifth of young adults of Turkish origins are cohabiting by age 26 . Should this be considered a high or a low level of cohabitation? Relative to those of nonTurkish origins in Sweden, the percentage is low; relative to their own cultural traditions (and the behaviour of their older relatives in Sweden or in Turkey) the percentage cohabiting among these young adults of Turkish origins is high. Even relative to their younger peers, especially women at age 22, the percentage cohabiting is high. Should the distinctiveness of ethnic Turkish young adults in Sweden as regards this aspect of partnering be highlighted? Or should the emphasis be placed on the increasing adaptation of Swedish partnership timing patterns among young adults of Turkish origins? The answer to these alternatives is best addressed after we have examined other family patterns to identify a more comprehensive picture.

\subsection{Generations of work-family balance}

One of the most dramatic changes in family patterns is the increase in mothers working outside the home. Motherhood is the period in the life course when the demands of childcare are the most intense. Yet it is often the moment when time spent at work has the greatest pay-off in long-term career earnings for both young men and young women. 
This life course pressure of work and family is relatively new for women, even in Swedish society. It is almost unheard of in societies with more traditional family systems, where the mothers of young children either earn income at tasks that can be combined with childcare or earn nothing at all.

We now focus on the attitudes young adults hold about the ideal way to balance these pressures: the work-family balance. We explore whether the traditional gender structure defining this balance that many immigrants have brought with them will be reproduced among their adult children. Work-family balance attitudes reveal the family role norms of young adults of different ethnic origins and, in turn, are another aspect of the social integration of immigrants and their children in Swedish society.

As a basis for understanding young adults, we will also examine the actual work-family balance for couples with young children among those born outside of Sweden, based on the immigrant survey within the Level of Living Survey of I997. Combined with the information on ideals from the young adults, this comparison will provide hints about generational differences between ideals and reality in the work-family balance. Even if immigrants from more traditional family cultures such as Turkey prefer mothers of small children to stay at home, the reality of the Swedish labour market, which often provides more jobs for immigrant women than for immigrant men, means that family support might require mothers to work. We show the actual work-family balance for couples with young children (under age seven) for those born in Sweden, in Poland, and Turkey. These actual patterns are then compared to the ideals expressed by those born in Sweden but whose parents were born in Poland and Turkey.

The data show that the proportion with full-time stay-at-home mothers of small children is much higher for Turkish-born immigrants than for Polish-born immigrants (table II.4). In turn, Polish-born immigrant women in Sweden have somewhat higher levels of staying at home than native Swedes. Nevertheless, fully one-third of Turkish couples with young children have a gender-equal balance of work and family ('equal' or 'she works more' category). The proportions are even higher if we exclude those families in which neither parent works. In about half of the Turkish couples with young children in which at least one parent is working, the father works and the mother stays at home. This gender segregated 'balance' is much less common among Polishborn immigrants (about 30 per cent), and characterises less than onefifth of Swedish-born families.

However, group differences in total 'equality' are not nearly as great, because the opposite pattern appears for the proportions in the category 'father works full-time, mother works part-time.' In both Polish 
Table 11.4 Work division among couples with small children by origin (percentage)

\begin{tabular}{lrrr}
\hline Work division & Swedish & Polish & Turkish \\
\hline Actual: immigrant survey & & & \\
He works, she doesn't & & & \\
He full-, she part-time & 17.1 & 19.5 & 42.2 \\
Equal or she works more & 34.7 & 41.9 & 9.4 \\
Neither works & 45.5 & 12.0 & 32.3 \\
Total & 2.7 & 100.0 & 24.7 \\
& 100.0 & & 100.0 \\
Ideal: young adult survey & & 7.1 & \\
He works, she doesn't & 6.6 & 14.0 & 16.8 \\
He full-, she part-time & 16.2 & 78.9 & 23.2 \\
Equal or she works more & 77.2 & 100.0 & 60.0 \\
Total & 100.0 & & 100.0 \\
\hline
\end{tabular}

Note: (a) couples with children under seven

Source: 'Family and working life in the 21 st century' survey 1999

and Swedish families, a little less than half are egalitarian, with an equal work commitment on the part of both parents (including the small fraction in which mothers work full-time while fathers work part-time), with Turkish families not far behind (43 per cent). The big difference, which accounts for most of the distinctions among groups, is in the semi-traditional pattern in which the mother only works parttime, presumably to spend more time with the children, while the father continues to work full-time. More than one-third of Swedish couples with small children follow this semi-traditional pattern $(36$ per cent); it is less common among Polish couples (22 per cent), and only characterises one in eight Turkish couples.

Much of this, of course, may reflect the realities of the Swedish labour market, which, at least for those with a low educational level, offers more job opportunities for women, and also makes it much easier for women than for men to hold part time jobs. Even the children of immigrants will have to adjust to this new reality. Our question turns to the normative: what do young adults in Sweden prefer? Do they want or hope to be egalitarian or would they prefer a traditional or semi-traditional work-family balance? The data in the lower panel of table II.4 show clearly that all three groups, even those whose parents were born in Turkey, are enthusiastic about an egalitarian work-family balance.

The differences in work-family balance that characterised immigrant families appear among these children of immigrants, but they are much more muted. Twice as many of those of Turkish origin expect a traditional work-family balance in which the man works and the woman does not than among young adults of Polish or Swedish origin. 
The levels are quite low for all groups: 7 per cent for those of Polish or Swedish origin, I7 per cent for those of Turkish origin. (Adding controls for other factors likely to affect such attitudes does not change these origin effects; see Bernhardt et al. 2007).

The semi-traditional pattern in which the mother works part-time is also a more popular ideal among young adults of Turkish origin than in the other two groups: 23 per cent versus about 15 per cent. These small differences in attitudes match the actual behaviour we documented previously, in which it was Swedish couples who were most likely to choose the semi-traditional balance between work and family when children are young. The proportion of young adults of Turkish origin expecting an egalitarian work-family balance (6o per cent) is less than the more than three-quarters of young adults of Polish or Swedish origin. Nevertheless, the significant majority of young adults who expect an egalitarian solution to the problem of integrating work with the care of young children is impressive evidence of the absorption of Swedish ideals among immigrant families. This indicator of family integration characterises even young adults of Turkish origins who are considered culturally most distinctive.

\subsection{Education, parental intermarriage and ethnic intensity}

Up to this point we have considered non-family living, cohabitation, out-partnering and the work-family balance among young Swedishborn adults differentiated by ethnic origin (Swedish, Polish and Turkish origins), often separately for men and women. We now turn to three other sources of differentiation within ethnic and gender categories: education, parental intermarriage and ethnic intensity. We ask: are these characteristics linked to family processes and are they potential sources of change? More specifically, do young adults of Polish and Turkish origins with higher levels of education, or who come from families who are already inter-ethnically married, or those from areas with higher levels of ethnic concentration have different family patterns in the transition to adulthood?

To address these questions, we first consider how these three factors - education, parental intermarriage, and growing up in immigrant neighbourhoods - differ among these groups. Do educational levels differ among these three groups, and does having inter-ethnic parents or living in a primarily Swedish, as opposed to immigrant, neighbourhood differ for the two second-generation groups?

As with the other dimensions we have considered, differences in educational level are much smaller between those of Polish origin and those of Swedish origin, with those of Turkish origin standing out at 
Table 11.5 Origin differences in education, neighbourhood ethnicity and parental out-marriage (percentage)

\begin{tabular}{lrrr}
\hline & Swedish & Polish & Turkish \\
\hline & & & \\
Education & 23.7 & 13.1 & 38.1 \\
Basic, lower secondary & 41.2 & 23.0 & 42.9 \\
Upper secondary & 17.6 & 34.3 & 11.9 \\
Lower-post secondary & 17.5 & 29.6 & 7.1 \\
Upper-post secondary & 100.0 & 100.0 & 100.0 \\
Total & & & \\
Parental intermarriage & - & 20 & 63 \\
Homogamous & - & 61 & 25 \\
Intermarried to a Swede & - & 19 & 12 \\
Intermarried to another nationality & - & 100 & 100 \\
Total & & & \\
Neighbourhood ethnicity & - & 85 & 55 \\
\% mostly Swedish & & & \\
\hline
\end{tabular}

Source: 'Family and working life in the 21 st century' survey 1999

lower levels (table II.5). Differences between those of Polish and Swedish origin in education actually favour the second generation of Polish origin. More young adults of Swedish origin have relatively low levels of education (no more than a secondary level) than those of Polish origin (64.9 per cent versus 36.I per cent, respectively, combining the two lower levels). At the other extreme, young adults of Turkish origins are even more concentrated below the post-secondary level (8I per cent).

Those of Polish and Turkish origins are also markedly different in terms of neighbourhood ethnicity and parental intermarriage. For these two indicators, there is no information for those of Swedish origin, as it would not be meaningful in the same sense for them. Far more of the second generation of Turkish origin have parents who are both from the home country than those of Polish origin $\left(6_{3}\right.$ per cent versus 20 per cent); a substantial majority of those with at least one Polish origin parent had a Swedish parent, as well (6I per cent). There are also substantial differences in the proportions that grew up in primarily Swedish neighbourhoods $(85$ per cent among those of Polish origins compared with 55 per cent among those of Turkish origins).

Clearly, differences in the levels of these three factors could affect the family patterns we have shown. Of even more importance, we want to examine how these differences shape differences in patterns of nonfamily living, partnering, and attitudes about work-family balance. We start with leaving home among men (table Ir.6a) and women (table II.6b). 
Table 11.6a Factors affecting variation in transitions in young adulthood by origin, males (percentage)

\begin{tabular}{llll}
\hline Origin and characteristics & $\begin{array}{l}\text { Non-family living } \\
\text { with neither } \\
\text { parents nor partner }\end{array}$ & $\begin{array}{l}\text { Lives with a } \\
\text { co-residential }\end{array}$ & $\begin{array}{l}\text { Traditional } \\
\text { attitudes on work- }\end{array}$ \\
family balance
\end{tabular}

Swedish

Own education:

Basic lower secondary

70.9

43.4

30.0

Upper secondary

71.9

39.1

30.5

Lower post-secondary

85.0

30.0

24.9

Upper post-secondary

86.9

36.1

19.4

Parental intermarriage:

Parents not intermarried

37.5

28.3

Parents intermarried

Polish

Own education:

Basic lower secondary

76.2

52.3

35.0

Upper secondary

68.4

42.9

25.0

Lower post-secondary

90.3

19.5

26.3

Upper post-secondary

90.0

23.5

12.5

Parental intermarriage:

Parents not intermarried

84.0

25.0

35.7

Parents intermarried

79.8

33.9

20.2

Neighbourhood ethnicity:

Mostly Swedish

76.7

34.4

25.7

Many born outside Sweden

88.8

20.0

23.5

Turkish

Own education:

Basic lower secondary

50.0

50.0

69.0

Upper secondary

70.6

48.3

48.2

Lower post-secondary

87.5

5.9

37.5

Upper post-secondary

100.0

14.3

33.3

Parental intermarriage:

Parents not intermarried

53.8

37.3

62.5

Parents intermarried

78.6

41.2

35.5

Neighbourhood ethnicity:

Mostly Swedish

80.0

21.1

45.7

Many born outside Sweden

55.0

48.6

58.8

Source: 'Family and working life in the 21st century' survey 1999 
Table 11.6b Factors affecting variation in transitions in young adulthood by origin, females (percentage)

\begin{tabular}{llll}
\hline Origin and characteristics & $\begin{array}{l}\text { Non-family living } \\
\text { with neither } \\
\text { parents nor partner }\end{array}$ & $\begin{array}{l}\text { Lives with a co- } \\
\text { residential partner }\end{array}$ & $\begin{array}{l}\text { Traditional } \\
\text { attitudes on work- } \\
\text { family balance }\end{array}$ \\
& & fam bat
\end{tabular}

Swedish

Own education:

Basic lower secondary

Upper secondary

Parental intermarriage:

Parents not intermarried

Parents intermarried

Polish

Own education:

Basic lower secondary Upper secondary Lower post-secondary Upper post-secondary

Parental intermarriage:

Parents not intermarried

Parents intermarried

Neighbourhood ethnicity:

$$
\text { Mostly Swedish }
$$

Many born outside Sweden

Turkish

Own education:

$\begin{array}{llll}\text { Basic lower secondary } & 37.5 & 66.7 & 35.5 \\ \text { Upper secondary } & 33.3 & 46.3 & 25.0 \\ \text { Lower post-secondary } & 89.5 & 21.4 & 36.0 \\ \text { Upper post-secondary } & 90.9 & 17.6 & 17.7\end{array}$

Parental intermarriage:

$\begin{array}{llll}\text { Parents not intermarried } & 51.0 & 42.9 & 34.2\end{array}$

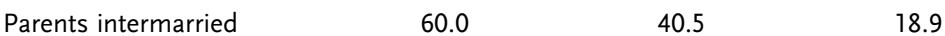

Neighbourhood ethnicity:

$\begin{array}{llll}\text { Mostly Swedish } & 52.2 & 50.9 & 26.0\end{array}$

$\begin{array}{llll}\text { Many born outside Sweden } & 48.3 & 33.3 & 32.0\end{array}$

Source: 'Family and working life in the 21st century' survey 1999 


\subsubsection{Leaving Home}

Educational attainment seems to be positively correlated with leaving home for non-family living, i.e. the highly educated of all three origin groups leave home without a partner (i.e. for non-family living). Ethnic differences in the routes out of the parental home converge among those with a post-secondary education, with about 90 per cent of all young adults leaving home for independent living. Women of Turkish origin with lower educational levels are the least likely to leave home for non-family living of all ethnic origin groups, with around 35 per cent leaving home for non-family living among those with less than a post-secondary education.

Turkish-origin young adults who grew up with one non-Turkish parent or who grew up in neighbourhoods with mostly Swedish residents were much more likely than other Turkish young adults to leave home for non-family living. This is particularly the case for young men, where 80 per cent who grew up in neighbourhoods with mostly Swedes leave home for independent living, compared to 55 per cent of those from immigrant neighbourhoods.

To the extent that continuous ties to the parental home reinforce ethnic commitments and leaving home for non-family living encourages independence, these ethnic and gender differences among the more educated and those with greater exposure to Swedish society are important both to understand the transition to adulthood and in the study of ethnic generational relationships.

\subsubsection{Partnering}

Better-educated young adults of Polish or Turkish origin are not 'assimilating' to the Swedish partnering model. If anything, it is the lowereducated Polish and Turkish young adults who more closely resemble the partnering patterns of young adults of Swedish origin. Unlike the patterns for leaving home for non-family living, educational attainment does not result in convergences in partnering between those of Swedish and those of either Polish or Turkish origins. There is a consistent pattern among Turkish men whose parents have intermarried or whose neighbourhoods have mostly Swedes to have higher actual partnering patterns. This is not the case for women.

\subsubsection{Work-family balance}

Some of the largest and most interesting differences appear to be related to these young adults' family-related decisions, both in terms of their relationship with their family of origin, as indicated by the route 
they took out of the home, and their new family relationships, particularly marriage and cohabitation. Generally, the married and those who left home to enter a partnership hold more traditional attitudes about the ideal balance of work and family care when they have young children. This probably reflects both their orientations, which led to early partnering and the realities of their situations, given the pressures that young children, whether already born or planned, can put on a couple. This pattern (not shown in tabular form) is particularly clear among young adults of Swedish origin. Young men and women who left home to form a partnership are quite similar in their attitudes, while those who either left home to live independently or were still living with their parents are less traditional, with a larger gender gap in their attitudes. The evidence further suggests that cohabiting partners are less traditional in their attitudes than married ones, at least among young men of Turkish origin and young women of Swedish origin.

Our last finding relates to the Swedish-origin community, where cohabitation is strongly institutionalised and many perceive that there are few differences between cohabiting and married couples. Among young couples of Swedish origin we identify the only case in which women are more traditional than otherwise comparable men. The nature of the partnership makes almost no difference to men; if anything, married men are a little less traditional in their attitudes towards workfamily balance than are men who are cohabiting. But it appears that the decision to marry rather than to cohabit may reflect the preferences of young women of Swedish origin, who idealise a more traditional work-family balance (of either staying home or only working part-time) when their children are young. It may be that in those rare couples in Sweden who have already married by age 26 , the men will be putting pressure on their wives to work more, just as the wives are more likely to accept a more traditional role in the home.

Exposure to Swedish society, through living in more Swedish neighbourhoods, having a Swedish parent, or attaining a college education, greatly reduces differences in the work-family balance by ethnic origin. This characterises all native-born Swedish populations of Turkish and Polish origins, with some exceptions among Turkish men.

\subsection{Concluding thoughts}

Three general findings emerge. First, there are systematic family differences among the second generation that reflect their ethnic origins, with marked differences between young adults of Turkish and Swedish origins. Swedes of Polish origins much more closely resemble those of Swedish origins. However, both groups of young women and men of 
non-Swedish origins appear to be approaching Swedish-origin young adults in their family behaviour and attitudes, particularly relative to the family patterns in their parents' home communities.

Our second set of findings focuses on the impact of education and residential concentration on these family processes. Young adults of Polish and Turkish origins with higher education and those who live outside communities with high proportions of immigrants more closely resemble the family patterns of Swedes of Swedish origins than do those with less education or who live in residentially more concentrated communities.

Third, the data show that ethnic differences in attitudes towards family transitions are smaller than differences in behaviour. The distinction between attitudes and behaviour is particularly conspicuous in the choices about cohabitation versus marriage and in the selection of partners of different national origins. These findings shed light on the multiple dimensions of the relative integration of the second generation of young men and women of Turkish and Polish origins in Sweden and on its measurement. The transition from immigrant group to distinctive ethnic population is not complete for either the Polish origin or the Turkish-origin population in Sweden. But to a larger extent, the family patterns of those of Polish origin are becoming indistinguishable from those of Swedish origins. Young adults of Turkish origin are moving in that direction but continue to have distinguishing family patterns.

In a broader context, the data point to the importance of moving beyond economic integration and stress the need to focus on family-related issues in the integration of immigrants. Gender issues have become of critical importance in the context of state policies directed at egalitarianism and in assessing the relative assimilation of immigrants and their adult children from culturally and socially diverse origins. The distinctive family patterns of some recent immigrants in Sweden (e.g. early marriage, large family size, extended family obligations, and dominance of mother and childcare roles for women) are clearly challenged when there are contacts with the economic and political realities of Swedish society. Our research has documented that the transition to adulthood for many adult children of immigrants to Sweden is rapidly becoming similar to those born of Swedish-origin parents. The family patterns and plans of young men and women of Turkish and Polish origins in Sweden clearly differ from their parents and less so from their peers of Swedish origin. If attitudes are predictive of future behaviour patterns, we can expect continuing changes in the next decade among all adults of immigrant origins and particularly among those from cultures that are distant from the Swedish experience. 


\section{Note}

I Although we do not examine this in detail, we note here that divorce rates are high in the parental generation, reflecting some of the tensions of the first generation and influencing their children as they make the transition to adulthood and begin their own families.

\section{References}

Bernhardt, E. (1992), 'Working parents in Sweden: An example for Europe?', in Human resources in Europe at the dawn of the 21st century, 235-254. Luxembourg: Eurostat.

Bernhardt, E., M. Gähler \& F. Goldscheider (2005), 'Cohabitation or residential independence in Sweden? The impact of childhood family structure and conflict on routes out of the parent home', Acta Sociologica 48 (2): 99-II5.

Bernhardt, E., C. Goldscheider \& F. Goldscheider (2007), 'Integrating the second generation: Gender and family attitudes in early adulthood in Sweden', Zeitschrift für Femilienforschung I9: 55-70.

Bernhardt, E., C. Goldscheider, F. Goldscheider \& G. Bjerén (2005), Entering adulthood in Sweden: Gender, family, and immigrant origins. Stockholm: Center for Gender Studies, Stockholm University.

Bernhardt, E., C. Goldscheider, F. Goldscheider \& G. Bjerén, (2007), Immigration, gender, and family transitions to adulthood in Sweden. Lanham, MD: University Press of America.

Bjeren, G. (1997), 'Gender and reproduction', in T. Hammar, G. Brochmann, K. Tamas \& T. Faist (eds.), International migration, immobility and development, 219-246. New York: Berg.

Brubaker, R. (200I), 'The return of assimilation? Changing perspectives on immigration and its sequels in France, Germany, and the United States'. Ethnic and Racial Studies 24 (4): 53I-548.

Hugo, G. (I997), 'Migration and female empowerment', in H. B. Presser \& G. Sen (eds.), Women's empowerment and demographic processes: Moving beyond Cairo, 287-317. Oxford: Oxford University Press.

Lesthaeghe, R. (1995), 'The second demographic transition in Western countries: An interpretation', in K. O. Mason \& A.-M. Jensen (eds.), Gender and family change in industrialized countries, I7-62. Oxford: Oxford University Press.

Murdie, R. \& L.-E. Borgegård (I996) 'Immigration, spatial segregation and housing segmentation in metropolitan Stockholm, 1960-95'. Working paper No.2. Gävle: Institutet för bostadsforskning.

Pedraza, S. (I99I), 'Women and migration: The social consequences of gender', Annual Review of Sociology I7: 303-325.

Portes, A. (I995), 'Economic sociology and the sociology of immigration: A conceptual overview', in A. Portes (ed.), The economic sociology of immigration. Essays on networks, ethnicity, and entrepreneurship, I-4I. New York: Russell Sage Foundation.

Pred, A. (2000), Even in Sweden. Racisms, racialized spaces, and the popular geographic imagination. Berkeley: University of California Press.

Zhou, M. (200I), 'Straddling different worlds: The acculturation of Vietnamese refugee children', in R. Rumbaut \& A. Portes (eds.), Ethnicities. Children of immigrants in America, I87-227. Berkeley: University of California Press. 


\section{Appendix: The Survey}

Our analysis is based on a survey of young adults in Sweden ('Family and working life in the 2ist century'), funded by the Swedish Social Science Research Council. It was a mail questionnaire survey with about 2,800 respondents, both males and females. The fieldwork was carried out in the spring of 1999, with the help of the survey unit of Statistics Sweden. In addition to the main sample of young adults born in Sweden with two Swedish-born parents, there was also a special smaller sample of young adults born in Sweden, but with one or both parents born in Poland or in Turkey.

The Swedish sample of about 2,300 respondents consisted of individuals who were 22,26 or 30 years old at the time of the survey. Their response rate was 67 per cent. The second generation of Polish or Turkish origins was a sample of about 500 respondents. It consisted of individuals who were 22 or 26 years old, since there were so few 30 year olds in this group. The questionnaire contained questions about their plans, expectations and attitudes regarding family and working life, as well as factual information about their current situation and background characteristics. For more details, see Bernhardt et al. 2007. 



\title{
12 Discrimination despite integration: Immigrants and the second generation in education and the labour market in France
}

\author{
Dominique Meurs, Ariane Pailhé and Patrick Simon
}

For more than one and a half centuries, the 'French model of integration' has shaped policies and regimes concerning migrants. Even though the features of the model have encountered many changes over time, its main objective has remained quite stable: to enable immigrants to become French citizens within a generation (HCI I993). To achieve this aim, the model prevents the reproduction of 'foreignness' or 'otherness' across generations by encouraging the naturalisation of migrants, and the automatic acquisition of French citizenship for the children of foreigners when they come of age. The key dimension of the French doctrine of integration - the implicit contract - is that the 'invisibility' of migrants and their descendants in public and political spheres will offer access to social mobility (Simon 2003). In return, the system grants minority groups de jure equal rights before the law regardless of their origin. The linkage between cultural assimilation and socioeconomic outcomes has been challenged by two major parameters of change: I) the contesting of the paradigm of uniformity with requests for the recognition of 'diversity' in the French make-up; 2) the increase in discrimination against not only migrants but also for those belonging to the second generation, who should be protected by the legal provisions for equality.

In contrast with the classical theory of assimilation which maintains that structural assimilation in schools and the labour market (i.e. the reduction of the gaps between the status of migrants and natives) is closely linked with cultural assimilation (Alba \& Nee 2003), we make the hypothesis in this paper that there is a potential mismatch between full cultural assimilation and widespread experiences of discrimination for certain groups of the descendants of immigrants in France. Evidence of quite a generalised cultural assimilation of the descendants of immigrants has already been stressed in scientific literature (Tribalat, Simon \& Riandey 1996; Viprey 2002; Safi 2006). In this paper we focus on the educational attainment and position in the labour market of immigrants and the 'second generations'. Has economic restructuring affected immigrants and subsequent generations in the same way? Or 
have the benefits of the 'contract of integration' proved able to produce equal access to socioeconomic upward mobility? The question is even more precise for French-born children of workers who came to France from post-colonial countries, most of whom are themselves French citizens. Do we observe disparities in the intensity of 'ethnic penalisation' according to the origins of the 'second generations'? And last but not least, are the obstacles to the upward mobility of descendants of immigrants to be understood as a general feature of the socioeconomic system, making no distinction between family descent, or is it a situation specific to the 'second generations' that could be called discrimination?

This chapter uses data from the EHF survey combined with data from the I999 census. The survey questions included the parental country of birth, thus making it possible to create the descendants of immigrants' category and to compare the labour market status of the different generations of immigrant origin. By combining nationality at birth and country of birth of the individuals and of their parents, we formed three categories of 'generations', two of which are split into subgroups, one by age at entry into France, the other by the mixed origins of the parents (see box). The total number of survey respondents was 380,000 , so relatively large numbers of individuals could be included in each of our 'generations' and analyses performed according to exact origin. Our study is concerned with the labour market status of the second generations relative to immigrants of comparable age, and not with the labour market position of immigrants' children relative to their own parents. To minimise the effects of age structure on comparisons between our 'generations', the analysis is restricted to the population aged eighteen to 40 , which corresponds to 80 per cent of the second generations of North African, sub-Saharan African, Turkish, Portuguese and Asian origin. Also excluded from our study are school or university students and unpaid trainees, since they are not available to take up wage employment as their main activity. ${ }^{2}$ The final sample contains 129,366 individuals.

In the first part of the paper, we will compare the educational and social characteristics of the immigrant and 'second generation' youths with those of 'native' French youths. The second part looks at the employment prospects of youths from different backgrounds. Finally, we examine the prevalence of insecure jobs and segregation in the occupational structure, with a special emphasis on the inequalities in access to civil service employment. 


\section{The INSEE Family History (EHF) survey}

In order to study the different 'generations' we have set up the following categories, which will be compared. :

- An immigrant is defined as any person born without French nationality and outside France, whatever his/her current nationality may be. People born abroad of French parents are, therefore, not included in the immigrant population, even if they were adults when they came to France.

- The total population is divided into five categories, based on each individual's link with immigration over two generations. The first two categories group together immigrants according to the age at which they entered France; the next three are composed of people born in France of immigrant or French parents.

1. 'Immigrants': immigrants who were more than ten years old when they came to France (including those at ten years old);

2. 'Generation 1.5': immigrants who were less than ten years old when they came;

3. 'Second generation': people born in France to parents both born abroad;

4. 'Mixed second generation': people born in France to a mixed couple (one parent born abroad, the other in France);

5. 'Natives of natives': people born in France whose parents were both born in France.

- Schooling in France and immersion in French society from an early age are factors that favour the learning of French and the acquisition of national diplomas, which both have an impact on professional integration. This is the reason why we have chosen the age of ten (inclusive) as a threshold.

- To limit the effects of age structuring in our comparison of the professional situation of the generations defined above, we have restricted our statistical survey to the population aged between eighteen and 40.

\subsection{Educational attainment and social background of migrants and second generations}

\subsubsection{A generation's gap}

Comparisons between the educational trajectories of the different background categories are bound to be rather artificial due to structural effects. The differences between the education systems of Northern countries and those of Southern countries - from which a large propor- 
tion of the immigrants come - are responsible for many of the inequalities observed, even though these tend to be lower for the younger generations and despite the fact that migration tends to select individuals who have an above-average level of education in their countries of origin (Tribalat et al. I996). The large proportion of immigrants with higher education diplomas bears witness to this, ${ }^{3}$ although this must be seen in the context of a highly polarised distribution, with a large proportion of individuals having left school without any qualifications (table 12.1). As in many countries, the French educational system went through a process of 'massification' in the 1980s, i.e. an opening up of the upper level of secondary schools and higher education to workingclass background students (Beaud 2002). Descendants of immigrants have benefited from this trend and have gained increasing access to universities, but this kind of upward mobility in education has been obtained by a filtering process leading to unqualified and unattractive career paths. As a result, higher prospects in education do not offer higher diplomas.

Immigrants who came to France before the age of ten display a similar structure of education levels to the 'second generations', with an over-representation of short technical diplomas for women. On the

Table 12.1 Educational attainment according to the generation since immigration (percentage)

\begin{tabular}{|c|c|c|c|c|c|}
\hline & $\begin{array}{l}\text { None or } \\
\text { BEPC } \\
\text { (exams } \\
\text { taken at end } \\
\text { of fourth } \\
\text { form) }\end{array}$ & $\begin{array}{l}\text { CAP, BEP } \\
\text { (vocational } \\
\text { training } \\
\text { certificates } \\
\text { taken } \\
\text { at } 16 \text { ) }\end{array}$ & $\begin{array}{l}\text { Bac général } \\
\text { (general } \\
\text { high school } \\
\text { diploma) }\end{array}$ & $\begin{array}{l}\text { Bac } \\
\text { technique } \\
\text { (technical } \\
\text { high school } \\
\text { diploma) }\end{array}$ & $\begin{array}{l}\text { Higher } \\
\text { education }\end{array}$ \\
\hline \multicolumn{6}{|l|}{ Men 18 to 40} \\
\hline Immigrants & 37.5 & 17.7 & 9.3 & 5.4 & 30.1 \\
\hline Generation 1.5 & 32.9 & 36.7 & 5.8 & 9.1 & 15.5 \\
\hline Second generation & 29.8 & 33.7 & 7.6 & 10.3 & 18.5 \\
\hline Mixed second generation & 23.9 & 29.0 & 9.8 & 10.8 & 26.5 \\
\hline Natives of natives & 23.7 & 34.9 & 7.1 & 11.0 & 23.4 \\
\hline Overall & 25.0 & 33.5 & 7.4 & 10.6 & 23.5 \\
\hline \multicolumn{6}{|l|}{ Women 18 to 40} \\
\hline Immigrants & 47.7 & 12.6 & 9.7 & 5.0 & 24.9 \\
\hline Generation 1.5 & 33.3 & 28.3 & 8.9 & 9.9 & 19.7 \\
\hline Second generation & 26.9 & 28.3 & 10.4 & 12.4 & 22.1 \\
\hline Mixed second generation & 22.8 & 22.3 & 12.8 & 10.7 & 31.5 \\
\hline Natives of natives & 23.8 & 25.9 & 9.9 & 11.9 & 28.6 \\
\hline Overall & 25.5 & 25.0 & 10.1 & 11.4 & 28.0 \\
\hline
\end{tabular}

Field: population aged between eighteen and 40

Source: INSEE, Enquête Etude de l'Histoire Familiale (Family History Survey) 1999 
other hand, the diploma structure for 'second generation' children of mixed couples shows an over-representation of university degree courses, both for men and women. More generally, the gender inequalities observed among immigrants, with a very low level of training for women, are reversed for the other generations. This reversal is expressed in the form of men taking short technical courses, and greater numbers of women following higher education courses.

If the position of second-generation pupils in the school system is summarised, it can be said that, on average, they obtain lower results than those of other pupils, but that these distances are attributable to domestic and social characteristics. Moreover, the path through secondary education would work even more favourably if there were more control of the aforementioned characteristics (Vallet \& Caille 1996). A greater mobilisation of immigrant families seems to be responsible for this slight advantage. On this point, the authors take up the hypothesis developed by Zéroulou (1988) that states that immigrant families, those from the Maghreb in particular, compensate for a lack of cultural and social resources through over-investing in education. The school is thus charged by these parents with readjusting the disparities of social conditions and offering opportunities of advancement for their children, a process, which demonstrates the internalisation by immigrant families of the republican creed in educational terms. Brinbaum and Kieffer (2005) also highlight the 'expectations effect' on immigrant children's success at school. By analysing recent data from a survey on parents and pupils' expectations from school and projects in educational attainment, the authors have shown that not only do families of Maghrebian origin favour a longer period in education, but their children also have more expectations from the school system. Even when their grades at school are lower than those of French natives from the same social background, descendants of Maghrebian immigrants are trying to stay in education for longer, and often succeed in doing so.

Nevertheless, the indicators which describe relations between immigrant families and educational institutions evoke a certain disillusionment and difficulty in communication. At the end of the day, whilst the mobilisation process for immigrant families is doubtless active, its consequences in terms of educational success have yet to be proven. Can motivation alone compensate for the deficiencies of the education system and school responsibility?

\subsubsection{A comparison of three groups}

The educational trajectories of the children of immigrants also vary according to the parents' country of origin (table I2.2). Children of immigrants from Turkey were much more likely to leave school without any 
qualifications (more than 46 per cent, compared with an average of 25 per cent in France). Second generation Turkish youths reproduce their parents' model of gender inequality: the girls leave school early, while the boys remain in education, taking vocational courses. Although the levels of education are higher than they were in the parents' generation, university remains a very rare option.

Participation in higher education is only slightly higher for secondgeneration Portuguese youths, who favour short vocational courses. The number of individuals leaving school before taking the baccalauréat (high school diploma) is slightly higher than the French average. Paradoxically, the children of immigrant parents continue their education longer than the children of mixed Franco-Portuguese couples. The advantage generally provided by having a French parent cannot be observed in the case of the Portuguese.

In contrast to these two groups, second-generation Moroccan youths obtain relatively high-level positions, close to the French average. The rate of access to academic courses is actually higher than average,

Table 12.2 Educational attainment of the 'second generations', according to gender and parents' country of birth (percentage)

\begin{tabular}{|c|c|c|c|c|c|}
\hline & & $\begin{array}{l}\text { None or BEPC } \\
\text { (exams taken } \\
\text { at end of } \\
\text { fourth form) }\end{array}$ & $\begin{array}{l}\text { CAP, BEP (vo- } \\
\text { cational train- } \\
\text { ing certificates } \\
\text { taken at } 16 \text { ) }\end{array}$ & $\begin{array}{l}\text { Bac } \\
\text { (high school } \\
\text { diploma) }\end{array}$ & $\begin{array}{l}\text { Higher } \\
\text { education }\end{array}$ \\
\hline \multicolumn{6}{|l|}{ Turkey: } \\
\hline & Men & 40.1 & 27.8 & 19.1 & 13.1 \\
\hline & Women & 51.6 & 15.3 & 23.3 & 7.7 \\
\hline \multicolumn{6}{|l|}{ Morocco: } \\
\hline & Men & 26.1 & 25.1 & 25.6 & 23.3 \\
\hline & Women & 22.6 & 21.9 & 27.3 & 28.3 \\
\hline & $\begin{array}{l}\text { Second } \\
\text { generation }\end{array}$ & 30.9 & 29.8 & 24.1 & 15.2 \\
\hline & $\begin{array}{l}\text { Mixed second } \\
\text { generation }\end{array}$ & 19.8 & 18.6 & 27.0 & 34.6 \\
\hline \multicolumn{6}{|l|}{ Portugal: } \\
\hline & Men & 27.5 & 36.8 & 18.8 & 17.0 \\
\hline & Women & 23.5 & 29 & 25.7 & 21.8 \\
\hline & $\begin{array}{l}\text { Second } \\
\text { generation }\end{array}$ & 24.1 & 34.2 & 21.0 & 20.7 \\
\hline & $\begin{array}{l}\text { Mixed second } \\
\text { generation }\end{array}$ & 30.1 & 30.6 & 24.6 & 14.6 \\
\hline
\end{tabular}

Field: population aged between eighteen and 40

Source: INSEE, Enquête Etude de l'Histoire Familiale (Family History Survey) 1999 
while participation in vocational courses, a characteristic choice for children of working-class origins, is lower than average. However, the overall results for this group are highly influenced by the trajectories of the children of mixed couples. For these children, rates of access to the baccalauréat and to university are higher than the French average, whereas for children with two Moroccan parents, the level is much closer to that of the Turkish and Portuguese second generations. Here, this very marked influence of the composition of the parental couple on their children's educational trajectories can be explained in terms of the social origin of Franco-Moroccan couples, the particular features of which require a separate analysis (Simon 2003). In fact, when social selection accompanying the formation of mixed parental couples is taken into account, the social mobility of both second-generation groups is no more than moderate.

There is a relatively low level of gender inequality, slightly favouring women, among individuals of Moroccan or Portuguese descent. This stands in sharp contrast to the situation of their immigrant parents, where the women did not have the same access to educational opportunities as the men. This relative levelling in trajectories, marking a significant break with the past, can be explained by participation in a more egalitarian educational system and, paradoxically, by genderbased differences in family investment in education. The boys are more likely to be steered towards short courses, while for the girls, academic work provides the means to acquire a certain independence from their families (Caille \& Vallet I995). In contrast, inequalities continue to weigh heavily on second-generation women of Turkish descent, although the situation has improved considerably in comparison with first-generation immigrants. For the Turkish second generation, the children of mixed couples have not been analysed separately because of their low number.

\subsection{The transition to the labour market}

During the 'trente glorieuses' (France's 30-year post-war period of economic prosperity), France recruited large numbers of immigrant workers in order to satisfy the demand for low-qualified labour. Today, the jobs occupied by these workers still reflect the historic conditions in which they were recruited. Immigrants have not experienced the same ascendant social mobility in their careers as their French colleagues, and most of them are still unqualified workers. In their survey concerning immigrants' professional careers, Dayan, Echardour and Glaude (1996) observed that after twenty to 25 years of work, threequarters of immigrant employees are still low-skilled workers, and one- 
third of these have no qualifications at all. Comparatively, for men born in France, the proportion of low-skilled workers fell to 30 per cent and the number of unqualified workers has been divided by four. The survey also shows that Spanish immigrants enjoy above-average professional mobility, whereas the careers of Turkish and Moroccan workers are marked by immobility.

Not only do immigrant workers have limited opportunities for promotion but they are also more vulnerable to the consequences of industrial restructuring. The greatest impact of this restructuring concerns sectors employing a high proportion of immigrant workers, and particularly the low-skilled jobs they occupy. The relatively unfavourable situation of immigrants in the labour market can be explained in terms of the function they fulfil. Theoretically, however, the children of immigrants, born and raised in France and benefiting from a system intended to provide upward mobility should not inherit the subordinate position of their parents. By comparing the situation experienced by the five different categories of generations relating to immigration, we can explore the hypothesis of the reproduction of vulnerability to unemployment.

Of course, there is a high heterogeneity in the age structure of the five different categories above. To reduce the effects of age structure on our comparisons, we have limited the analysis to the population aged between eighteen and 40. This population accounts for 80 per cent of the 'second generations' of North African, African, Turkish, Portuguese and Asian origins (Borrel \& Simon 2004). The tables presented in the rest of this section concern this age group.

\subsubsection{Position in the labour market: the reduction of the gender gap through the generations}

Analysis of the employment situation of the different backgrounds in the eighteen to 40 age group shows that their levels of activity are quite similar (table I2.3). The 'under-activity' observed among women tends to decrease for 'Generation I.5', and 'second-generation' youths, and is close to the national average for women. Male children of immigrant descent, on the other hand, have lower levels of activity than immigrant men. This can be explained partly by the difficulties they encounter in trying to enter the labour market that can increase their withdrawal from the labour market into inactivity.

The idea that children of immigrants encounter greater difficulties is confirmed by the unemployment figures. The relative decrease in unemployment among women of 'Generation I.5', and 'second-generation' youths cannot be observed among the men of the same backgrounds, although it is true that levels of unemployment among immi- 
Table 12.3 Positions on the labour market of the different generations since immigration (percentage)

\begin{tabular}{|c|c|c|c|c|c|c|}
\hline & \multicolumn{2}{|c|}{ Rate of activity } & \multicolumn{4}{|c|}{ Rate of unemployment } \\
\hline & \multirow[b]{2}{*}{ Men } & \multirow[b]{2}{*}{ Women } & \multirow[b]{2}{*}{ Men } & \multirow[b]{2}{*}{ Women } & \multicolumn{2}{|c|}{$\begin{array}{c}\text { Corrected for age } \\
\text { structure }\end{array}$} \\
\hline & & & & & Men & Women \\
\hline Immigrants & 87.2 & 60 & 19 & 29.7 & 20.7 & 31.9 \\
\hline Generation 1.5 & 82.9 & 69.2 & 19.7 & 26.3 & 19.3 & 26.6 \\
\hline Second generation & 80.9 & 71.3 & 20 & 23.1 & 19.3 & 23.7 \\
\hline Mixed second generation & 82 & 71 & 13.4 & 18 & 13.4 & 18.9 \\
\hline Natives of natives & 86.8 & 75.6 & 10.1 & 15.1 & 10.7 & 16.9 \\
\hline Overall & 86 & 73.8 & 11.7 & 16.8 & & \\
\hline
\end{tabular}

Field: population aged between eighteen and 40

Source: INSEE, Enquête Etude de l'Histoire Familiale (Family History Survey) 1999

grant women are particularly high (30 per cent). This absence of change suggests that the potential gain from early socialisation (GI.5) or birth in France does not translate into improved chances of finding a job. The 'mixed second generation' tends to occupy a position closer to that of natives, initiating the real break between the 'generations'. Rooth and Ekberg (2000) identify the same pattern in Sweden and attribute it to an input of 'Swedish-specific' social capital particular to mixed couples. To sum up, the inequalities in unemployment between men and women, which are very high in the immigrant background categories, remain relatively high in all the other groups.

\subsubsection{Participation in the labour market}

The rates of activity and unemployment by country of origin for immigrants, or by parents' country of origin for children of immigrants, display a high level of internal heterogeneity (tables I2.4 and I2.5). The rates of activity for women immigrants from Morocco, and above all from Turkey are particularly low. The highest unemployment rates are three times as high as the lowest rates for men, and four times as high for women. Most vulnerable are immigrants from North Africa, subSaharan Africa and Turkey. Immigrants from Portugal and Italy, on the other hand, display a very high level of participation in the labour market and a rate of unemployment even lower than the reference, with barely perceptible gender differences (table I2.4).

These contrasting models of participation in the labour market tend to be reproduced for 'second generation' youths. Table i2.5 shows that 
Table 12.4 Position on the labour market of immigrants by origin (percentage)

\begin{tabular}{|c|c|c|c|c|}
\hline & \multicolumn{2}{|c|}{ Rate of activity } & \multicolumn{2}{|c|}{ Rate of unemployment } \\
\hline & Men & Women & Men & Women \\
\hline Italy & 92.7 & 67.0 & 10.8 & 9.0 \\
\hline Portugal & 96.1 & 79.6 & 9.5 & 10.3 \\
\hline Algeria & 84.6 & 63.2 & 30.1 & 35.8 \\
\hline Morocco & 84.3 & 52.8 & 26.1 & 35.9 \\
\hline Sub-Saharan Africa & 77.1 & 67.1 & 27.9 & 36.0 \\
\hline Turkey & 91.7 & 36.3 & 25.3 & 45.4 \\
\hline South-East Asia & 80.5 & 60.9 & 14.1 & 19.8 \\
\hline All immigrants & 87.2 & 60 & 19 & 29.7 \\
\hline
\end{tabular}

Field: whole immigrant population aged between eighteen and 40

Source: INSEE, Enquête Etude de l'Histoire Familiale (Family History Survey) 1999

there is a comparable difference between the second generations from Southern Europe and those from North Africa. Furthermore, in this survey, we cannot make a distinction between the children of North African immigrants and the children of French nationals repatriated from the same region. This probably results in an underestimation of the rate of unemployment in this population. In their comparison of returnees from Algeria and Algerian immigrants, Alba and Silberman (2002) show that the former have a higher educational level and are much less likely than the latter to be manual workers. The real figure may well be higher than that given in the table, which should be treated as a lower limit. The results for children of mixed couples are close to the reference level, but children born in France of immigrant parents show levels of vulnerability to unemployment very similar to those of their parents. Thus, belonging to the 'second generation' offers no significant improvement in the conditions of entry into the labour mar-

Table 12.5 Position on the labour market of 'second generations' by origin (percentage)

\begin{tabular}{|c|c|c|c|c|}
\hline & \multicolumn{2}{|c|}{ Rate of activity } & \multicolumn{2}{|c|}{ Rate of unemployment } \\
\hline & Men & Women & Men & Women \\
\hline Italy & 96.0 & 80.6 & 8.8 & 15.4 \\
\hline France and Italy & 87.4 & 79.7 & 10.3 & 13.1 \\
\hline Portugal & 90.5 & 78.1 & 11.3 & 14.2 \\
\hline Algeria & 85.6 & 70.0 & 28.5 & 30.4 \\
\hline France and Algeria & 81.4 & 69.7 & 16.3 & 21.1 \\
\hline Morocco & 76.0 & 54.3 & 27.2 & 38.7 \\
\hline France and Morocco & 74.6 & 65.8 & 14.5 & 20.0 \\
\hline Total second generation & 80.9 & 71.2 & 16.9 & 20.7 \\
\hline Natives of natives & 86.7 & 75.6 & 10.1 & 15.1 \\
\hline
\end{tabular}

Field: population aged from eighteen to 40

Source: INSEE, Enquête Etude de l'Histoire Familiale (Family History Survey) 1999 
ket, despite the fact that levels of qualification have risen considerably from one generation to the next.

\subsubsection{Who is at risk of unequal exposure to unemployment?}

The differences observed between the various generations of immigrants in terms of vulnerability to unemployment may be partly due to structural differences (age, education and region of residence). We have therefore used logistic regression to calculate the relative probability of being unemployed, once the individual characteristics observed have been taken into account (table I2.6). The risk of being unemployed is three times higher for the 'immigrant' and remains considerably higher than the reference group for all the other groups, including the mixed second generation, who belong to a higher social class than the others. The same orders of magnitude can be observed for the women. The most worrying figures are those for the descendants of immigrants, who still experience significant differentials, although these are lower than those experienced by their parents.

In table I2.6, immigrants who arrived as adults are considered as a homogenous group, for which we measure the relative risk of unemployment. However, as we have shown above, the risk of unemployment varies according to the country of origin. Therefore, in table I2.7 we use the same model of logistic regression, but now it is applied to the relative risk of being unemployed according to the country of origin for immigrants and for the parents of the second generations. As previously, natives of natives constitute the reference group. Immigrants from Algeria, Morocco and Africa are two to four times more likely to be unemployed than the reference group. For Italian and Spanish im-

Table 12.6 Relative risk of being unemployed, by generation since immigration

\begin{tabular}{|c|c|c|c|c|}
\hline & \multicolumn{2}{|c|}{$\begin{array}{l}\text { Men, } 18 \text { to } 40 \text { years old. } \\
N=50,976\end{array}$} & \multicolumn{2}{|c|}{$\begin{array}{l}\text { Women, } 18 \text { to } 40 \text { years old } \\
N=77,668\end{array}$} \\
\hline & Odds-ratio & $\begin{array}{l}\text { Tde } \\
\text { student }\end{array}$ & Odds-ratio & $\begin{array}{l}\text { Tde } \\
\text { Student }\end{array}$ \\
\hline Immigrant & $2,722 * * * *$ & 15,67 & $2,170 * * * *$ & 15,68 \\
\hline Generation 1.5 & $1,804 * * *$ & 6,50 & $1,421 * * *$ & 4,94 \\
\hline Second generation & $1,595 * * * *$ & 8,30 & $1,392 * * *$ & 6,81 \\
\hline Mixed second generation & $1,236 * * * *$ & 3,77 & $1,152 * * *$ & 3,52 \\
\hline Natives of natives & Ref & Ref & Ref. & Ref. \\
\hline
\end{tabular}

Source: INSEE, Enquête Etude de l'Histoire Familiale (Family History Survey) 1999

Field: active population aged between eighteen and 40

Dependent variable: being unemployed versus being employed

Control variables: age, age squared, living in a couple (ref: single), qualification (seven levels, ref: $C E P), B E P$ (vocational training certificates taken at sixteen), regions (ref: Paris region) 
Table 12.7 Relative risk of being unemployed according to immigrants' and second-generation ethnic background

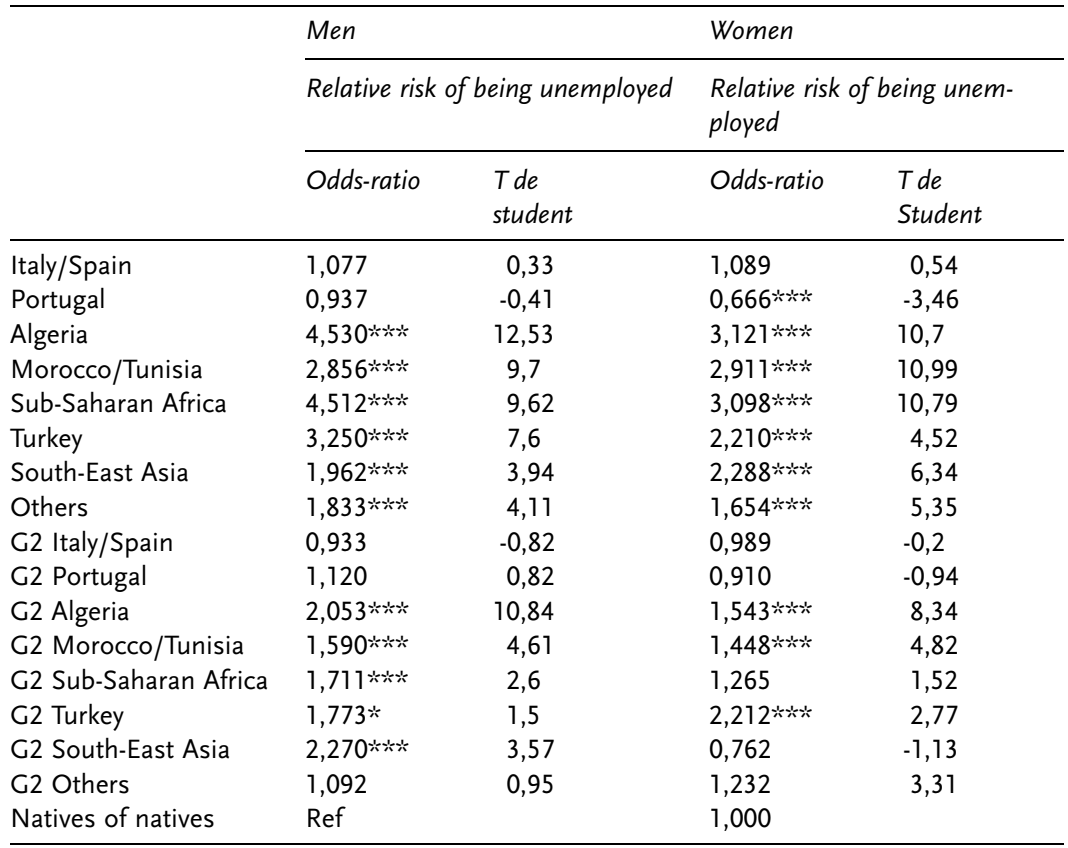

Source: INSEE, Enquête Etude de l'Histoire Familiale (Family History Survey) 1999

Field: active immigrant population aged between eighteen and 40

Dependent variable: being unemployed

Control variables: age, age squared, living in a couple (ref: single), number of children, qualification (seven levels, ref: CEP), BEP (vocational training certificates taken at sixteen), family background (ref: father as worker, mother as inactive), regional unemployment rate (ref:

Paris region)

migrants, the risk is the same as for natives of natives, while for Portuguese women immigrants it is significantly lower. These results confirm those presented by E. Maurin (I99I) based on the I982 census, from which he drew the conclusion that foreign labour was caught in a 'spiral of precariousness'. He calculated a risk of unemployment for North African immigrants that was 79 per cent higher than the French reference, while for Portuguese immigrants it was 49 per cent lower. Nearly twenty years later, our results and other studies based on the census (see Borrel \& Boëldieu 200I) show that the situation has not improved.

The additional risk borne by immigrants is reproduced in the 'second generation'. The level of incidence is reduced but still significant for the same countries or group of countries. This now concerns the parents' countries of origin. This repetition of over-exposure to the risk of unemployment, despite access to higher levels of education and 
training and despite socialisation within French society, bears witness to a certain level of inertia, a reproduction of parental situations that goes against the aspiration for social mobility. We shall see below how an explanation for this transmission of vulnerability to unemployment can be found in the functioning of the labour market. These results confirm those obtained by Silberman and Fournier (2006). These authors conclude that young people of North African origin follow markedly less positive trajectories than other young people of immigrant origin, and less so again than those with parents born in France. In the four years after the end of their schooling they experience more periods of unemployment and benefit less than others from employment support measures. This situation persists after controlling for qualification level and is due to a lesser mobilisation of social capital (family members and contacts in the labour market) and a poorer match between qualifications and the labour market. Frickey, Murdoch \& Primon (2005) show that young people of North African origin wait longer to find their first job than young native French people (4 months against 3.3 months), are more often in subsidised jobs, and spend longer out of work during the first three years after leaving school.

\subsection{Ethnicity and the split labour market}

We have shown that immigrants and their descendants experience discrimination in their access to jobs (higher rates of unemployment, lower rates of activity for women compared with the whole population). It remains to be seen whether origin-related inequalities exist within employment relations. More precisely, is there any evidence of vertical segregation (unequal distribution within the professional hierarchy) and/ or horizontal segregation (i.e. a distinct, origin-based distribution of employment between the different sectors of activity and occupations)? Civil service positions are filled through competitive examinations, which in theory guarantee recruitment without discrimination on grounds of sex, or social or ethnic origins. To what extent are civil service jobs really accessible to immigrants and second generations?

\subsubsection{Lower positions in the social hierarchy}

Immigrants and their descendants generally occupy lower positions in the social hierarchy. Less than one-third of immigrants belong to the categories of executive, intellectual and intermediate professions. Nearly half of immigrant men are workmen, often skilled (27 per cent of immigrant men who came to France after the age of ten and 34 per 
cent of those who came before the age of ten are skilled workers, compared with 26 per cent of the whole population of working men). Women immigrants are slightly more likely to be employees (55 per cent of immigrant women and 57 per cent of Generation I.5, compared with $5^{\text {I }}$ per cent of the whole population of working women), but the distinction is clear in the category 'employees in direct services to individuals' (25 per cent for immigrant women and I5 per cent for Generation I.5, compared with II per cent of the whole population of working women).

Like their parents, the majority of children of immigrants become either workers (for the men) or employees (for the women). Among them, children of mixed couples stand out: the men are less likely to be workers and more likely to be employees than among children whose parents were both born abroad. Likewise, the socio-professional distribution of women born to mixed couples is similar to that of working women whose parents were both born in France. The proportion of executives is even slightly higher.

The distribution between socio-professional categories varies widely depending on the country of origin. There is a higher proportion of skilled workers among immigrant men of Turkish, Portuguese and Italian origin. Immigrants born in Algeria and sub-Saharan Africa are less likely to be skilled workers and more likely to be public service or company employees. Lastly, the proportion of farm workers is high among immigrants born in Morocco. For women, the category of employees is predominant, for all countries of origin except Italy. Women of Italian origin are more likely to belong to the executive and intermediate professions (about 50 per cent of them). Three-quarters of women of Portuguese origin are employees, mainly as personnel in direct services to individuals, which also accounts for a large proportion of women from sub-Saharan Africa (66 per cent). Women from Turkey are more likely to be workers than are women from other countries, and women from Italy are more likely to be executives.

Origin-related differences are less pronounced for the second generations, but the same distribution can be observed: there are more unskilled workers among men whose parents were born in sub-Saharan Africa or Portugal; there is a large proportion of skilled workers among second generation men of Turkish, Italian and Portuguese descent; there is a higher proportion of intermediate and executive professions among men whose parents came from Asia, Morocco and Algeria. Nearly half of second-generation women are employees, whatever the origins of their parents. The proportion is particularly high for women of Portuguese descent ( 64 per cent). There are more workers among women whose parents were born in sub-Saharan Africa (25 per cent), 
and more intermediate professions among women of Moroccan descent (3I per cent).

\subsubsection{Service sector for immigrant men}

The service sector now employs the majority both of immigrant men aged between eighteen and 40 ( 64 per cent) and of second-generation men ( 69 per cent). This is slightly higher than the percentage for the whole active population ( 63 per cent). Male immigrant employment remains polarised around a few sectors of activity, whereas employment of Generations 3 and above shows a more even spread. A high proportion of immigrant men still work in the construction industry: I7 per cent of men who came to France after the age of ten and i3 per cent of Generation I.5. The other main sectors of employment for immigrant men are operational services ${ }^{6}$ and the hotel and catering industry. sectors with a high labour turnover and very dependent on fluctuations in production. Operational services employ 11 per cent of immigrant men (Generations 1 and 1.5); the hotel and catering industry employs 7 per cent. The proportion of male immigrants employed in these three sectors is higher than that of the population as a whole (for which the figures are 9,7 and 3 per cents, respectively), while the proportion employed in public administration is lower than that of the whole population (see below).

Immigrants born in Portugal, Turkey and, to a lesser extent, Italy, Morocco and sub-Saharan Africa are most likely to work in the construction industry $(38,30, \mathrm{I} 8$, II and 9 per cents of them, respectively). Portuguese and Turkish men who came to France after the age of ten are even more likely to work in construction ( 48 per cent and 36 per cent of them, respectively). The operational services sector, which besides temping includes outsourced services such as cleaning and security, employs I8, I7, I2 and 8 per cent of male immigrants from sub-Saharan Africa, Algeria, Morocco and Turkey, respectively. A relatively large proportion of male immigrants from Italy, Algeria, Morocco, Turkey and South-East Asia also work in the retailing sector. The hotel and catering industry employs the majority of immigrant men from SouthEast Asia.

For second-generation men, the spread of employment in different sectors of activity is closer to that observed for men of French origin, although the construction industry remains the largest employer (Io per cent of Generation 2 work in this sector, compared with 8 per cent of Generation 3 and above), and they are more likely than Generation 3 and above to work in operational services (9 per cent of Generation 2, compared with 7 per cent of Generation 3 and above). They are as likely as Generation 3 to work in administration (9 per cent) and in 
transport. In the second generations, children of mixed parentage are more likely to work in public administration (II per cent of 'mixeds', compared with 8 per cent of 'non-mixeds') and less likely to work in construction (II per cent of 'non-mixeds', 8 per cent of 'mixeds'). Like their elders, the second generations of Turkish and Portuguese origin work mainly in construction, but their participation in this sector is lower (23 per cent and I7 per cent, respectively). On the other hand, Portuguese, Turkish and Asian second generations are more likely than their elders to work in operational services.

\subsubsection{Women's sectors of activity vary little from one generation to another}

Unlike men, the spread of employment in different sectors is very similar for all generations of women (immigrant, second generation, Generation 3 and above). Around I5 per cent of immigrant women and I8 per cent of second-generation women work in the health and social welfare sector, compared with ig per cent of Generation 3 and above. However, sectors of activity do differ according to the women's countries of origin. Thus, a large proportion of women immigrants from Turkey, Algeria, Morocco, sub-Saharan Africa, Italy and Portugal work in the health and social welfare sector (2I, I9, I9, I4, I4 and I2 per cents, respectively). The 'services to individuals' sector employs 23 per cent of women immigrants from Algeria, I5 per cent from sub-Saharan Africa and II per cent from Morocco. On the other hand, women immigrants of Italian origin are the only ones to be represented to any large extent in 'advice and assistance' (I7 per cent) and 'recreational activities' (Io per cent). Women immigrants from South-East Asia are mainly employed in retailing (I7 per cent) wholesaling (I2 per cent) and the hotel and catering industry (Io per cent).

On average, the sectorial distribution of second-generation women is very similar to that of women of French origin, although women whose parents were born in Portugal or Turkey are less likely to work in the health and social welfare sector and more likely to work in retailing.

\subsubsection{Under-representation of immigrants in the public sector}

Faced with these difficulties in the labour market, immigrants, and above all their children, may seek a form of refuge against job discrimination in the public sector. The impartial character of its examinationbased mode of recruitment might be expected to reduce the risk of discrimination on grounds of skin colour or origins. However, it is known that the propensity to enter the examinations is not randomly distributed and that the civil service tends to attract people with similar socio- 
cultural profiles (Calvès 2005; Peres 2004). So is the civil service open or closed to the descendants of immigrants?

Access to the status of civil servant is regulated by relatively stringent conditions, of which at least two automatically weigh against immigrants: applicants are required to be French citizens or - since very recently - nationals of EU member states, and the age limit for taking the examinations is between 35 and 45 years (CERC-association I996). These two restrictions are cumulative, since not all immigrants become French nationals, while for those that are, acquisition of French nationality often occurs at a relatively high age, thereby effectively limiting the possibilities of entry into the civil service. 'Logically, therefore, immigrants of both sexes, whether or not they went to primary school in France, are found to be under-represented in the three branches of civil service employment (state, local government, hospital services). For those with French nationality, under-representation among wage earners in the public sector (all statuses combined) ceases for men and becomes less acute for women. However, the immigrants with French nationality who enter the civil service do so with an insecure status, on fixed-term contracts and in subsidised jobs. Thus, from ages eighteen to 40 , only 4 per cent of male immigrants with French nationality are fully tenured civil servants, compared to 11 per cent of native French men, and 6 per cent of female immigrants compared to 18 per cent of native women. Immigrants, particularly men who entered France after age ten, are much more likely to be working on fixed-term contracts: 39 per cent of male immigrants with French nationality in civil service employment are on a fixed-term contract compared 13 per cent of native men, and 24 per cent compared to 13 per cent for women. Note also that a large proportion of female immigrants are in subsidised jobs.

The rules relating to the entrance examinations and the effects of the nationality requirement go some way to explaining the difficulties that immigrants experience in acquiring the status of tenured civil servant. But what is the situation for their children, who have French nationality at least from the age of majority? Although their general level of civil service employment is close to that observed for native French, children of immigrants are also less often tenured civil servants and are more frequently in subsidised jobs or on fixed-term contracts. Here too, the second generation of mixed parentage stands out for having a high level of civil service employment, though the proportion in untenured positions is higher than among natives.

How can these differences be explained? Immigrants - especially those who arrived as adults - may be disadvantaged by the examination-based recruitment that is the norm in the civil service. ${ }^{8}$ This is due to the fact that most of the jobs on offer are skilled positions for which the minimum requirement is three years in higher education, and by 
the importance of formal criteria particular to the French educational system (notably, a written essay on a topic of general knowledge). This selection method can also be an obstacle for the second generations, who have grown up in a minority cultural environment that affords limited contact with the 'common cultural background'. Assimilating this 'common cultural background' is a prerequisite for the examinations, and whereas for native French people it is acquired spontaneously in everyday life, for the children of immigrants it often demands a specific effort of learning.

For all immigrant wage earners with French nationality, both men and women, the probability of being civil servants is lower than for natives, but it is particularly low for those from South-East Asia, sub-Saharan Africa, Portugal, Italy and Spain (for men). The Italian and Spanish second generations, like their parents' generation, are less likely than natives to be civil servants. The Algerian second generations, by contrast, have the same likelihood as natives of being civil servants, for men and women alike. But that last result could be due to the heterogeneity of the group and by the 'statistical noise' linked to the presence of children of repatriated settlers from Algeria.

\subsubsection{More jobs of a precarious nature}

Immigrants are more often exposed to job precariousness than Generation 3, and women are even more vulnerable than men are (table I2.8). Under the age of 40 , more than a quarter of immigrants do not have a stable job, compared with about one-fifth of employees with two French-born parents. Immigrants, both men and women, from Morocco, sub-Saharan Africa and Turkey are more likely to be in precarious employment, whereas immigrants from Portugal and Italy, and women from South-East Asia, are more likely to have unlimited employment contracts (table I2.9). Children of immigrants are also more likely to be exposed to precariousness than are employees with French-born parents, whatever their parents' country of birth (except for those of Italian descent). Overall, children of immigrants are slightly less affected by job precariousness than their parents, but the second generations of Portuguese and African origin are an exception to this, suffering from greater levels of precariousness than their elders do.

\subsection{Conclusion}

The situation of immigrant-descended populations is a central issue of political and social debate in multicultural societies. In an unprecedented movement of convergence, social science scholarship in North 


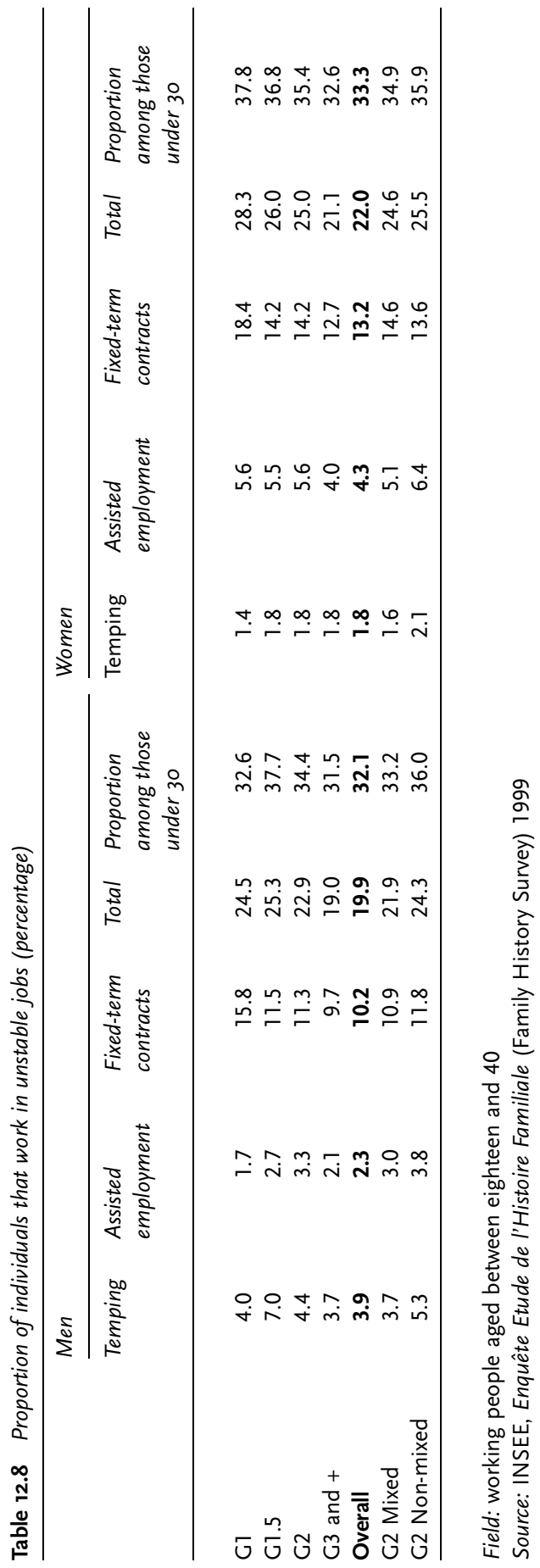


Table 12.9 Proportion of individuals at work in unstable jobs according to country of origin (percentage)

\begin{tabular}{lrrrrrrr}
\hline & Italy & Portugal & Algeria & Morocco & Africa & Turkey & Asia \\
\hline Men & & & & & & & \\
G1 & 17.5 & 13.7 & 27.9 & 30.5 & 37.0 & 24.4 & 27.9 \\
G1.5 & 7.3 & 12.1 & 26.9 & 44.5 & 55.3 & 39.2 & 22.5 \\
G2 & 15.8 & 25.4 & 26.8 & 29.0 & 46.1 & 31.9 & 24.6 \\
Women & & & & & & & \\
G1 & 32.0 & 14.8 & 30.0 & 40.0 & 33.3 & 33.3 & 14.2 \\
G1.5 & 14.1 & 14.5 & 33.5 & 46.6 & 36.5 & 37.6 & 18.7 \\
G2 & 17.0 & 26.5 & 27.7 & 34.9 & 35.6 & 37.5 & 25.7 \\
\hline
\end{tabular}

Field: working people aged between eighteen and 40

Source: INSEE, Enquête Etude de l'Histoire Familiale (Family History Survey) 1999

America and in Europe is giving close attention to the trajectories followed by the second generations (Crul \& Vermeulen 2003; Portes \& Zhou I993). This interest shares the perspective of the classic works on intergenerational mobility, the innovation here being that the categories studied relate not to social class but to immigrant origins. The main theories proposed for studying the processes of integration - i.e. full and unrestricted participation in the host society - assume that these processes unfold over several generations. Extending analysis to members of the second generation enables us to observe the different modes of integration of immigrants and their descendants and the capacity of the host societies to integrate these populations. With the new quantitative data sources now available, the labour market positions of the second generations can be examined in detail and compared with those of immigrants and natives. We made this comparison using the EHF survey, first by looking at levels of labour force participation, and particularly the risk of unemployment, and then by analysing the characteristics of labour market participation from the viewpoint of employment status and type of occupation.

Despite the limitations specific to this source (which does not distinguish between descendants of immigrants and descendants of French nationals born abroad), our results show clearly that the types of employment occupied have changed substantially from one generation to the next, but equally that the second generations continue to face serious difficulties in accessing the labour market. Considerable heterogeneity is observed, however, between groups from different countries of origin. Descendants of immigrants from southern Europe are relatively unaffected by unemployment, whereas second generations of North African, sub-Saharan African and Turkish origin are extremely vulnerable. This greater exposure to unemployment is not determined exclu- 
sively by personal characteristics such as initial educational levels, social background, age and family composition. All other things being equal, the discrepancies are considerable for non-European immigrants, and remain large for second generations of North African, Turkish and sub-Saharan African origin. In addition to unemployment, they experience greater job insecurity and rely heavily on subsidised employment schemes. On the other hand, the marked occupational segregation observed for immigrants declines for the next generation, indicating a process of occupational assimilation. A degree of occupational specialisation is nonetheless observed for second generations, notably in the building trade and small industrial sector for the offspring of Portuguese immigrants, and in social services for the descendants of immigrants from the Maghreb countries.

Several studies have produced similar results that highlight the overexposure of descendants of North African immigrants to unemployment, their over-representation in insecure jobs and even their downward assimilation. After controlling for the active variables, all conclude that immigrant origin has a specific effect on labour market integration. The disadvantage associated with an 'inherited' origin is reflected in a wide range of constraints that affect not just the chances of finding a job but the characteristics of the job held. It attests to the existence of discrimination whose widespread and persistent character pertains more to the system as a whole than to individual measures by employers. This discrimination weighs primarily on the trajectories of immigrants from the Maghreb countries, Africa and Turkey, but also on those of their children. Silberman and Fournier (2006) reach the same conclusion, arguing that improvement in the overall employment situation is not, in itself, enough to solve the difficulties related to discrimination.

In a context of labour market discrimination, the civil service could function as a refuge or even as an exemplary model. Our findings and those of Fougère and Pouget (2004) show that this is not the case, and that although there is a strong tendency for second generation Maghrebians to look for civil service jobs, their access is still characterised by inequality and low-level entry. This point deserves attention, since the civil service not only accounts for a large proportion of employment opportunities in France but its accessibility to the descendants of immigrants, and most particularly those of North African or sub-Saharan African origin, is a strategic component of anti-discrimination policies (Versini 2004). It remains to be seen whether this discrimination and its consequences on access to employment and the careers of immigrants' children will prove enduring or transitory. A longitudinal follow-up of the occupational trajectories of immigrants' descendants will provide an answer to this question. 


\section{Notes}

I As in many European countries, anti-discrimination policies were implemented in France shortly before the enactment of the 2000 EU 'race' directive; and then reinforced after the transposition process. The last issue of the Eurobarometer on discrimination (January 2007) stresses the fact that 80 per cent of the French sample consider racial discrimination to be widespread in society, whereas 64 per cent of the average European opinion shares this belief.

2 Among eighteen to 40 year olds, I0.2 per cent report being school or university students or unpaid trainees. The proportion of eighteen to 40 year olds in education is highest among the immigrants who entered after age ten ( 17 per cent), as it includes immigrants who entered the country to pursue their education. The proportion is lowest among the children of mixed couples (5 per cent) and stands at around 9 per cent for the other three categories.

3 Indeed, 39 per cent of higher education diplomas obtained by immigrants were obtained in France. Note that as part of the population was still in education, the proportion of higher education diplomas in our survey is lower than it would be with a population aged between 25 and 40 .

4 See definitions of categories at the beginning of the chapter.

5 We have used a relatively restrictive definition of 'active', particularly for the unemployed. People who declare themselves unemployed but who have not sought employment during the year are considered inactive.

6 Temping is the biggest item in this sector.

7 Even though only part of the population studied (aged eighteen 40 in I999) is potentially affected directly by the age limit. Note that the age limits were abolished in 2005 except for certain examinations to occupy positions classed as active service (police, prison staff, nurses, etc.) or requiring more than two years of postexamination training.

8 Some 90 per cent of jobs in the state civil service are filled though competitive examination. Candidates are selected on the basis of anonymous written examinations and assessment interviews. In the local government civil service, 50 per cent of recruitment is by competitive examination.

\section{References}

Alba, R. \& R. Silberman (2002), 'Decolonisation immigrations and the social origins of the second generation: The case of North Africans in France', International Migration Review 36 (4): II69-II93.

Alba, R. \& V. Nee (2003), Remaking the American mainstream: Assimilation and contemporary immigration. Cambridge: Harvard University Press.

Beaud, S. (2002), 80\% d'une génération au bac...et après? Les enfants de la démocratisation scolaire. Paris: La découverte.

Brinbaum, Y. \& A. Kieffer (2005), 'D’une génération à l'autre, les aspirations éducatives des familles immigrées: Ambition et persévérance', Education et Formations 72: 53-75.

Boëldieu, J. \& C. Borrel (200I), 'De plus en plus de femmes immigrées sur le marché du travail', INSEE Première, 79I.

Borrel, C. \& P. Simon (2005), 'Les origines des Français', in C. Lefèvre \& A. Filhon (eds.), Histoires de famille, histoires familiales, Cahier de l'Ined 156, 425-44I. Paris: Ined-Puf.

Caille, J.-P. \& L.-A. Vallet (I995), 'Les carrières scolaires au collège des élèves étrangers ou issus de l'immigration', Education et Formations 40: 5-I4. 
Calvès, G. (2005), Renouvellement démographique de la fonction publique de l'État: Vers une intégration prioritaire des Français issus de l'immigration? Paris: La documentation française.

Canaméro, C., G. Canceill \& N. Cloarec (2000), 'Chômeurs étrangers et chômeurs d'origine étrangère', Premières Synthèses, DARES 46 (2).

CERC-ASSOCIATION (I999), 'Immigration, emploi et chômage', Les dossiers de Cerc-association 3 .

Crul, M. \& H. Vermeulen (2003), 'The second generation in Europe', International Migration Review 37 (4): 965-986.

Dayan, J-L., A. Echardour \& M. Glaude (I996), 'Le parcours professionnel des immigrants en France: Une analyse longitudinale', Economie et statistiques 299: I07-I28.

Fougère D. \& J. Pouget (2004), 'L'emploi public s'est-il diversifié? Sexe, niveau d'étude, origine sociale et origine nationale des salariés de la fonction publique', addendum to a report on La diversité dans la fonction publique submitted by Madame Dominique Versini to the Minister for the Civil Service and State Reform. Paris: La Documentation française.

Frickey, A., J. Murdoch \& J.-L. Primon (2005), 'From higher education to employment: Inequalities between ethnic backgrounds in France', European Education 37 (4): 6I74 .

Gissot, C., F. Heran \& N. Manont (I994), 'Les efforts éducatif des familles', INSEE-Résultats, coll. Consommation-modes de vie, no. 33I-332.

HCI (I993), L'intégration à la française. Paris: UGE IO/I8.

Maurin, E. (I99I), 'Les étrangers: une main d'œuvre à part?', Economie et Statistique 242: 39-50.

Meurs, D., A. Pailhé \& P. Simon (2006), 'The persistence of intergenerational inequalities linked to immigration: Labour market outcomes for immigrants and their descendants in France', Population-E 6I (5-6): 645-682.

Pérès, H. (2004), 'L'accès aux fonctions publiques des jeunes d'origine immigrée', Migrations Études 22.

Portes, A. \& M. Zhou (I993), 'The new second generation: Segmented assimilation and its variants', Annals of the American Academy of Political and Social Science 530: 74-96.

Portes, A. \& R. Rumbaut (200I), Legacies: The story of the immigrant second generation. Berkeley: University of California Press and New York: Russell Sage Foundation.

Rooth, D.-O. \& J. Ekberg (2003), 'Unemployment and earnings for second generation immigrants in Sweden: Ethnic background and parent composition', Journal of Population Economics I6: 787-8I4.

Safi, M. (2006), 'Le Processus d'Intégration des Immigrés en France: Inégalités et Segmentation', Revue Française de Sociologie 47 (I): 3-48.

Silberman, R. \& I. Fournier (2006), 'Les secondes générations sur le marché du travail en France: Une pénalité ethnique ancrée dans le temps. Contribution à la théorie de l'assimilation segmentée', Revue Française de Sociologie 47 (2): 243-292.

Simon, P. (2003), 'France and the unknown second generation', International Immigration Review 37 (4): IOgI-III9.

Tribalat, M., P. Simon \& B. Riandey (I996), De l'immigration à l'assimilation: Enquête sur les populations étrangères en France. Paris: INED/La Découverte.

Versini, D. (2004), Rapport sur la diversité dans la fonction publique, report presented to Mr. Renaud Dutreil, Minister of the Civil Service and State Reform. Paris: La Documentation Française.

Viprey, M. (2002), L'insertion des jeunes d'origine étrangère: Etude. Section des Affaires Sociales, Conseil Economique et social.

Zeroulou, Z. (I988), 'La réussite scolaire des enfants d'immigrés: L'apport d'une approche en termes de mobilisation', Revue française de sociologie 29 (4): 447-470. 



\section{Part IV}

SPECIAL SURVEYS IN INTERNATIONAL MIGRATION STUDIES 



\title{
13 One-way or both-ways migration surveys
}

\author{
Jean Louis Rallu
}

In the nineteenth century, demography started by studying registered events: births and deaths. Migration, as a move, is an event that involves two places. Statistics for this type of event did not become available until much later. In fact we had to wait for modern censuses to record people according to places: first the place where they resided, later the place where they were born, and more recently a place where they resided some time ago - usually five years before a census. Population registers also record people according to places where they live and have lived in the past. These data are at the origin of the modern study of migration, as a part of demography.

At first, migration was only considered as a factor of bias in mortality and fertility estimates. The study of migration as a demographic phenomenon in itself has developed more recently for methodological reasons. Migration is a repeatable event and, unlike other repeatable events such as births, it takes various forms - forward, backward, circular - and has various types when geographical boundaries are considered - moves within or between geographical units - and can be called internal or external. Data on moves between countries (international migration) only recently became available and are still the poorest. Therefore, the study of migration started with internal migration data from censuses and population registers and later from specific surveys. As a repeatable event varying in its form and types, migration is best described as a succession of events or a process (Massey I987): short distance moves often precede long distance moves; migration also often follows family events, like marriage. Thus, the study of migration developed more rapidly when progress was made in the analysis of biographies collected by surveys (Courgeau I989, I990; Courgeau \& Lelievre I992; Findley I982; Goldstein \& Goldstein I98I; Massey I993) or from population registers (Baccaini \& Courgeau r996).

The study of internal migration has already reached a very high technical and theoretical level but international migration lags behind, due to poor quality data and a scarcity of surveys providing results that can be generalised. This is certainly due to the fact that the study of international migration involves different countries and administrations, and that the topic is highly sensitive for sending and receiving coun- 
tries as well, hindering cooperation in legal as well as scientific matters. Therefore, surveys of international migrants in one country, usually a host country, are much more frequent than surveys at both origin and destination i.e. in the sending and host countries. Let us call the latter 'both-ways migration surveys', meaning that they capture all migrants on the move between two (or more) places.

In the last two decades, the study of international migration has become increasingly important in demography. Moderate before I950, international migration increased in the I950s and I960s, with a new growth in the I970s following easier and cheaper long-distance transport. Since the I990s, new behaviours and new forms of migration have been linked with the development of global markets and the emergence of regional entities that transcend countries. These new patterns have been discovered by using various approaches such as qualitative studies and, more rarely, quantitative ones.

This paper will address surveys on international migration with the aim of making them as comprehensive and representative as possible, and altogether as similar as possible to surveys of internal migration. First, theoretical considerations will aim at defining surveys for collecting information on migration without bias, not only one-way migrations, but both-ways migrations or migrations in their various directions. Then, we shall present a survey carried out by the Institut National de la Statistique et des Études Économiques (INSEE) in I99II992 on migration between Départements d'Outre-Mer (DOM) ('overseas territories') and mainland France. Although it cannot be called international migration, the DOM-to-mainland France migration is typically a South-North migration and shows patterns that are only emerging in international migration in the frame of supranational entities like the European Union or the North American Free Trade Agreement (NAFTA). Finally, other examples of 'both-ways migration surveys' will be reviewed and insights will be presented on future developments of this approach within the framework of ever-changing migration patterns in the context of globalisation.

\subsection{A theoretical approach}

\subsubsection{From internal to international migration surveys}

Internal migration data from censuses, registers or surveys usually cover a whole country, and migration out of the study area is considered a negligible bias. Given that data cover all the areas where internal migration occurs, they capture all migrants (with the exception mentioned above) and thus collect information on all types of moves: forward and backward (return) migration, as well as circular migration 
(between two or more places) and more complex itineraries. Census data only provides information on forward and backward migrations, usually recording only two moves: between the birthplace, one (more rarely two - Spain, or three - Portugal) previous residence(s) and the place of enumeration. In the case of censuses, previous residences yield only a fragment of biography and return migrants as well as successive movers are only partially captured. Population registers also have difficulties in capturing all moves.

International migration surveys are usually carried out in one country only, mostly in a receiving country and more rarely in a sending country. In the former, surveys interview only migrants, and in the latter only return migrants. Surveys in sending countries also interview non-migrants as a reference group and to determine their migration intentions. There is obviously a bias because the information collected in a host country does not include migrants who have left either to return home or to re-emigrate to a third country. Furthermore, information collected in the sending country does not include migrants who did not return or return migrants who re-emigrated, either to the same destination or to a new one. Although biographic data collected from multi-movers may include return migrations and re-emigrations, the bias remains because not all the migrations are recorded since a sizeable part of migrants are not surveyed. This affects not only the measurement of flows, but also migration patterns, characteristics of migrants and migration factors, as well as settlement, return and re-emigration factors. The bias due to data limitation in either receiving or sending countries can be very high, and it is certainly increasing with the trend towards higher migrant mobility.

The necessity of surveying both at origins and destinations has been acknowledged since the I970s (Zachariah \& Condé I980; Fawcett \& Arnold I987). In the early i980s, Massey (I987) started his first ethnosurvey in five Mexican villages and also interviewed a few migrants in Los Angeles whose addresses had been provided by relatives in Mexico. More recently, large-scale surveys have covered several countries, such as the DOM survey by INSEE in I99I-I992, the I993 Réseau Migrations et Urbanisation en Afrique de l'Ouest (REMUAO) survey by the Institut de Recherche pour le Développement (IRD) on African migrations (Remuao 2004) and the Netherlands Interdisciplinary Demographic Institute (NIDI) survey on push and pull factors in international migration in I994-I999 (Schoorl et al. 2000). The NIDI survey covered five sending countries - Egypt, Ghana, Turkey, Morocco and Senegal - and two host countries - Italy and Spain - plus the Netherlands from a comparable survey. The REMUAO surveys covered eight sending and receiving countries in Africa. 
A survey of international migrants that tries to reproduce the conditions of a survey of internal migration has to overcome various methodological difficulties and also avoid some of the latter's shortcomings.

First, we must set the goals for a both-ways international migration survey, aiming at measuring flows and types of migration, including discovering new types. It also aims at describing the characteristics of migrants and estimating factors of migration and settlement without the bias of migrants not being interviewed because they live outside of the surveyed area. Even if surveys are not the best way to measure flows because of small numbers and sampling biases, they should provide, as far as possible, reliable estimates of inflows and outflows. As this information aims at covering a few years or decades before the survey, it is necessary to cover all the migrants who entered and left the country during the period, making it necessary to survey in all the countries sharing the migrants' diasporas. Of course, it is also possible to limit the survey to countries hosting (including the country of origin that 'hosts' return migrants) a large proportion of the migrant diasporas so that those not surveyed represent a negligible bias. This is also a condition for capturing the various types of itineraries and being able to discover emerging migration patterns. The same condition applies to studying the characteristics of all migrants (not only those who settled). As regards the factors of settlement/return/re-emigration, complete data on migrants, return migrants and re-emigrants are necessary in order to estimate them. The data should support a regression analysis of return (or re-emigration) by duration since migration, age and cohort of migration with time-varying variables for labour force participation, family situation, etc. Therefore, the data on the demoeconomic situation of migrants in the different countries, at different stages of their migration process, should be as complete as possible, requiring the collection of information through migration, family and work biographies. It is also important that return migration, a long-neglected topic of internal migration, be considered not as a permanent return a priori, but as a temporary move in the frame of itineraries that are always potentially incomplete. Finally, whenever the survey covers different countries, it is a single survey and questionnaires should include a core of similar biographic information so that data can be pooled in a single dataset.

\subsection{Previous both-ways migration surveys}

We shall now review various surveys that attempted to cover most of the area of migration, either between mainland France and its overseas 
departments, between several West African countries or between two countries involved in a back and forth migration like Mexico and the US.

\subsubsection{The DOM Migration survey 1991-1992}

The 'Enquête sur la migration des personnes nées et residents dans les DOMs' was carried out by the INSEE in I99I-I992 in DOMs and mainland France.

Although it is not international migration, DOM-to-mainland France migration is not much different from mass migration from the Caribbean to the United States or the United Kingdom for instance, at least insofar as it represents a South-North migration. As inhabitants from DOMs have French citizenship and freedom of movement to mainland France, it is more an internal migration from an administrative viewpoint, but as it involves areas separated by sea, it also looks like overseas 'international' migration. But, as moves have become easier and more frequent, they show migration patterns that are also emerging in international migration. The methodology can be extended to countries with only some adjustments to the questionnaire, mostly a citizenship section. Actually, it is precisely this context of both internal and overseas migration that led to the specificity of the DOM survey, with a unique dataset and basically a unique questionnaire, although it also includes special focus sections on return migration.

\section{The project}

The original project ${ }^{2}$ was a fully representative survey at national level. The survey was to include migration and family biographies. Migration biography was intended to record not only external moves (between DOMs and mainland France or between different DOMs), but also internal moves within DOMs or mainland France. It was designed to assess the step-by-step process that leads to external migration. No complete work biographies were to be recorded, but sections of the questionnaire would record the labour force situation before every migration, with more detail before the first migration and at time of survey.

\section{The survey}

Due to the length of interviews and cost considerations, detailed information on the socioeconomic situation of interviewees was only recorded before the first migration, following arrival of the first migration and at time of survey, including the situation of their spouse at that time. For people interviewed in DOMs, socioeconomic situation 
was also recorded at the end of the first migration and at the beginning and end of a second migration (chosen by the interviewee).

It would actually have been better to collect labour force status before and after all moves, and the best would be complete work biographies to be able to compare migrants, re-emigrants and return migrants by employment status and migration cohorts at similar durations.

Although simultaneous collection of data in DOMs and mainland France would have been preferable, the survey was carried out in the last quarter of I99I in the DOMs and in the last quarter of 1992 in mainland France. The bias incurred is not very important as the aim was not to measure flows, but to understand the process leading to migration and integration in mainland France.

\section{The sample}

The sample includes DOM-born migrants to mainland France, interDOM migrants, foreign migrants and return migrants, as well as mainland France-born migrants to DOMs. The latter could be Europeans, but they were excluded from the scope of the survey and among people born in mainland France, only those who are children of DOM-born migrants (second-generation migrants 'returning' to DOMs) were surveyed. A reference group of non-migrants was interviewed in the DOMs; no reference group of mainlanders and no second-generation migrants were interviewed in mainland France.

In the DOMs, households were drawn up through multistage cluster sampling. Migrants are people born outside of the DOM and DOMborn people who lived outside of their DOM of birth for six months or more. If there was no migrant in the household, one interview was carried out in every tenth household to constitute the reference group. If all household members were migrants, one person was interviewed in every second household. If the household contained both migrants and non-migrants, in every fifth household a non-migrant was interviewed and a migrant was interviewed in other cases (Dagas 1993). The person to be interviewed was designated by a KISH test, a procedure that enable enumerators to randomly chose one respondent in a household where there are several eligible respondents.

In mainland France, the sample was drawn from households including at least one DOM-born person in the I990 census. The survey was limited to seven regions where 82 per cent of DOM-born people resided in 1990. Migrants are simply defined as DOM-born people, irrespective of their duration of stay - the survey occurring more than two years after the census, only migrants in newly built houses or new occupants of enumerated houses in 1990 could have less than six months stay. ${ }^{4}$ Only one person was interviewed in each household (de- 
signated by a KISH test) and people above 45 were over-represented to have significant results for the earlier cohorts.

\section{The questionnaire}

Although migration was considered an individual move, information on household and family composition, as well as on parents (such as parents' occupation at age fifteen of interviewee) was collected. However, there was no information collected on household structure prior to migration or as regards split households following migration (although one question asked if interviewees had relatives in mainland France/DOMs). One section of the questionnaire dealt with contacts between DOMs and mainland France (by mail, phone or short visits), but not in relation to information about mainland France that is publicised through the various media. Moreover, migration is most often aided by administration. The questionnaire also included sections on housing, income, the interviewees' intentions to (re-)emigrate or return as well as that of their children, and intended place of retirement.

Biographic sections of the questionnaire were exactly the same in mainland France and DOMs so that data could be pooled in one dataset, which is the main new advantage of this type of survey: it enables us to study migrants/return migrants in different locations from similar core information. However, different sections applied specifically to non-migrants, migrants or return migrants, leading to different booklets.

However, the survey suffered from shortages as regards the various types of migrations. The six-month period to record migration is too long to find 'circular' migrants. Bi-residence, a recent phenomenon, and short moves were not recorded. For short and frequent moves by businessmen, it might be possible to ask how many trips they had made in a given year without recording all trips.

\section{Socio-political context}

It can be seen that the survey met with various 'political' problems. The project was launched by Réunion and was not fully welcomed in the Caribbean DOMs. Therefore, interviewers were not well trained in using the KISH test in the Caribbean and they frequently interviewed the migrant designated by the head of the household who was too proud to have a migrant in the family. Other 'political' concerns also probably led to scarce publications, including Réunion despite a higher quality of data (Widmer 2005). It was necessary to mention these aspects because they are likely to occur frequently in the field of migration surveys. 


\section{Expected results}

Migration biographies of all migrants in the sending country and the various host countries would theoretically enable us to calculate, without bias, rates of migrations by rank and cohort (birth cohort for first migration and migration cohort from migration $n+1)$. Thus, it is possible to calculate the number of migrants who made a migration of rank $n+1$ by duration since previous migration $n$, and the rate and probability of migration $(n+1)$ by cohort of previous migration. Due to the small numbers of inter-DOM migrants, analysis was limited to two areas: DOMs and mainland France. Rather than results from the complete sample, readers would probably be more interested in seeing the extent of the bias that represents the limiting of data to the host country by calculating return migration rates from biographies of migrants in mainland France only. The bias is actually linked to the frequency of returns that is dependent on the duration considered to account for a migration. The six-month stay condition results in very low proportions of migrants in mainland France having a recorded return migration and the bias would appear huge. This shows that the duration condition for recording events has very important effects on results. In our analysis, migrations (n) are either returns or re-emigrations to mainland France (table I3.I). Rates of further migration vary greatly among cohorts. The I965-1969 cohort returned more frequently (in the early I970s) than the I960-I964 cohort because it was hit by the economic slowdown of the first 'oil shock' during its phase of integration into the labour market. Later, however, it re-emigrated massively, one out of two returnees leaving again for mainland France. The I970-1974 cohort experienced increasing probabilities in each further migration back and forth between the islands and mainland France. Despite that, the I970I974 cohort shows a lower proportion of multi-movers than the I965I969 cohort due to the higher re-migration rates of the latter (table I3.2).

Table 13.1 Rates of further migration $[\operatorname{migr}(n+1) / \operatorname{migr}(n)]$ by cohort of first migration, rates cumulated up to nine years after arrival (percentage)

\begin{tabular}{lcccc}
\hline & $\begin{array}{c}\text { 1st return to } \\
\text { DOM }\end{array}$ & $\begin{array}{l}\text { 2nd migration to } \\
\text { mainland France }\end{array}$ & $\begin{array}{c}\text { 2nd return to } \\
\text { DOM }\end{array}$ & $\begin{array}{c}\text { 3rd migration to } \\
\text { mainland France }\end{array}$ \\
\hline$n=$ & 2 & 3 & 4 & 5 \\
$1960-1964$ & 12.9 & 22.0 & 7.2 & 42.0 \\
$1965-1969$ & 23.9 & 49.6 & 37.4 & 37.9 \\
$1970-1974$ & 16.2 & 20.6 & 37.4 & 41.5 \\
$1975-1979$ & 31.6 & 25.8 & 29.8 & 20.0 \\
$1980-1984$ & 44.0 & 13.3 & 25.2 & 7.5 \\
\hline
\end{tabular}

Source: INSEE, DOM survey 1991-1992 
Table 13.2 Combined rates of migration $[\operatorname{migr}(n) * \operatorname{migr}(n+1) * \ldots m i g r(n+x)]$, by cohort of first migration, rates cumulated up to nine years after arrival (percentage)

\begin{tabular}{lcccc}
\hline & $\begin{array}{c}\text { 1st return to } \\
\text { DOM }\end{array}$ & $\begin{array}{c}\text { 2nd migration to } \\
\text { mainland France }\end{array}$ & $\begin{array}{l}\text { 2nd return to } \\
\text { DOM }\end{array}$ & $\begin{array}{c}\text { 3rd migration to } \\
\text { mainland France }\end{array}$ \\
\hline$n=$ & 2 & 3 & 4 & 5 \\
$1960-1964$ & 12.9 & 2.8 & 0.2 & 0.1 \\
$1965-1969$ & 23.9 & 11.8 & 4.4 & 1.7 \\
$1970-1974$ & 16.2 & 3.3 & 1.2 & 0.5 \\
$1975-1979$ & 31.6 & 8.2 & 2.4 & 0.5 \\
$1980-1984$ & 44.0 & 5.8 & 1.5 & 740.1 \\
\hline
\end{tabular}

Source: INSEE, DOM survey 1991-1992

More recent cohorts seem less mobile. They have much higher rates of first return than earlier cohorts, mostly in the first years after arrival, with about a third of migrants having returned once after five years. But they have lower re-emigration after each return. This is not what is usually reported by qualitative studies, but rather the effect of the sixmonth stay condition. People now move more rapidly, migrants returning or re-emigrating after shorter stays if they do not find a job or only find a temporary one. The six-month duration is also the reason why such low proportions of migrants are found with four or more migrations. In fact, there has been an acceleration in circulation (Marshall I985; Reyes 200I), with more stays of less than six months, in mainland France as well as after return to the home-DOM or to another DOM, and these stays/migrations are not recorded by the survey. Therefore, we would recommend that the duration condition for recording events is not taken from past studies, but is chosen with possible recent behavioural changes in mind. Due to increasing circulation, younger cohorts are not accurately described under the methodology that applied to older ones.

The most interesting results are certainly those obtained from the combined analysis of migration and work biographies to observe the effect of employment or occupational change, through time-varying variables, on the decision to migrate. As work biographies are not available, we shall present a few results showing in what direction studies could be oriented. For men, before the first migration the influence of the situation is very strong on working life thereafter. But significant proportions of males, not only students, had their first job after migrating due to a lack of secondary-sector jobs in DOMs. There is also a strong influence of employment and occupation on decisions to return, and we can expect the effect would be different for return and forward migration. We would expect there to be a need for some success in the labour market before trying for better luck in forward migration, at least to other EU countries, whereas failure to integrate the labour mar- 
ket would be more a determinant of return. We shall see that it is not always like that, at least for the latter (see below). Similar results appear for females, but for those with the lowest qualifications, migration to mainland France was the only chance of having paid employment. Most of those who returned did not enter the labour force again.

As regards occupations, a typical V-shape is often seen, migrants having higher occupations at home than in host countries and again higher occupations after return. It could be the same for re-emigration, the new migration being triggered by the need to find a better job. This pattern is frequently observed but is not a hard and fast rule. Qualified migrants usually improve their situation during return migrations, but they also improve their situation during migration: after accepting jobs below their qualifications at arrival, they manage, as time goes by, to find jobs that better match their skills. The same can apply to return migrants: they take a temporary job, or even spend some time not working, in order to have time to consider the economic situation before investing in their own business.

As regards factors of settlement/return, our analysis also produced a few unexpected results. Although it is well known that a few successful migrants return home, it is often assumed that return migrants are failed migrants. When measuring factors for return from data for all migrants, it is surprising to see that success (rapid access to a stable job, high income) is a strong factor of return. This can actually cover very different situations. First, some public service workers (in 'intermediate' or middle-level occupations) are sent for one or more years training (sometimes several times in their working life) in mainland France and have to return at the end of their contract, as most of them do. Second, those who have high human capital rapidly find a managerial job or set up a business and frequently return as managerial staff or owners of a company that has branches in DOMs and mainland France (in IT, imports, etc.).

These relations between work and migration should be kept in mind when designing a questionnaire intending to assess factors of settlement/return. Leaving before the first job covers very different segments of the population, according to qualifications, with consequences for the success of migration. Successful migration does not exclude returning and, when it leads to return, the link may not be immediate. A period out of the labour force or in lower occupations can take place. Thus the questionnaire should collect, and analysis should consider, complete work biographies rather than the situation immediately before or after migration. However, it is also necessary to think of how these relations could change in the future.

Let us mention some new trends in DOM-to-mainland France emigration since the survey. First, inter-DOM migration - often following 
a migration to mainland France - has seen more than a threefold increase in rates in the 1990-1999 period compared to 1982-1990, raising a new interest in this topic. Second, bi-residence has developed to the point that it is thought to have been the main cause of stabilisation in the DOM-born population in mainland France between 1990 and I999, whenever estimates of net migration from DOMs are very negative. The reason could be that DOM-born people on short duration and uncertain of their future in mainland France consider that they still reside in DOMs and do not answer the census or report as 'visitors'. Part of them have actually been in mainland France for several months and could be considered bi-residents.

\subsubsection{The REMUAO survey}

The REMUAO survey covered eight countries in West Africa: Burkina Faso, Guinea, Ivory Coast (Côte d'Ivoire), Mali, Mauritania, Niger, Nigeria and Senegal. This area was supposed to include most migrants of these countries residing in Africa. All were surveyed between December I992 and July I993. It was carried out by the IRD in connection with national statistics offices and local universities. It collected internal and international migration (changes of residence at least six months apart) biographies with a special focus on the last five years for migrants and the last ten years for returned migrants. A reference group of non-migrants was interviewed. Information on village infrastructures was also recorded.

A representative sample was collected in each country (REMUAO 2004), from strata; administrative and census districts; and sampling of households in each stratum. ${ }^{6}$ These steps were carried out satisfactorily given the various levels of information available in the countries. Households that could not be contacted because of seasonal moves, weather, difficult access, insecurity (warfare) or refusal were replaced by a neighbouring household when possible. Only Côte d'Ivoire gave a report on the number of cases involved. Households visited were fully enumerated and the biographic and in-depth questionnaires were eventually used, the former to all (six months or more) migrants aged fifteen or more. In-depth questionnaires were applied to the various categories of people: migrants at their current residence for five years or less; return migrants at their current residence for ten years or less; or non-migrants people aged fifteen or more who have never migrated. To avoid interviewing too many people with in-depth questionnaires, a further selection of households was necessary. The process was quite similar to that used in the DOM survey: interviewing every third or sixth household for a given category, with a minimum of 2,000 filled-in questionnaires for each category although several countries did not fulfil this re- 
quirement. Inside households, the interviewee was chosen without using a KISH test and countries did not report how it was done. As for the DOM survey, there were various difficulties due to interviewers who tended to report erroneous periods of migration (earlier than five or ten years ago) to avoid doing too many in-depth interviews. ${ }^{7}$ Weights had to be corrected accordingly. Long and repetitive interviews, due to filling in the biographic questionnaire for all migrants of the household, caused some fatigue, inaccuracies or refusals from respondents.

With the survey covering most of the West African migration area, a matrix of international migration in the REMUAO area was calculated using data on immigrants in each country. Information on emigrants collected in households was only used for migration outside the REMUAO area to other African countries and Europe. Data have not been pooled in one dataset but it is possible to do so. The questionnaires were quite similar and variables have similar names, but a minor standardisation would be necessary. Thus, it would be possible to measure changes in in- and out-flows in the various countries of the region (Beauchemin \& Bocquier 2004). Analysis of integration of migrants in labour markets also resulted from this survey.

\subsubsection{The MMP ethno-survey}

The originality of the Mexican Migration Project (MMP) 'ethno-survey' (Massey 1987, 2000) is in combining qualitative and quantitative approaches. The ethnographic approach counterbalances some of the shortcomings of quantitative surveys as regards the real-life experience of migrants as individuals and family members, and the lack of representativeness of classical ethnographic surveys is offset by the quantitative aspects brought by the demo-survey side of the study. However, it is not a fully representative survey.

The origin of the ethno-survey was a study of five villages in West Mexico in I982, supplemented by interviews with emigrants in a major US city (Los Angeles) whose contacts had been given by interviewees in Mexico. It developed into the MMP from I987, with yearly rounds of surveys covering 34 Mexican communities. A few studies have used the ethno-survey in Eastern Europe (Frejka I996; Sipavicienne I997) and South America (Parrado \& Cerrutti 2003, lamp.opr.princeton.edu).

Sampling of households within each community is by simple random sampling, based on the census and the mapping of dwellings. However, for metropolitan areas, only 'specific working-class neighbourhoods are demarcated and sampled.' Interviews are usually conducted from December to January when most migrants return and 'Mexican community samples are representative of the dwelling units occupied during December of the survey year.' Nevertheless, communities are not sampled randomly and there is a quasi-exclusive focus on 
Western Mexico (38 out of 39 communities). They do, however, include a large variety of situations, from agrarian villages to large metropolitan areas. It is noticeable that 'communities are not selected because they are thought to contain a large number of US migrants.' Typically, 200 households are interviewed, with 'an average of about 187'.

Starting from a few addresses and phone numbers given by people interviewed in Mexico, the snowballing technique was used to sample respondents in the US. They were interviewed about six months after the survey of the Mexican communities. Due to cost considerations, the sample was very small, with a modal size of twenty interviewees and a mean of seventeen. It seems that only migrants who did not return in the last three years were interviewed. Data were pooled in one dataset and weighed. The data-file can be publicly accessed through the web (Massey 2000: 767).

The questionnaire gathered information about 'first and last trips within Mexico and to the United States' of each household member. The focus was mainly on heads of households with a work biography (from age fifteen or first job if earlier) plus a migration biography if they had US migration experience. More detailed data on work and use of social services are available for last stay in the US. Household activity, mostly agriculture, was also recorded.

The Encuesta Nacional de la Dinamica Demografica (ENADID) allowed the representativeness of the Mexican sample to be checked. Not surprisingly, given the non-random sampling of communities, the origin of migrants differs between ENADID and MMP, with far fewer migrants originating from small communities $(<2,500)$ and from large places (> I00,000) with 39 per cent and 28 per cent, respectively, for the former and 7 per cent and II per cent for the latter. However, characteristics of international migrants - sex, age, years of schooling, trip duration (slightly longer for the MMP) - seem to match better. The MMP also found more unmarried children of the head of household currently in the US; they may no longer be considered as 'normally living in the unit' by the ENADID, in common with longer stays in the US recorded by the MMP. Whenever the biases were limited for the Mexican sample, the small number of observations in the US and the snowballing effects certainly mean that this part of the survey cannot be generalised.

As it is now, it is not clear who was interviewed in the Mexican sample: 'December and January are the best times to locate and interview seasonal US migrants within Mexico, because most return to spend the Christmas holidays...' The US sample aimed at interviewing 'people who have settled abroad and no longer return home with any frequency (generally those who have been abroad at least three years).' It is not explicitly said if return migrants who had been back for a long 
period or in the last $y$ years were interviewed. Actually, in the MMP, migrants are not defined a priori ${ }^{9}$ and are found through interviews of heads of households (biographies were only collected for the latter) and members. Thus return migrants from several years ago were included, but there was no special focus on them; they were simply 'migrants' (who could eventually re-emigrate). In the same way, migrants who returned for holidays were considered as 'migrants', not short-term return migrants. The lack of focus on return migration stemmed from the MMP's approach to migrants as 'people who settled in the US'. Thus, there was little attention to the small numbers of long-term return migrants surveyed. However, this approach is consistent with the concept of migrants in the process of building their itineraries.

Thirty-four communities were surveyed from I987 to I995 (plus five surveyed in I982 with a similar method). Altogether, about 7,300 households were surveyed in Mexico, and nearly 600 in the US (Massey 2000). It is probable that the cost of the more than thirty ethnosurveys carried out so far would cover a fully representative survey in both Mexico and the US. However, there was a need to start something rather than to wait to be granted a large amount of money. It can be expected that these studies will draw attention to the need for a large survey and help find funding. Then, lessons from the existing work in Mexico, Africa and DOMs can be used for designing it.

\subsection{Future both-ways migration surveys}

The technical feasibility of such surveys is not in question, because some have already been carried out successfully: at least for the REMUAO, the NIDI and the Réunion-DOM surveys - although the DOM survey in the Caribbean failed somewhat due to administrative reasons, the fact that the interviewers had been badly trained and that the status of the migrants in sending values had not been correctly evaluated. This is also a good example of problems that are likely to arise in other countries.

The most encouraging new results from the DOM survey are a better knowledge of factors for migration, return and re-emigration in the framework of the particular administrative and labour force context of this migration. The REMUAO survey gave a first estimate of flows in the form of a migration atlas for West Africa. Reasons for migration and the integration of migrants in labour markets in receiving countries were also studied. The MMP gives a good description/understanding of migration processes including reasons for moves, integration and the economic role of migrants. 
Flows remain difficult to assess from survey data, but the both-way approach is certainly more complete than a survey in one country only. Accurate flow data would be necessary to evaluate the quality of flows collected by a both-way migration survey, but such data are rarely available or of poor quality. However, surveys remain affected by a bias of mortality and migration out of the surveyed area, but the former can be considered negligible at migration ages and a survey covering most of the area of migration should also limit the latter. It is normal that surveys, and both-ways migration surveys as well, show different results from those of a census, unless they are tabulated to reflect census data: from information at the date of census and date of previous residence only, for instance. In developing countries, there are also difficulties in building a representative sample and for the survey to follow the sample frame. The MMP does not pay much attention to representative sampling in the receiving country, and is more interested in processes, but the frequency of these processes/types of migrants cannot be assessed precisely and is therefore generalised.

Both-ways migration surveys should carefully design the sampling procedure in order to find the various types of migrants. As intra-EU migration has become of great interest, several host countries should be surveyed and a significant percentage of migrants will be return migrants, with host countries' birthplace and citizenship. This is also the case for second- and third-generation migrants. Thus, sampling has to start from a household framework and cannot use birthplace to spot migrants, including in host countries. This is also an advantage as it can identify new types of migrants among natives and second or third generations. It is also a way to trace unauthorised migrants not in the census (Blangiardo 2004).

During the design of the survey, it must be kept in mind that it aims at a better knowledge of migration and its various forms, some of which are just starting to appear - such as 'astronaut' migration, bi-residence, the return of second-generation migrants or transients who sometimes make long stops - so that it is necessary to cover all the areas of migration and all types of migrants to reach this goal. The issue is to trace migrants in more and more varied definitions due to changes in migration patterns, in the framework of complex itineraries and multi-generational migration. We will be confronted with increasing forward migration to new destinations inside the EU and migration will become shorter in duration. The duration for a migration should be chosen accordingly. But it should also consider new aspects linked with more rapid circulation. Given shorter stays, second-generation migrants can be born incidentally in the country of birth of their parents, as often happens for DOM migrants. In the host country, they will appear as migrants and in the sending country as natives, whereas they 
Table 13.3 Comparison of multi-country international migration surveys

\begin{tabular}{|c|c|c|c|}
\hline & INSEE-DOM & REMUAO & $M M P$ \\
\hline Sending countries & 4 DOMs & $\begin{array}{l}8 \text { sending and } \\
\text { receiving African }\end{array}$ & Mexico \\
\hline Receiving countries & Mainland France & Countries & United States \\
\hline \multicolumn{4}{|l|}{ Sampling base: } \\
\hline - Sending countries & Households & Households & Households \\
\hline - Receiving countries & Birthplace & Households & Snowballing \\
\hline \multicolumn{4}{|l|}{$\begin{array}{l}\text { Definition of } \\
\text { migrants: }\end{array}$} \\
\hline - Duration condition & 6 months & 6 months & None \\
\hline - Types of migrants covered & $\begin{array}{l}\text { All types of } \\
\text { migrants: } \\
\text { Inter-DOM, } \\
\text { DOM-ml France, } \\
\text { foreign migrants to } \\
\text { DOMs, second } \\
\text { generation } \\
\text { migrants }\end{array}$ & $\begin{array}{l}\text { Urban migrants } \\
\text { All types of } \\
\text { international } \\
\text { urban migrants }\end{array}$ & $\begin{array}{l}\text { Migrants with US } \\
\text { experience } \\
\text { (focus 'currently } \\
\text { US migrants' and } \\
3+\text { years) }\end{array}$ \\
\hline Period covered & No limit & $\begin{array}{l}\text { last } 5 \text { years } \\
\text { migrants } \\
\text { last } 10 \text { years return } \\
\text { migrants }\end{array}$ & No limit \\
\hline \multicolumn{4}{|l|}{ Questionnaire: } \\
\hline \multicolumn{4}{|l|}{ Migration biography } \\
\hline International migration & Yes (all migrants) & Yes (all migrants) & Yes (hh heads) \\
\hline Internal migration & Yes & & No \\
\hline Family biography & Yes (all migrants) & No & Yes (hh heads) \\
\hline Work biography & No & No & Yes (hh heads) \\
\hline One data file & Yes & Possible & Yes \\
\hline
\end{tabular}

Source: own elaboration

are second-generation migrants in the former and 'return' second-generation migrants in the latter. Thus information on parents' birthplace and migration history is necessary to decide if a foreign-born migrant is a migrant or a second-generation migrant. For the third generation, a question on ethnic origin/ancestry is probably the only way to assign them, although it is still difficult to assign them to acountry, as for frequent migrants, given the many back-and-forth moves, births can occur in host country as well as in home country. Ultimately, bi-residence should be considered in such a way that these people appear as migrants or as a separate category.

It is also important that the approach towards migrants in the sending country does not consider returned migration as permanent, which 
would lead to considering mostly retirees and older migrants. Various studies show that return migrants consist mostly of working age adults (Lidgard \& Bedford I994; Rallu, Munoz-Perez \& Carrilho 2000). Theoretically, it is better to consider a 'return' as a (possibly permanent) move to the region or country of birth or any place previously visited (Rallu 2003). Return migration can happen in the frame of 'circular' moves between two or more places. The survey design should always consider migrants as being in the process of building their itineraries.

The main question relates to the desire for and the cost of such a survey. The first condition is the agreement of various sending and receiving countries to carry out a common survey using questionnaires including common biographic sections and adequate sampling techniques so that the data are of good quality, comparable and can be pooled in a single dataset. Cooperation between host and sending countries' administrations and researchers has already been achieved for large migration surveys. But the topic is still highly sensitive and the aims of the survey could be a matter of discussion. Both sending and host countries need better knowledge of the migration process that affects them, mostly when migrants are found in both locations, and this should lead to effective collaboration. As regards costs, they would not be so high, and would depend on the number of countries included. A lot of money is spent on small local surveys, the results of which cannot be generalised and which amount to costs that would cover a large representative survey.

\subsection{Conclusion}

International migration surveys aim at measuring flows retrospectively, defining migration types, characterising migrants and estimating factors of migration as well as settlement/return/re-emigration. This is also the aim of internal migration surveys, but the latter have the advantage of covering all the space where migration occurs, with the bias due to migration out of the area under study usually considered negligible. International migration surveys should try to reach similar completeness, covering as much as possible the entire area of migration to avoid missing various types of migrants, which results in biased estimates.

A review of existing international migration surveys simultaneously conducted in several countries shows that this type of survey provides substantial information on flows and determinants of moves. But they can miss new forms of migration and new types of migrants, because itineraries become more complex and circulation increases and accelerates. This has implications for the sampling procedure as well as on 
the content of questionnaires. Sampling must ensure that representative data are collected and capture return migrants as well as moves of second-generation migrants. The content of the questionnaire, mostly as regards the duration of recorded migrations, is another condition for finding the various emerging types of migration, and triple biographies (migration, family formation and work) are the basic way to study the determinants of migration. Mostly, questionnaires should ensure comparable data that can be pooled in a single dataset.

Both-way migration surveys also encountered various difficulties that are caused more by political problems than by technical failures. A large survey in several host and sending countries could cover many subjects, such as developing forward migration between host countries, in the framework of regional entities like the EU, as well as between different sending countries. The distinction between sending and receiving countries becomes difficult as more of these countries become transit countries. This should certainly raise interest in both types of countries in an inclusive survey that would provide better knowledge of the factors for international migration and help define policies to benefit both sending and host countries. Such a big project may be pure utopia, but would also provide a stimulating conceptual framework.

\section{Notes}

I Migration had previously been studied by archaeologists and historians, but geographers then also began studying migration from modern census data.

2 We are grateful to Daniel Courgeau who gave us access to documents from the original project.

3 This may cause a difficulty for analysis as there may be no information on the migration preceding the last return if none of the migrations with detailed information is the last migration. This problem was more or less solved by the fact that most interviewees only had one or two migrations of six months or more. It would have been more of a problem if shorter periods had been recorded.

4 DOM-born people of the sample who moved away were replaced by new residents if they were DOM-born people; if not, former residents were tracked within the regions under survey.

5 In total, 42,000 households were contacted in the DOMs, and 3,4IO migrants and I,050 non-migrants were interviewed there, and I,750 people aged sixteen or over were interviewed in mainland France.

6 At the first level, strata were to be established according to population size and not to household numbers to avoid a clustering effect for individuals. However, some countries had to follow their usual way and base the sampling on households. Nigeria's survey is not representative; only 22 states out of 32 were surveyed and sampling did not follow recommendations and was not in itself acceptable.

7 Similar bias exists in the DHS (Demography and Health Survey) and other surveys as regards dates of birth and ages of women, which are sometimes considered an effect of interviewers, not only of reporting by interviewees.

8 All quotations in this section are from Massey 2000. 
9 I am grateful to Cris Beauchemin for this information about MMP data.

Io Astronaut migration was first used before the reunification of Hong Kong with the People's Republic of China to describe frequent moves of Hong Kong citizens trying to settle in Western countries while having businesses in Hong Kong and the West.

\section{References}

Baccaïni, B. \& D. Courgeau (1996), 'Approche individuelle et approche agrégée: Utilisation du registre de population norvégien pour l'étude des migrations', in J. P. Bocquet-Appel, D. Courgeau \& D. Pumain (eds.), Spatial Analysis of Biodemographic Data/Analyse spatiale de données biodémographiques, 79-Io4. Congresses and Colloquia, John Libbey - INED.

Blangiardo, G. C. (2004), 'Center sampling: From applicative issues to methodological aspects', Atti della XLII Riunione Scientifica della Società Italiana di Statistica, Bari, 9II June 2004, Vol. I, 377-388. Padua: Cleup.

Beauchemin, C. \& P. Bocquier (2004), 'Migration and urbanisation in Francophone West Africa: An overview of the recent empirical evidence', Urban Studies 4I (II): 22452272.

Courgeau, D. (I989), 'Recent conceptual advances in the study of migration in France', in P. Ogden \& P. White (eds.), Migrants in Modern France, 6o-73. London: Unwin Hyman.

Courgeau, D. (I990), 'Migration, Family, and Career: A life course approach', in P. Baltes, D. Featherman \& R. Lerner (eds.), Life-span development and behaviour, Vol. 10, 219256. New Jersey: Lawrence Erlbaum Associates.

Courgeau, D. \& E. Lelièvre (1992), Event history analysis in demography. Oxford: Clarendon Press.

Dagas, S. (1993), Enquête Migrations 1991-1992: Résultats. Paris: INSEE - ANT.

Fawcett, J. T. \& F. Arnold (I987), 'The role of surveys in the study of international migration: An Appraisal', International Migration Review 2I: I523-I54O.

Findley, S. E. (1982), Migration survey methodologies. A review of design issues, paper no. 20. Liege: IUSSP.

Frejka, T. (ed.) (1996), International migration in Central and Eastern Europe and the Commonwealth of Independent States. New York: United Nations.

Goldstein, S. \& A. Goldstein (I98I), Surveys of migration in developing countries: A methodological review, papers of the East-West Center Population Institute no. 7I. Honolulu.

Lidgard, J. M. \& R. D. Bedford (I994), 'Returning New Zealanders: An ignored dimension of international migration', in Proceedings of the 16th New Zealand Geography Conference, 427-452. Christchurch. New Zealand: Geographical Society.

Marshall, D. I. (1985), 'International migration as circulation: Haitian movement to the Bahamas', in R. M. Prothero \& M. Chapman (eds.), Circulation in Third World countries. London: Routledge and Kegan Paul.

Massey, D. S. (1987), 'The ethnosurvey in theory and practice', International Migration Review 2I: I498-I522.

Massey, D. S. (3 I993), 'The methodology of an ethnosurvey', in D. J. Bogue, E.E. Arriaga, D.L. Anderton \& G.W. Rumsey (eds.), Readings in population research methodology. Vol. 6 (Adavnced basic tools) 24-89:24-93New York: UNFPA.

Massey, D. S. (2000), 'A validation of the ethnosurvey: The case of Mexico-U.S. migration', International Migration Review 34 (3): 766-793.

Parrado, E. A. \& M. Cerrutti (2003), 'Labor migration between Paraguay and Argentina', International Migration Review 37 (I): IOI-I32. 
Rallu, J. L. (2003), 'Létude des migrations de retour: Données de recensement, d'enquêtes et de fichiers', in G. Caselli, J. Vallin \& G. Wunsch (eds.), Démographie: analyse et synthèse Vol. IV (Les Déterminants de la migration), I99-209. Paris: INED.

Rallu, J. L., F. Munoz-Perez \& M. J. Carrilho (2000), 'Return migration from Europe to Spain and Portugal', Studi Emigrazione/Migration Studies XXXVII (139): 625-649.

Remuao, Bureau de Coordination (2004), Synthèse sur la collecte des données par pays. Bamako: CERPOD.

Reyes, B. I. (200I), 'Immigrant trip duration : The case of immigrants from Western Mexico', International Migration Review 35 (4): II85-I204.

Schoorl, J., L. Heering, I. Esveldt, G. Groenewold, R. F. van der Erf, A. M. Bosch, H. de Valk \& B. J. de Bruijn (2000), Push and pull factors of international migration: A comparative report. Brussels: European Commission.

Sipavicienne, A. (1997), International migration in Lithuania: Causes, consequences, strategy. Vilnius: Lithuanian Institute of Philosophy and Sociology and United Nations Economic Commission for Europe.

Widmer, I. (2005), Parcours de deux îles australes: La Réunion et Maurice des origines au XXe siècle, Travaux et Documents no. I55. Paris: INED.

Zachariah, K. C. \& J. Condé (I980), Migration in West Africa: Demographic aspects. Oxford: Oxford University Press. 


\title{
14 Design of samples for international migration surveys: Methodological considerations and lessons learned from a multi-country study in Africa and Europe
}

\author{
George Groenewold and Richard Bilsborrow ${ }^{1}$
}

\subsection{Introduction}

Worldwide, international migration is attracting increased attention, which is manifested in the rapidly growing literature in migration and other social science journals, in increasingly restrictive immigration policies in most receiving countries, and in a rising interest in the role of international migration in economic development of developing nations. The growing importance of international migration is evident in the data and in contemporary policies on international migration (UN I998; Castles \& Miller I998; UN 2000; UN 2004). Thus, the total number of international migrants in the world was estimated as I9I million in 2005, including II5 million in developed countries (many in an unauthorised state), compared to 75 million in 1960 and 155 million in 1990 (UN 2006). The number of countries wishing to change their international migration rose from seven in 1976 to nineteen by 1986 and thirty-five in 2003, most of these wishing to restrict it (UN 2004).

In recent decades, migration flows to the EU have increased in magnitude and complexity. The proportion of the world's population of international migrants living in the EU doubled from 3 to 6 per cent between 1960 and 2000 , even excluding the effects of border changes since I990. Migration within the EU has also become a major policy issue, requiring better insight about migration processes, including migration stocks and flows (European Commission I996; Coppel 200I; IOM 2003). Unfortunately, both data and studies on the determinants or consequences of international migration are deficient as existing data sources do not collect the type and detail of information required to study migration processes.

However, it is possible for specialised migration surveys to provide the needed data provided that adequate sampling procedures and questionnaires are used, that surveys are carried out in both sending and receiving countries, and that, ideally, surveys are linked. In this chapter we il- 
lustrate this by describing the design and application of specialised sampling procedures in a multi-country study of migration to EU countries from West Africa and the Mediterranean region. The study was funded by the Commission of European Communities ('the European Commission'), executed by Eurostat and the Netherlands Interdisciplinary Demographic Institute (NIDI), and implemented by national research institutes. Data were collected in I996-1997.

In the following section, we briefly address the main existing approaches to data collection on international migration and describe the need for specialised migration surveys. In section 3 we describe the NIDI/Eurostat migration project, including the model sampling design that served as the basis for country teams to develop their own samples. In section 4, we summarise the country-specific sampling designs and their implementation in the seven participating countries. Finally, in section 5 we reflect on sampling approaches as implemented and conclude with recommendations on how to improve future surveys on international migration.

\subsection{Collection of data on international migration}

Different types of demographic measurement systems collect data on international migration, including population censuses and registers, border or admission statistics, administrative systems controlling the admission and duration of stay of foreigners, records on refugees and asylum seekers, and work permit statistics (see Bilsborrow et al. 1997). All of these systems gather information on international migration but it is invariably too limited for analysis of the causes or consequences of migration, even if person-records could be linked. A key shortcoming of these systems is that they do not collect data on the situation of migrants before migration. In addition, they do not collect data on migrants departing, and use different, non-inclusive definitions. But their biggest shortcoming is the limited breadth of data that can be recorded on migrants so that it is not possible to understand well either the causes or consequences of international migration.

General-purpose surveys can be more useful sources of information, as they allow in-depth questioning on the characteristics and motivations of the respondent, and include data on non-migrants as a comparison group. But the numbers of migrants covered are too small to yield statistically reliable results as migrants usually comprise only a very small part of the general population, which will be reflected in the sample. This is the rare elements or 'needle in the haystack' problem common to virtually all studies of migration, especially if the main in- 
terest is in recent migration as is usually the case, particularly for policy-oriented studies (Bilsborrow et al. I997: chapter VII).

Therefore, specialised migration surveys are needed to collect the breadth of data needed to study international migration. To do this, data should ideally be collected in both sending and receiving countries on the same migration process, and survey designs must ensure that data are collected on a sufficient number of individuals and households with and without international migration experience. The key issue is to collect data on people and households that constitute appropriate comparison groups. To study the determinants of migration, the appropriate groups are: I) households in the country of origin that have no outmigrant; 2) households remaining in the origin country from which someone migrated to a particular destination country; 3) households in the country of destination that migrated as entire households from the origin country; and 4) individual migrants in the country of destination from that same country of origin. Data from points I and 2 can be pooled to investigate determinants of household migration and data from 3 and 4 can be used to examine determinants of migration of individuals. Having these data would thus also allow distinguishing the factors affecting the international migration of individuals from those affecting migration of households (Bilsborrow et al. I997).

Ideally, it is desirable to have comparable data on out-migrants going to several destination countries from a particular origin country (and from several origin countries as well), with all countries together comprising a migration system (for example Bilsborrow \& Zlotnik I995; Zlotnik I992). However, in the absence of a large international project akin to the Demographic and Health Survey programme, this is not feasible. The best that can be hoped for is paired surveys involving countries that constitute an international migration system (Kritz \& Zlotnik I992), that is, surveys in two countries with a significant migration flow between them, in which data are collected for appropriate households and people (see above).

Similarly, to examine consequences of migration for migrants and their households in areas of origin and destination, surveys should collect data on similar groups in both the country of origin and that of destination (Bilsborrow et al. I997). In all such surveys, specialised sampling strategies are required, which is the main topic of this paper.

\subsection{The NIDI/Eurostat project: study and sample design}

\subsubsection{Study design}

Migration systems theory, social network theory and cumulative causation theory together guided the design and content of the NIDI/Euro- 
stat study in multiple sending and receiving countries. The simultaneous study of several countries in the same migration system has the advantage that several key types of comparisons can be made, such as: I) migrants from the same sending country who migrate to different receiving countries; and 2) migrants from different sending countries who move to the same receiving country (Kritz \& Zlotnik I992; Massey et al. I993).

Guided by these considerations, the NIDI/Eurostat project objective was to study the push and pull factors and mechanisms of international migration in the context of five sending countries (Ghana, Senegal, Morocco, Egypt and Turkey) and two receiving countries (Spain and Italy), all belonging to the same migration system, i.e. migration from Africa and the Mediterranean region to EU countries. In each country a single-round household survey was carried out, including retrospective questions on the situation prior to migration and a migration history, for both current migrants and return migrants. Moreover, as migration decisions are affected not only by personal and household characteristics, contextual data were also collected, on socioeconomic, institutional, policy and administrative characteristics at multiple levels. As the main research and policy interest was on factors explaining recent migration flows, the reference period was limited to ten years preceding the survey to distinguish recent from non-recent migrants. From a sampling design point of view, a shorter reference period was considered undesirable because it would further exacerbate the 'rareelements' problem of finding households with recent international migrants (Schoorl et al. 2000).

\subsubsection{Model sampling design}

The original sampling objectives were: I) to generate survey results representative at the country (receiving countries) or regional (sending countries) level; and 2) to design a sampling strategy that ensures that a sufficient number of migrants and migrant households will be in the sample for statistically meaningful analyses. The second objective implies that migrant households, which in most countries are 'rare-elements', must have a much higher probability of being selected than non-migrant households, that is, migrant households must be oversampled. In probability samples, the selection probability of each household can be determined. Based on this, a sample design (or compensation) weight can be derived, which is the inverse of the selection probability of each person/household. As a result, the sample population, once weighted, is representative of the population of the study area. 
The approach in sending countries was to consider a household a migrant household if it had a recent out-migrant to any international destination, whereby of course the country of destination would be documented. Most such migrant households were selected in the sample, as well as a smaller proportion of non-migrant households. In the two receiving countries, in contrast, the goal was to collect data only on migrants coming from two particular countries of origin, both sending countries in the project. In Spain, the objective was to sample Senegalese and Moroccan immigrants, while in Italy it was Ghanaian and Egyptian immigrants. Thus, in the receiving countries, migrants from other countries as well as natives were not included. Based on resources available, target sample sizes in sending countries were set at I,500-2,000 households, about half to include recent out-migrants. In receiving countries, the target sample size was set at 600-800 households for each of the two immigrant groups.

In sending countries, country teams were asked to identify four regions based on: I) the level of economic development of the region (high versus low); and 2) the length of time that the region had experienced international out-migration (recent versus a long tradition). Thus, areas thought to not have had significant out-migration to Europe were excluded a priori. The design also allowed for the study of migration under different economic conditions. This approach was used in each sending country to select regions purposively in the first stage.

The concept of 'region' used requires clarification. In most of the five sending countries, the region was an artificial construct, created by purposively selecting geographical or administrative areas for which it is known/expected that they contain relatively high proportions of households with out-migrants. Such areas were usually provinces, districts or census tracts, or parts of provinces or districts comprising smaller geographical or administrative units. Such a region may contain areas that are not necessarily contiguous. In receiving countries, the objective was to generate survey results representative of the two immigrant groups at the level of the country as a whole.

To develop an adequate sampling strategy, the following constraints were confronted:

- The tendency of migrant households to concentrate in particular regions and sectors;

- The rarity of migrant households, even more so in receiving countries; and

- The lack of an adequate sampling frame, including coverage of undocumented migrants.

Given these constraints, a model sampling strategy was developed for all countries, to be adapted by each only as necessary to deal with local 
conditions, resulting in over-sampling migrant households. The model sampling design was a multi-stage, stratified, two-phase sample with disproportionate allocation of sample areas to strata with a high expected prevalence of international migrants. This model design involved the following steps:

I. Choose appropriate study regions, and collect demographic and other data on areas constituting them (for example provinces, districts).

2. Determine the desired total sample size, including migrant and non-migrant households, allowing for non-response, based on available resources and cost.

3. For each study region, estimate the prevalence of migrant households in each constituent area, based on data from a census, population register or key informants; create strata based on the expected prevalence of migrant households.

4. Determine the numbers of migrant and non-migrant households to select in each area, and allocate to regions and strata such that areas in the high prevalence strata are over-sampled.

5. For each stratum, compute the number of areas to select and sample from a list using systematic selection.

6. Conduct two-phase sampling in each sample area:

- Phase I: use a screening questionnaire to list all households according to their status as migrant or non-migrant households.

- Phase 2: select migrant and non-migrant households from the lists by systematic selection based on predetermined criteria regarding the numbers of each to select in the last stage, and then interview those sample households.

Thus, the two key aspects of the model sampling design are the use of: a) disproportionate sampling to over-sample areas with high proportions of international migrants; and b) two-phase sampling to identify and select migrant and non-migrant households at the last stage.

The objective was to ensure that a sufficient number of migrant households would be selected, that is, 'disproportionately', taking into account the 'rare' and imperfectly known prevalence of migrant households in the general population (Kish 1965; Bilsborrow et al. 1997). As this model sampling strategy is not self-weighting, sample design weights must be computed from the selection probabilities of households. Therefore country teams were asked to carefully document each stage of implementation in the field, describing procedures used for selecting the original regions, areas within regions, primary sampling units (PSUs) and households, as well as those visited and refusals, to ensure that precise sample design weights could be determined for 
each household. Of course, this must include adjusting for non-response in each final stage area or PSU sampled.

\subsection{Country-specific sample designs and implementation}

We present below brief summaries of the sample designs and implementation issues for each of the seven participating countries in the NIDI project. The main design features, including sample size, are presented in table I4.I.

\subsubsection{Sending Countries}

Turkey

The objective was to sample a total of 1,800 households, divided equally (i.e. 450) among four study regions differing in economic development and experience with international migration. Regions were formed from sub-districts using the most recent (I990) census and survey information on prevalence of migrant households and level of economic development (Dinçer I996). Thus, a region comprised spatially proximate but often non-contiguous sub-districts of two adjacent provinces, with the four regions having a total of 56 sub-districts in eight provinces (Denizli, Uşak (region I); Aksaray, Yozgat (region 2); Kahramanmaraş, Gaziantep (region 3); Adıyaman and Şanlıurfa (region 4)). In each region, sub-districts were grouped in two strata based on their migrant household prevalence rate (high/low). The number of sub-districts to sample was based on interviewer team workload computations. Sub-districts were sampled by systematic selection using stratified sampling based on migrant household prevalence rates. Finally, in sample sub-districts, two-phase sampling was used, with households screened in phase one to determine their migration status and create lists of migrant and non-migrant households. In the second phase, in each sample sub-district a total of twelve households were selected, both migrant and non-migrant, using systematic selection (Kish I965), over-sampling migrant households. The final result is shown in table I4.I.

\section{Egypt}

Projected populations for 1996 based on the I986 census plus other data were used to classify all 27 governorates into four regions according to duration of exposure to international out-migration since/prior to I986 and economic development: I) main metropolitan areas (Cairo and Alexandria); 2) other urban governorates; 3) rural governorates of northern Egypt; and 4) rural governorates of southern Egypt. Adminis- 
trative areas in each region were grouped into an urban and rural substratum. A nationally representative, stratified multi-stage, self-weighting 'master sample' of administrative areas and households was then generated in which areas were sampled in proportion to the projected number of households. In a second stage, a self-weighting sub-sample of areas and households was selected for the migration survey proper.

Previous studies suggested that about one in ten Egyptian households is a recent migrant household and that the non-response rate could be as high as 25 per cent, so that for a nationally representative migration survey of current, return and non-migrant households, 28,960 households had to be sampled and screened in areas selected from the 'master sample' frame, resulting in successfully interviewing I,943 households.

\section{Morocco}

Using data from the I982 and I994 censuses, economic studies of the Direction de la Statistique, and several migration studies (CERED I993; Fadloullah I994), the Moroccan team selected five (Nador, Tiznit, Settat, Larache and Khenifra) of the 49 provinces to establish four study regions. These are the main areas of out-migration, with varying levels of economic development. Three and a half per cent of urban and 2.5 per cent of rural households were expected to have one or more recent emigrants.

Based on figures on expected non-response, the target sample was set at 2,240 households, which were allocated to the regions, half urban and half rural. In the absence of emigration statistics, key informants were consulted in each province to identify administrative units expected to have relatively high proportions of households with emigrants. This led to the selection of all provincial capitals plus one or two towns in each province (i.e. 'villes'). In addition, two or three rural communities ('communes rurales') were also selected by judgment in each province. However, since 'villes' and 'communes rurales' were too large to screen, smaller administrative units were selected, called 'quartiers' (neighborhoods) and 'douars' (rural villages), based on views of key informants about which quartiers and douars were likely to have high proportions of households with international migrants. This led to a purposive selection of 23 'quartiers' and 26 'douars'.

A total of $4,5 \mathrm{I} 2$ households were screened to determine migration status (i.e. recent current, recent return, non-recent, mixed, ${ }^{3}$ and nonmigrant households). Then, in each province, the target samples in urban and rural strata were divided equally among the five migration status substrata. In the final step, systematic selection method was used to sample households, over-sampling migrants, for interview. 


\section{Senegal}

The two main cities of Dakar/Pikine and Touba were chosen to constitute the two main study regions, based on the expectation that the likelihood of locating migrants was highest there. Within the Dakar/Pikine region, eight communities were selected, representing 65 per cent of the population of I.9 million. In Touba, eight neighbourhoods were also selected, representing 80 per cent of the 550,000 inhabitants (Direction de la Prévision et de la Statistique i998). Allowing for a non-response rate of Io per cent, the target sample size was set at I,97I households.

Although the ig88 census did not collect data on international migration and other up-to-date sampling frames were absent, the census blocks that constitute the selected communities and neighborhoods were used as sampling frames and as PSUs. Key informants were asked to rate each block in terms of the prevalence of households with international migrants. This resulted in two strata based on migration prevalence. After deciding on the (fixed) number of migrant and nonmigrant households to sample in each census block and the allocation of the total target sample size to study areas and census block strata, the number of census blocks to sample from each stratum was computed and selected, followed by two-phase sampling in sample census blocks to select households for interview.

In developing the full design, a number of decisions had to be made. First, a disproportionate share (half) of the target sample was allocated to the Touba study area as it had recently become a major focal point for emigrants and return migrants. Second, census blocks in study areas with a higher expected prevalence of households with emigrants were given greater weight, so 80 per cent of the census blocks were allocated to the high stratum. Third, the I993 Demographic and Health Survey in Senegal found the mean number of households in sample census blocks in the Dakar and Touba study areas was I68, averaging six people per household. In addition, other studies (Condé, Diagne \& Ouaidou I986; Findley, Ouedraogo \& Ouaidou I988) suggested that at least Io per cent of the households in these areas are likely to contain international migrants. Fourth, to increase the efficiency of the survey in obtaining information on international migrants, the number of migrant households selected in each census block (when available) was to be twice the number of non-migrant households.

The above procedures indicated that about seventeen migrant households (io per cent of I68) could be expected on average in a census block, along with 8.5 non-migrant households, so allowing for Io per cent non-response resulted in the total number of households to be sampled in a block to be 27. This means a total of 73 census blocks (I,97I divided by 27) needed to be sampled in the two study areas to- 
gether. Following stratified sampling, sample blocks were screened to determine the migration status of all households, and eighteen migrant and nine non-migrant households were sampled and interviewed. In total, 13,290 households were screened in order to successfully interview I,740 households (table I4.I).

\section{Ghana}

Brong Ahafo, Ashanti, Eastern, and Greater Accra were chosen purposively as study regions as they were thought to include the main regions of origin of migration to Europe, especially the Greater Accra and Ashanti regions. The only recent sampling frame available was an updated address list - the latest census was in 1984 - of people eighteen years and older from electoral areas (EA) created for the 1996 national elections. Ghana was divided into 200 electoral constituencies, each with several EAs. The four selected regions have I02 constituencies with 450 EAs, including 675,343 residential addresses.

As the four regions comprise a very large area, it was decided to represent each by one or two purposively selected constituencies and by one EA per constituency. This was done as follows. First, all constituencies in a region were grouped into three strata: $\mathrm{I}$ ) regional capital cities; 2) other urban areas; and 3) rural areas. From each of the first two strata, one constituency was selected by judgment, while two or three constituencies were selected from stratum 3. The selection of constituencies was based on perceptions of key informants in communities regarding the prevalence of households with emigrants. Second, one EA was purposively selected from each sample constituency and screened to determine the migration status of households $(2 \mathrm{I}, 475)$.

The target sample size was set at 52I households per region, including an allowance of $\mathrm{I} 6$ per cent for non-response, leading to a total target sample size of 2,084 households. Households in urban settings were then selected with double the probabilities of those in rural settings, as that is where potential emigrants in Ghana tend to live before they move abroad. Second, once target samples were allocated to EAs, one-quarter was allocated each to the recent current migrant and recent-return migrant household strata, and the remaining half to the non-recent/non-migrant household stratum. Households were then sampled and interviewed from these migration status strata in each EA using systematic selection. In the end, complete information was obtained for 1,576 households in seventeen EAs.

\subsubsection{Receiving countries}

The immigrant populations of interest in Italy (Egyptians and Ghanainias) and Spain (Moroccans and Senegalese) were chosen a priori, 
since, consistent with the migration systems theory, they are the countries of origin where the project was undertaking surveys (see section $\mathrm{I} 4.2)$.

\section{Italy}

The objective was to select a nationally representative sample of 800 Egyptian and 800 Ghanaian immigrants. Significant immigration is recent in Italy, and Egyptian and Ghanaian immigrants are rare, being the tenth and fourteenth largest immigrant populations (ISTAT I999). In I997, there were only 23,500 Egyptian and I5,600 Ghanaian documented immigrants residing in Italy. Though precise figures are lacking, the Ministry of Interior estimated that undocumented immigrants constituted 18-27 per cent of total immigrants (Ministero dell'Interno I998). Thus even if account is taken of under-registration, the two groups were 'rare' elements in a population of 58 million in 1997.

In the absence of an adequate national sampling frame, traditional sampling strategies were considered inadequate so an alternative methodology was developed, the 'centre sampling method' (CSM) (Blangiardo I993). Its main features are: I) the creation of novel sampling frames to select Ghanaian and Egyptian immigrants, listings of meeting places where Ghanaians or Egyptians get together with others from their country, such as mosques/places of worship, entertainment venues, healthcare centres, institutions providing assistance, telephone calling centres, butcher's shops, public squares, homeless shelters and population registration offices; (2) the derivation of ex-post rather than ex-ante respondent selection probabilities, computed from answers to questions on frequency of visiting meeting places; and 3) coverage of undocumented as well as legal immigrants. The underlying assumption is that every Ghanaian or Egyptian immigrant visits at least one of the listed meeting places.

Based on information from various sources (ISTAT I998, I999; Ministero dell'Interno I998) including local key informants and a pilot survey, study regions and provinces were identified where most Egyptian and a large share of Ghanaian immigrants were thought to live. Egyptians appeared to be concentrated in the provinces of Milan, Rome and Latina (estimated 77 per cent), while Ghanaians, many in commerce, moved around and were widely dispersed, with 36 per cent in Bergamo, Brescia, Modena, Rome, Caserta and Naples combined. These provinces altogether constitute the two main study regions: Central-South, comprising Rome, Latina, Naples and Caserta; and North, comprising Milan, Brescia, Bergamo and Modena.

For each province and for each immigrant group, sampling frames were developed, with the assistance of Caritas, comprising meeting places thought to be frequented by all members of the particular immi- 
grant group. For each, the same sampling strategy was followed. First, the total target sample of 800 respondents was allocated to the eight provinces in proportion to the estimated number of immigrants of that group. Then a popularity index was developed based on the frequency of visits to each meeting place, to allocate the sample for the province to meeting places in proportion to the popularity index. In the third step, the allocated number of respondents was randomly selected from those visiting the meeting place, and they were interviewed.

After the interview, respondents completed a short questionnaire on their frequency of visits to each of the listed meeting places. Attendance profiles for all respondents were then derived, leading to an expost classification of the likelihood of each respondent having visited each meeting place in the time period, yielding ex-post popularity index values for each place. The ratio of the ex-post and ex-ante popularity index values was computed to derive an ex-post sample design weight, which was further adjusted to take account of non-response in each meeting place and province. The use of these overall weights for each immigrant interviewed ensured that the survey data represented the population of Egyptian and Ghanaian immigrants in the two study areas (Eurostat/NIDI 2000). Of the I,605 immigrants contacted, I,I77 were successfully interviewed.

\section{Spain}

As in Italy, there was no up-to-date continuous population register that covered both documented and irregular immigrants that could serve as a sampling frame. The only feasible sampling frame was thus the I99I census. However, the census counted only I,202 Senegalese and 35,318 Moroccan immigrants among the 40 million residents in Spain, so that these immigrant groups, especially the Senegalese, were truly rare elements. The census also showed that these immigrants were dispersed over 30 of the 52 provinces of Spain, with one-third of Moroccan immigrants in the provinces of Mellila and Ceuta, in North Africa, bordering Morocco, and another 40 per cent in Gerona, Málaga and Barcelona. Of the Senegalese, 55 per cent were in only five provinces: Las Palmas (Canary Islands), Barcelona, Valencia, Gerona and Alicante. In I99I, Spain had 3I,88I census blocks and Moroccan and Senegalese immigrants were recorded in only 5,342 and 359 census blocks, respectively.

The a priori objective in Spain was to select about 600 households in each of the two immigrant groups, allowing for 20 per cent non-response. For each, identical sample procedures were used, to develop a nationally representative, two-stage, stratified sample, with census blocks as the PSUs. Disproportionate sampling was used, to over-sample census blocks with a high expected prevalence of the immigrant 
group. Therefore, first, all census blocks containing any member of that immigrant population were grouped into strata based on the percentage of immigrants of that group in the population. Moroccans were accordingly grouped into five 'prevalence rate' strata and Senegalese into four strata, with the high prevalence-rate stratum containing few blocks compared to the low prevalence-rate strata, as expected. The target sample number of households was then initially distributed equally across the strata, so that a higher proportion of census blocks would be selected in the higher prevalence rate strata. To improve the efficiency of fieldwork, a decision was made to sample even larger numbers of migrant households in blocks in the high prevalence strata. Thus, for the Senegalese, three households would be sampled from the lowest prevalence stratum, versus six, nine and twelve households in blocks in the higher prevalence strata. Blocks were then selected into the sample from each stratum using systematic selection. For Moroccans, this resulted in the selection of 107 census blocks in 25 provinces, while for Senegalese it was 174 blocks in 30 provinces. These figures demonstrate how spatially dispersed the sample was.

Finally, two-phase sampling was used: r) to screen sample blocks to identify Moroccan (or Senegalese) households; and 2) to sample the predetermined number (three to twelve) of migrant households from the list of migrant households, using systematic selection.

Unfortunately, the geographic distribution of sample blocks was found to be far too dispersed for the budget, so the sample design was altered. The uniform distribution of the census blocks across strata was replaced with disproportionate sampling (see Kish 1965; Bilsborrow et al. I997), which would also improve the efficiency of fieldwork further (sample weights could adjust for the new sample procedures in the analysis). Unfortunately, after the sample of census blocks was drawn, some blocks were arbitrarily replaced by more convenient ones, which was the first distortion in the otherwise ideal probability sample design.

Once in the field, the team was confronted with finding far fewer immigrants than expected, likely reflecting the high internal mobility of migrants following the recording of their addresses in the I99I census used as the sample frame. Thus, interviewers were instructed to search for additional immigrants, by asking respondents in sample households if they knew of other immigrants from the same country nearby or in adjacent census blocks. An attempt was then made to locate and interview those additional households, even though they were not part of the sample, using this snowball sampling procedure (Goodman I96I). Unfortunately, interviewers did not keep track of which households were added by this snowball procedure, so it was not possi- 
ble to identify which households ultimately interviewed were actually part of the sample and which were 'snowball' households.

Given these arbitrary adjustments after the sample was drawn, the survey lost its probability sampling nature, so results cannot claim to be statistically representative of the two immigrant groups.

\subsubsection{Common features and differences in sample designs}

Despite significant differences between sending and receiving countries in levels of development, international migration, and the availability of sampling frames, the sample designs have a number of features in common. First, in all seven countries, the main issue was the 'rare elements' problem, requiring specialised sample designs. This problem arises in any survey that focuses on a minority group, such as on gay populations (Thompson I990), the disabled, the unemployed, adolescents, the elderly and of course immigrants or emigrants.

Thus:

- In the first step in all seven countries, available quantitative data were used to identify regions and sometimes areas within regions thought to have relatively high proportions of (households with) international migrants. If quantitative data were not available to establish a sampling frame, regions were selected purposively, based on informed opinion.

- Second, primary sampling units (PSUs) were selected in the study regions using probability sampling, in one or more stages. Thus PSUs in the form of districts within provinces, villages within districts or census blocks were first classified and stratified according to the expected proportion of households with migrants, forming migrant-prevalence rate strata. Disproportionate stratified sampling was then used to over-sample areas with higher proportions of migrants.

- In the last stage, all countries adopted some form of two-phase sampling. In the first phase, a screening operation was performed to list households with and without qualified migrants. In the second phase, 'recent migrant households' were over-sampled in sending countries, together with a sample of non-migrant households, while in receiving countries (households with) the specific international migrant of interest were selected.

Table I4.I shows that in all sending countries except Turkey, the sampling goal was realised in that about half of the total sample consisted of households with recent migrants. Still, differences in country experiences were considerable and reflect differences in country goals including the desire to concentrate the survey geographically or in particular 


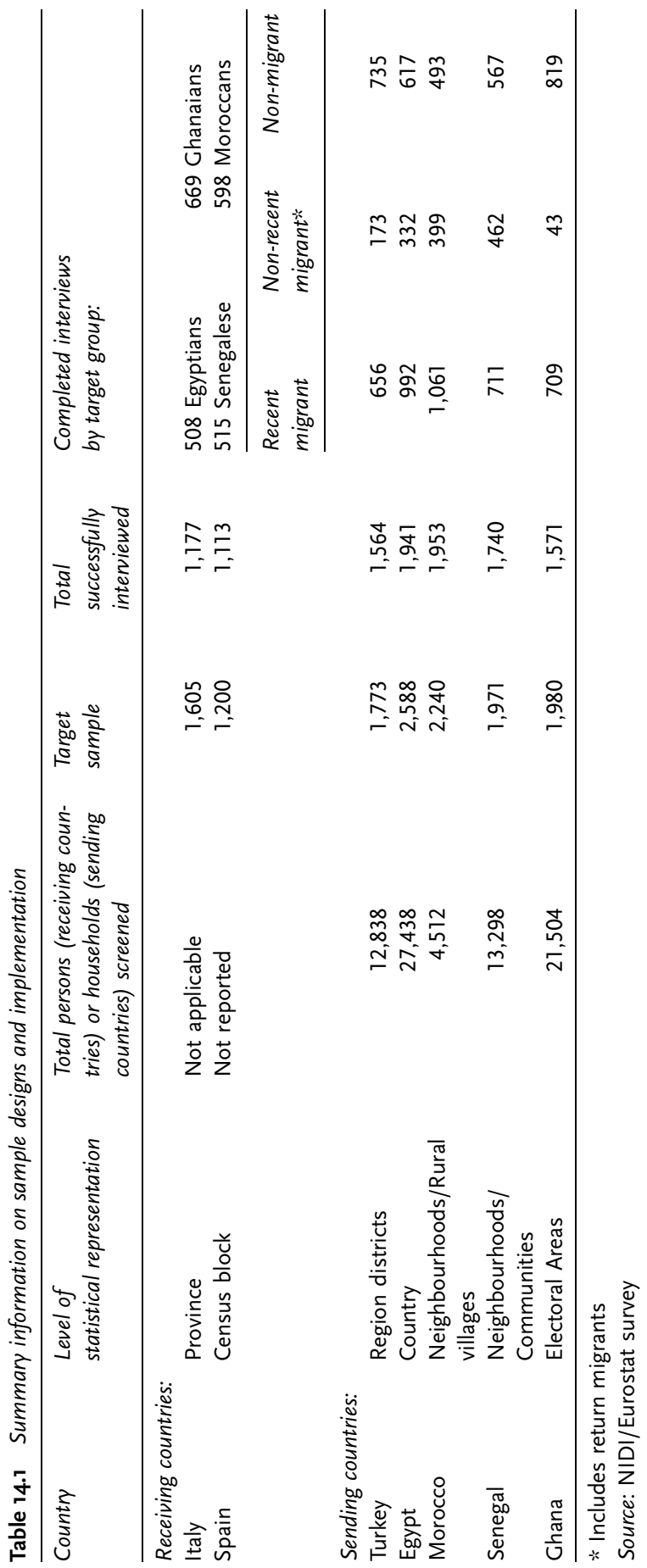


areas, the adequacy of information for establishing a sampling frame, and local knowledge about migrant prevalence. The numbers of households screened varied by a factor of six, from Morocco (about 4,500) to Egypt (over 27,000), because of different ways the screening operation was performed. Also, some sending countries collected data on return migrants while others did not.

\subsection{Conclusions and recommendations}

The main sampling objective of the project was to select samples representative of the population at the level of the region, in sending countries, and at the level of the nation as a whole, in receiving countries. In practice, due to the lack of adequate sample frames, the difficulty of finding rare elements in the field, and budgetary limitations, this objective was only partially achieved, with compromises and deviations of greater or lesser importance in all countries.

Thus, in sending countries the meaning of 'region' varied from one country to another, resulting in very different sizes of the geographical region considered, and indeed whether a 'region' even comprised contiguous geographic units. Usually administrative or political jurisdictions were used for the first and/or second stage sampling units; for example in Turkey, Egypt, Morocco, Senegal and Spain, the spatial units used are sub-districts or census blocks selected through probability sampling within regions purposively selected at the first stage. However, in Ghana, judgement was also used at the second stage, that is, voting districts were purposively selected using key informant information, and within each, one election area was also purposely 'sampled'. As this approach does not yield a probability sample, the results are not strictly representative of the population of the region but only of the population living in the selected election areas. And in Spain, the combination of the extreme rarity of the target immigrant populations and budgetary limitations led the survey team to deviate from the a priori design during implementation, weakening the claim of representativeness. In Italy, an innovative sampling approach resulted in a sample that can claim to be approximately representative only for the eight provinces of northern and central Italy where the majority of Egyptians and a large share of Ghanaian immigrants are thought to reside.

Some of the shortcuts or compromises that weakened the representativity of samples were difficult if not impossible to avoid, as a result of lack of sample frames or budgetary limitations. Others could have been remedied later if careful records had been kept of deviations from the planned approach in the field (in Ghana, Morocco and Spain). 
Although the surveys were conducted in both sending and receiving countries, the study designs, because of financial constraints, were not ideal and embodied unavoidable biases. First, in sending countries, either individuals or whole households emigrate. In the latter case there is no one left behind to be interviewed. To the extent that the demographic or economic characteristics of migrants who moved as entire households differed from those of migrants who moved as individuals, analyses about the determinants of migration are biased if based only on data from the latter. Similarly, a survey of international migrants carried out in a receiving country obtains data from both individuals and households migrating to that country, but this is insufficient to assess either the determinants or consequences of migration for the migrants since it does not include data on the appropriate comparison group of non-migrant households and individuals in the origin country. Data from the latter should be pooled with data on migrant households in the destination country to statistically assess why some moved and others did not, or to assess the consequences of migration for migrants. Moreover, surveys in destination countries evidently only covered those migrants who chose to migrate to that particular country. Their characteristics, motives, etc. may differ from those of migrants from the same origin country who migrated to other destination countries as well as from those who came to the country in question but later died, migrated onward to other countries, or returned to their country of origin.

The ideal situation, consistent with the systems approach to international migration, would have been to undertake surveys of the same migration flow in both countries of origin and destination, in order to pool or match equivalent migrants (Bilsborrow et al. 1997). Based on the seven countries that did participate, only a few matching pairs of migrant flows between specific origin and destination countries are available. One example is individual migrants from households with emigrants from Egypt and Ghana to Italy, interviewed in the sending countries of Egypt and Ghana, which can be matched with individual and household migrants from those origin countries interviewed in Italy. The other example is the two countries of origin (Morocco and Senegal) which have matching populations in the destination country (Spain).

Despite these limitations, the NIDI/Eurostat study is unique in involving the design and implementation of similar specialised surveys of international migration that resulted in a unique, multi-country dataset useful for studying the determinants and mechanisms of migration to the EU. Data were collected in countries that are part of the same migration system, in more or less the same time frame, using very similar survey instruments and data collection methods. Particular attention was paid to sampling procedures, in an effort to adhere to rules of 
probability sampling, by developing a model sampling strategy that would serve as the basis for country-specific sample designs. With the exception of Italy, variants of this model design were applied, which resulted in obtaining sufficient numbers of households with international migrants as well as non-migrants (in origin countries), which has permitted a wide range of analyses (for example Schoorl et al. 200I; Dalen et al. 2005; Groenewold et al. 2006).

Several important lessons were learned from having multiple countries use a common model sample design. First, it is desirable to establish the number and identity of countries to participate in the project. If a migration system approach is intended, then countries should be chosen accordingly, so that the destination countries are indeed the major destinations of emigrants from the origin countries covered in the project. Following that, we recommend the following for future surveys of international migration:

I. Carefully plan all phases of the project at the outset, including sampling and questionnaire design and the stages of fieldwork, and secure full funding, to minimise the likelihood of later compromising the selection of study sites or fieldwork.

2. Organise a pre-project workshop on sampling design and implementation that brings together sampling experts from each country to discuss appropriate sampling designs and identify potential implementation problems (for example lack of census data or of an adequate sample frame, lack of data on prevalence of international migrants). Approaches for confronting those problems can then be developed a priori with the aid of lead institute sampling specialists.

3. Monitor and document problems encountered in the field, as well as solutions adopted, to assess the extent to which the survey adhered to the rules of probability sampling, and to make necessary adjustments in sample design weights. This would have made it possible to make adjustments in Spain, to perform analyses based on a probability sample.

The methods described here for sampling international migrants forming strata according to the prevalence of migrants of interest, selecting areas using disproportionate sampling, and using two-phase sampling in the last stage to over-sample migrants - are useful in household sample surveys on international (or internal) migration. While the methods are not new and are described in the sampling literature, they have rarely been used in studies of international migration. The great value of collecting data through the proposed sampling method is its potential for covering much larger and more representative populations of the rare elements that are international migrants. 
That in turn results in data whose analysis is far more useful for elucidating the determinants of international migration.

\section{Notes}

I The authors are grateful to the European Commission for funding the project and to the staff of collaborating institutes at: Cairo Demographic Centre and CAPMAS in Egypt; the University of Ghana, Institute of Statistical, Social and Economic Research, and Cape Coast University; Institute for Population Research in Ghana; the University of Milan-Bicocca and University of Bologna in Italy; EDESA and the University Med V Rabat in Morocco; the Institute for Development Studies and the Directorate of Projections and Statistics in Senegal; the Centre for Sociological Research of the Universidad Complutense and the Ortega y Gasset Research University Institute in Spain, and Hacettepe Institute of Population Studies, Bilkent University, and Middle East Technical University in Turkey.

2 This problem occurs in all surveys on minority groups, for example ethnic minorities, refugees, the elderly (Thompson I990; Kalsbeek 2003).

3 A mixed household (ménage mixte) comprises more than one type of migrant, such as recent and non-recent current migrants, or one of those categories plus a return migrant.

\section{References}

Bilsborrow, R. \& H. Zlotnik (I995), 'The systems approach and the measurement of the determinants of international migration', in R. van der Erf \& L. Heering (eds.), Causes of international migration, 6I-76. Luxembourg: Eurostat.

Bilsborrow, R. E., G. Hugo, A. S. Oberai \& H. Zlotnik (1997), International migration statistics: Guidelines for improving data collection systems. Geneva: International Labour Office.

Blangiardo, G. (1993), 'Una nuova metodologia di campionamento per le indagini sulla presenza straniera', in L. Di Comite \& M. De Candia (eds.), I fenomeni migratori nel bacino mediterraneo, 27-44. Bari: Cacucci.

Castles, S. \& M. Miller (1998), The age of migration: International population movements in the modern world. New York: Guilford Press.

Centre d'Etudes et de Recherches Démographiques (CERED) (I993), Migration et Urbanisation. Rabat: CERED.

Condé, J., P. S. Diagne \& N. Ouaidou (1986), Les migrations internationales sud-nord: Une étude de cas: les migrants maliens, mauritaniens et sénégalais de la vallée du fleuve Sénégal, en France. Paris: OECD.

Coppel, J., J. C. Dumond \& I. Visco, (200I), Trends in immigration and economic consequences, OECD/Economics Department Working Papers, No. 284. Paris: OECD.

Dalen, H. P. van, G. Groenewold \& T. Fokkema, (2005), 'The effect of remittances on emigration intentions in Egypt, Morocco, and Turkey', Population Studies 59: 375-392.

Dinçer, B. (1996), 'Socio-economic development index for sub-provincial levels'. Ankara: DPT Bölgelsel Gelisme ve Yapisal Uyum Genel Müdürlügü.

Direction de la Prévision et de la Statistique (I998), Enquête sur les Migrations et l'Urbanisation au Sénégal (EMUS), 1992-1993: Rapport national descriptif. Dakar: Direction de la Prévision et de la Statistique. 
European Commission (I996), Comparative research on international migration and international migration policy. Migration from the Maghreb and Turkey to the European Union, and from Mexico, Guatemala and El Salvador to the United States. Luxembourg: European Communities.

Eurostat/Nidi (2000), Push and pull factors of international migration: Country report Italy, report number 3/2000/E/no. 5. Brussels: European Commission.

Fadloullah, A. (I994), 'Migration flows from the countries of the South to Western countries', in Migration and development cooperation, population studies. Strasbourg: Council of Europe.

Findley, S., D. Ouedraogo \& N. Ouaidou (I988), 'From seasonal migration to international migration: An analysis of the factors affecting the choices made by families of the Senegal river valley', in African Population Conference, Dakar 1988 (2): 39-53. Liège: IUSSP.

Goodman, L. A. (I96I), 'Snowball sampling', in Annals of Mathematical Statistics, (32): I48-I70.

Groenewold, G., B. De Bruijn \& R. Bilsborrow (2006), Migration of the health belief model: A framework for psychosocial determinants of migration, paper presented to the 2006 conference of the Population Association of America (PAA), Los Angeles, I-3 April 2006 .

IOM (2003), 'Challenges and effective approaches to national, regional and international migration data collection, sharing and management: Focusing on short term and practical solutions', IOM International Dialogue on Migration: Workshop on Approaches to Data Collection and Data Management, Geneva, 8-9 September 2003.

ISTAT (1998), Foreign immigration in Italy in the '9os. Rome: ISTAT.

ISTAT (I999), Foreign immigration in Italy: Demographic characteristics. Rome: ISTAT.

Kalsbeek, W.D. (2003), 'Sampling minority groups in health surveys', Statistics in Medicine 22 (9): I527-I549.

Kish, L. (1965), Survey Sampling. New York: John Wiley \& Sons.

Kritz, M. M. \& H. Zlotnik (I992), 'Global interactions. Migration systems, processes and policies', in M. M. Kritz, L. L. Lim \& H. Zlotnik (eds.), International migration systems. A global approach, I-I8. Oxford: Clarendon Press.

Massey, D., J. Arango, G. Hugo, A. Kouaouci, A. Pellegrino \& J.E. Taylor (I993), 'Theories of international migration: A review and appraisal', Population and Development Review I9 (3): 43I-466.

Ministro dell'Interno (1998), Relazione sulla presenza straniera in Italia e sulle situazioni di irregolarità [Report on foreign immigration in Italy and on illegal immigrants]. Rome: Ministro dell'Interno .

Schoorl, J. J., L. Heering, I. Esveldt, G. Groenewold, R.F. van der Erf, A. M. Bosch, H. de Valk \& B. J. de Bruijn (2000), Push and pull factors of international migration: A comparative report, report 3/2000/E/no.I4. Luxembourg: European Commission/Eurostat.

Thompson, S. K. (I990), 'Adaptive cluster sampling', Journal of the American Statistical Association 4I2: I050-I059.

United Nations (I998), World population monitoring 1997: International migration and development. New York: UN Population Division.

United Nations (2000), Replacement migration: Is it a solution to declining and ageing Populations?, report number ESA/P/WP.I6o. New York: UN Population Division, DESA

United Nations (2004), International migration and development. New York: UN Department of Economic and Social Affairs.

Zlotnik, H. (I992), 'Empirical identification of international migration systems', in M. M. Kritz, L. L. Lim \& H. Zlotnik (eds.), International Migration Systems: A Global Approach, I9-40. New York: Oxford University Press. 


\title{
15 Quality of asylum decisions: Uses and limitations of surveys of asylum case files
}

\author{
Işık Kulu-Glasgow
}

\subsection{Introduction}

Asylum-seeking, in addition to regular immigration, is traditionally one of the most common and legal ways of gaining a residence permit in Western European countries. These countries base their admission laws for asylum seekers partially on international obligations (for example, the 1965 Geneva Convention, or the European Convention of Human Rights, Article 3) and partially on their own domestic policies (for example by developing temporary, country-specific admission policies in cases of political unrest or war). Since the end of the I990s, several treaties have been signed by the member states of the EU with the final aim of fully harmonising asylum policies and asylum law (Baatjes 2004; EC 2006). Within the last decade, there has been a tendency for domestic asylum policies to become more restrictive. In addition, Western European countries like the Netherlands, the United Kingdom, Denmark and Ireland, as well as the United States and Canada, are increasingly putting more emphasis on so-called accelerated procedures, as 'gatekeepers' to regular asylum procedures. For the cases that are handled in the accelerated process, the outcome of the decision is the rejection of the application. For the applications treated in the regular asylum procedure, the outcome of the application can be either a refusal or an approval.

Restrictive admission policies and emphasis on accelerated asylum procedures are becoming increasingly criticised by national and international refugee and human rights organisations, lawyers and legal-aid workers, and other stakeholders. The criticisms focus on the fairness, sustainability and quality of asylum decisions made in the accelerated procedures. As a result, not only researchers of international migration but also legal and human rights organisations are increasingly focusing on these topics. This interest has also led to the increasing use of a fairly uncommon research method in the field of migration studies, the so-called survey of asylum case files. In the Netherlands, surveys of case files are mostly carried out in juridical research on topics such as 
criminal justice or cases investigated by the police, although one can find rare examples of this type of research in migration studies (e.g. Doornhein \& Dijkhoff i995).

This article will concentrate on this atypical survey method, using examples from the Netherlands and Ireland, ${ }^{1}$ as both countries use gatekeeping or accelerated asylum procedures. The purpose is to present the strengths and weaknesses of surveys of asylum case files to measure the quality of asylum decisions and the methodological challenges they present.

In the following section, the background and aim of recent research in the Netherlands and Ireland based on a survey of asylum case files are presented. Section 3 presents the method and data used in the Dutch survey of asylum case files. In section 4, possibilities, methodological and practical challenges in conducting this type of survey are discussed. Comparisons between the Dutch and Irish studies are made in these sections wherever possible. Finally, we present some concluding remarks and findings from the Dutch survey in section 5.

\subsection{Background of recent research using a survey of asylum files}

\subsubsection{The Dutch example}

The Dutch asylum procedure consists of two different procedures: an accelerated and a normal procedure. In principle, all asylum applications start in an accelerated procedure, where a decision on the application has to be taken within 48 hours. In cases where the Immigration and Naturalisation Service (IND) judges that more time or research is required to evaluate the application, the case is referred to the regular procedure (where the initial decision period is six months). For remaining cases that are further evaluated in the accelerated procedure, the outcome is a refusal of the application. In the Netherlands a new aliens act (referred as the Aliens Act 2000) has been in effect since I April 200I. One of the main aims of the Act is to improve the quality of asylum decisions taken by the IND. The Act introduced two new statuary instruments for this purpose (TK 2000-200I):

I. The possibility of extending the decision period in the normal procedure for individual cases beyond the initial six months, in order to gather additional information to prevent unjust decisions; ${ }^{2}$ and

2. The replacement of the 'objection' procedure with the 'intention' procedure.

The legislator's assumption by introducing the first instrument was that the additional period would make it possible to collect complemen- 
tary information about the case. This would in turn improve the quality of the asylum decisions.

The second instrument introduced a significant change in the asylum procedure. Under the previous aliens act, Aliens Act I994, the IND took an initial decision after a substantive interview with the asylum seeker. In cases where the decision was a refusal, the asylum seeker could fight this decision by lodging a written objection. During the objection process, in some cases asylum seekers could further be questioned by a special commission. Consequently, after the objection phase the IND took a second decision (decision on objection). If the asylum seeker did not agree with this decision, he could appeal. In the Aliens Act 2000 this procedure is abolished and replaced by an 'intention' procedure, mainly with the aim of shortening the asylum procedure. Namely, this procedure is only followed when the intention of the IND is to reject the application. In these cases, also following a substantive interview, the IND presents an asylum seeker with a written 'intention' to refuse the application. The asylum seeker then has the chance to submit a written reaction with arguments within a certain period of time. If the decision still results in rejection, the asylum seeker can proceed by appeal. As the decision under the Aliens Act 2000 already takes into account the arguments of the asylum seeker, the legislator's assumption was that the 'intention' procedure would improve the quality of the asylum decisions compared to that of initial decisions under the Aliens Act of 1994.

In spite of the intentions of the legislator, abolition of the objection procedure has received continuous criticisms among scientists, legal aid workers, solicitors and refugee organisations. Critics argue that as the possibility of an extended oral hearing by a special commission no longer exists, as was the case in the objection process, and the viewpoints of asylum seekers are submitted in writing, the quality of asylum decisions under the new Aliens Act is poorer than that of the decision on an objection (Bruin 200I; Ficq 200I). Furthermore, the procedural differences in the accelerated and normal asylum procedures are continuously criticised ${ }^{4}$ (NCJM 2003; Terlouw 2004; ACV 2004). Critics claim that the quality of asylum decisions taken in the accelerated procedure is poorer than those taken in the normal procedure. Arguments include that in the accelerated procedure the IND cannot make just decisions through a full and fair examination, especially when the claim could actually be manifestly founded.

The Scientific Research and Documentation Center (WODC) of the Ministry of Justice in the Netherlands has recently conducted an evaluation study to investigate the influence of the two aforementioned new instruments in the Aliens Act of 2000 on the quality of asylum 
decisions. The evaluation utilised a survey of asylum case files as the main method of data collection.

\subsubsection{The Irish example}

Ireland is a country that has experienced a flow of asylum applications only within the last decade. The small number of refugee applications was accompanied by a lack of legislation in the area of asylum and immigration (Almirall \& Lawton 2000). Until 2000 Ireland based its immigration procedure on the I935 Aliens Act, and its asylum procedures on a letter sent by the Department of Justice in I985 to the representative of the Office of the United Nations High Commissioner for Refugees (UNHCR) in which the procedures to be followed were outlined. A more comprehensive legislative approach came initially in the form of the I996 Refugee Act, but lay largely unimplemented. The Immigration Act of 1999 made amendments to the Refugee Act of I996, but the procedures to be followed in the processing of asylum claims were not operational (Almirall \& Lawton 2000). In November 2000, the Refugee Act was launched for implementation. ${ }^{5}$ One aspect of the Refugee Act is the use of the definition of refugee as defined in the 1951 Convention, and the UNHCR Handbook on Procedures and Criteria for Determining Refugee Status (Mullally 2001). In the early years of this century, two surveys of asylum case files were conducted in Ireland to evaluate the quality of asylum decisions (Almirall \& Lawton 2000; Mullally 2001). The study by Almirall and Lawton (2000) focuses on the shortcomings of the asylum determination process before the Refugee Act was launched for implementation. The purpose of this study was: 1) to ascertain whether asylum decisions were being made using the refugee definition criteria in international regulations; and 2) to determine whether the asylum decisions were sustainable in law.

The second study concentrated on the quality of asylum decisions made in accelerated asylum procedures after the launching of the new Refugees' Act (Mullally 200I). Mullally argues that the I996 Act was gradually transformed through a series of legislative amendments that intended to streamline the asylum process in Ireland, often at the cost of the quality of the asylum procedure. He reports a growing concern among stakeholders due to the fact that the percentage of asylum applications declared as manifestly unfounded in the accelerated procedure increased from about 2 per cent in 1999 to about 19 per cent in 2000 . The study was conducted to analyse the quality of the asylum decisions that were declared as manifestly unfounded. 


\subsection{Method and data of the surveys of asylum case files}

In this section, the method and data used in surveys of asylum case files are presented, using the Dutch case as an example. Comparisons with the Irish case studies are made wherever possible.

The Dutch survey contains a total of 458 asylum case files. These include 20I case files evaluated under the current Aliens Act (IOI in the accelerated asylum procedure and roo in the regular asylum procedure), and 147 case files (7I in the accelerated asylum procedure and 76 in the regular asylum procedure) evaluated under the previous act. These cases include asylum applications that were refused, as well as those approved by the IND. In addition, another 80 case files, evaluated in the regular procedure, were selected, where the IND exceeded the formal decision period of six months. Also in these cases, the outcome could be either positive or negative for the asylum seeker. The case files were randomly selected, but numbers were proportional to the percentage of asylum decisions made in different regional IND offices to ensure national distribution of the case files. The selection was subject to several criteria. For example, only first asylum applications and completed procedures,' applications made after a certain date (in the case of the current act, this is the date of initiation of the law, i.e. 1 April 2001) and decisions on the applications made by the IND by a certain date (under the previous act, the final decision had to be made no later than 30 March 2001), no unaccompanied minors or suspected war criminals (who are subject to special procedures) etc. were chosen.

The selection of the case files was taken from the national information system of the IND where all the asylum applications and the results of these applications are registered. The selection resulted in file numbers per requested criterion. Later on, these case files were physically retrieved by the IND (paper dossiers) and were provided to the researchers who worked under strict rules of absolute confidentiality.

The Irish studies were based on a smaller number of files, but all solely analysed by qualitative methods, differing from the Dutch case (see section on data collection). The study by Almirall \& Lawton (2000) was based on a survey of Ioo asylum case files where the result of the application was always a rejection (to analyse the reasons for rejection of asylum applications). The study conducted by Mullally (200I) contains an analysis of 65 asylum case files handled in the accelerated procedure, where the outcome of the application was manifestly unfounded. In this study, selection of files was also subject to restriction criteria (e.g. cases for the period of I January I999 to 30 June 200I, thus case applications under the previous and the new Refugee Act - as in the Dutch survey). Both Irish studies made use of randomly 
selected case files that were made directly available for researchers by the asylum seekers and their solicitors.

\subsubsection{Steps in the survey}

The Dutch survey of asylum case files made use of an extended checklist instead of questionnaires used in typical surveys. Although this checklist looks like a questionnaire, it was passively used by the researchers to extract information from the asylum case files. In a typical face-to-face survey, a questionnaire has an active use where an interaction between the researcher and the respondent takes place and can be adjusted, if necessary, during the interview. Despite this difference, the development of the checklist followed steps similar to that of the development of a questionnaire in a typical survey.

\section{Conceptualising and measuring the key term in the research: quality of asylum decisions}

In any research, an initial challenge is to define and measure the key concepts of the study. Conceptualising the concept of the quality of asylum decisions is not a simple task. In an earlier study in the Netherlands, the quality of asylum decisions was defined in terms of procedural aspects, where compliance with the requirements of the asylum procedure were examined (e.g. whether the decision was made within the period set by the law, the presence of essential documents in the asylum case files, the presence of a translator during oral hearings, whether the asylum seeker was informed about deadlines to submit essential documents and whether the decision to refuse the asylum application was based on a motivation) (Boom \& Wierda I999; Bekke et al. 2002). In the WODC study, this definition was not used because it was considered to be incomplete for the definition of quality of asylum decisions. In the WODC study, quality was instead conceptualised as carefulness, where the concept is further divided into two components: carefulness of the procedure that leads to an asylum decision (procedural quality); and the way in which the position of the asylum seeker is dealt in decisions of the IND, for example the line of reasoning used to reach the decision and build the arguments on which the decision is based (content-related quality) - see section I5.4.2.

The Irish examples, on the other hand, used a different approach in conceptualising quality and took the fairness and sustainability of the decisions in the law as a starting point. The study by Almiral and Lawton (2000) examined the methods used by the Department of Justice, Equality and Law Reform when assessing asylum applications. It used concepts like standard of proof and arguments used by the decisionmaker to evaluate the credibility of the asylum seeker. Almiral and 
Lawton (2000), however, did not aim to state which cases deserved refugee status, but rather attempted to ascertain whether the rejections of asylum applications were sustainable by law. Mullally (200I), on the other hand, concentrates on cases that were declared 'manifestly unfounded' by the decision-maker in the accelerated asylum procedure and scrutinises if these decisions were made in accordance with constitutional guarantees of fair procedures and international standards.

\section{Pilot study and development of a draft checklist}

The checklist to be developed in the Dutch study had to both extract information from the files about the aforementioned aspects of quality and be compatible for the analysis of cases that are handled under the current as well as the previous aliens act. To start with, a pilot study was conducted and a number of asylum case files were analysed at the office of the IND. The aim of the pilot was twofold:

I. To discover what type of information was available in the asylum case files; and

2. To discover the details of procedural differences between the current and previous aliens acts.

As a result of the pilot, a draft checklist was developed. It contained quantitative as well as qualitative questions. The quantitative questions in particular focused on aspects of procedural quality. These items attempted to capture different aspects of the asylum procedure from the moment of application to the point of decision-making: reasons for the evaluation of the asylum application in the accelerated versus the regular procedure; data with regards to important moments in the procedure; aspects of the screening interview and the substantive interview by the IND; any research conducted by the IND to evaluate the application; any evidence collected by the asylum seeker to support his or her refuge story; any additional hearing, etc.

The qualitative questions aimed at collecting information related to content-related quality: the nature of the facts that were unknown until the moment of research and/or (additional) hearings conducted by the IND, and use of these facts in the (initial) decision; the arguments of the asylum seeker against the intention of the IND to refuse the application (or against the initial decision), and how the IND incorporated these arguments in the (final) decision; the arguments of the IND to refuse a residence permit based on the articles of the aliens act under question; the nature of any communication and/or communication problems between the asylum seeker and the IND, etc.

In addition to the main checklist, a shorter checklist was developed to analyse the files where the IND officially extended the formal six- 
month decision period. The construction of this checklist followed the same procedures as the main checklist.

\section{Training of researchers and finalising the checklist}

After the draft checklist was developed, three researchers with some background in previous and current aliens acts were recruited to analyse the asylum case files. They were subjected to a three-month training period during which they individually analysed a total of 25 asylum case files, under the current as well as the previous aliens act. The aims of the training period were as follows:

I. To ensure uniformity in the researchers' analyses. Each of the asylum case files was analysed by each researcher. After a file was analysed by all three researchers, they discussed it as a group to discover any differences in the coding of the quantitative questions and the description of the answers to the qualitative questions. In cases where differences were observed in coding and/or description, a mutual decision was made on how to proceed (see section 15.4.2).

2. To finalise the draft checklist. Based on the information that was collected from the files analysed during the training period, the draft checklist was further developed and finalised.

\section{Data collection}

The main survey was held between June and December 2003. All 458 case files were coded quantitatively on the checklist, thus mostly on procedural aspects of quality of asylum decisions. Out of these files, about Io० were further qualitatively analysed on content-related aspects of quality. These files were selected randomly but with an eye to the distribution of aspects such as: whether the asylum seeker provided the IND with a written document of his or her standpoint on the intention of the IND to reject the application (under the current law); whether there was an additional hearing apart from the substantive interview (under both laws); whether there was an oral hearing during the objection procedure (under the previous law); and whether there was any communication or communication problems between the asylum seeker and the IND (under both laws).

In addition to these files, another 30 files were also qualitatively analysed to answer the research question on the influence of the possibility of extending the individual decision period. ${ }^{8}$ These files were subject to a different selection criteria: a decision-making period no longer than the formal six-month limit, and an official letter of the IND in the case file announcing to the asylum seeker that the decision-making period was extended. An additional 50 files where the decision-making period was longer than six months but where the IND had not an- 
nounced this formally to the asylum seeker were analysed quantitatively.

\subsection{Possibilities, practical and methodological challenges of surveys of asylum case files}

\subsubsection{Possibilities}

\section{Nature of data}

Asylum case files are a rich source of data on different topics ranging from the characteristics of the asylum seeker to the decision-making process. Some examples are: the demographic and social background of the asylum seekers (age, education, people accompanying the asylum seeker during his or her flight); motives for fleeing from country of origin; transit countries before entering the receiving country, if any; and experiences en route, including the nature of relations with smugglers who organise the 'journey'. In addition, asylum case files provide information on the process of decision-making on asylum applications, from the moment of application to decision-making and - if relevant a (higher) appeal. This gives researchers not only the opportunity to gain insight into specific stages of the process but also the application and evaluation process as a whole (e.g. screening/substantive interviews, any additional oral hearings, the written intention of the immigration office to reject the asylum application, written objection of the asylum seeker to this intention and the decision of the immigration office).

Nature of analyses using data from asylum case files

As is mostly the case in surveys, a survey of asylum case files also collects information at the individual level; this information is aggregated during analyses to different groups and generalised (e.g. quality of decisions under the new versus previous aliens act, quality of decisions under the accelerated versus regular procedure). Survey of asylum case files differ, however, from other types of surveys. The files collect data continuously from the moment an asylum seeker makes an application to the moment the final decision on the application is made. This supply of relatively unbroken information makes it also possible to apply research methods that aim at 'following' asylum seekers from different case files. These asylum seekers may, for example, share common characteristics or history (such as motives for fleeing and refugee history) as well as other demographic, social or economic characteristics. This opportunity leads researchers to analyse different cohorts of refugees. By doing so, surveys of case files also eliminate disadvantages related to single round retrospective surveys (such as memory lapses, gaps in 
information) or panel studies (for example, high costs and the risks of losing members of the panel).

In addition to their potential for cohort analysis, surveys of asylum case files can provide longitudinal data. This makes it possible to gain insight into the changing structure of asylum flows (e.g. age and sex patterns, changes in the countries from which the asylum seekers originate), changes in asylum motives or the decision-making process.

\subsubsection{Methodological challenges: problems of reliability}

As is the case with any survey, maximising the reliability of results is an important challenge for researchers while conducting a survey of asylum case files. Some of the problems encountered can be controlled by researchers while others are impossible to influence. In surveys of asylum case files, the most important factor that lies beyond the control of the researcher is the compilation of the files. The researcher is limited to the written information available in the files and is not aware of any biases that could have occurred during the compiling of this information. The reliability problems discussed below, however, can be controlled to some extent by the researcher.

In all kinds of surveys, the 'transfer' of information from a respondent to the researcher presents reliability problems. These problems mostly depend on the nature of the questions (e.g. 'culture-sensitive' questions). Surveys of asylum case files are no different. Especially in cases where the subjectivity of the researchers is the main issue, improving the reliability of answers becomes a methodological challenge. In the Dutch case, as mentioned above, quality is defined in terms of process- and content-related aspects. While process aspects refer to more objective facts (such as the duration of decision-making, whether or not the asylum seeker was referred to the regular procedure, the presence of a translator in the oral hearings and whether or not the objections of the asylum seeker to the arguments in the intention to refuse the application were taken into account by the IND in the final decision, etc.) content-related quality aspects refer to the nature of the arguments where the IND announces its intention to reject the asylum application, the written objection of the asylum seeker to this intention and the decision taken by the IND.

There were two 'controllable' methodological problems related to the reliability of answers in the Dutch survey. The first was specific to the measurement of quality of asylum decisions, and the second was related to the reliability of the results of the survey of asylum case files. 


\section{Problems in measurement of quality}

At the early stages of the study, an exercise was conducted to see if it was possible to assign values to the quality of asylum decisions, such as good or poor.

Ten items were developed that could reflect the quality of the motivation of the asylum decisions. These items included content-related aspects of quality such as the extent to which a decision was made using arguments on individual cases or using standard arguments; the extent to which the objections of the asylum seeker were taken into account in the final decision, etc. Each item was scored using an index ( $\mathrm{I}=$ very poor to 5 = very good). Ten asylum case files were individually scored on these quality aspects by the three researchers. Figure I5.I shows the results of this exercise.

It was concluded that the scoring of content-related quality (motivation of asylum decisions) by social scientists was subject to a high risk of subjectivity. It meant, in a sense, that the researchers had to reconstruct the decision made by the IND and would play the role of the judge who decides on the legitimacy of the decisions made by the IND in cases of appeal by asylum seekers. Such variations in opinion were also demonstrated in previous asylum research, even among lawyers, judges or IND decision-makers (Doornbos \& Sellies I997). Doornbos and Sellies point out that the extent of such variations can be decreased in small groups through the exchange of ideas. They also remark, however, that outcomes of (certain) quality aspects are vulnerable to interpretation (such as arguments used and the way the story of the asylum seeker is handled in the decision). On the basis of these considerations, it was decided to abandon the approach of assigning a score to the quality of asylum decisions, and limit research to the description of the

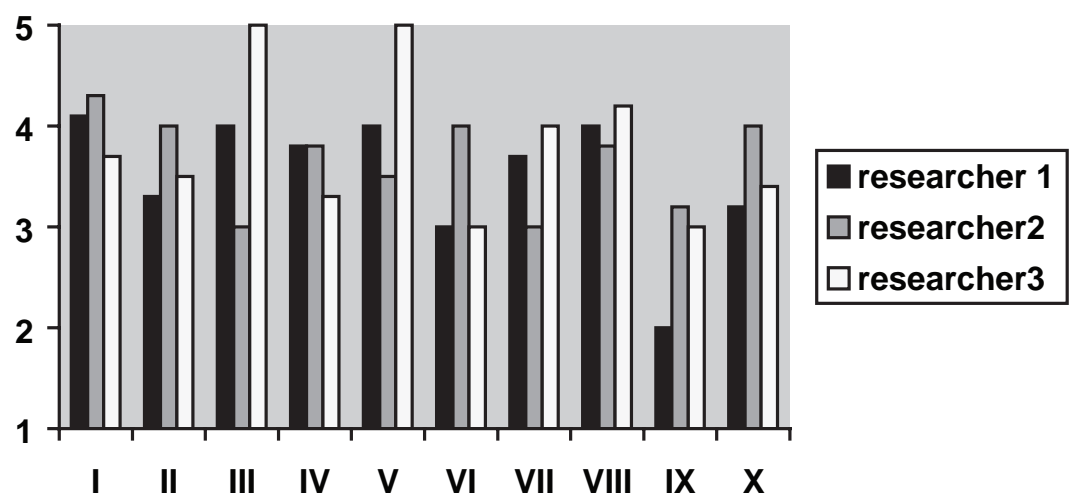

Figure 15.1 Average score of quality per researcher, per analysed file*

* x-axis: asylum case files, y-axis: mean quality score 
nature of the arguments used in the motivation of asylum decisions, and a comparison of the description of the decision processes under both aliens acts.

\section{Inter-researcher reliability}

The second methodological problem encountered in the Dutch study was how to increase the reliability of answers. Even if it was decided that the research would only limit itself to the description of the ways the asylum decisions were made, the descriptions of these arguments by the researchers could be potentially subjective, too. To increase the reliability of answers the following measures were taken:

- Intensive training (see section I5.3.I);

- Concepts that are sensitive to personal interpretations of the researchers were discussed as a group and a common definition was made for these concepts (for example definition of a 'standard' argument versus an 'individual' argument in the motivation of a decision); and

- Where necessary, the wording of the questions in the checklist was modified to avoid subjective answers by leaving out terms that were proven to be sensitive to subjectivity and reformulating the questions in a more neutral way (for example, instead of 'What is the proportion of standard arguments - to the total arguments - in the motivation of the decision?', consider instead 'Which standard and which individual arguments are used?').

In order to determine the reliability of the information collected by the researchers from the asylum case files, an index for inter-researcher reliability was calculated. In order to measure the inter-researcher variance, a set of questions from the checklist was selected, including those questions that were considered to be most vulnerable to interpretation. Questions that could be objectively answered were left out. On the basis of the following conformity measure, the inter-researcher reliability for the checklist was calculated (Miles \& Huberman 1994):

$$
\frac{\text { Number of agreements }}{\text { Number of agreements }+ \text { Number of differences }} \times \text { I०० }
$$

The index is calculated on the basis of the analyses of the last ten asylum case files analysed during the training period. Conformity between the researchers, in general, is calculated to be 76 per cent halfway through the training period. For the most subjectivity-sensitive items, the index was lower yet; it varied between 33 and 64 per cent. The aim here was to obtain a minimum conformity rate of 70 per cent. ${ }^{9}$ After several rounds and revising the checklist to its final state, the following 
rates were achieved: an average of 89 for all the selected items, and 85 per cent for the most sensitive items.

\subsubsection{Methodological limitations: gaps in information in the case files}

Surveys of asylum case files will probably almost always be based on the paper version of the files. ${ }^{10}$ As pointed out before, paper files are, however, limited to information that is in writing. Although these files provide copious information on various topics, this limitation causes a methodological bottleneck. Results based on the written information from the asylum files cannot capture reality as fully as participant observation would. Due to this restriction, certain aspects of the quality of the procedure such as the treatment of asylum seekers, any communication and communication problems between decision-makers, translators, lawyers and the asylum seeker that are not put down in writing cannot be entirely registered. It is also possible that some of the existing information in the files could be replaced by new information. Researchers conducting surveys of asylum case files therefore (can) choose to fill in these information gaps with complementary methods of data collection. Data on aspects that could not be retrieved from the written information can be collected through interviews with stakeholders that are involved in the asylum procedure. Researchers can choose from two different approaches: going back to those involved in a specific asylum file and interviewing them, or interviewing a sample of the stakeholders without making a match with the files. The first approach might, however, encounter privacy problems or be time-intensive as well as potentially biased due to 'socially desirable answers'. Another problem here is that, in cases where the stakeholders are the asylum seekers themselves, researchers probably can only trace those asylum seekers who are still in the procedure or those who have been granted a status.

The study conducted by the WODC and the two studies in Ireland chose the latter approach. In both of the Irish studies, in addition to the analyses of asylum case files, a mail interview was conducted among the legal practitioners (Almirall \& Lawton 2000; Mullally 200I) and representatives of non-governmental organisations working with refugees (Mullally 200I). The questionnaires included questions (statements with 'agree/disagree' responses) about the bottlenecks of the (accelerated) asylum procedures that were observed in the analyses of the asylum case files and views of the respondents on the fairness and sustainability of the asylum decisions.

In the WODC study a similar approach was chosen. Various stakeholders involved in the asylum procedure were interviewed: decisionmakers of asylum decisions, legal-aid workers and lawyers, judges, and representatives of the Dutch Refugee Organisation were interviewed. 
These interviews were conducted by using the Delphi method, where the respondents are interviewed by e-mail in two different stages. The first stage aimed at compiling the views of the respondents on the main research questions (see section I5.2.I); looking for answers to questions that remained unanswered during the survey of asylum case files due to the nature of the information (for example, why lawyers or legal-aid workers do not always make use of legal instruments provided by the Aliens Act of 2000); and answering questions that cannot be fully answered by a survey of asylum case files (for example, common problems that are encountered in accelerated procedures). In the second stage of the Delphi method, the respondents were confronted with the answers of other respondents - anonymously - and were asked to react to each other's views. The results of these interviews were used to complement the results of analyses from the survey of asylum case files and to fill in certain information gaps.

\subsubsection{Practical challenges}

Surveys of asylum case files pose practical challenges to researchers. Although some of these problems can be recognised as general problems in surveys, the nature of the information and the nature of the data make these problems more specific:

- Surveys of asylum case files are highly labour- and time-intensive. In the Dutch example, a maximum of one-and-a-half files per researcher per day could be analysed. The data collection period of the survey was about six months. In the study by Mullally (200I), the duration of analyses was six months for 65 case files. In this latter case the study used qualitative methods only, which are far more labour- and time-intensive.

- Due to the nature of the information, reliability problems, and any requirement for training on specific documents, the duration of training is far longer than for an average survey. In the Irish case, the researchers were specifically trained in the importance of country of origin information and on the evaluation of the fairness of the asylum decision (Mullally 200I).

- Due to extended periods of training and survey implementation, the method is very costly.

- Information in the files is personalised and therefore highly subject to strict privacy regulations. Gaining access to asylum case files therefore entails encounters with bureaucratic barriers and long waiting periods for researchers. While the Irish studies used asylum seekers and solicitors as an 'entry' point, in the Dutch case, access to the files was gained through the research department of the IND. In some cases there might be other additional impediments 
that the researchers did not foresee (e.g. electronic information systems being unsuited to select cases in accordance with the required criteria by the researchers, leading to delays in research).

\subsection{Conclusion}

In spite of their weaknesses (definition problems in case of research on 'quality' of asylum decisions, inter-researcher reliability problems in analysing the files with respect to content-related quality aspects, high costs, being a labour-intensive and time-consuming method) surveys of asylum case files provide researchers with a detailed variety of information about all phases of an asylum procedure, starting from the moment of the application to the final decision, including an eventual appeal procedure. During surveys of asylum files qualitative and quantitative research methods can be combined. While quantitative data allow for the analysis of the procedural aspects of quality of asylum decisions, qualitative approaches enable an in-depth analysis of the quality of the motivation of the decisions made by the immigration offices (for example, grounds used for rejection of asylum applications or the extent to which the viewpoints of asylum seekers are taken into account). These types of surveys may also provide information on other topics, such as the motives of asylum seekers for fleeing from their country of origin, and/or strategies used to flee from countries of origin, and could be used as an alternative to traditional face-to-face interview techniques. Furthermore, through a single round of surveys of asylum files it is possible to analyse different cohorts of asylum seekers without having to rely on longitudinal surveys or panel studies.

Because data collected from the asylum files are limited to the compiling and reporting in these files, and information in the files regarding what the case workers report and what asylum seekers themselves report can sometimes be contradictory, exploiting additional research methods might be necessary.

The large-scale Dutch survey of asylum files reporting on the quality of asylum decisions, conducted within the context of the evaluation of the Aliens Act 2000 was completed in 2006 . The survey has provided results on a variety of comparisons of the procedural and content-related aspects of the quality of asylum decisions under the current and previous aliens acts, as well as of the quality of asylum decisions taken in the accelerated and regular asylum procedure under the current Act. Some of the findings regarding the new instruments in the Aliens Act 2000 to improve the quality of asylum decisions are as follows (Kromhout et al. 2006): 
- The IND often does not inform the asylum seeker of an extension of the decision period, even if it has not come to a decision within the initial decision-making period but lets the decision period extent automatically. In this sense, the instrument does not function procedurally as it was intended by the legislator. In cases where the decision period was extended, additional research for the evaluation of the application was conducted. In cases where the application is rejected, information resulting from this research is used by the IND to assess the credibility of asylum seekers' stories. In these cases, the quality of the asylum decisions are better than cases if the decision would have been taken without an extension of the decision period. ${ }^{12}$

- In the accelerated procedure, asylum seekers present documents to support their story less often compared to the normal procedure. In addition, legal representatives of asylum seekers submit written arguments against the intention of the IND to refuse an application less often than their counterparts representing a case evaluated in the normal procedure.

- In decisions taken in the accelerated procedure, the IND responds to a lesser extent to the written arguments of asylum seekers in comparison with those decisions taken in the normal procedure.

- Both in the accelerated and the normal procedure, in cases where no written arguments are presented, the intention procedure does not result in the viewpoints of asylum seekers being used for the decision. In these cases the content quality of a rejection decision under the Aliens Act 2000 is equal to that of a rejection decision at first instance under the Aliens Act 1994.

- In cases where written arguments by asylum seekers are presented against the intention of the IND to refuse the asylum application, the content quality of a decision under the Aliens Act 2000 is better than that of a decision at first instance under the Aliens Act 1994.

- The content quality of a decision under the Aliens Act 2000 is better than that of a decision on objection under the Aliens Act I994. This conclusion however applies only to cases under the Aliens Act I994 where the asylum seeker was not heard by a special commission. The number of cases where the hearing took place was very small in this research to be able to come to a conclusion.

On the basis of research on the quality of asylum decisions and other research conducted for the evaluation of the Aliens Act 2000, the Commission on the Evaluation of the Aliens Act 2000 brought out a series of recommendations to the Dutch government regarding further evaluations of the Aliens Act 2000 and the quality of the asylum procedure. These include, among other things, seeking possibilities to keep 
the advantages of the accelerated procedure (quick decisions on asylum applications) and overcome the pressure on the quality of the asylum decisions caused by time limits.

\section{Notes}

I As far as we could trace in the literature, Ireland is the only other country that conducted surveys of asylum case files on the quality of asylum decisions.

2 The initial decision-making period can be extended for a maximum of six months in cases where additional research is required.

3 It is possible that the asylum seeker is further questioned by the IND following his or her written reaction.

4 Although these two different asylum procedures also existed under the previous Aliens Act, the accelerated procedure recently gained increasing emphasis in the asylum procedure.

5 During the time this article was revised (2006), a proposal on an Immigration, Residence and Protection Bill by the Department of Justice, Equality and Law Reform was under discussion. Proposals in this bill also have implications for the Refugee Law.

6 According to the UNHCR definition of 1983 , 'manifestly unfounded' decisions are those 'so obviously without foundation as not to merit full examination at every level of the procedure' (Mullally 200I).

7 Cases that were still under evaluation by the IND or were still under appeal or higher appeal were excluded from the survey, mainly because access to these files was not feasible.

8 The number of case files to be analysed was determined through the representativeness of the contents. After the analysis of 30 case files, there were no more variations observed in the reasons why the IND officially extended the decision period. Therefore the data collection was terminated.

9 The conformity rate to be aimed at according to the formula used here is controversial. According to Beukelaar, Van Donselaa and Tavecchio (I980), in explorative research usually a relatively low percentage (such as 60 per cent) is used. Klomp (1992), on the other hand, argues that the minimum percentage according to this formula has to be 70. Miles and Huberman (1994) claim that a value of 90 per cent is necessary (see Kromhout 2002).

Io In the Dutch case, electronic information contained only limited information on a number of essential aspects of the asylum procedure, such as date of application, dates of oral hearings and the date of the final decision, whether an appeal was made, country of origin, etc.

II For more elaborate results, see Kromhout et al. 2006 (in Dutch with an English summary) or www.wodc.nl.

I2 In cases where the asylum application was granted, it was difficult to trace the effects of the extension period on the quality of the decisions. In these situations the IND does not motivate her decisions (Kromhout et al. 2006). 


\section{References}

Advies Commissie voor Vreemdelingenzaken (ACV) (2004), Naar één snelle en zorgvuldige procedure. Den Haag: ACV.

Almirall, L. \& N. Lawton (2000), Asylum in Ireland: A report on the fairness and sustainability of asylum determinations at first instance. Dublin: Irish Refugee Council.

Baatjes, H. (2004), 'Het Europese Asielrecht', Justitiële verkenningen 6 (4): 85-95,

Bekke, R., P. Coskun, W. Gelderloos, Y. Huizing \& D. Vliegenhart (2002), De kwaliteit van asielbeslissingen gemeten. Den Haag: B\&A Groep Beleidsonderzoek \& - Advies.

Beukelaar, L., G. van Donselaa \& L. Tavecchio (1980), Die verdraaide werkelijkheid: Hoe komt de onderzoeker aan zijn gegevens? Baarn: Ambo.

Boom, J. W. \& R. Wierda (I999), Eindrapportage IND. Den Haag: IND.

Bruin, R. (200I), 'Ongehoord: het recht op een inhoudelijk gehoor in eerste aanleg onder de hamer', in Amnesty International, Wederzijds wantrouwen: de asielzoeker, de staat en de waarheid, 54-62. Amsterdam: Amnesty International.

Doornbos, N. \& J. P. P. Sellies (1997), Het overlegmodel in de asielprocedure. Nijmegen: Institute for Sociology of Law, Katholieke Universiteit Nijmegen. Law and Society Series.

Doornhein, L. \& N. Dijkhoff (I995), Toevlucht zoeken in Nederland. Onderzoek en Beleid, nr. I48. Arnhem: Gouda Quint.

EC (European Commission) (2006), "The European Union policy towards a common European asylum system'. <ec.europa.eu/justice_home/fsj/asylum/fsi_asylum_intro_en.htm>.

Ficq, B. J. P. M. (200I), 'De nieuwe Vreemdelingenwet: Eerste ervaringen in de asiel-advocatuur', Justitiële verkenningen 27 (8): 6I-69.

Klomp, M. (1992), Hulpverlening aan adolescenten: Een bijdrage aan methodologiekontwikkeling in trainingscentra voor kamerbewoning. Groningen: Rijksuniversiteit Groningen.

Kromhout, M. (2002), Marokkaanse jongeren in de residentiële hulpverlening: Een exploratief onderzoek naar probleemvisies, interculturalisatie en hulpverleningsverloop. Leiden: Universiteit Leiden.

Kromhout, M. H. C., M. Olde Monnikhof, I. Kulu Glasgow, K. Munk \& E. M. Th. Beenakkers (2006), Zorgvuldigheid van asielbeslissingen - Een vergelijking tussen de oude en de nieuwe Vreemdelingenwet (Evaluatie Vreemdelingenwet 2000, De asielprocedure - Deel 2), WODC, Significant. Den Haag: Boom Juridische Uitgevers.

Miles, M.B. \& A.M. Huberman (I994), Qualitative data analysis: An expanded source book. London: Sage Publications.

Mullally, S. (200I), Manifestly unjust: A report on the fairness and sustainability of accelerated procedures for asylum determinations. Cork: University College Cork, Faculty of Law.

Nederlands Juristen Comité voor de Mensenrechten (NJCM) (2003), De AC-procedure: De achilleshiel van het asielbeleid. Een commentaar van het Nederlands Juristen Comité voor de Mensenrechten op het gebruik van de versnelde asielprocedure in de aanmeldcentra. Leiden: NJCM.

Terlouw, A. (2004) (ed.), Binnen 48 uur: Zorgvuldige behandeling van asielverzoeken? Nijmegen: World Legal Publishers.

Tweede Kamer (TK) (2000-200I), Parliamentary Discussions, 26 732, no. 94. 


\section{List of contributors}

Eva Bernhardt, Professor Emeritus, Stockholm University eva.bernhardt@kvinfo.su.se

Jakub Bijak, Senior Researcher, Central European Forum for Migration and Population Research (CEFMR), Warsaw

j.bijak@cefmr.pan.pl

Rob V. Bijl, Deputy Director, The Netherlands Institute for Social Research / SCP, The Hague

r.bij1@scp.nl

Richard Bilsborrow, Professor, Department of Biostatistics and Carolina Population Center, University of North Carolina at Chapel Hill richard_bilsborrow@unc.edu

Martine Blom, Researcher, Ministry of Justice Research and Documentation Centre (WODC), The Hague m.blomi@minjus.nl

Corrado Bonifazi, Director of Research, Institute of Research on Population and Social Policies of the National Research Council (IRPPS-CNR), Rome c.bonifazi@irpps.cnr.it

Alessio Cangiano, Research Officer, Centre on Migration, Policy and Society (COMPAS), University of Oxford alessio.cangiano@compas.ox.ac.uk

Barbara Dietz, Senior Researcher, Osteuropa-Institut, Regensburg dietz@osteuropa-institut.de

Calvin Goldscheider, Professor Emeritus, Brown University, Providence, Rhode Island calvin_goldscheider@Brown.edu 
Frances Goldscheider, Professor, University of Maryland, College Park frances_goldscheider@brown.edu

George Groenewold, Researcher, Netherlands Interdisciplinary

Demographic Institute (NIDI), The Hague

groenewold@nidi.nl

Roel P. W. Jennissen, Researcher, Ministry of Justice Research and Documentation Centre (WODC), The Hague r.p.w.jennissen@minjus.nl

Pawel Kaczmarczyk, Assistant Professor, Faculty of Economics, University of Warsaw

Researcher, Centre of Migration Research (CMR), Warsaw p.kaczmarczyk@uw.edu.pl

Anna Kicinger, Researcher, Central European Forum for Migration and Population Research (CEFMR), Warsaw kicinger@cefmr.pan.pl

Ișik Kulu-Glasgow, Scientific Researcher, Ministry of Justice Research and Documentation Centre (WODC), The Hague i.kulu@minjus.nl

Dorota Kupiszewska, Principal Research Fellow, Central European Forum for Migration and Population Research (CEFMR), Warsaw d.kupisz@cefmr.pan.pl

Marek Kupiszewski, Director, Central European Forum for Migration and Population Research (CEFMR), Warsaw m.kupisz@cefmr.pan.pl

Dominique Meurs, Professor, ERMES University of Arras National Demographic Institute (INED), Paris dominique.meurs@ined.fr

Marek Okólski, Chair of Demography, Faculty of Economic Sciences, University of Warsaw

Director, Centre of Migration Research (CMR), Warsaw moko@uw.edu.pl

Ariane Pailhé, Senior Researcher, National Demographic Institute (INED), Paris pailhe@ined.fr 
João Peixoto, Associate Professor, School of Economics and Management, Technical University of Lisbon

Researcher, Research Centre on Economic Sociology and

Organizational Sociology, Lisbon jpeixoto@iseg.utl.pt

Swanie Potot, Permanent Researcher, Research Unit on Migration and Society, Pôle Universitaire Saint Jean d'Angély potot@unice.fr

Jean Louis Rallu, Director of Research, National Demographic Institute (INED), Paris rallu@ined.fr

Paolo Ruspini, Senior Researcher, University of Lugano

Associate Fellow, University of Warwick paolo.ruspini@lu.unisi.ch

John Salt, Professor, Department of Geography, University College London

Director, Migration Research Unit, University College London jsalt@geog.ucl.ac.uk

Jeannette Schoorl, Senior Researcher, Netherlands Interdisciplinary Demographic Institute (NIDI), The Hague schoorl@nidi.nl

Patrick Simon, Director of Research, National Demographic Institute (INED), Paris simon@ined.fr

Salvatore Strozza, Professor of Demography, Department of Statistical Science, University of Naples Federico II strozza@unina.it

Aslan Zorlu, Researcher, Amsterdam Institute for Advanced Labour Studies (AIAS), University of Amsterdam a.zorlu@uva.nl 



\section{Index*}

Africa $\quad 283-284$

migration from II5, I22, 295

Ager, A. 200, 204, 22I

agreements

bilateral I2, 87, II3, II5-II6, I30-I3I

by Germany $37,39-40$

Albania II9, I36, I6I, I74

Ahlburg, D.A. I29, 149

Alba, R. 247, 256, 268

Albu, L.L. 98, I03

Alvarez-Plata, P. I32, I49

Anderson, B. 79, 85

Anderton, D.L. 29I

Angenendt, S. 39, 62

Apap, J. I87, I94

Arango, J. 35, II7, I25-I26, I28, I57, I77, 312

Arigoni, I. I74, I78

Arnold, F. 275, 29I

Aronowitz, A.A. 66, 85

Arriaga, E.E. 29I

Arts, C.H. 207, 22I

assimilation I5, 44, 267

see also integration

asylum

policies I83, I88-I9O, 3I3

in Greece I7I

procedure

in Ireland $3 \mathrm{I} 6$

in the Netherlands 314-316

asylum case files

surveys of 3I4, 32I-329

the Dutch survey 317-32I

asylum seekers 9, I2, 20, II9, 202, 2I4216
Baccaïni, B. 273, 29I

Baganha, M.I. 22, 34, 68, 70, 72, 84-85, I74, I77

Bakker, B.F.M. 222-223

Balch, A. 23, 34

Baldwin-Edwards, M. I6I-I62, I76-I77

Baltes, P. 29I

Barbagli, M. II6, І26

Barros, L. I9I, I94

Barth, F. 95, I02

Bauböck, R. 200, 222

Bauer, T. 47, 62, 132, I49

Beauchemin, C. 284, 29I

Beaud, S. 250, 268

Beaverstock, J.V. 22, 34

Bedford, R.D. 289, 29I

Benattig, R. 89, I02

Bender, S. 40, 62

Bernhardt, E. I5, 225-226, 229-230, 233, $237,244-245$

Biezeveld, R. 200, 222

Biffl, G. 60,62

Bijak, J. I3, I29, I49-150

Bijl, R.V. I4, I99-200, 206, 222-223

Bilsborrow, R. I5, 293-295, 298, 305, 309, 3II-3I2

Bjerén, G. 225, 244

Blanchard, O. I5I

Blangiardo, G.C. I66, I75-I77, 287, 29I, 303, 3II

Blauw, W. 35

Blom, M. I99, 218, 222

Blossfeld, H.P. 42, 6I-62

Boardwell, J.T. 22, 34

Bocquet-Appel, J.P. 29I

Bocquier, P. 284, 29I

Boëldieu, J. 258, 269

* Prepared by Roberta Ruggieri of the Institute of Research on Population and Social Policies of the National Research Council (IRPPS-CNR). 
Boeri, T. I32, I50

Boffo, S. II7, I26, I74, I77

Bogue, D.J. 29I

Bonifazi, C. 9, I3, I07-I08, II4, I20, I27, I66, I74, I77

Bonin, H. 47, 62

Borgegård, L.E. $\quad 226,244$

Borjas, G. 42, 60, 62

Borrel, C. 254, 258, 269

Bosch, A.M. 292, 3I2

Bourdieu, P. IOI, IO3

Bouw, C. 2I7, 223

Bovenkerk, F. 218, 222

Bowe, J. 56, 62

Brachet, O. $89, \mathrm{IO} 2$

Brazil 68-69, 73-80, 83

Brinbaum, Y. 25I, 268

Brochmann, G. 244

Brown, G.K. 64

Brücker, H. I32, I49-I5I, I8I-I82, I94

Caille, J.P. 25I, 253, 269

Calvès, G. 263, 269

Canaméro, C. 269

Canceill, G. 269

Cangiano, A. I23, I53

capital

human $4 \mathrm{I}-45,52-53$

social 203-204

Carchedi, F. I74, I78

Card, D. 6o, 62

career development 29

Carella, M. I66, I77

Carfagna, M. I75, I77

Carrilho, M.J. 289, 292

Caselli, G. I27, 292

Castles, S. II8, I24, I27, I85, I94, 293, 3II

Cavounidis, J. I62, I7I, I76, I78

census data I54, 275, 287, 310

Central and Eastern Europe 9, I09, II7, I34, I4I, I67, I70, I72, I74, I8I migration from $\mathrm{I} 32, \mathrm{I} 35, \mathrm{I} 64$

Cerrutti, M. 284, 29I

Chapman, M. 29I

China migrants from ${ }_{13} 6,{ }_{1} 64$

Chiswick, B.R. 206, 222

Clarke, A. I5I

Cloarec, N. 269

Clout, H. D. เо8, І28

Coleman, D.A. I49-I5O
Collinson, S. $\quad 40,60,62, \mathrm{I} 24, \mathrm{I} 27$

Colombo, A. II6, І26, I77

Compton, P. I5I, I76, I78

Condé, J. 275, 292, 30I, 3II

Constant, A. 44, 62

Conti, C. I74, I77-I78

Coppel, J. 293, 3II

Costa, P. 84,86

Courbage, Y. I76, I78

Courgeau, D. 273, 290-29I

crime I88, I99, 2I8

Crul, M. 266, 269

Dacyl, J.W. I03

Dagas, S. 278, 29I

Dagevos, J. 216, 222

Davidson, J. 79,85

Dayan, J.L. $\quad 253,269$

De Beer, J. I37-I38, I50

De Bruijn, B.J. 292, 3I2

De Candia, M. 3II

De Filippo, E. I74, I78

De Seabra, H. I59, I78

De Valk, H. 292, 3I2

Den Adel, M. 23, 35

Densham, P.J. I5I

Di Comite, L. 3II

Diagne, P.S. 30I, 3II

Dietz, B. 5, I3, 37

Diminescu, D. 88, I03

Dinçer, B. 299, 3II

discrimination IO, I5, 43-44, 202, 219, $226,247-248,259,262,267$

Dobson, J. 35

Doeringer, P. 42, 63

Dominguez Martinez, S. 218, 222

Dornbusch, R. I5I

Drew, C. I82, I95

dual labour market 38, 4I-42 see also discrimination, labour market segmentation

Duchêne, G. 98, I03

Duell, N. I5I

Dumond, J.C. 3II

Duquenne, M.N. I6I, I78

Durlauf, S.N. 204, 222

Duszczyk, M. I30, I50

Echardour, A. 253,269

education 25-26, 2II, 237-24I, 252-253

and ICT sector 30

and the labour market 52,256 
Egypt 275, 296, 299-300, 308-309

Ehrenberg, R.G. 42,63

Ekberg, J. 255, 269

Entzinger, H. 22, 34, 200, 222

Erel, U. I03

Escoffier, C. $\quad$ I94

Esser, H. 200, 203, 222

Esveldt, I. 292, 312

ethnic

differences 226, 243

minorities II3, I3I, I84

ethnicity 238-240, 259

Europe

international migration in 9-16, 94 regional patterns I07-126

European Economic Community (EEC) II6

European Union (EU) 9, 62-63, 87, I29, I59, I79, I84, I94, 274

countries IO, I3, 60, 70, 87, I07, I20, I3I, I7I, I82, I88, 28I, 294, 296

enlargement I30-I32, I79-I83, I9O193

migration scenarios $\quad$ I36-I44 impact on population I44-I48 migration policies $\mathrm{I} 83$-190

Faccioli Pintozzi, L. I95

Fadloullah, A. 300, 3I2

Fafchamps, M. 204, 222

Faist, T. $\quad 64,244$

Fakiolas, R. I6I, I76, I78

Farina, P. I77

Farrington, D.P. 221-222

Fassmann, H. 60, 63, II3, I27, I32, I50

Favell, A. I86, I95

Fawcett, J.T. 275, 29I

Featherman, D. 29I

Fellini, I. 34

Ferro, A. 34

Ferting, M. I32, I50

Findlay, A.M. II8, I27

Findley, S.E. 273, 29I, 30I, 3I2

Flaig, G. I5I

Flap, H. 204, 222

Fleischhacker, J. I5I

Fokkema, T. 3II

Fonseca, M.L. 68, 70, 85

forced migration II2-II3

foreign population in Greece $\quad{ }_{160-163}$ by area of origin I70-I7I

in Italy $154-156$

by area of origin I64-166

in Portugal I58-160

by area of origin I68-170

in Spain $156-158$

by area of origin I66-I68

Fougère, D. 267,269

Fournier, I. 259, 267, 269

France $247-268,277-283$

educational attainment of migrants 247-249, 250-253

position on the labour market of migrants 253-268

Franzmeyer, F. I32, I5I

Frejka, T. I74, I78, 284, 29I

Frey, M. 39-4I, 43, 63

Frickey, A. 259, 269

Fullin, G. 34

Gähler, M. 230, 244

Gallo, G. I22, I27

Gang, I.N. 205, 222

Garson, J.P. I08, I2O, I27

Geddes, A. I88, I95

gender

differences 23I, 24I, 255

inequality $25 \mathrm{I}$

relationships 225-226, 228

Germany 37-60

labour market in $\quad 37-38$

theory $4 \mathrm{I}-48$

Gesano, G. I27, I74, I77

Ghana 275, 296, 302, 308-309

Giddens, A. 82, 85

Gijsberts, M. 2II, 222

Gissot, C. 269

Giusti, S. 197

Glaude, M. 253, 269

globalisation $\quad 88$, I20, II6, I79, I87

Góis, P. I74, I77

Goldscheider, C. I4, 225, 229, 244

Goldscheider, F. I5, 225, 229-230, 244

Goldstein, A. 273, 29I

Goldstein, S. 273, 29I

Golini, A. I22, I27

Golinowska, S. $6_{3}$

Gomel, G. I77

Goodman, L.A. 305, 312

Górny, A. I84-I85, I95-I96

government policy 33, 202 see also migration policies 
Gott, C. 2I, 35

Gottfredson, D.C. 222

Gould, W.T.S. II8, I27

Goytisolo, J. IO2

Granovetter, M. 91, IO3

Greece I53, I60-I63, I70-I7I

Greenhalgh, T. 223

Groeneveld, S. 218, 222

Groenewold, G. I5, 292-293, 310-3I2

Grossman, J.B. 6o, 63

Hagendoorn, L. 200, 222

Hammar, T. 244

Hansen, R. I86, I95

Harris, N. 38, 4I, 63

Harvey, G. 223

Haug, W. I76, I78

Heering, L. 292, 3II-3I2

Heller, A. 222

Heran, F. 269

Herweijer, L. 2II, 222

Hille, H. I32, I5I

Hillmann, F. 64

Hintermann C. I32, I5O

Hoesch, K. 35

Hofmann, H. I5I

Hogarth, J. I5I

Holzmann, R. I74, I78

Hönekopp, E. 47,63

Hooghiemstra, E. 2I7, 222

Hoogteijling, E.M.J. 27, 22I

Horálek, M. $6_{3}$

Hugo, G. 35, I28, 225, 244, 3II-3I2

Hunger, U. 34

\section{ICT}

companies 27

firm 3I-33

recruitment 29-30

sector 24-28

Iglicka, K. I85, I95

Immigrants

see migrants

immigration

Brazilian in Portugal 73-75

Eastern European to Portugal 69-73

INSEE Family History (EHF)

survey 248-249

integration IO-I6

actors $20 \mathrm{I}$

definition 200, 205

domains 200-20I family relationship for $\mathbf{2 2 5}$

indicators of 210-2I8

processes 202-206

integration evaluation in the

Netherlands I99-200, 2I9-22I

Integration Monitor 200, 206-210

Social Statistics Database (SSD) 206

intra-European migration I22, I32, I39

Ireland 3I4, 3I6, 325

Italy I53-156, I64-I66, 296, 302-304, 308-310

Ivakhniouk, I. I9I, I95

Jachimowicz, M. I57, I77

Jahn, A. 63

Jaźwińska, E. 52, 63

Jennissen, R.P.W. I99, 222

Jensen, A.M. 244

Johnston, K. 2I, 35

Jordan, B. I89, I95

Jóźwiak, J. I27

Kaczmarczyk, P. I3, 37, 53, 63

Kaklamani, S. I6I, I78

Kalsbeek, W.D. 3II, 3I2

Kempe, W. 47, 62

Kępińska, E. I83, I85, I95

Kicinger, A. I3, I29, I49-I50

Kieffer, A. 25I, 268

Kim, B.Y. 98, I03

King, R. IO8-I09, II3, II5, II7, I20, I27I2 $8, \mathrm{I} 74, \mathrm{I} 78$

Kish, L. 298-299, 305, 3I2

Kohlbacher, J. 63

Kolb, H. 23, 34-35

Komen, M. 222

Korcelli, P. I5I

Koser, K. 22, 35, 80, 85

Koslowski, R. $\quad 67,8$ I, 85, I83, I95

Kotowska, I.E. $\quad$ I27

Kouaouci, A. 35, I28, 312

Kraal, K. 223

Kratsev, I. I92, I94-I95

Krikorian, M. 56, 63

Kritz, M.M. 8I, 85, I23, I27-I28, 295296, 312

Kromhout, M. 218, 222, 327, 329-330

Krugman, P. I5I

Kruisbergen, E. 218, 222

Kubosova, L. I86, I95

Kulu-Glasgow, I. I5, 3I3, 330

Kupiszewska, D. I3, I29, I39, I44, I5O-I5I 
Kupiszewski, M. I3, I29, I32-I33, I35, I39, I44, I49-I5I

Kyle, D. $\quad 67,8$ I, 85

labour

foreign $\quad 38,40-4 \mathrm{I}$

mobility I3, 2I, 32

shortages $26,45,188$

labour market

external 22, 29, 3I

internal (ILMs) 28-29

segmentation 49, 62, II6

see also dual labour market

Lahlou, M. I94

language 32, 206

Layard, R. I32, I5I

Layton MacKenzie, D. 222

Lazaridis, G. I27, I74, I78

Leal, M.F. $\quad 76,85$

Leal, M.L. 76,85

Lee, Y.L. 206, 222

Lelièvre, E. 273, 29I

Lenz, I. I03

Lerner, R. 29I

Lesthaeghe, R. 228, 244

Lhomel, E. 88, I03

Li, P.S. 204-205, 222

Lidgard, J.M. 289, 29I

Lim, L.L. $\quad$ 8I, 85, I23, I27, 3I2

Livi Bacci, M. $\quad$ I77

Lock Kunz, J. 204, 222

Loizillon, A. I08, I20, I27

Lukowski, W. 63

Lundborg, P. I32, I5I

Lutz, W. I29, I49

Mabogunje, A.L. I23, I27

Machado, I. 73-74, 85

McLaughlan, G. 2I, 35

Malheiros, J.M. $\quad 68,70,85$, I59, I78

Mammey, U. 39-4I, 43, 63

Manont, N. 269

Marcus, G.E. $\quad$ IO3

Mare, R.D. 2II, 222

Marques J.C. $70,84-85$, I74, I77

Marshall, D.I. I94, 28I, 29I

Martin, P.L. $\quad 56,63$

Martiniello, M. 223

Mason, K.O. 244

Massey, D.S. 2I, 35, 44, 62, I23, I28, 273, 275, 284-286, 290-29I, 296, 3I2

Maurin, E. 258, 269
Mayer, K.U. 6I-62

methodology I33, I48, 22I

research 68

Meurs, D. I5, 247, 269

Mexico 284-286

Michalon, B. 87, I03

migrant population see foreign population

migrants

from developing countries $\mathrm{I} 22, \mathrm{I} 64$

highly skilled 2I

irregular I2, 80, 83, I35, I82, I9I

migration

data I25, 273-274

dynamics 9, II, I3, I07, I86

flows I24

history $138,170,225$

incentives 228

market 20-24

measures of 94, I3I, I8I, I88

policies 9-IO, I3O-I3I, I33, I62, I83I90

see also government policy

push and pull factors 83, II 8

rates I38-I40, 280

Romanian 87-91, 99

network 9I-95

systems I07-I08, I23-I26

trends II, I3, IO8, I2O-I22

Millar, J. 28, 35

Miller, M.J. II8, I24, I27, I85, I94, 293, 3II

Miller, P.W. 206, 222

mobility

see migration

Moretti, E. $\quad$ I78

Morocco 252-268, 296, 300, 308-310

Morokvasic, M. 88, I03

Motta, G. I80, I95

multi-country study of migration NIDI/Eurostat migration project 2953II

Münz, R. 6o, 63, II3, I27, I5I, I74, I78

Munoz-Perez, F. 289, 292

Munz, S. I5I

Murdie, R. 226, 244

Murdoch, J. 259, 269

Murteira, S. $35,84,86$

Muus, P. I74, I78

Naïr, S. IO2

Natale, M. I78 
Nee, V. $\quad 247,268$

neighbouring countries I37, I60, I7I, I92

Niessen, J. 85

Oberai, A. S. 3II

Ogden, P. 29I

Okólski, M. 9, 45, 52, 63, 67, 77, 85, 87, I03, I20, I28, I74, I78

Orchidea, A. I74, I78

Orłowski, W.M. I32, I5I

Ouaidou, N. 30I, 3II-3I2

Oudhof, J. 222

Ouedraogo, D. 30I, 3I2

Pace, R. I66, I77

Padilla, B. 73,85

Pailhé, A. I5, 247, 269

Parrado, E.A. 284, 29I

Pawson, R. 223

Pedraza, S. 225, 244

Peixoto, J. I3, 35, 65, 68, 69-70, 85-86, I5 $8, \mathrm{I} 60, \mathrm{I} 78$

Pellegrino, A. 35, I28, I67, I78, 312

PEMINT project 24

PEMINT survey 26

Penninx, R. 200, 202, 223

Péraldi, M. I03

Pereira S. 84,86

Pérès, H. 263, 269

Perrin, N. Iо8, I2 8

Piore, M. 42, 63

Pires, R.P. $\quad 68,70,86$

Poland 226-243

Portes, A. 8I, 86, 93, 103, 204, 223, 225, $244,266,269$

Portugal I53, I58-I60, I68-I70 trafficking and/or smuggling of immigrants in $65-78,82-83$

agents $80-8 \mathrm{I}$

causes $8 \mathrm{I}-82$

networks 7I-73

victims 72

Potot, S. I3, 87, 89, I03

Pouget, J. 267, 269

Poulain, M. I08, I28

Pred, A. 226, 244

Presser, H.B. 244

Primon, J.L. 259, 269

Prothero, R.M. 29I

Pugliese, E. II7, I28, I74, I78

Pumain, D. 29I

Pumares, P. I94 questionnaires survey $279,283,285,318$

racism 95

see also xenophobia

recruitment programme in Germany

38-4I

Radu, D. 44,63

Rallu, J.L. I5, 273, 289, 292

Réa, A. IOI, IO3

Reeger, U. $6_{3}$

return migrants to Romania 96-97,

IOO-IOI

consumption $97-99$

Rex, J. I93, 196

Reyes, B.I. 28I, 292

Reyneri, E. I76, I78

Rhoades, R. 39-40, 63

Riandey, B. 247,269

Richmond, A.H. 60,63

Rivera-Batiz, F. 6o, 64

Roccas, M. I77

Romania 87-IO2

Rooth, D.O. 255, 269

Rosa, M.J.V. I58-I59, I78

routes of entry I9-20, 33

Ruhs, M. 60, 64

Rumbaut, R. 244, 269

Rumsey, G.W. 29I

Ruspini, P. I3, I79, I84, I86, I89-190, I92-196

Rybaczuk, K. II7, I27

Sabino, C. $34-35,84,86$

Saczuk K. 150

Safi, M. 247, 269

Salem, G. 92, IO3

Salt, J. I3, I9, 2I-22, 28, 35, 66-67, 8I, 86, IO8, II4, II7, I2O-I2I, I23-I24, I2 8, I32, I5I, I64, I74, I7 8

Santos, T. I58-I59, I78

Sarig, Y. 6I, 64

Sayad, A. 97, I03

Scheffer, P. I99, 223

Schibel, Y. 85

Schmidt, C.M. I32, I5O

Schmidt, S. I5I

Schneider, H. 47, 62

Schoorl, J. 9, 275, 292, 296, 310, 312

Sciortino, G. II6, I26, I77

second-generation 249

assimilation 202-203

see also integration 
Turks and Moroccans in the

Netherlands ???

Seifert, W. 40, 43-44, 60, 62-64

Sen, G. 244

Senegal 275, 283, 296, 30I-302, 308-309

Sherman, L.W. 222

Shinozaki, K. I03

Silberman, R. 256, 259, 267, 268, 269

Siliverstovs, B. I32, I49

Silva, S. $\quad 68,85$

Simon, P. 9, I5, 247, 253-254, 269

Singleton, A. I08, I28

Sinn, H.W. I32, I5I

Sipavicienne, A. 284,292

skill shortages 2I

Smith, R.S. 42,63

Soares, G. 84,86

Southern Europe foreign population in 153 , I72-I75

Spahn, A. 46-47, 64

Spain I53, I56-158, I66-168, 296, 304306, 308-310

Sriskandarajah, D. I82, I95

Stalker, P. 6I, 64

Stein, J. 8I, 86

Sterckx, L. 2I7, 223

Stola, D. I83, I95

Strang, A. 200, 204, 22I

Stråth, B. I89, I95

Straubhaar, T. 63, I32, I5I

Strozza, S. I3, I08, II4, I22, I27, I53, I66, I77

surveys

method 3I7, 326-327

migration I5, 245, 249, 273-277, 286-290, 293-294

The DOM migration survey $277-283$

The MMP ethno-survey $\quad 284-286$ The REMUAO surveys 283-284

Sweden 225-243

Szydlik, M. 42-43, 6I, 64

Tajoli, L. I96

Tamas, K. 224

Tanturri, M.L. I66, I76-I77

Taylor, J.E. $\quad 35$, I28, 312

Thompson, C. 85

Thompson, J.F. 64

Thompson, S.K. 306, 3II-3I2

trafficking in woman for sexual exploitation from Brazil $\quad 75-77$

from Eastern Europe 78

transition to adulthood for children of migrants in Sweden

family patterns 226-244

Traser, J. I80-18I, I96

Triandafyllidou, A. I89, I95

Tribalat, M. 247, 250, 269

Tsardanidis, C. I27, I74, I78

Tsolakis, E. I80, I96

Turkey 226-243, 252-268, 296, 299, 308-310

undocumented migration $\quad 59-60$

Vallet, L. A. 25I, 253, 269

Vallin, J. I27, 292

Van Dalen, H.P. 3IO, 3II

Van der Erf, R.F. 292, 3II-3I2

Van Praag, C. 222

Van Rijn, A.S. $200,206,222-223$

Van San, M. 218, 222

Van Selm, J. I80, I96

Van Tubergen, F. 205, 223

Van Wissen, L. I37-I38, I50

Veenman, J. 222

Velling, J. 44, 60, 64

Vermeulen, H. 266, 269

Versini, D. 267, 269-270

Vertovec, S. 223

Viprey, M. 247, 270

Visco, I. 3II

Visetti, G. I87, 196

Völker, B. 204, 222

Vollebergh, W. 222

wage gap

unskilled 42-45

Waldinger, R.D. 90, IOI, I03

Wallace, H. I86, I87-190, I96

Wallace, W. I96

Walshe, K. 223

Wanner, P. I22, I28

Weil, P. I82, I96

Welsh, B.C. 222

Werding, M. I5I

Werner, H. 6o, 64

White, P. I25, I28, 29I

Widmer, I. 279, 292

William, A.M. 34-35

women immigrants

labour position $42-43,255,258,262$ 
Woolcock, M. 204, 223

workers low-skilled 253

Polish seasonal in German 48-53 impact in agriculture $55-60$

Wunsch, G. I27, 292

xenophobia see also racism Roma 96

Yesilgöz, Y. 222
Zachariah, K.C. 275, 292

Zeroulou, Z. 25I, 270

Zhou, M. 225, 244, 266, 269

Zienkowski, L. I32, I5I

Zimmermann, K.F. 47,62, I32, I49, 205, 222

Zlotnik, H. 8I, 85, I23, I27-I28, 295296, 3II-3I2

Zollberg, A.R. 222

Zorlu, A. I99, 222-223

Zühlke-Robinet, K. 64 
Other IMISCOE titles

IMISCOE Research

Rinus Penninx, Maria Berger, Karen Kraal, Eds.

The Dynamics of International Migration and Settlement in Europe:

A State of the Art

2006 (ISBN 9789053568668 )

(originally appearing in IMISCOE Joint Studies)

Leo Lucassen, David Feldman, Jochen Oltmer, Eds.

Paths of Integration: Migrants in Western Europe (1880-2004)

2006 (ISBN 9789053568835 )

Rainer Bauböck, Eva Ersbøll, Kees Groenendijk, Harald Waldrauch, Eds. Acquisition and Loss of Nationality: Policies and Trends in 15 European

Countries, Volume 1: Comparative Analyses

2006 (ISBN 9789053569207 )

Rainer Bauböck, Eva Ersbøll, Kees Groenendijk, Harald Waldrauch, Eds. Acquisition and Loss of Nationality: Policies and Trends in 15 European

Countries, Volume 2: Country Analyses

2006 (ISBN 978905356 92I 4)

Rainer Bauböck, Bernhard Perchinig, Wiebke Sievers, Eds.

Citizenship Policies in the New Europe

2007 (ISBN $978905356922 \mathrm{I}$ )

Veit Bader

Secularism or Democracy? Associational Governance of Religious Diversity 2007 (ISBN 978905356999 3)

Holger Kolb \& Henrik Egbert

Migrants and Markets: Perspectives from Economics and the Other

Social Sciences

2008 (ISBN 9789053566848 )

Ralph Grillo

The Family in Question: Immigrant and Ethnic Minorities in

Multicultural Europe

2008 (ISBN 978905356869 9) 


\section{IMISCOE Reports}

Rainer Bauböck, Ed.

Migration and Citizenship: Legal Status, Rights and Political Participation 2006 (ISBN 978905356888 ㅇ)

Michael Jandl, Ed.

Innovative Concepts for Alternative Migration Policies:

Ten Innovative Approaches to the Challenges of Migration in the 21st Century 2007 (ISBN 978905356990 o)

\section{IMISCOE Dissertations}

Panos Arion Hatziprokopiou

Globalisation, Migration and Socio-Economic Change in Contemporary

Greece: Processes of Social Incorporation of Balkan Immigrants

in Thessaloniki

2006 (ISBN 9789053568736 )

Floris Vermeulen

The Immigrant Organising Process: Turkish Organisations in Amsterdam and Berlin and Surinamese Organisations in Amsterdam, 1960-2000 2006 (ISBN 978905356875 o)

Anastasia Christou

Narratives of Place, Culture and Identity:

Second-Generation Greek-Americans Return 'Home'

2006 (ISBN 978905356878 I)

Katja Rušinović

Dynamic Entrepreneurship:

First and Second-Generation Immigrant Entrepreneurs in Dutch Cities 2006 (ISBN 9789053569726 )

Ilse van Liempt

Navigating Borders: Inside Perspectives on the Process of Human Smuggling into the Netherlands

2007 (ISBN 9789053569306 )

Myriam Cherti

Paradoxes of Social Capital:

A Multi-Generational Study of Moroccans in London

2008 (ISBN 978905356032 7) 
Marc Helbling

Practising Citizenship and Heterogeneous Nationhood: Naturalisations in Swiss Municipalities

2008 (ISBN 978908964034 5) 